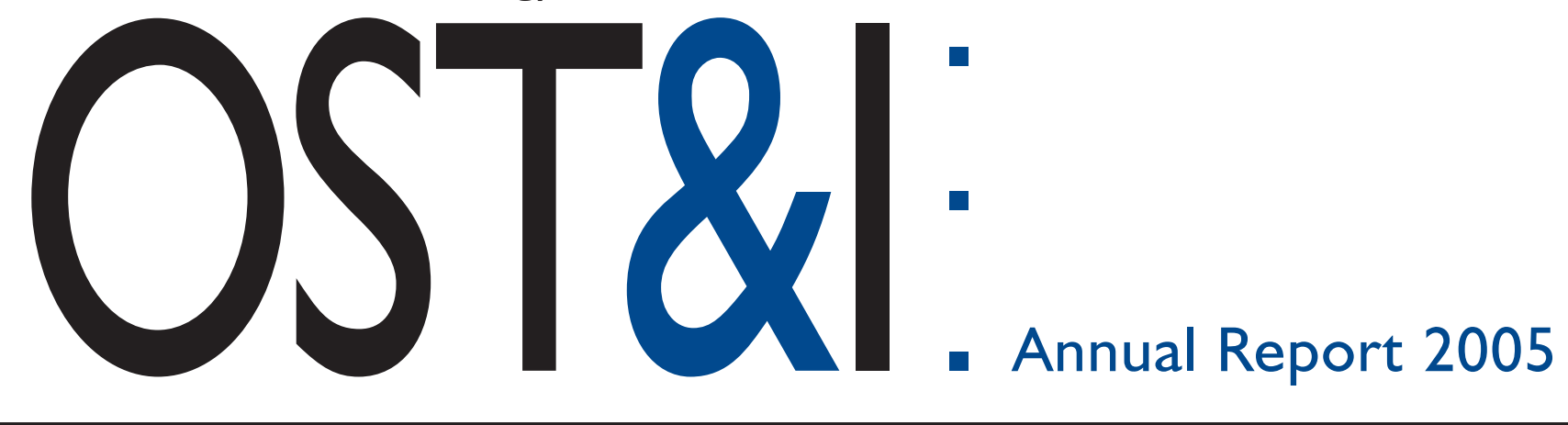




\section{Contacts}

This publication was produced by the U.S. Department of Energy Office of Civilian Radioactive Waste Management (OCRWM)

For further information, contact:

U.S. Department of Energy Office of Civilian Radioactive Waste Management Office of Science and Technology and International (RW-40)

1000 Independence Avenue, SW

Washington, D.C. 20585

For additional copies, call: I-800-225-6972 or write:

I55I Hillshire Drive Las Vegas, Nevada 89134-6321 or visit the OCRWM Home Page: http://www.OCRWM.DOE.gov 
口

DOE/RW-058।

LBNL-59067

Office of Science and Technology and International
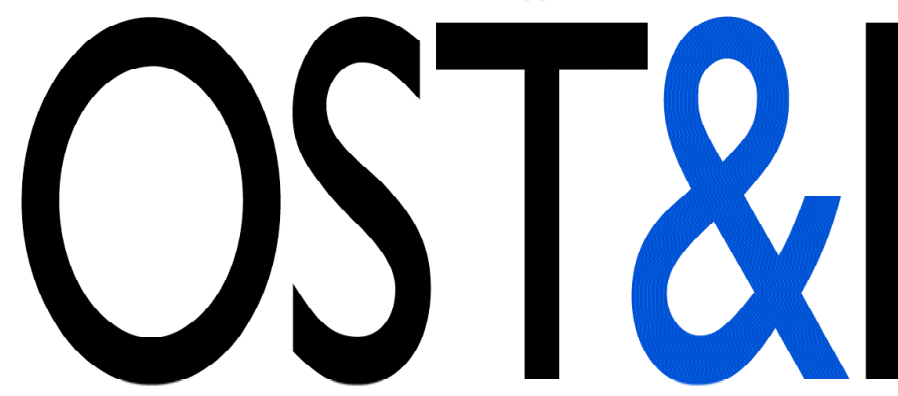

- Annual Report 2005

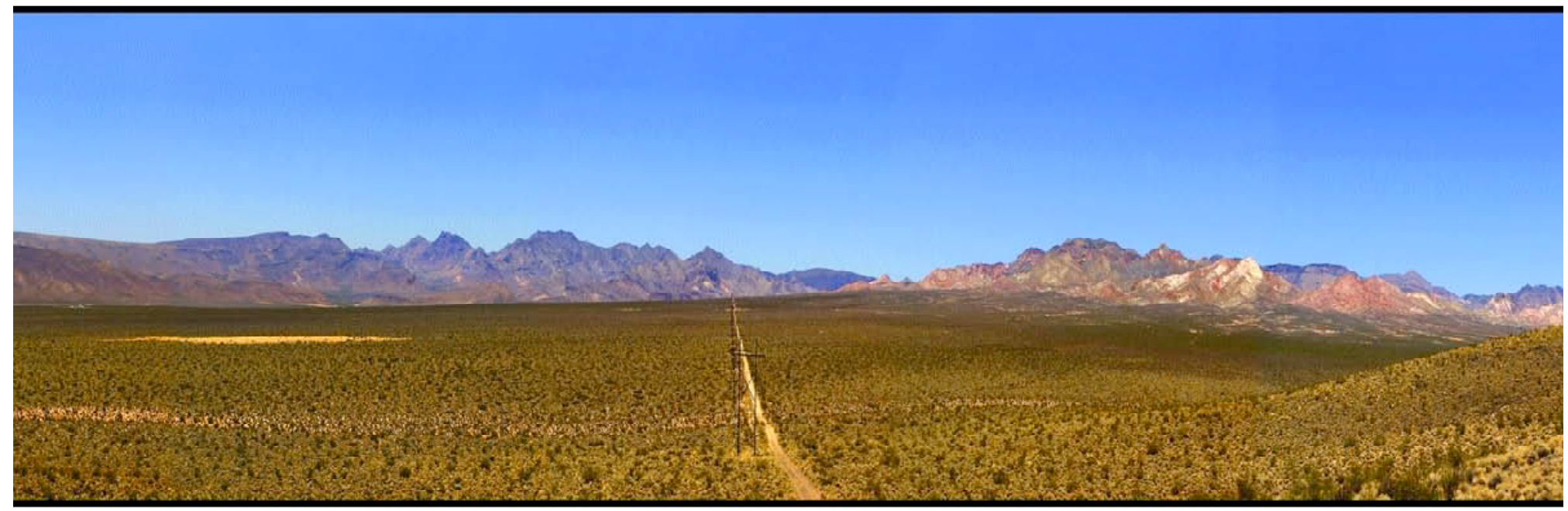

John Wengle, Director 


\section{CONTENTS}

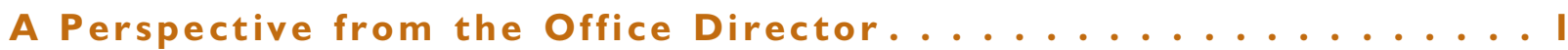
John Wengle, Director, Office of Science and Technology and International

\section{Thrust Areas:}

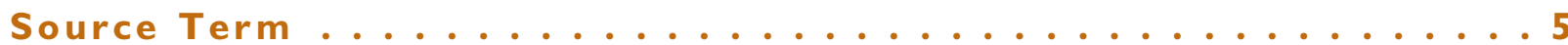

Rodney C. Ewing and Mark T. Peters, Directors, Source Term Thrust Area

SNF Dissolution Mechanisms and Rates

Actinide Thermodynamics at Elevated Temperatures ............ I Judah Friese and Linfeng Ra

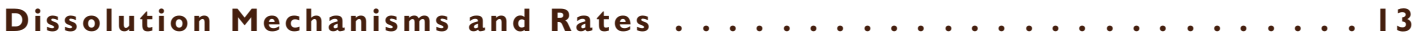

Brady Hanson, Edgar Buck, Amanda Kline, and William Miller

Implications of Deliquescence and Decay Heat on Source Term

Degradation ............................ 5

James Jerden

Formation and Properties of $\mathrm{U}^{6+}$ Secondary Phases

Mitigation of the Release of 129 from Spent Nuclear Fuel

via Uptake by Uranyl Alteration Phases ................. I9

Thomas E. Albrecht-Schmitt and lain May

Impact of Uranyl Alteration Phases of Spent Fuel on Mobility of Neptunium (Np) and Plutonium (Pu) in Yucca Mountain ........ 2 Peter C. Burns

Actinide Adsorption to $U(V I)$ Silicates ...................... 23 S.B. Clark and Lawrence C. Hull

Corrosion of Spent Nuclear Fuel: The Long-Term Assessment . . . . . 25 Rodney C. Ewing

Direct Determination of the Thermodynamic Properties of Uranyl Minerals Important for the Performance of the Proposed Geological Repository at Yucca Mountain ............... 27 Jeremy B. Fein, Peter C. Burns, and Alexandra Navrotsky

Chemical and Coordination Structure of Radionuclides in Spent Nuclear Fuel and Its Alteration Products: Understanding Release

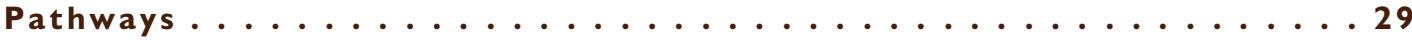
Jeffrey A. Fortner, A. Jeremy Kropf, and James C. Cunnane 
An In Situ Spectroelectrochemical Study of Neptunium (Np) Redox, Dissolution, and Precipitation Behavior at the Corroding Spent

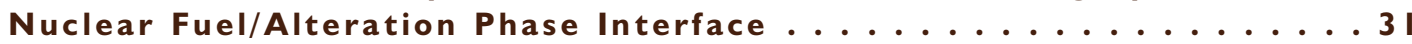

Artem Guelis, Jeremy Kropf, Christopher Johnson, Jeffrey Fortner, and Petr Vanysek

Natural Sequestration of Radionuclides In Volcanic Tuff . . . . . . . 33 Jonathan Icenhower, Edgar Buck, Eric Pierce, Dawn Wellman, and Andreas Lüttge

Surface Charge and Radionuclide Adsorption Characteristics of U(IV,VI) Oxyhydroxides at 25-I50 $0^{\circ} \mathrm{C} \ldots \ldots \ldots \ldots \ldots$

David J. Wesolowski, Donald A. Palmer, Laetitia Delmau, Lawrence M. Anovitz, and Michael L. Machesky

Waste Form-Waste Package Interactions in the Near Field

Waste Package Corrosion Studies Using Small Mockup Experiments . . 39 Patrick V. Brady, B. Elizabeth Anderson, and Katheryn B. Helean

In-Package Sequestration of Radionuclides at Yucca Mountain:

Neptunium Surface Complexation Subtask................ I James Jerden

Uptake of Technetium (Tc) by Iron-Based Materials ...........43 Kenneth Krupka, Chris Brown, Michelle Valenta, H. Todd Schaef, and Bruce Arey

Integration of In-Package Chemical and Physical Processes

Neptunium Incorporation into the $\mathbf{U}^{6+}$ Alteration Phases of Spent Nuclear Fuel and Neptunium Sorption onto Oxide Phases ....47 Udo Becker and Lindsay C. Shuller

A Model for Radionuclide Release from Commercial Spent Nuclear Fuel 49 Carl I. Steefel, John Apps, Nic Spycher, and Eric Sonnenthal

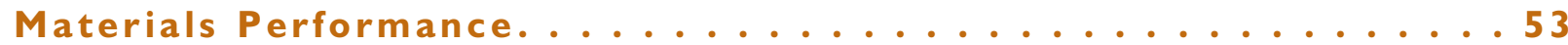
Joe H. Payer, Director, Materials Performance Thrust Area

Corrosion of Metal Surfaces Covered with Particulate and Deposits

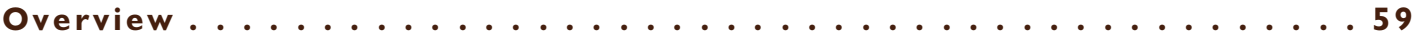

Kinetics of the Cathodic Reduction of Oxygen on Passive Metals ....6I David W. Shoesmith

Oxygen Electro-Reduction on Passive Metals in Particulate and

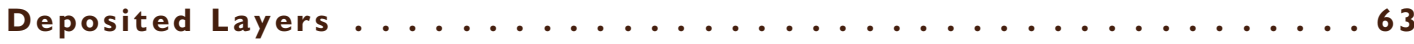
Dominic Gervasio

Corrosion Cells Beneath Thin Films, Particulate, and Deposited Layers 65 Joe H. Payer, Pallavi Pharkya, and Xi Shan

Electrochemical Measurements of Corrosion under Thin Brine Layers . . 67 Gerald S. Frankel and Rudolph G. Buchheit

Mechanism of Mixed-Ion Effects on Corrosion in Thin Films.......69 Roger C. Newman, Chris Healey, and Anatolie Carcea

Effect of Environmental Variables on the Structure and Composition of Passive Films ............................... I Thomas M. Devine, Zeuyuan Zhang, and Marcela Miyagusuku 
Evolution of Corrosion Damage by Localized Corrosion

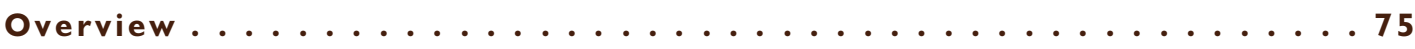

Crevice-Corrosion Electrochemistry and Propagation Behavior . . . . 77 John R. Scully, Florent Bocher, and Francisco Presuel-Moreno

Modeling of Critical Chemistry for Crevice Corrosion . . . . . . . . 79

R.G. Kelly, A.J. Hodges, and F. Presuel-Moreno

Experimental Determination of the Evolution of Crevice-Corrosion

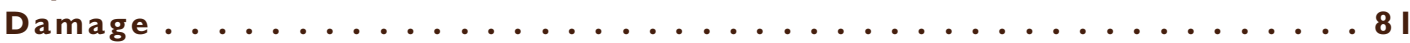

David W. Shoesmith and Jamie Nöel

Coupled Crevice Tests for Initiation, Propagation, and Arrest of

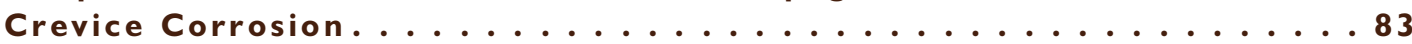

Brian M. Ikeda and C.D. Litke

Localized Corrosion Stability in the Presence of Non-Chloride Anions . 85 Roger C. Newman, David D. He, and Anatolie Carcea

Metallurgical Effects on Localized Corrosion of Ni-Cr-Mo Alloys . . . 87 Gerald S. Frankel and Rudolph G. Buchheit

Effect of Crevice Former on Corrosion Damage Propagation ......89 Joe H. Payer, Uziel Landau, Xi Shan, and Arun S. Agarwal

Combinatorial Chemistry Approaches for Alloy Composition

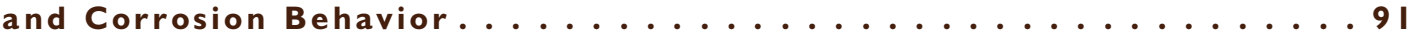
Rudolph G. Buchheit and Gerald S. Frankel

Prediction of the Time Evolution of Localized Corrosion Damage.... 93 Digby D. Macdonald, Shaofeng Yang, and George R. Engelhardt (Consultant)

Data Mining of Experimental Localized Corrosion Data . . . . . . . 95 Mirna Urquidi-Macdonald and Kamrun Nahar

Evolution of Moisture Environment on Metal Surfaces

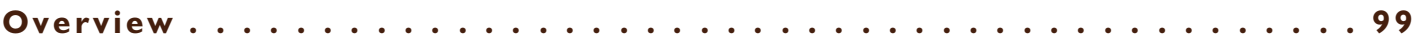

Thin Solution Layer Properties and Their Effect on Corrosion ..... I0I R.G. Kelly, F. Cui, and F. Preseul-Moreno

Modeling and Measurement of Current Distribution in Particulate

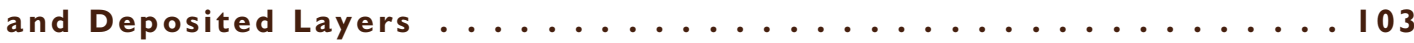
Uziel Landau, Arun Agarwal, Xi Shan, and Joe H. Payer

Microelectronic and MEMS Devices for Solution Properties

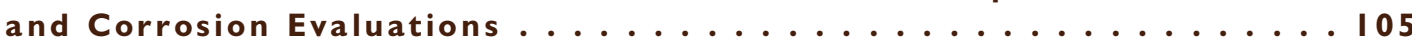
Chung-Chiun Liu, Joe H. Payer, Jinsong Yu, and Laurie Dudik

Optical Probes and Sensors to Determine Concentration Distributions in Thin Films on Reactive Surfaces ................... 07 William H. Smyrl

High-Temperature, Multi-Species Solution Properties and Behavior.. I09 David R. Cole, Donald A. Palmer, Lawrence N. Anovitz, Mostafa Fayek, Miroslaw S. Gruszkiewicz, Lee R. Riciputi, David J. Wesolowski, George Engelhardt, and Digby D. Macdonald 
Coupling Thermal-Hydrological-Chemical Models to Process Models on Waste Packages ...........................II3 N. Spycher, G. Zhang, C. Steefel, E. Sonnenthal, and Z. Zheng

Integration of Materials Performance Process Models with Those in Natural Barriers and Source Term Thrusts ............... I 5 Bo Bodvarsson, Mark Peters, and Joe H. Payer

Radionuclide Getters .......................... I 7 Hong-Nian Jow (Director), Robert C. Moore (Co-Director), and Shas Mattigod (Co-Director),

Radionuclide Getters Thrust Area

Development of Coated Mesoporous and Small Spherical Technetium

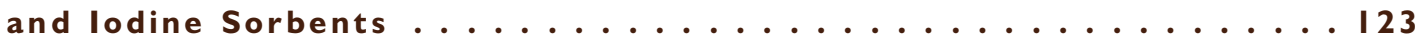
Jun Liu, Yifeng Wang, Qisheng Huo, and Huizhen Gao

Development and Testing of Nanoporous Sorbents for Technetium,

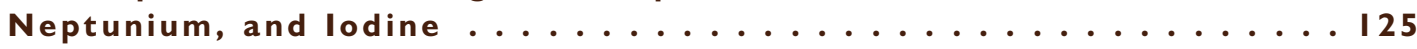
Shas V. Mattigod, Dawn M. Wellman, Glen E. Fryxell, X. Shari Li, Andrea R. Courtney, Kent E. Parker, and Wassana Yantasee

New Nanoporous Phosphate-Based Getter Materials:

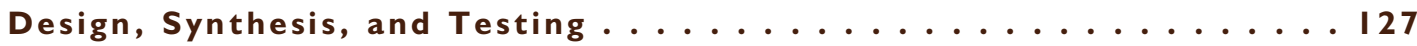
Shas V. Mattigod, Dawn M. Wellman, Glen E. Fryxell, and Kent E. Parker

Optimization of Layer Double Hydroxides and Related Materials . . . I29 Yifeng Wang and Huizhen Gao

Hydroxyapatite for Technetium Sequestration ................... I Katheryn B. Helean

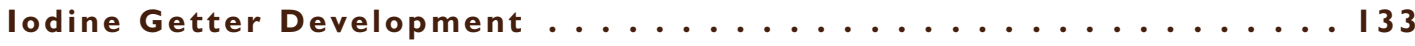
James L. Krumhansl, Jason D. Pless, and J. Benjamin Chwirka

BiOX-Based Solid Radionuclide Getters................. I35 Ranko P. Bontchev

Exploring the Use of Manganese Oxides as Anionic Getters . . . . . I37 Michael Hochella and Heike Pieper

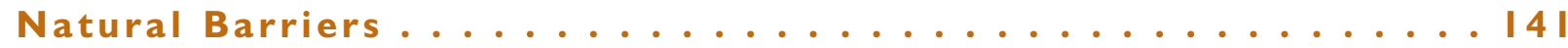
G.S. (Bo) Bodvarsson, Director, Natural Barriers Thrust Area

Drift Seepage

Coupled In-Drift, Near-Field, and Mountain-Scale Fluid and Heat Flow Processes...................... I49 George Danko, Jens T. Birkholzer, and Stefan Finsterle

Integrated Assessment of Critical Chemical and Mechanical Processes

Affecting Drift Performance: Laboratory and Modeling Studies .... I I I Derek Elsworth, Jonny Rutqvist, Abraham S. Grader, Chris J. Marone, and Eric Sonnenthal

\section{In-Drift Environment}

An Integrated In-Drift/Near-Field Flow and Transport Model with Reactive Chemistry ...................... I55 J. Birkholzer, E. Sonnenthal, S. Mukhopadhyay, M. Reagan, and T. Xu 


\section{Drift Shadow}

Nature of Drift Shadows at Analogue Sites .............. I59

T. Kneafsey, T. Ghezzehei, G. Su, P. Dobson, and B. Marshall

Testing the Concept of Drift Shadow................... I6I James Paces, Leonid Neymark, Teamrat Ghezzehei, Ernest Majer, and Patrick Dobson

Testing the Concept of Drift Shadow with X-Ray Absorption

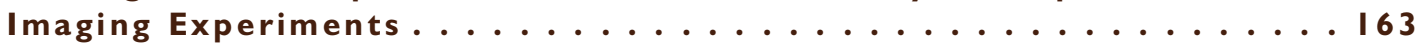
Susan J. Altman, Clifford K. Ho, Aleeca Forsberg, and William Peplinski

Unsaturated Zone Flow and Transport

Enhanced Retardation of Radionuclide Transport in Fractured Rock.. I67 Hui-Hai Liu, Yinqi Zhang, Quanlin Zhou, and Fred J. Molz

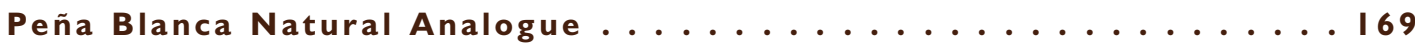
Schön S. Levy, Patrick F. Dobson, Mostafa Fayek, Philip Goodell, Richard Ku, and Michael T. Murrell

Matrix/Fracture Flow in Subrepository Units .............. I I Leonid Neymark, James Paces, David Vaniman, and Steve Chipera

Pore Connectivity, Episodic Flow, and Unsaturated Diffusion

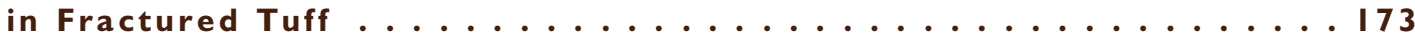
Qinhong Hu, Robert P. Ewing, and Liviu Tomutsa

Saturated Zone Flow and Transport

Determining the Redox Properties of Yucca Mountain-Related Groundwater Using Trace-Element Speciation for Predicting the Mobility of Nuclear Waste ..................... I77 James Cizdziel, Vernon Hodge, and Karen H. Johannesson

Field Studies for the Determination of Transport Properties of Radioactive Solutes and Colloids Using Chemical Analogues..... I79 Barry Freifeld, Paul Reimus, Dale Hammermeister, John Apps, and George Moridis

Improved Characterization of Radionuclide Retardation

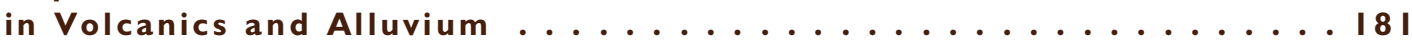
Paul W. Reimus, Mei Ding, Cindy Scism, Cheryl Sedlacek, Schon Levy, and Steve Chipera

Carbon-I 4 Groundwater Analysis .................... I83 Gary L. Patterson and James Thomas

Large-Scale Natural Gradient Tracer Test ............... I85 M.J. Umari (Co-P.I.), Allen Shapiro (Co-P.I.), Paul Reimus (Co-P.I.), Ed Kwicklis, John Earle, and Mike Fahy

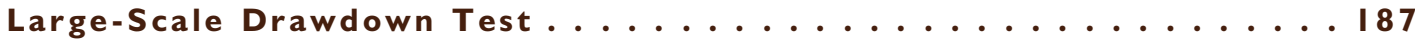
Paul Reimus, Robert C. Roback, Ed Kwicklis, M. J. Umari, John Earle, Michael Fahey, Richard L. Beauheim, Randall M. Roberts, Susan J. Altman, Bill Arnold, Stephanie Kuzio, Chin-Fu Tsang, Hui-Hai Liu and Kenzi Karasaki

Integration of Data and Models for the Coupled Regional-

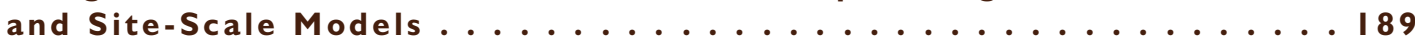
A.A. Eddebbarh, G.A. Zyvoloski, S.C. James, Steffen Mehl, and Mary C. Hill

Saturated Zone Plumes in Volcanic Rock................ I9I Sharad Kelkar and Robert Roback 


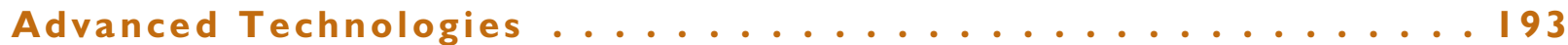
Jeffrey Walker, Director, Advanced Technologies Thrust Area

Assessment of Welding Technology and Welding-Related Issues for Alloy 22 Nuclear Waste Packages .................. 197 John C. Lippold

Evaluation of Reduced-Pressure Electron-Beam Welding Technologies for Nuclear Waste Containment ................... 199 Frank Wong

Solicitation for Conceptual Design, Development, and Demonstration of Alternative Approaches to the Final Waste Package Closure Weld

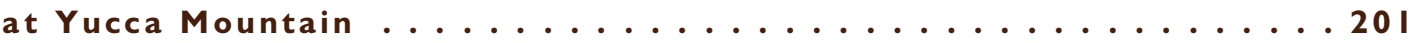
Choon Quan, T. James Dorsch, and Ron Kaplan

High-Performance Corrosion-Resistant Metal Coatings .........203 Craig Blue, Nancy Yang, and Joe Farmer

Evaluation of the Feasibility and Benefit of Cutting a Flat-Bottomed

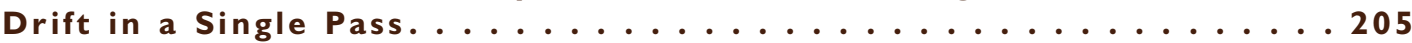
Choon Quan, Ray Mele, and Frank Wong

Scoping Study to Evaluate Advances in Robotic Technologies That Support Enhanced Efficiencies for Proposed Yucca Mountain

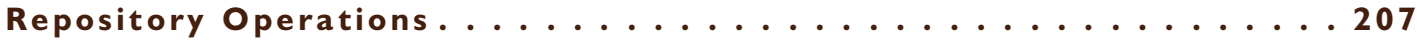
Thomas W. Burgess, Mark W. Noakes, and Philip T. Spampinato

Workshop on State-of-the-Art Tele-Operated Robotic Manipulators and Other Technology Improvements to Enhance Yucca Mountain Remote Material-Handling Capabilities ................... 209 Thomas W. Burgess, Mark W. Noakes, and Philip T. Spampinato

Low-Alkalinity Phosphate-Bonded and Portland Cements as Cost-Effective Cementitious Material Compatible with Proposed Yucca Mountain Repository Geochemistry ....................... II Les Dole, Arun Wagh, Catherine Mattus, and Lee R. Riciputi

Evaluation of Structurally Amorphous Materials to Improve Rock-Cutting Tools for Subsurface Excavation .............. 213 Frank Wong and Craig Blue

Development of a Methodology to Produce Hazard-Consistent Structural Demands and In-Structure Design Response Spectra .... 2 I5 Tom Houston, Carl Costantino, and Walt Silva

Development and Verification of an Improved Model for Extreme Ground Motions Produced by Earthquakes ................ 217 Norm Abrahamson and Lloyd Cluft

Ap pendix A: Programmatic Evaluation and Peer Review Panels.......... 2 II 9

Appendix B: OST\& I Participating Organizations ............ 220 


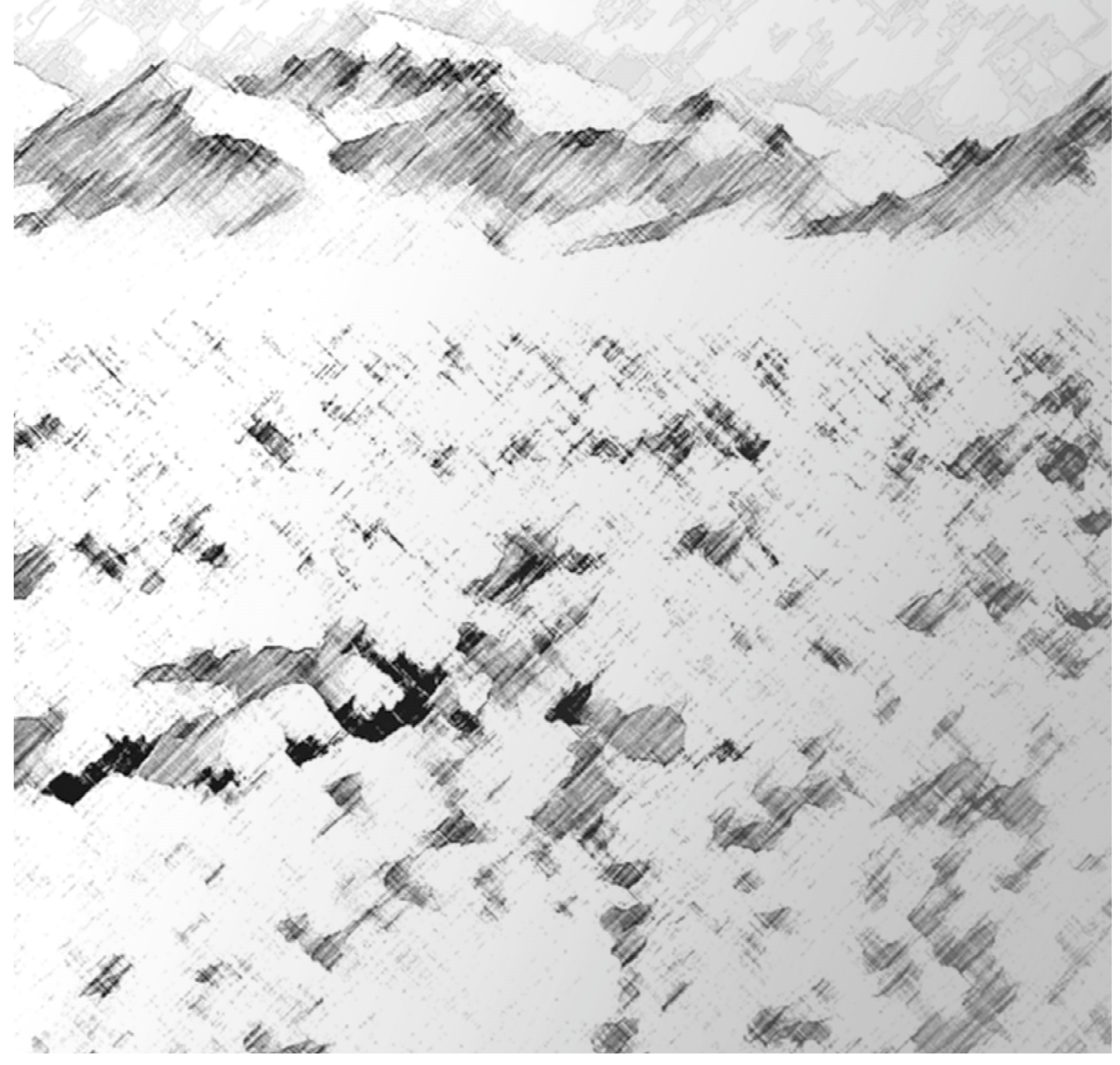


A PERSPECTIVE FROM THE OFFICE DIRECTOR

John Wengle, Director, Office of Science and Technology and International

Contact: john.wengle@rw.doe.gov

We are living in a time of rapid and thoroughgoing change. We stand at a point where, for the first time in history, it is possible to envision a very-near-term future in which most of the world will experience relative modernization at an unprecedentedly rapid pace. This rapid modernization, especially among Asian countries, but also in Latin America and Africa, will place demands on the world's energy resources that will far outstrip present supply. The need for increased energy resources to power these countries' industrial infrastructure, literally and figuratively, will require significant deployment of baseload power plants.

We can say with some certainty that this need for increased energy resources will not be supplied, at least primarily, by increased use of fossil fuel. Among the growing list of cautionary prophets, we find that ExxonMobil, one of the largest publicly owned petroleum companies in the world, has already called for increased conservation measures, in light of their forecast that production of non-OPEC oil reserves will peak in about five years, sometime around 2010. In addition, the growing concern over global climate change, driven at least in part by the emission of greenhouse gases, suggests that other, non-fossil-fuel-based energy resources must be developed.

Taken in total, our current situation represents a major new opportunity for the expansion of nuclear power. At the same time, however, the issue of nuclear waste will be a key environmental issue in the future. It is generally argued, perhaps correctly, that dealing successfully with spent nuclear fuel disposition is required if a new generation of nuclear plants is to become a reality.

The governing framework for disposal of spent nuclear fuel in the United States is the Nuclear Waste Policy Act (NWPA), which in 1982 established the Office of Civilian Radioactive Waste Management (OCRWM) within the Department of Energy. The NWPA adopted geologic dis- posal as the USA's long-term strategy for the safe isolation of radioactive waste, and confirmed the Federal Government's responsibility for managing and disposing of commercial spent nuclear fuel. On February 14, 2002, the Secretary of Energy recommended the Yucca Mountain site to the President for development of a geologic repository. The President subsequently recommended the site to Congress. Following the Nevada Governor's disapproval of the site on April 8, 2002, the U.S. Congress overrode Nevada's disapproval on July 9, 2002, and established Yucca Mountain as the site of the nation's first geological repository for spent nuclear fuel.

This document is the inaugural Annual Report for the Office of Science and Technology and International (OST\&I), which is part of the Department of Energy's Office of Civilian Radioactive Waste Management (OCRWM). The Science and Technology (S\&T) Program provides a range of science and technology resources and capabilities, from targeted applied research through technology development and demonstration, needed to deliver scientific and technological enhancements to enhance our understanding, and to optimize performance, of the proposed Yucca Mountain repository.

Our S\&T Program mission is to provide advanced science and technology to continually enhance our understanding of the repository system and to reduce the cost and schedule for the OCRWM mission without sacrificing safety. We are collectively driven by our vision that OCRWM and the affected public will value the contributions that scientific and technological advances have made toward safer, more expeditious, and more cost-effective waste isolation. The S\&T effort complements the proposed repository design, performance assessment, and other baseline engineering and scientific studies conducted by OCRWM's Office of Repository Development (ORD) at the Yucca Mountain site. As such, the S\&T Program works in close collaboration with the ORD to assure timely transfer of research results.

In this document, we present summaries of our current research projects. While not a complete accounting, in the sense that a summary can never do justice to the richness and depth of intellectual vigor characteristic of each of these studies, it is representative of the nature and breadth of our research effort. We are proud of our scientific and technology development efforts, and we hope that you will find our research useful and exciting. Any comments on our program are appreciated and can be sent to me personally.

This report is divided into five sections that correspond to the major research programs (or "thrusts") in OST\&I: 
- Source Term

- Materials Performance

- Radionuclide Getters

- Natural Barriers

- Advanced Technologies.

A brief introduction in each section describes the overall organization and goals of each program area. All of these areas have great potential for improving our understanding of the safety performance of the proposed Yucca Mountain repository, as processes within these areas are generally very conservatively represented in the Total System Performance Assessment. In addition, some of the technology thrust areas in particular may enhance system efficiency and reduce risk to workers. Thus, rather modest effort in the S\&T Program could lead to large savings in the lifetime repository total cost and significantly enhanced understanding of the behavior of the proposed Yucca Mountain repository, without safety being compromised, and in some instances being enhanced.
An overall strength of the S\&T Program is the significant amount of integration that has already been achieved after two years of research. As an example (illustrated in Figure 1), our understanding of the behavior of the total waste isolation system has been enhanced through integration of the Source Term, Materials Performance, and Natural Barriers Thrust areas. All three thrust areas contribute to the integration of different processes in the in-drift environment. These processes include seepage into the drift, dust accumulation on the waste package, brine formation and precipitation on the waste package, mass transfer through the fuel cladding, changes in the seepage-water chemical composition, and transport of released radionuclides through the invert and natural barriers.

During FY2005, each of our program areas assembled a team of external experts to conduct an independent review of their respective projects, research directions, and emphasis. In addition, the S\&T Program as a whole was independently reviewed by the S\&T Programmatic

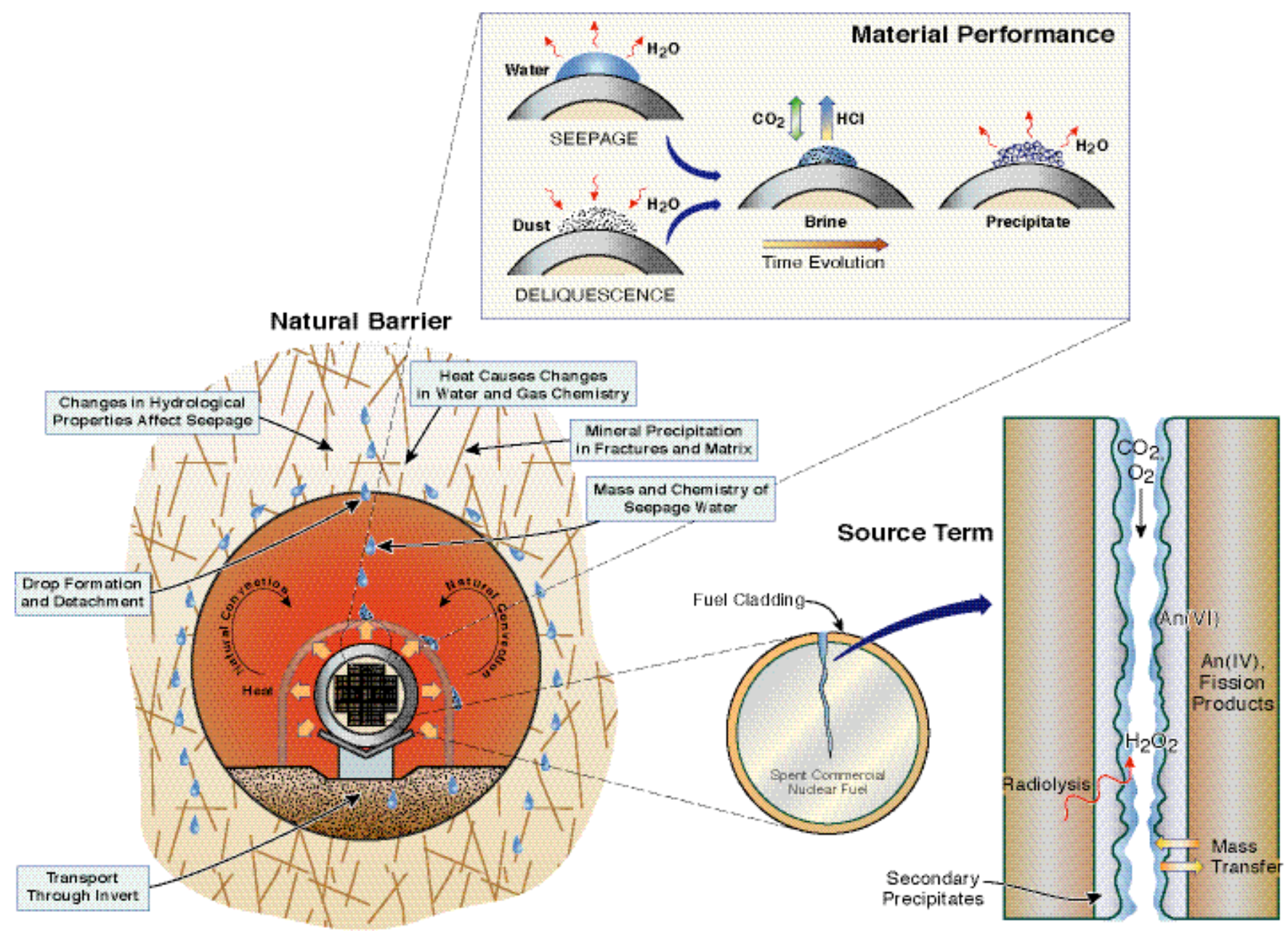

Figure I. Integration of in-drift environment with contributions from Natural Barriers, Materials Performance, and Source Term Thrust Areas 
Evaluation Panel. As a result of these reviews, adjustments to the S\&T Program will be implemented in FY2006 to ensure that the Program is properly aligned with OCRWM's priorities.

Also during FY2005, several programmatic documents were published, including the Science and Technology Program Strategic Plan, the Science and Technology Program Management Plan, and the Science and Technology Program Plan. These and other communication products are available on the OCRWM web site under the Science and Technology section

(http://www.ocrwm.doe.gov/osti/index.shtml)

\section{Acknowledgments}

We gratefully acknowledge the contributions made by our program participants throughout FY2005. Our principal investigators are drawn from Department of Energy national laboratories, the United States Geological Survey, the Defense Advanced Research Projects Agency, and other Federal agencies, local government agencies, academia, and industry. The talents and efforts of these individuals have set a firm foundation in bringing world-class science and technology to bear on the national priority of safe and efficient nuclear waste disposal - a foundation that will contribute to expanding the use of nuclear energy to meet our national needs.

Also deserving of a special note of thanks are our thrust area leaders: Rod Ewing, Mark Peters, Joe Payer, HongNian Jow, Bo Bodvarsson, and Jef Walker, and technical staff Bob Budnitz, Doug Duncan, Mic Griben, Bob Finch, and Katheryn Helean. Each of these individuals is responsible, through their clarity of vision and depth and rigor of intellectual pursuit, for the robustness and vigor of their respective thrust areas. Certainly, I would be remiss if I failed to single out our collaborators at ORD as well: Russ Dyer, Abe Van Luik, Steve Hanauer, Bill Boyle, Debbie Barr, Claudia Newbury, Paige Russell, Scott Wade, Paul Harrington, Allen Benson, and Jane Summerson. All have been remarkably supportive, and intellectually challenging, in helping us to refine our S\&T Program. The production of this report would not have been possible without the skillful, untiring, and always enthusiastic support of the following individuals: Maria Atkinson, Dan Hawkes, Vince Ceci, Vivi Fissekidou, Cindy Lepouttre, and Diana Swantek.

This document remains a footprint of, not a monument to, OST\&I. 


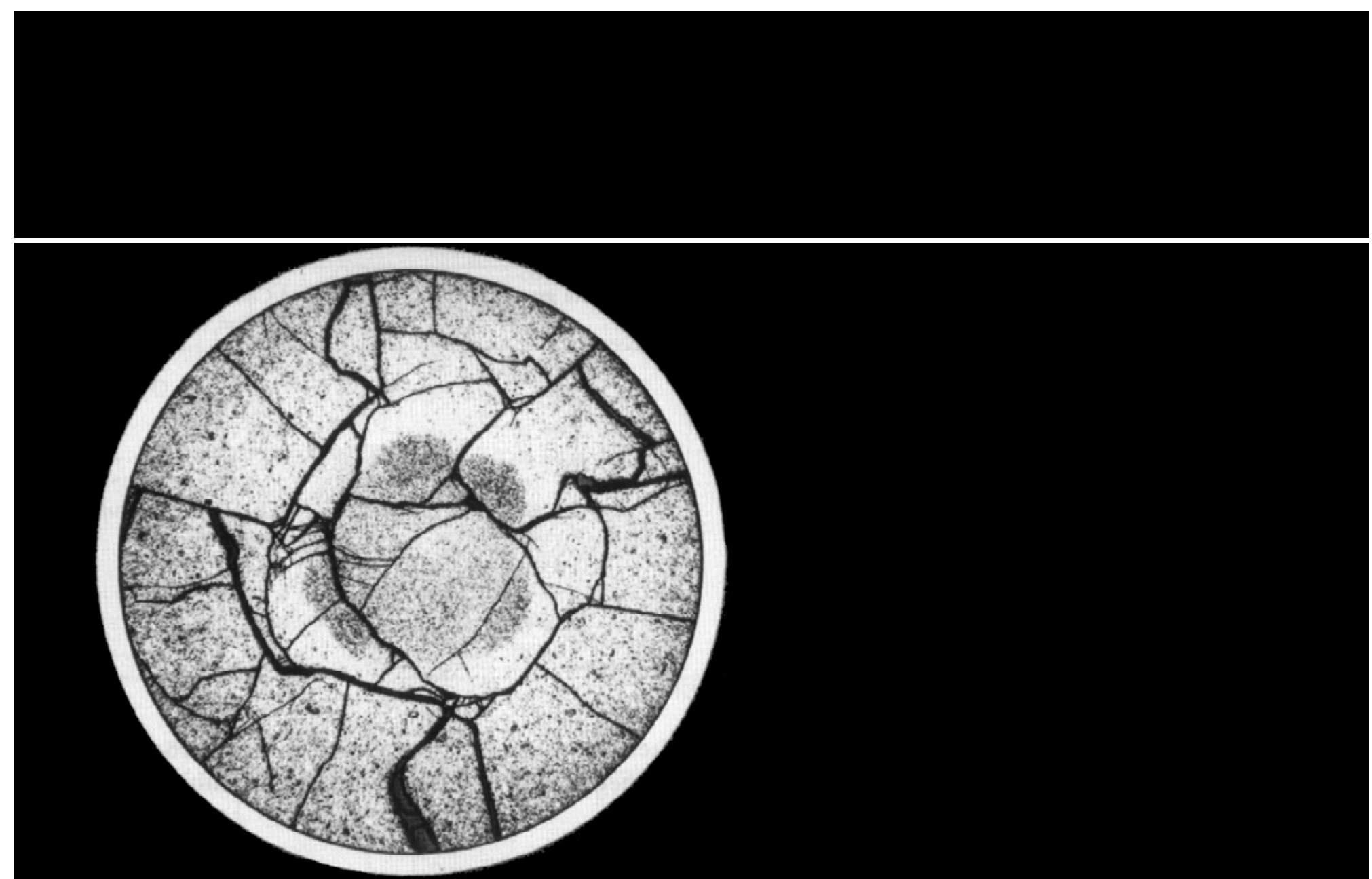

Cross section of spent nuclear fuel with Zircaloy cladding. Diameter $=10 \mathrm{~mm}$.

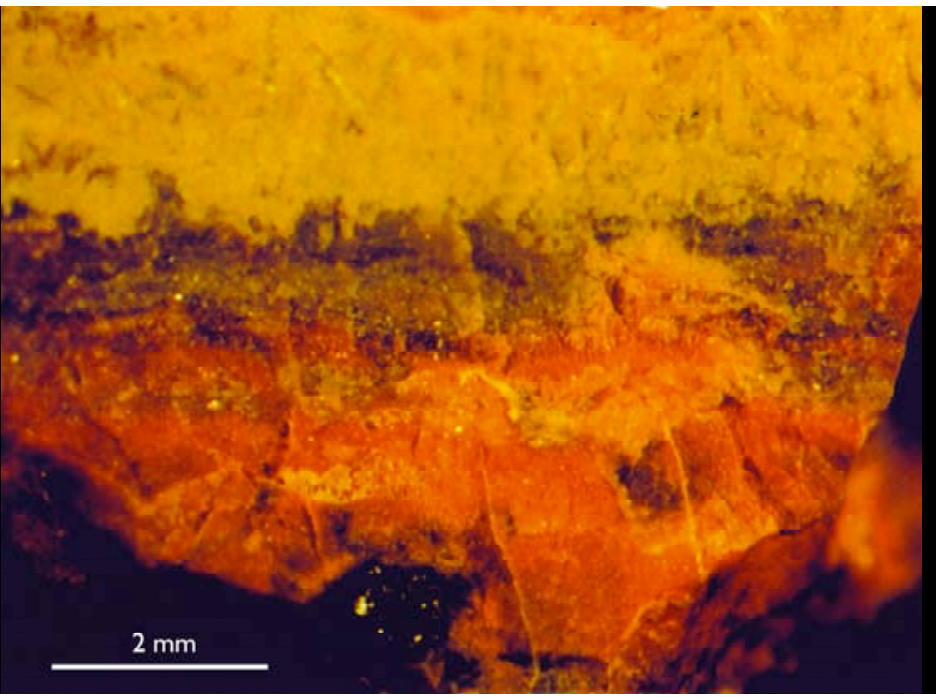

Photomicrograph of a corrosion rind on uraninite $\left(\mathrm{UO}_{2+\mathrm{x}}\right)$ formed under oxidizing conditions. The yellow material consists of $\mathrm{U}(\mathrm{VI})$ minerals formed by the alteration of the uraninite. The small black grain in the lower left edge of the sample is unaltered uraninite. (Finch and Ewing, 1992, Journal of Nuclear Materials) 


\section{SOURCE TERM THRUST}

\author{
Rodney C. Ewing ' and Mark T. Peters ${ }^{2}$, Directors, \\ Source Term Thrust Area \\ I University of Michigan | ${ }^{2}$ Argonne National Laboratory (ANL) \\ Contact: Rod Ewing: rodewing@umich.edu \\ Mark Peters: mtpeters@anl.gov
}

The goal of the Source Term Thrust is to enhance the under standing of the performance of nuclear waste forms (mainly spent nuclear fuel (SNF) and nuclear waste glass) and to quanti fy the release of radionuclides in the evolving near-field environ ment expected at the proposed nuclear waste repository at Yucca Mountain, Nevada. The behavior of the source term, mainly SNF and vitrified waste, limits radionuclide releases, both initially and over the long term. Interactions of the source term with the near-field environment, such as corroded waste packages, place additional constraints on the longterm behavior, including retention and mobility of important radionuclides.

This program is directed at developing a basic understanding of the fundamental mechanisms of radionuclide release and a quantification of the release as repository conditions evolve over time. Radionuclide release will be critically sensitive to variations in temperature, radiation field, redox conditions, $\mathrm{pH}, \mathrm{pCO}_{2}$, surface area-to-solution volume, and presence of near-field materials. Among the important processes that can control radionuclide release are: (1) kinetics of waste form corrosion, (2) formation of secondary, alteration phases, and (3) reduction and sorption onto the surfaces of near-field materials.

Predictions of the long-term behavior of nuclear waste forms cannot be based entirely on models of laboratory results that are then extrapolated to long periods. Hence, this program will integrate multiple lines of evidence (e.g., results from natural analogue studies) to clarify the scientific basis for waste form degradation mechanisms in relation to source term models. The program will evaluate the uncertainties introduced by parametric uncertainty, variations in environmental conditions, and the use of different conceptual models.

The present source term and near-field models in the Yucca Mountain performance assessment are conservative, but the uncertainties are large. To the extent that the mechanisms of release for specific radionuclides can be understood or the uncertainties decreased, the subsequent analysis of the far-field barriers becomes less important. In the present performance assessment, important processes that will certainly occur are not explicitly included, such as the formation of secondary, $\mathrm{U}^{6+}$ alteration phases. Very little credit is taken for the potential chemical interactions between released radionuclides and the alteration products of the SNF and metal waste packages, or their internal components. The conservatism of the present models may be reduced by an improved understanding of the fundamental geochemical/hydrologic processes that will control the corrosion of SNF under oxidizing conditions and the potential interactions that may occur among the corroded nuclear fuel, the high-level-waste (HLW)-borosilicate glass, and the waste package components. This focused and integrated research program will provide the scientific basis for the development of the next generation of more realistic models for source term and near-field processes.

Although there has been considerable research on the corrosion of SNF and nuclear waste glasses, there has been much less work on developing models that are applicable to an oxidizing environment, such as that at the proposed Yucca Mountain repository.

There are two compelling reasons for the importance of understanding the source term and near-field behavior. First, essentally all radioactivity is initially in the waste form, mainly SNF or nuclear waste glass. An enhanced understanding and realistic estimates of the extent to which radionuclides will be retained in the waste form or near-field environment reduce demands on the performance of subsequent, far-field barriers. Realistic estimates of radionuclide release can also reduce uncertainties in the Total System Performance Assessment. Second, over long periods, as engineered barriers degrade, it is the waste forms that eventually provide the release of radioactivity to the environment. Thus, it is essential to predict with confidence the physical and chemical evolution of the waste form over hundreds of thousands of years.

Finally, the need to understand the corrosion and alteration of SNF and nuclear waste glasses is a research subject unique to the needs of the Office of Civilian Radioactive Waste Management (OCRWM), Office of Science and Technology and International Program. Other agencies and DOE offices, such as the National Science Foundation (NSF) or Basic Energy Sciences (BES), generally do not fund research on the properties or corrosion of SNF or nuclear waste glasses. Hence, OCRWM, by supporting this program, is creating a community of scientists and engineers who are actively working on and knowledgeable in this field. An important component of this program is the connection to international efforts, particularly to the European Community (EC) programs. We are in the process of connecting our research program to NF-Pro, a four-year integrated project (2004-2007) supported by the EC, as part of their Sixth Framework Program. NF-Pro brings together 40 nuclear research and waste management organizations with the aim of integrating European 
research on the near field. We have also initiated contact with the EU MICADO (Model uncertainty for the mechanism of dissolution of spent fuel in a nuclear waste repository) program. Through these collaborations, we will leverage present U.S. funding for increased understanding and enhance the international knowledge and reputation of the U.S. program.

The present program, summarized in the following pages, consists of 15 separate programs that involve five national laboratories and five universities (one in Great Britain). In many instances, university investigators have programs closely tied to national laboratories in order to utilize unique facilities for handling highly radioactive materials. Three of the graduate students in this program are supported by OCRWM Fellowships and have completed practica at national laboratories this past summer.

The research programs address four critical areas:

\section{SNF Dissolution Mechanisms and Rates}

The initial release of radionuclides is governed by the specific mechanisms and rates of dissolution, which in turn, vary as a function of $\mathrm{pH}$, dissolved oxygen concentration, temperature, solution composition, fuel chemistry (i.e., burn-up), and mode of contact with water. Systematic studies are being conducted of radionuclide release from
SNF as a function of these parameters, with special attention being paid to the effects of radiolysis on matrix dissolution rates and the formation of secondary phases. The program also investigates the effects of water that may condense and accumulate on failed spent fuel pins. By the process of deliquescence of hygroscopic fission product phases, alteration products may form on the surfaces of the SNF.

Descriptions of this individual program area are provided in the two-page summaries on pp. 9-16.

\section{Formation and Properties of $\mathrm{U}^{6+}$ Secondary Phases}

Under an oxidizing environment, the corrosion of SNF leads to the formation of a complicated array of $\mathrm{U}^{6+} \mathrm{sec}-$ ondary phases that may retard release of radionuclides either by co-precipitation/incorporation, sorption, or by forming a physical barrier to the continued contact with water or release of radionuclides. We have established a multi-pronged approach that includes carefully controlled experiments to determine the means and extent of radionuclide incorporation (e.g., ${ }^{237} \mathrm{~Np},{ }^{239} \mathrm{Pu}$, and ${ }^{129} \mathrm{I}$ ) and sorption into and onto the structures of $\mathrm{U}^{6+}$ secondary phases. The experimental work is supported by the application of advanced techniques (e.g., x-ray absorption spectroscopy at the Advanced Photon Source at Argonne National Laboratory, laser-ablation inductively coupled

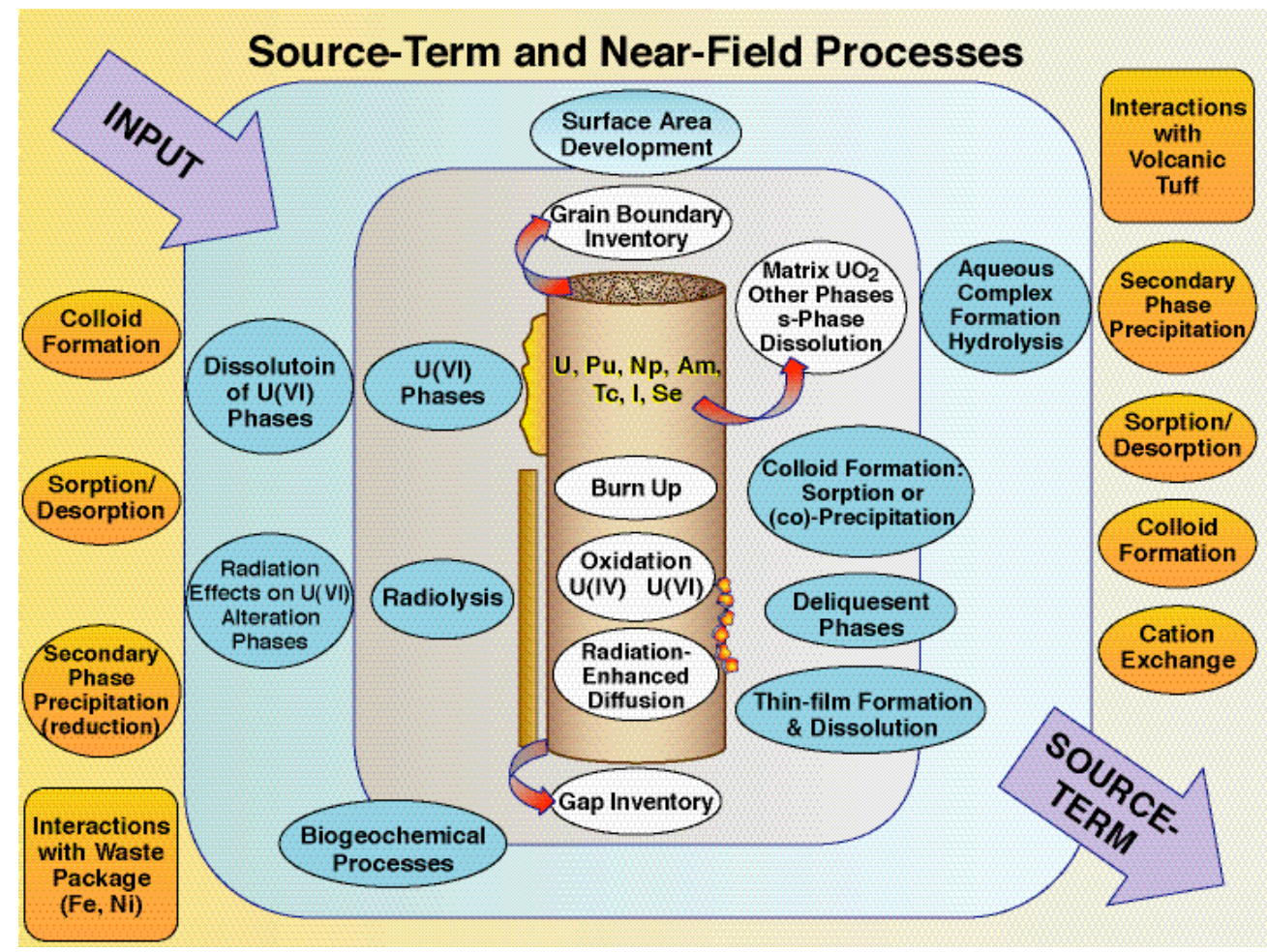

Figure I. Schematic illustration of the potentially important processes in the Source Term Thrust research program 
plasma mass spectroscopy, and in situ spectroelectrochemical techniques) in order to determine the extent of incorporation and sorption of radionuclides in/on $\mathrm{U}^{6+}$ secondary phases. The stability of these phases is being determined by high-temperature oxide-melt solution calorimetry and reversible solubility measurements, as well as systematic irradiation experiments. Computational simulations involving quantum mechanical calculations are being used to investigate the energetics of the incorporation and sorption processes. In addition, actinide complex stability constants at elevated temperatures are being measured using potentiometry, solvent extraction, spectrophotometric, and nuclear magnetic resonance measurements. The experimental and modeling studies are supported and confirmed by studies of natural occurrences of SNF, namely at the Oklo natural reactors.

Descriptions of this individual program area are provided in the two-page summaries on pp. 17-36.

\section{Waste Form-Waste Package Interactions in the Near Field}

The SNF will corrode and release radionuclides in an environment dominated by the presence of uranium, iron, and solutions whose compositions are the result of interactions with the waste forms, waste packages, and the surrounding volcanic tuff. These interactions buffer the environment in which the SNF corrodes and also offer additional opportunities for reduced mobility of radionuclides. We have research programs to investigate the types and behaviors of waste package corrosion products, and their potential for reduction and sorption of key radionuclides (e.g., uptake of ${ }^{99} \mathrm{Tc}$ onto iron oxyhydroxides). We also will investigate the interactions of $\mathrm{UO}_{2}$ with solutions in contact with volcanic tuff using the pressurized unsaturated flow (PUF) system and in situ analytical techniques to investigate and characterize the secondary phases that form. Again, computational simulations of atomic-scale interactions will be used to interpret and support the experimental results.

Descriptions of this individual program area are provided in the two-page summaries on pp. 37-44.

\section{Integration of In-Package Chemical and Physical Processes}

The greatest challenge for this program is to integrate the scientific results into a larger scale model of the source term and near-field interactions. To accomplish this, we have immediately begun creating numerical models that capture the important physical and chemical processes that lead to radionuclide release from SNF. The source term model will be coupled to a drift/near-field-scale model that captures the relevant thermal-hydrologicchemical regimes as a function of time. This integrated model will be used to establish the scientific links among our science programs and provide a basis for understanding the behavior of SNF at different time frames: (1) prior to breach of the waste package; (2) at the time of early breaches of the waste package at elevated temperature; and (3) after breach at long periods, greater than 100,000 years, but at essentially ambient conditions.

Descriptions of this individual program area are provided in the two-page summaries on pp. 45-51.

\section{Acknowledgments}

This work is supported by the Director, Office of Civilian Radioactive Waste Management, Office of Science and Technology and International, of the U.S. Department of Energy. 
This page intentionally left blank. 


\section{SNF DISSOLUTION \\ MECHANISMS AND RATES}

\section{Actinide Thermodynamics at Elevated Temperatures}

Judah Friese, Pacific Northwest National Laboratory (PNNL); Linfeng Rao, Lawrence Berkeley National Laboratory (LBNL)

\section{Dissolution Mechanisms and Rates}

Brady Hanson and Edgar Buck, Pacific Northwest National Laboratory (PNNL); Amanda Kline and William Miller, University of Missouri-Columbia

Implications of Deliquescence and Decay Heat on Source Term Degradation James Jerden, Argonne National Laboratory (ANL) 
This page intentionally left blank. 


\title{
Actinide Thermodynamics at Elevated Temperatures
}

\author{
Judah Friese ' and Linfeng Rao² \\ IPacific Northwest National Laboratory (PNNL) | ${ }^{2}$ Lawrence Berkeley National Laboratory (LBNL)
}

\section{Research Objectives}

The postclosure chemical environment in the proposed Yucca Mountain repository is expected to experience elevated temperatures (OCRWM, 2002). Predicting migration of actinides is possible if sufficient, reliable thermodynamic data on hydrolysis and complexation are available for these temperatures. Data are scarce and scattered for $25^{\circ} \mathrm{C}$, and nonexistent for elevated temperatures (NEA-OECD, 2001).

This collaborative project between LBNL and PNNL collects thermodynamic data at elevated temperatures on actinide complexes that may be formed at Yucca

Mountain. The PNNL team will measure actinide-complex stability constants via potentiometry, solvent extraction, and spectrophotometric and nuclear magnetic resonance measurements, while LBNL will perform calorimetric studies on actinide complexation at elevated temperatures. These data allow calculation of thermodynamic parameters for actinide complexation in the $25-70^{\circ} \mathrm{C}$ temperature range.

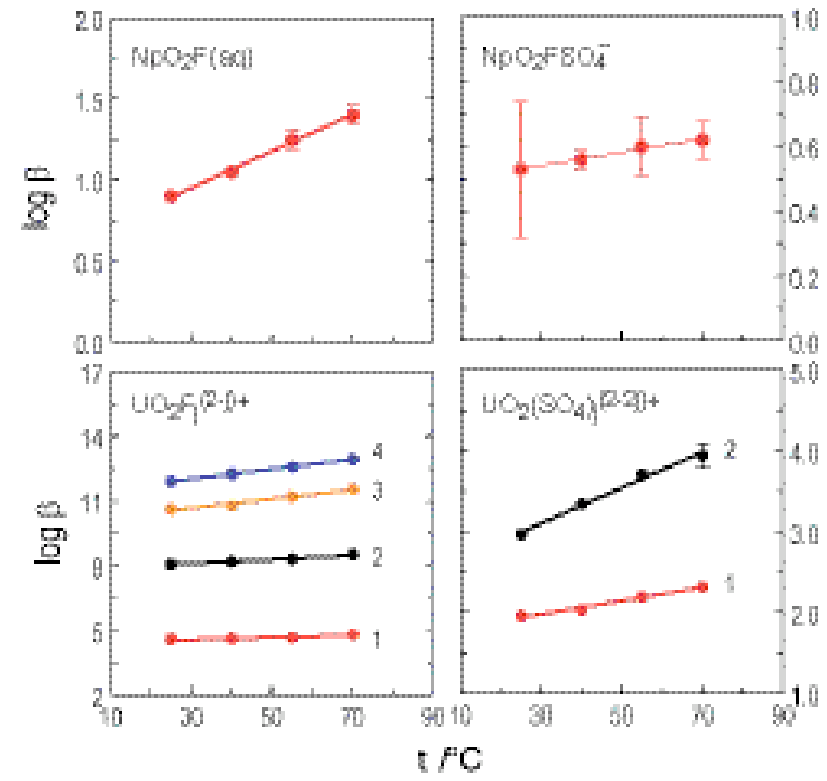

Figure I. Effect of temperature on the stability of the $\mathrm{Np}(\mathrm{V}) /$ fluoride, $\mathrm{Np}(\mathrm{V}) / \mathrm{sul}$ fate, $\mathrm{U}(\mathrm{VI}) /$ fluoride and $\mathrm{U}(\mathrm{VI}) /$ sulfate complexes at different temperatures $(\mathrm{I}=\mathrm{I}$ $\mathrm{M} \mathrm{NaClO4)}$

\section{Approach}

Potentiometry measures voltage as a function of changing concentration; the measured voltage is used to calculate ion concentrations and determine stability constants for complexing agents. Solvent extraction uses differences in the distribution coefficient to determine metal complexation stability constants. Titration calorimetry directly measures reaction heat of actinide complexation with ligands at variable temperatures. Nuclear magnetic resonance (NMR) spectroscopy measures chemical shifts in species of nuclei present according to fractional populations. Since quantities depend on values of the equilibrium constant, the chemical shift becomes a function determined analogously to the potentiometric case. Spectrophotometric methods measure species that arise from a combination of actinide and complexant, described in terms of their characteristic absorbance found in literature. This knowledge identifies species or oxidation states given a variety of conditions.

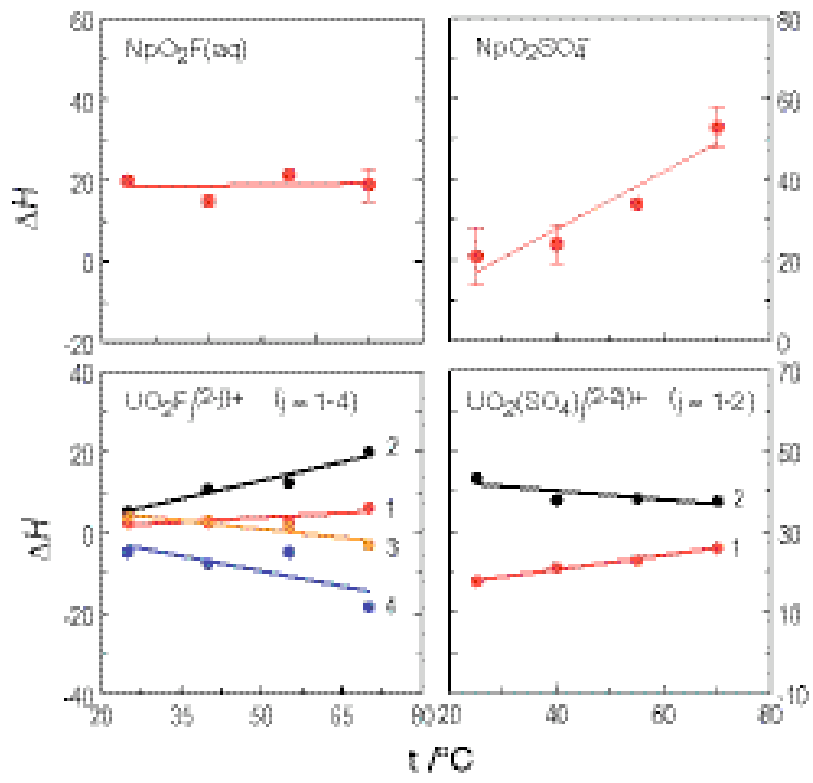

Figure 2. The enthalpy of complexation (in $\mathrm{k} \cdot \bullet \mathrm{mol}-\mathrm{I}$ ) at different temperatures for the $\mathrm{Np}(\mathrm{V}) /$ fluoride, $\mathrm{Np}(\mathrm{V}) /$ sulfate, $\mathrm{U}(\mathrm{VI}) /$ fluoride, and $\mathrm{U}(\mathrm{VI})$ /sulfate complexes $(I=I \mathrm{M} \mathrm{NaClO} 4)$ 


\section{Accomplishments}

Potentiometric titration experiments determined stability constant values at 25 and $40^{\circ} \mathrm{C}$ for fluoride, phosphate, and sulfate ligands. Solvent extraction experiments determined stability constants of $\mathrm{Np}(\mathrm{V})$ fluoride, sulfate, and phosphate complexes at variable temperatures; results were summarized and submitted for publication. Titration calorimetry experiments measured the stability constants and/or enthalpy of complexation for the $\mathrm{Np}(\mathrm{V}) /$ fluoride, $\mathrm{Np}(\mathrm{V}) /$ sulfate, $\mathrm{U}(\mathrm{VI}) /$ fluoride, and $\mathrm{U}(\mathrm{VI}) /$ sulfate complexes in a temperature range of $25-70^{\circ} \mathrm{C}$.

Complexation of $\mathrm{Np}(\mathrm{V})$ and $\mathrm{U}(\mathrm{VI})$ with fluoride and sulfate is enhanced at higher temperatures. The change of enthalpy with temperature is more diverse, indicating complexation reactions have different heat capacity changes.

The NMR and spectroscopy experiments investigated chemical- and temperature-dependent perturbations to the known speciation of the actinyl carbonates in the $\mathrm{pH}$ region between 5 and 9 . Results were summarized in two papers on the speciation of mixed uranyl carbonato-peroxy complexes in slightly basic and slightly acidic solution.

Accurate thermodynamic data at elevated temperatures for the complexation of $\mathrm{Np}(\mathrm{V})$ and $\mathrm{U}(\mathrm{VI})$ with inorganic ligands likely to be present in the proposed Yucca Mountain repository are important to the performance assessment of the repository. Accurate and realistic predictions can be made for release and transport of actinides in the postclosure chemical environment, significantly reducing uncertainty in the long-term performance assessment of the proposed repository.

Temperature in the near field of the proposed repository is expected to be $70-80^{\circ} \mathrm{C}$ to ambient for most of the postclosure period (OCRWM, 2002). Data from this work extend the thermodynamic database from 25 to $70^{\circ} \mathrm{C}$; inclusion of the stability constant, enthalpy, and heat capacity of complexation data allows accurate calculation of dissolved actinide species concentrations in solution.

\section{References}

OCRWM, Yucca Mountain Science and Engineering Report Rev.1, DOE/RW-0539-1, Office of Civilian Radioactive Waste Management: North Las Vegas, NV, 2002.

NEA-OECD, Chemical Thermodynamics of Neptunium and Plutonium, NEA-OECD, Elsevier, Amsterdam, 2001.
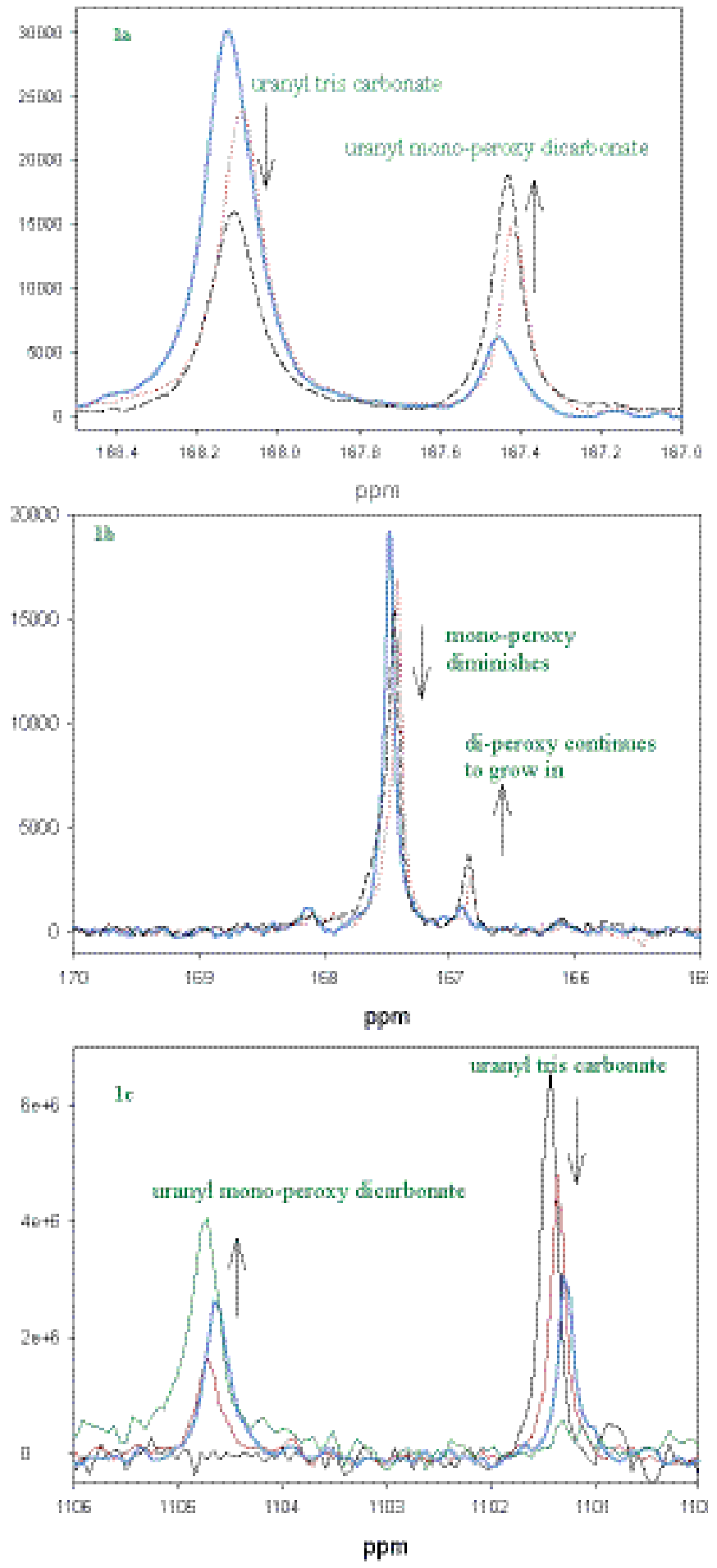

Figure 3. The chemical shift of the NMR resonances have units of parts-per-million (ppm). All ${ }^{3} \mathrm{C}$ chemical shifts are reported in ppm relative to the carbonyl carbon of acetone- $\mathrm{d}^{6}$ at $\delta=206.0 \mathrm{ppm}$ from zero. All ${ }^{17} \mathrm{O}$ NMR chemical shifts are referenced to the ${ }^{17} \mathrm{O}$ resonance in water at $\delta=0 \mathrm{ppm}$. The ${ }^{13} \mathrm{C}$ spectra in Figures $3 \mathrm{a}$ and $3 \mathrm{~b}$ follow the ingrowth of the $\mathrm{I}: \mathrm{I}$ mono-peroxy, di-carbonato complex and the 2:I di-peroxy, mono-carbonato complex (tentative assignments). Figure $3 \mathrm{c}$ is the ${ }^{17} \mathrm{O}$ NMR spectra of the same solutions shown in Figures $\mathrm{Ia}$ and $\mathrm{Ib}$. In both data sets, the addition of hydrogen peroxide lowered the solution $\mathrm{pH}$ and the NMR signals were shifted to slightly lower frequency. 


\title{
Dissolution Mechanisms and Rates
}

\author{
Brady Hanson', Edgar Buck', Amanda Kline², and William Miller² \\ IPacific Northwest National Laboratory (PNNL) | 2University of Missouri-Columbia
}

\section{Research Objectives}

This project consists of two tasks to examine: (1) matrix dissolution of commercial spent nuclear fuel (SNF) as a function of $\mathrm{pH}$, dissolved oxygen concentration, temperature, solution composition, etc., and more importantly as a function of fuel chemistry (i.e., burnup) and water contact mode and quantity; and (2) radiolysis of solutions in contact with the SNF and the effect on matrix dissolution rates and alteration phase formation.

\section{Approach}

The rate of SNF dissolution has been shown to decrease as the extent of dissolution increases. Examination of the altered fuel reveals enhanced concentrations of less soluble elements (zirconium [Zr], plutonium [Pu]) at the surface of the specimens. Oxidation of SNF also exhibits a strong dependence on burnup, with higher burnup fuels being more resistant to formation of higher oxidation states $\left(\mathrm{U}_{3} \mathrm{O}_{8}\right)$. These observations lead to the premise that the fission products and actinides in SNF alter the fuel chemistry

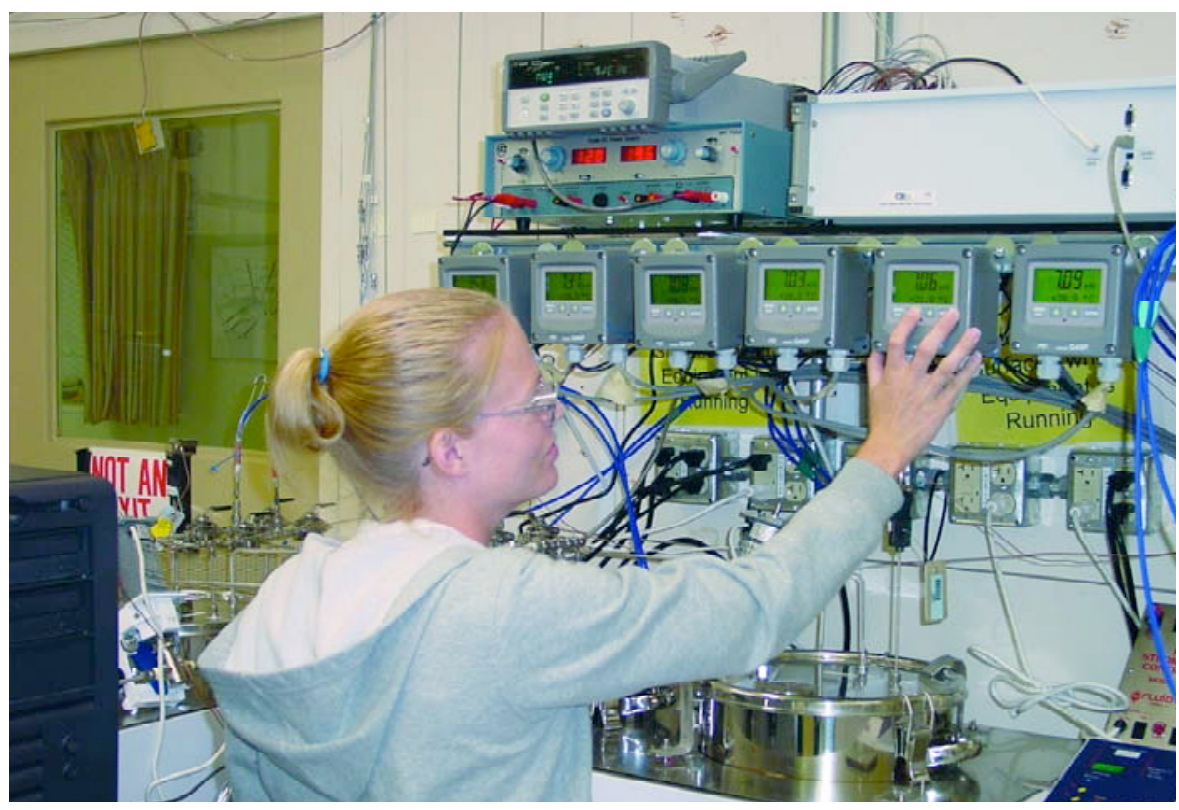

Figure I. Amanda Kline operates the state-of-the-art SPFT testing apparatus at PNNL as part of her Ph.D. research. sufficiently such that SNF in the absence of radiolysis should undergo oxidative dissolution slower than unirradiated or fresh SNF. This chemistry effect reduces the overall effective surface area of fuel exposed to leaching and reduces the sites for oxygen reduction.

The fuel-chemistry effects on dissolution are tested by preparing $\mathrm{UO}_{2}$ doped with various concentrations of elements representing fission products and actinides. First, the effect of single dopants of various concentrations, ionic radii, and charge density will be tested, followed by more complex mixtures. The doped- $\mathrm{UO}_{2}$ is pressed into pellets and sintered to more accurately imitate SNF. The sintered fuels are subjected to dissolution under various water contact modes to simulate the wide range of conditions that may exist within a geologic repository. Rate information is obtained by performing single-pass flowthrough (SPFT), static, and humid air corrosion tests, all utilizing single grain powders, fragments, and pellets to determine the effects of water contact mode and quantity, fuel-to-water ratios, solubility control, and effective surface area.

SNF dissolution is influenced by the radiolysis of water creating radicals and molecules that are more oxidizing than dissolved oxygen. However, the contribution of $\beta$ and $\gamma$ radiation decreases significantly over the first 500 years. The long-term radiolysis contribution will be from $\alpha$ decay of long-lived actinides. The effect of each type of radiation on water radiolysis and subsequent fuel dissolution will be examined by preparing sintered $\mathrm{UO}_{2}$ pellets doped with single radionuclides and subjecting the specimens to the various dissolution conditions described above. Simulated SNF, called RADFUEL (radiolytically aged fuel), containing the proper concentrations of all radioisotopes and stable elements present at long decay times (e.g., 500, 1,000, and 5,000 years), will then be prepared and tested. 


\section{Accomplishments}

A state-of-the-art SPFT testing system has been built (see Figure 1). Eight SPFT tests at each of three temperatures (to simulate different times in the repository evolution) can be performed simultaneously, producing significantly more data in short times than has been possible previously. The system allows proper control of the feedwater solutions to eliminate fluctuations in rate data. The $\mathrm{pH}$, dissolved oxygen concentration, and temperature are monitored continuously using inline sensors. Systems for static testing and humid air corrosion have been built and are operational.

$\mathrm{UO}_{2}$ pellets have been pressed and sintered, varying the pressure, temperature, and time to determine the effect on properties such as grain size, density, and porosity. Grain sizes typical of modern commercial fuels are achieved with a 24-hour sinter. Efforts to achieve densities and pore sizes comparable to commercial fuels continue. The new surface area analyzer has been installed and tested with standards and other samples. We have acquired an FEI 300 $\mathrm{keV}$ Tecnai 30S-Twin analytical transmission electron microscope for actinide-bearing materials research. Further work into the detection of neptunium with electron energy-loss spectroscopy has been conducted.

Monte Carlo-based codes to determine the energy deposited in water as a function of particle size, fuel-to-water ratio, and energy of the incident radiation have been developed at the University of Missouri-Columbia. Efforts continue to allow accurate prediction of the radiolytic production of oxidizing species for each radionuclide, allowing interpretation of the data produced under this project as well as previous SNF data. A detector system has been tested and evaluated for on-line monitoring or radiolytic $\mathrm{H}_{2}$ production. This provides effective G-values for radiolytic products formed during vapor-phase corrosion of RADFUELs.

Results of scoping studies indicate that some key radioelements of concern (Tc and $\mathrm{Pu}$ ) are not released congruently with the U matrix, but build up on the surface of the reacted fuel. The contribution of radiolysis, especially from $\alpha$ decay, are significantly less if the fuel remains as fragments or limits the water layer surrounding individual grains. Dissolution rates of older SNF under proposedrepository-relevant conditions may be less than the conservative values presented in literature.

\section{Acknowledgments}

The work of Amanda Kline was performed under appointment of the Office of Civilian Radioactive Waste Management Fellowship Program administered by Oak Ridge Institute for Science and Education, under a contract between the U.S. Department of Energy and the Oak Ridge Associated Universities. 


\section{Implications of Deliquescence and Decay Heat on Source Term Degradation}

James Jerden

Argonne National Laboratory (ANL)

\section{Research Objectives}

The goal of this project is to provide mechanistic insights into processes that could cause water to condense and accumulate on failed spent nuclear fuel (SNF) pins. A particularly important process in this regard is the deliquescence of hygroscopic fission product minerals present within fuel grain boundaries and the fuel/cladding gap. Deliquescence could lead to the accumulation of water, despite the fact that the fuel assemblies will be the hottest material in the waste packages. Therefore, an enhanced understanding of the deliquescence of hygroscopic fission product phases is important to the development of mechanistic-based models of SNF degradation.

Our specific experimental objectives are to: (1) develop a predictive understanding of the onset of deliquescence on SNF by quantifying the deliquescence thresholds (as a function of temperature) of hygroscopic primary phases in the fuel or fuel/cladding gap, (2) develop a predictive understanding of how the aqueous films that form from deliquescence evolve chemically as the fuel corrodes at relevant temperatures and relative humidities, and (3) determine the paragenesis, mineral chemistry, and deliques- cence behavior of alteration phases that form as SNF corrodes in aqueous films formed by deliquescence.

\section{Approach}

The deliquescence behavior of key fission product salts is being quantified using an isopiestic method. This approach is based on the fact that in a closed system consisting of a hygroscopic salt, an aqueous salt solution, and a gas phase, water will partition via evaporation or condensation until its chemical potential is equal in all phases (i.e., the system reaches equilibrium). Our experiments involve reacting a dry powder containing the hygroscopic mineral(s) of interest with air of a known relative humidity at a controlled temperature in a sealed system. The initial relative humidity is controlled using a sodium chloride salt solution. When the deliquescence threshold (relative humidity at which water will condense) of the sample is exceeded, the amount of water that accumulates due to deliquescence is measured gravimetrically. The amount of water that accumulates as the deliquescent solution equilibrates with the surrounding gas phase is also measured gravimetrically.

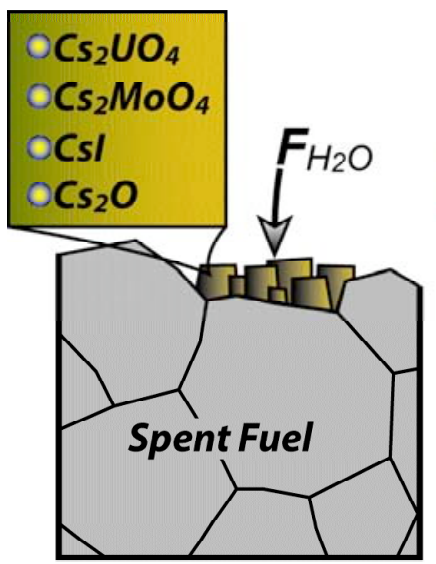

(a)

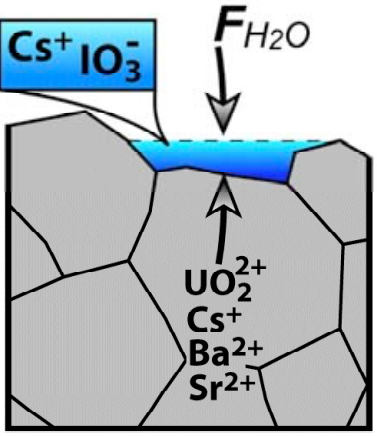

(b)

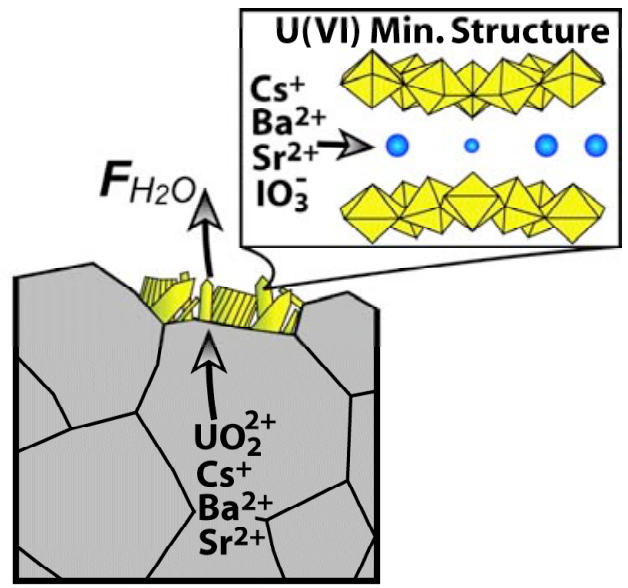

(c)

Figure I. A summary of the processes involved in fission-product mineral deliquescence: (a) If the ambient relative humidity increases above approximately $80 \%$, deliquescence will occur despite the fact that the fuel is $\mathrm{I}^{\circ} \mathrm{C}-5^{\circ} \mathrm{C}$ hotter than the surrounding environment; (b) water will continue to condense as long as the activity of water in the deliquescent brine is lower than the ambient relative humidity; (c) the precipitation of uranyl corrosion phases counteracts deliquescence (increases the activity of water in the deliquescent brine) as deliquescent components are incorporated into the nondeliquescent uranyl minerals. Thus, the precipitation of uranyl minerals promotes evaporation of brine solutions from the SNF surface. 


\section{Accomplishments}

We have quantified the deliquescence behavior of the key fission product minerals cesium iodide (CsI), cesium molybdate $\left(\mathrm{Cs}_{2} \mathrm{MoO}_{4}\right)$ and selected cesium uranates $\left(\mathrm{Cs}_{2} \mathrm{UO}_{4}\right.$ and $\left.\mathrm{Cs}_{2} \mathrm{U}_{2} \mathrm{O}_{7}\right)$ over temperatures ranging from $40^{\circ} \mathrm{C}$ to $90^{\circ} \mathrm{C}$. We have also completed experiments investigating how the deliquescence process, and subsequent chemical evolution of deliquescent solutions, is influenced by SNF corrosion. These tests involved performing the isopiestic deliquescence experiments in the presence of SNF surrogates (uranium oxides). Our experimental results have been used to quantify the conditions under which deliquescence could initiate SNF corrosion and how corrosion reactions may counteract deliquescent water accumulation.

Our experiments indicate that fission product deposits containing cesium iodide, cesium molybdate, and the cesium uranate $\mathrm{Cs}_{2} \mathrm{UO}_{4}$ will deliquesce (leading to brine accumulation) at relative humidities greater than $80 \%$ and temperatures ranging from $40^{\circ} \mathrm{C}$ to $90^{\circ} \mathrm{C}$. This process will occur even if the SNF is up to $5^{\circ} \mathrm{C}$ hotter than the surrounding environment. Once the deliquescence process has started, water will continue to condense on the surface of the fuel as long as the activity of water in the brine is lower than the ambient relative humidity. However, our results also show that once SNF corrosion phases (uranyl minerals) begin to form, the deliquescence process becomes self-limiting, owing to the incorporation of deliquescent components into these stable alteration phases. Our results therefore indicate that while deliquescence may lead to a transient accumulation of water and incipient corrosion, this process will be counteracted by the sequestration of deliquescent components into nondeliquescent minerals (Figure 1).

\section{Related Publications}

Jerden, J. L. Jr., M. Goldberg, J. Cunnane, T. Bauer, R. Wigeland, and R. Nietert, Can spent nuclear decay heat prevent radionuclide release? Materials Research Society Proceedings, Symposium CC, Scientific Basis for Nuclear Waste Management, 824, pp. 101-106, 2004. 


\title{
FORMATION AND PROPERTIES OF U6+ SECONDARY PHASES
}

\author{
Mitigation of the Release of ${ }^{129}$ I from Spent Nuclear Fuel via Uptake by \\ Uranyl Alteration Phases \\ Thomas E. Albrecht-Schmitt, Auburn University; lain May, The University of \\ Manchester, Great Britain
}

Impact of Uranyl Alteration Phases of Spent Fuel on Mobility of Neptunium (Np) and Plutonium (Pu) in Yucca Mountain

Peter C. Burns, University of Notre Dame

\section{Actinide Adsorption to U(VI) Silicates}

S. B. Clark, Washington State University; Lawrence C. Hull, Idaho National Laboratory

Corrosion of Spent Nuclear Fuel: The Long-Term Assessment

Rodney C. Ewing, University of Michigan

Direct Determination of the Thermodynamic Properties of Uranyl Minerals Important for the Performance of the Proposed Geological Repository at Yucca Mountain

Jeremy B. Fein, Peter C. Burns, University of Notre Dame; Alexandra Navrotsky, University of California, Davis

Chemical and Coordination Structure of Radionuclides in Spent Nuclear Fuel and Its Alteration Products: Understanding Release Pathways Jeffrey A. Fortner, A. Jeremy Kropf, and James C. Cunnane, Argonne National Laboratory (ANL)

An In Situ Spectroelectrochemical Study of Neptunium (Np) Redox, Dissolution, and Precipitation Behavior at the Corroding Spent Nuclear Fuel/Alteration Phase Interface

Artem Guelis, Jeremy Kropf, Christopher Johnson, and Jeffrey Fortner, Argonne National Laboratory (ANL); Petr Vanysek, Northern Illinois University

\section{Natural Sequestration of Radionuclides In Volcanic Tuff} Jonathan Icenhower, Edgar Buck, Eric Pierce, and Dawn Wellman, Pacific Northwest National Laboratory (PNNL); Andreas Lüttge, Rice University

\section{Surface Charge and Radionuclide Adsorption Characteristics of} U(IV,VI) Oxyhydroxides at $25-150^{\circ} \mathrm{C}$

David J. Wesolowski, Donald A. Palmer, Laetitia Delmau, and Lawrence M. Anovitz, Oak Ridge National Laboratory (ORNL); Michael L. Machesky, Illinois State Water Survey 
This page intentionally left blank. 


\title{
Mitigation of the Release of 129 from Spent Nuclear Fuel via Uptake by Uranyl Alteration Phases
}

\author{
Thomas E. Albrecht-Schmitt ${ }^{1}$ and lain May ${ }^{2}$ \\ 'Auburn University | ${ }^{2}$ The University of Manchester, Great Britain
}

\section{Research Objectives}

Iodine-129 $\left({ }^{129} \mathrm{I}\right)$ is a long-lived $\left(\mathrm{t}_{1 / 2}=1.7 \times 10^{7}\right) \beta$-emitting fission product present in spent nuclear fuel (SNF). In groundwater, such as that from the J-13 well near Yucca Mountain, it is expected to exist as iodate, $\mathrm{IO}_{3}{ }^{-}$, and iodide. The objective of this program is to study the potential incorporation of ${ }^{129} \mathrm{IO}_{3}$ - into uranyl alteration phases that will likely form as the result of the interaction of SNF fuel with groundwater at the proposed Yucca Mountain repository. We propose that the trigonal pyramidal iodate anion can substitute in trace amounts in the place of tetrahedral $\left[\mathrm{SiO}_{3}(\mathrm{OH})\right]^{3-}$ and $\mathrm{PO}_{4}{ }^{3-}$, as well as for trigonal planar $\mathrm{CO}_{3}{ }^{2-}$. Experiments will be performed whereby uranyl silicates, phosphates, and carbonates are synthesized in the presence of trace amounts of ${ }^{129} \mathrm{IO}_{3}$. Previously made uranyl alteration phases will also be equilibrated with ${ }^{129} \mathrm{IO}_{3}{ }^{-}$. The uptake of ${ }^{129} \mathrm{IO}_{3}{ }^{-}$will be studied by counter methods, x-ray diffraction, inductively coupled plasmamass spectroscopy (ICP-MS), and inductively coupled plasma-atomic emission spectroscopy (ICP-AES). In the case of uranyl carbonates such as rutherfordine,

$\mathrm{UO}_{2}\left(\mathrm{CO}_{3}\right)$, charge-balance requirements may allow for the simultaneous incorporation of both ${ }^{129} \mathrm{IO}_{3}{ }^{-}$and ${ }^{237} \mathrm{NpO}_{2}{ }^{+}$. Experiments to test for this concomitant uptake will also be performed. We anticipate that the formation of uranyl alteration phases will indeed act as a mechanism for the retardation of the release of ${ }^{129} \mathrm{I}$. Data that we generate may be used to modify current models for the release of 129I from SNF into the environment.

\section{Approach}

Most of the exploratory syntheses in recent uranyl chemistry have either been performed under ambient conditions or under hydrothermal conditions near $200^{\circ} \mathrm{C}$. Conditions relevant to the proposed Yucca Mountain repository are expected to be near $70-90^{\circ} \mathrm{C}$ and lower. We will approach the incorporation of ${ }^{237} \mathrm{~Np}$ and ${ }^{129} \mathrm{I}$ in two different ways. First, experiments will be performed whereby uranyl silicates, phosphates, and carbonates are crystallized in the presence of ${ }^{237} \mathrm{~Np}$ and ${ }^{129}$ I. Second, we will allow previously crystallized uranyl alteration phases to equilibrate with solutions containing trace amounts of $\mathrm{NpO}_{2}{ }^{+}$and $\mathrm{IO}_{3}{ }^{1-}$. Bulk-product composition will be determined using powder $x$-ray diffraction. The uptake of radionuclides will be measured using a scintillation counter, ICP-MS, and ICP-AES. It will be important to determine the structures of actinyl iodates that crystallize at near-neutral $\mathrm{pH}$ to show whether the structures of these compounds can lend some guidance in terms of which uranyl alteration products are likely to uptake $\mathrm{IO}_{3}{ }^{1-}$. Finally, while the solution complexation of uranyl by iodate has been studied at $25^{\circ} \mathrm{C}$ at low $\mathrm{pH}$, data for complexation at elevated temperatures and at $\mathrm{pH}$ conditions similar to those expected at Yucca Mountain have not been performed. We will determine the complexation thermodynamic parameters of $\mathrm{UO}_{2}{ }^{2+}$ with iodate at $90^{\circ} \mathrm{C}$. The complexation of $\mathrm{NpO}_{2}{ }^{+}$by iodate in solution has not been addressed at all, and this will also need to be done.

\section{Accomplishments}

The $\mathrm{Np}(\mathrm{V})$ compound $\alpha-\mathrm{AgNpO}_{2}\left(\mathrm{SeO}_{3}\right)$ was recently prepared by our group and its structure determined (Albrecht-Schmitt et al., 2003). The neptunyl selenite sheets in this compound are remarkably similar to those in $\mathrm{UO}_{2}\left(\mathrm{CO}_{3}\right)$ and $\mathrm{UO}_{2}\left(\mathrm{SeO}_{3}\right)$.

We propose that the structure of $\alpha-\mathrm{AgNpO}_{2}\left(\mathrm{SeO}_{3}\right)$ provides strong evidence that $\mathrm{SeO}_{3}{ }^{2-}$ can indeed substitute in the place of $\mathrm{CO}_{3}{ }^{2-}$, but will the same situation be true for iodate? There are two factors that need to be considered in these substitution patterns. First, is there a match between the geometry of two anions being considered? In the case of selenite versus carbonate, one is pyramidal and the other planar. In this case, the edge-length of the triangular anions may be more important. The edge-length of carbonate is approximately $0.22 \AA$, whereas selenite ranges from 0.255 to $0.266 \AA$. This small increase in size is apparently not a problem. Iodate I-O bond distances are approximately $0.1 \AA$ longer than the Se-O bonds in selenite. However, iodate is more pyramidalized than selenite, and the edgelength of iodate is only $0.01 \AA$ A larger. Therefore, from a purely structural perspective, iodate can probably also substitute in the place of carbonate. The second consideration is charge. How can iodate substitute in the place of carbonate and charge balance still be maintained? This is actually a difficult hurdle: it is extremely unlikely that the uranium will be reduced from the +6 oxidation state, because $\mathrm{U}(\mathrm{V})$ is subject to rapid disproportionation in water. However, since ${ }^{237} \mathrm{~Np}(\mathrm{~V})$ will also be present in the 
form of $\mathrm{NpO}_{2}{ }^{+}$from SNF, then it might be possible to do a simultaneous substitution of both $\mathrm{NpO}_{2}{ }^{+}$for $\mathrm{UO}_{2}{ }^{2+}$ and $\mathrm{IO}_{3}{ }^{1-}$ for $\mathrm{CO}_{3}{ }^{2-}$.

\section{References}

Albrecht-Schmitt, T.E., P. Almond, and R.E. Sykora, Cation-cation interactions in neptunyl(V) compounds: Hydrothermal preparation and structural characterization of $\mathrm{NpO}_{2}\left(\mathrm{IO}_{3}\right)$ and $\alpha$ - and $\beta-\mathrm{AgNpO}_{2}\left(\mathrm{SeO}_{3}\right)$. Inorganic Chemistry, 42, 3788-3795, 2003. 


\section{Impact of Uranyl Alteration Phases of Spent Fuel on Mobility of Neptunium ( $\mathrm{Np}$ ) and Plutonium (Pu) in Yucca Mountain}

Peter C. Burns

University of Notre Dame

\section{Research Objectives}

Uranyl alteration phases of spent nuclear fuel (SNF) that form in a repository such as proposed at Yucca Mountain will likely incorporate a variety of radionuclides, and will thus impact their future mobilities. The objective of this ongoing research is to understand the factors that impact incorporation of ${ }^{237} \mathrm{~Np}$ into uranyl phases that are likely to form as alteration products of SNF under moist, oxidizing conditions.

\section{Approach}

This research examines the incorporation of $\mathrm{Np}^{5+}$ into powders of uranophane, $\mathrm{Ca}\left[\left(\mathrm{UO}_{2}\right)\left(\mathrm{SiO}_{3} \mathrm{OH}\right)\right]_{2}\left(\mathrm{H}_{2} \mathrm{O}\right)_{5}$, and soddyite, $\left(\mathrm{UO}_{2}\right)_{2}\left(\mathrm{SiO}_{4}\right)\left(\mathrm{H}_{2} \mathrm{O}\right)_{2}$, under a range of $\mathrm{pH}$ and temperature conditions. It also examines incorporation of $\mathrm{Np}^{5+}$ into single crystals of uranyl phases to provide a compelling case for the importance of this process in repository performance. Following optimization of synthesis procedures, single crystals of becquerelite,

$\mathrm{Ca}\left[\left(\mathrm{UO}_{2}\right)_{3} \mathrm{O}_{2}(\mathrm{OH})_{3}\right]_{2}\left(\mathrm{H}_{2} \mathrm{O}\right)_{8}$, Na-substituted metaschoepite, $\mathrm{Na}\left[\left(\mathrm{UO}_{2}\right)_{4} \mathrm{O}_{2}(\mathrm{OH})_{5}\right]\left(\mathrm{H}_{2} \mathrm{O}\right)_{5}$, $\mathrm{K}\left(\mathrm{UO}_{2}\right)\left(\mathrm{SO}_{4}\right)(\mathrm{OH})$, and $\left(\mathrm{UO}_{2}\right)_{3}\left(\mathrm{PO}_{4}\right)_{2}\left(\mathrm{H}_{2} \mathrm{O}\right)_{4}$ were grown by mild hydrothermal methods at $145^{\circ} \mathrm{C}$. A stock solution of $\mathrm{Np}^{5+}$ was added to the reactants.

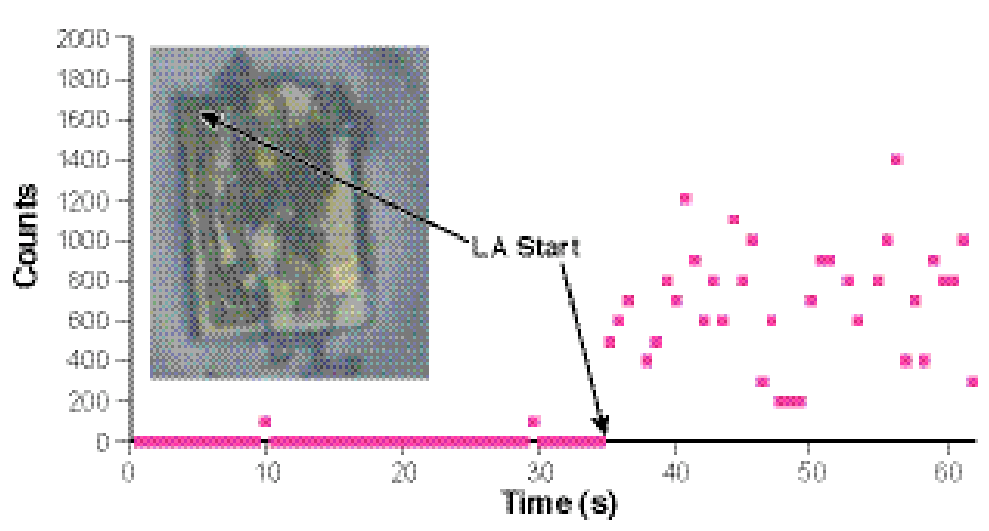

Figure I. LA-ICP-MS data collected for a crystal of synthetic becquerelite grown from a solution containing $\sim 700 \mathrm{ppm} \mathrm{Np}{ }^{5+}$. The crystal analyzed, as well as the laser ablation track, are shown in the photo inset. Note that the laser beam was turned on at 34 seconds; the signal prior to 34 seconds is the background.
To quantify trace levels of $\mathrm{Np}$ in uranyl phases, laser-ablation inductively coupled plasma mass spectroscopy (LAICP-MS) with a high-resolution magnetic sector ELEMENT 2 and a New Wave UP 213 nm laser ablation system has been utilized. This approach provides complete separation of the signals for Np-237 and U-238. A crystal of becquerelite exhibiting a laser ablation track is shown in Figure 1, together with the count-rate for Np-237. The average count-rate during laser ablation corresponds to $\sim 800$ ppm Np.

Uranyl oxide hydrates and uranyl silicates that could potentially form at Yucca Mountain in the vicinity of nuclear waste may later come in contact with solutions containing substantial peroxide (due to radiolysis of water). Synthetic soddyite, becquerelite, compreignacite, $\mathrm{K}_{2}\left[\left(\mathrm{UO}_{2}\right)_{3} \mathrm{O}_{2}(\mathrm{OH})_{3}\right]_{2}\left(\mathrm{H}_{2} \mathrm{O}\right)_{7}$, and dehydrated schoepite have been used in batch alteration experiments in the presence of peroxide-bearing water to determine the extent of alteration.

To further understand the fate of uranyl phases that form in the proposed repository, drop solution calorimetry has been used to derive the heats of formation of several uranyl oxide hydrates.

\section{Accomplishments}

We have found that the quantity of $\mathrm{Np}$ incorporated into powders of uranophane and soddyite depends upon both the $\mathrm{pH}$ and the temperature of the synthesis. We have also detected $\mathrm{Np}$ in synthetic single crystals of becquerelite, Na-substituted metaschoepite, and $\mathrm{K}\left(\mathrm{UO}_{2}\right)\left(\mathrm{SO}_{4}\right)(\mathrm{OH})$ at about the same concentrations as in the initial reactants. Much higher levels of $\mathrm{Np}$ were observed in $\left(\mathrm{UO}_{2}\right)_{3}\left(\mathrm{PO}_{4}\right)_{2}\left(\mathrm{H}_{2} \mathrm{O}\right)_{4}$. We are currently examining the oxidation state of the $\mathrm{Np}$ in this sample using $\mathrm{x}$ ray absorption spectroscopy.

Relationships between the extent of alteration of the uranyl minerals to uranyl peroxide and the peroxide concentration in the solution have been established, and indicate that contact of these minerals with solutions containing only a small quantity of peroxide leads to extensive alteration. 
Alteration of SNF in a geological repository such as that proposed at Yucca Mountain is expected to result in an extensive suite of uranyl alteration phases. These phases will likely incorporate a variety of radionuclides into their crystal structures, thereby substantially reducing their release rates from the source term. This research has provided the first conclusive evidence for $\mathrm{Np}$ incorporation into single crystals of uranyl phases that are expected to form under repository conditions.
Furthermore, this research has provided insight into the impact of formation conditions on $\mathrm{Np}$ incorporation into the uranyl phases that will be necessary for inclusion of this process in computational modeling of repository performance. The research has also provided important information concerning the longer-term stability of uranyl phases in a geologic repository, by (1) measuring the heats of formation of uranyl oxide hydrate minerals and (2) measuring their alteration in solutions containing peroxide. 


\section{Actinide Adsorption to $\mathrm{U}(\mathrm{VI})$ Silicates}

S. B. Clark' and Lawrence C. Hull2

'Washington State University | ${ }^{2}$ Idaho National Laboratory

\section{Research Objectives}

While a significant amount of research has been devoted to developing thermodynamic data describing the sorption of radionuclides to iron oxides and other geomedia, significant uncertainties exist in describing the interaction of key radionuclides found in high-level radioactive waste with the uranium (U) surfaces expected in corroded spent nuclear fuel. Recent work by us and others indicates that actinide adsorption to the $\mathrm{U}(\mathrm{VI})$ solids expected in the waste package may play a key role in the reduction of dissolved concentrations of radionuclides such as $\mathrm{Np}(\mathrm{V})$. However, the mechanism of adsorption is uncertain, and there is not sufficient knowledge or data to represent the phenomenon in predictive modeling codes. Unfortunately, this situation makes it difficult to consider actinide adsorption to the U(VI) silicates in either geochemical or performance assessment (PA) predictions. The goal of this project is to develop a thermodynamic description of the adsorption of key actinide cations to relevant U(VI) silicates. The thermodynamic description will be represented as surface complexation reaction. Our objectives are to:

1. Study the surface charge associated with well-characterized U(VI) silicate solids under chemical conditions representing the waste package after corrosion.

2. Develop thermodynamic data to describe the adsorption of actinide cations to well-characterized U(VI) silicate solids. Adsorption and desorption experiments are conducted under conditions designed to address the expected chemistries.

3. Verify surface charge behavior and adsorption process es/mechanisms with appropriate spectroscopic tools. We are developing a molecular description of surface roughness and actinide sequestration at $\mathrm{U}(\mathrm{VI})$ silicate surfaces.

4. Use experimental results to parameterize a geochemical model to describe actinide sorption to U(VI) silicate solids. This surface complexation approach will use the diffuse double layer model that can be incorporated into geochemical codes such as $\mathrm{EQ} 3 / 6$.

\section{Approach}

In this project, we are developing thermodynamic data to describe the adsorption of isotopes of $\mathrm{U},{ }^{239} \mathrm{Pu},{ }^{237} \mathrm{~Np}$, and ${ }^{241} \mathrm{Am}$ to U(VI) silicate solids. The data will be derived from experiments and will result in the development of a geochemical model that can predict the degree of adsorption of these radionuclides with changes in waste package chemistry. We are considering molecular-level processes that lead to hysteresis in sorption and that can further reduce dissolved concentrations of radionuclides.

\section{Task I: Measuring the Surface Charge of the U(VI) Silicates}

One of the most important parameters for understanding the sorption of contaminants to surfaces is the electrostatic charge of that surface as a function of $\mathrm{pH}$ and ionic strength. Task 1 must be completed for each U(VI) silicate solid before thermodynamic data describing actinide adsorption to these surfaces can be developed. We expect to determine surface charge for boltwoodite in the first 9 months of the project, and we will continue to determine surface charge for uranophane and sklodowsite for the next 9 months (1.5 years time).

\section{Task 2: Developing Thermodynamic Data on Adsorption Reactions of Key Radionuclides}

As we measure surface-charge parameters for the $\mathrm{U}(\mathrm{VI})$ solids, we will study the adsorption of actinides to these solids under a range of $\mathrm{pH}$ and in solutions relevant to the waste package. The radionuclides that we will focus on will be isotopes of $\mathrm{U},{ }^{239} \mathrm{Pu},{ }^{237} \mathrm{~Np}$, and ${ }^{241} \mathrm{Am}$.

Late in the first year of this project, we expect to complete surface charge experiments with uranophane. We are starting this task by studying $\mathrm{Np}$ interactions with boltwoodite, since $\mathrm{Np}$ represents a significant radionuclide for the Yucca Mountain Total System Performance Assessment (TSPA). We will continue our adsorption studies with uranophane by following with the other isotopes listed above. As we complete adsorption experiments, we are handing off the information to Task 4 . 
Task 3: Verify Speciation, Surface Structure, and Adsorption Processes/Mechanisms with Appropriate Spectroscopic Tools

Because it is unwise to rely simply on bulk-level observations and geochemical modeling to describe the adsorption of actinide cations to $\mathrm{U}(\mathrm{VI})$ silicate surfaces, verification of speciation, surface structure, and adsorption

processes/mechanisms is necessary. Modeling efforts may require consideration of more that one type of adsorption site (e.g., surface vs. edge, or $\mathrm{SiOH}$ vs. $\mathrm{UOH}$ ). Often these differences in interaction between the cation and the surface can be directly observed with spectroscopic tools. Such direct observation provides significant confidence in assumptions made during geochemical modeling (Task 4). Spectroscopic studies also provide direct evidence for hysteresis and the potential advantage in reduction of actinide dissolved concentrations, if these processes can be adequately represented. This task is being initiated during this first year of our work and will continue to the end of the project.

Task 4: Use Experimental Results to Parameterize a Geochemical Model Describing Radionuclide Sorption to $U(V I)$ Silicates

We are conceptualizing actinide adsorption to $\mathrm{U}(\mathrm{VI})$ silicates using a surface complexation model. This approach considers adsorption to result from direct interaction between the radionuclide and a specific surface site. The existence of surface charge can alter the extent of reaction via the electrostatic field at the mineral surface. Modeling sorption with the surface complexation model requires knowledge of: (1) the variation in surface charge with $\mathrm{pH}$ and concentration of adsorbed ions, (2) the number of available surface sites, and (3) the equilibrium constant for the formation of the intrinsic chemical interaction between the surface site and the solute/contaminant/radionuclide of interest. This information is incorporated into the geochemical model as (a) surface protonation constants for surface adsorption sites, (b) a site density per gram of mineral, and (c) intrinsic equilibrium constants for the adsorption of a radionuclide to a surface site. All of this is performed within the context of a conceptual model of the electrical double layer at the mineral surface.

\section{Accomplishments}

Adsorption of $\mathrm{Np}$ and other actinides to $\mathrm{U}(\mathrm{VI})$ solids may significantly reduce dissolved actinide concentrations. Unfortunately, actinide adsorption to these solids is an uncertain process, and consequently, this phenomenon is not considered in the TSPA. The knowledge and data gained from this science project will allow the incorporation of this process into future TSPAs. 


\section{Corrosion of Spent Nuclear Fuel: The Long-Term Assessment}

Rodney C. Ewing

University of Michigan

\section{Research Objectives}

Spent nuclear fuel (SNF), essentially $\mathrm{UO}_{2}$, accounts for over $95 \%$ of the total radioactivity of all of the radioactive wastes in the United States that require disposal, disposition, or remediation. The alteration of SNF results in the formation of new uranium (U) phases that can cause the release or retardation of actinide and fission-product radionuclides. Over the long term, and depending on the extent to which the secondary $U$ phases incorporate fission products and actinides, these alteration phases become the near-field source term.

This research program is a broadly based effort to understand the long-term behavior of SNF and its alteration products in a geologic repository. Fortunately, previous experiments and field studies have established that natural uraninite, $\mathrm{UO}_{2+x}$, and its alteration products are excellent "analogues" for the corrosion of $\mathrm{UO}_{2}$ in SNF. This program addresses the following questions: (1) What are the long-term corrosion products of natural $\mathrm{UO}_{2+x}$, uraninite, under oxidizing conditions? (2) What is the paragenesis of the $\mathrm{U}^{6+}$ phases that form under oxidizing conditions? (3) What is the radionuclide content of the corrosion products, as compared with the original $\mathrm{UO}_{2+\mathrm{x}}$ ? and (4) What are the effects of ionizing radiation and alpha-decay on the stability and composition of the $\mathrm{U}^{6+}$ phases?

\section{Approach}

This research program was initiated in July 2004 and

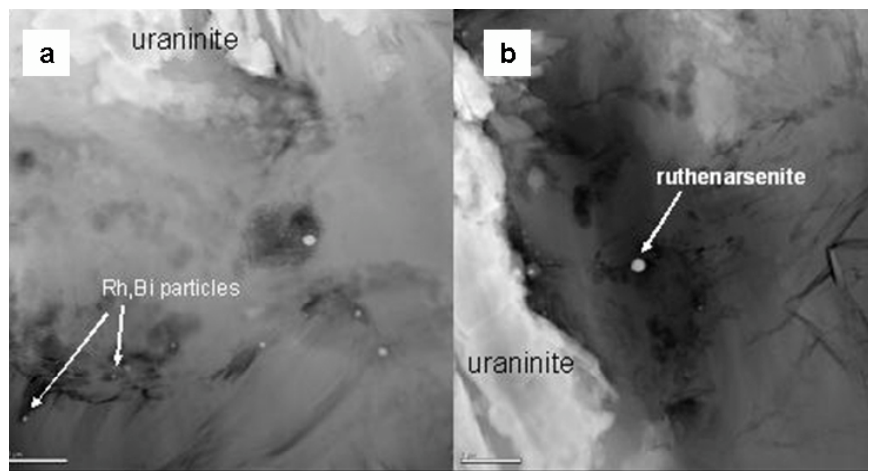

Figure I. HAADF-STEM images of particles containing Rh (la) and Ru (Ib) embedded in the secondary chlorite (scale bars in both images equal $\mathrm{I} \mu \mathrm{m}$ ) includes: two graduate students, Frannie Skomurski (OCRWM Fellow) and Elizabeth Anderson (OCRWM Fellow), as well as research scientist Satoshi Utsunomiya. Present investigations include: (1) computational studies of $\mathrm{UO}_{2}-\mathrm{H}_{2} \mathrm{O}$ interactions; (2) detailed characterization of the fate of the metallic fission-product elements in the Oklo natural reactors; (3) heavy-particle and ionizing radiation damage studies of $\mathrm{U}^{6+}$ phases; and (4) experiments on and computational studies of the interactions of $U$ and other radionuclides with the corrosion products of waste packages (in collaboration with SNL, PNNL, and WSU).

\section{Accomplishments}

\section{The Epsilon Phase in the Oklo and Okélobondo Natural Fission Reactors}

Technetium [99 $\mathrm{Tc}\left(\mathrm{t}^{1 / 2}=2.13 \times 10^{5}\right.$ years $\left.)\right]$ occurs in commercial SNF as part of a five-metal alloy (Tc, Mo, Pd, Ru, and Rh), commonly called the "epsilon phase" (in allusion to its structural similarity to $\varepsilon-\mathrm{Ru}$ ) or "5-metal particles" (because the five metals precipitate as micron- to-submicron-sized metallic particles within the fuel during irradiation). We have investigated uraninite from Oklo, Gabon, to discern the fate over geologic time of the five metals originally contained in epsilon particles that were presumably p roduced when the deposit experienced nuclear criticality. Because the Oklo natural reactor is 2.0 billion years old, essentially all ${ }^{99} \mathrm{Tc}$ has decayed to ${ }^{99} \mathrm{Ru}$. Ru-bearing particles are associated with $\mathrm{Pb}$-bearing phases, most commonly galena (PbS). Although the compositions of Ru-bearing phases at Oklo vary widely, several reveal that As and other metals (probably derived from fluids) are incorporated into the Ru-bearing phases, forming ruthenarsenite, whereas Mo is not found in the Ru-bearing particles. Nanometer-sized particles of ruthenarsenite are embedded within alteration products such as "chlorite" (Fe,Mg-aluminosilicate clay), and these Rh-Bi-bearing nanoparticles and ruthenarsenite nanoparticles occur close to uraninite grains. If transported from the edge of the uraninite, the transport was on the order of a few micrometers (Figure 1). 


\section{Computational Studies of the Interaction of Water and Oxygen with the Surfaces of $\mathrm{UO}_{2}$}

The very first interactions between uranium dioxide surfaces and adsorbates, such as water and oxygen, affect the chemical and electronic nature of SNF surfaces, which influences how surfaces will react with subsequent adsorbates. The oxidation behavior of $U$ in the presence of adsorbates is of particular interest because of the increase in $\mathrm{U}$ solubility when changing from the $\mathrm{U}^{4+}$ to the $\mathrm{U}^{6+}$ oxidation state. The exact mechanisms of oxidation and adsorption remain unclear at the atomic scale.

This work develops the framework for performing adsorption energy and electron transfer calculations on the $\mathrm{UO}_{2}$ surfaces to elucidate adsorption and oxidation processes on the atomic scale. Calculating surface energy values for different crystallographic faces of the same material is useful for determining relative surface reactivity. The physical and electronic structure of adsorbate-free $\mathrm{UO}_{2}$ surfaces was also determined based on quantum mechanical calculations. Figures $2 a$ and $2 b$ are a visualization of the differences in electron density observed in the case where only oxygen adsorbs to a $\mathrm{UO}_{2}$ (111) slab surface, versus the combined case where water and oxygen adsorb onto the same surface.

Principal scientific findings of this research include:

1. Based on Oklo samples, ruthenarsenite exists as colloid-sized nanoparticles, but they have not migrated more than a few micrometers from the uraninite, perhaps because of their density. Thus, colloidal transport of the epsilon-particles was unlikely.

2. $\mathrm{U}^{6+}$ phases are not expected to amorphize at the ionizing doses that they will experience at the surfaces of SNF. However, heavy-particle irradiations have shown that ballistic interactions (e.g., with the alpha-recoil) cause the $\mathrm{U}^{6+}$ phases to decompose to nanocrystals of $\mathrm{UO}_{2}$. This may provide a mechanism for the release of incorporated radionuclides, and this process remains under investigation.

3. Based on computational studies of the energetics of different $\mathrm{UO}_{2}$ surfaces, the presence of water and oxygen increase the reactivity of $\mathrm{UO}_{2}$ with potential adsorbates. Thus, $\mathrm{UO}_{2}$ surfaces in SNF may actively sorb and retard the transport of some radionuclides.
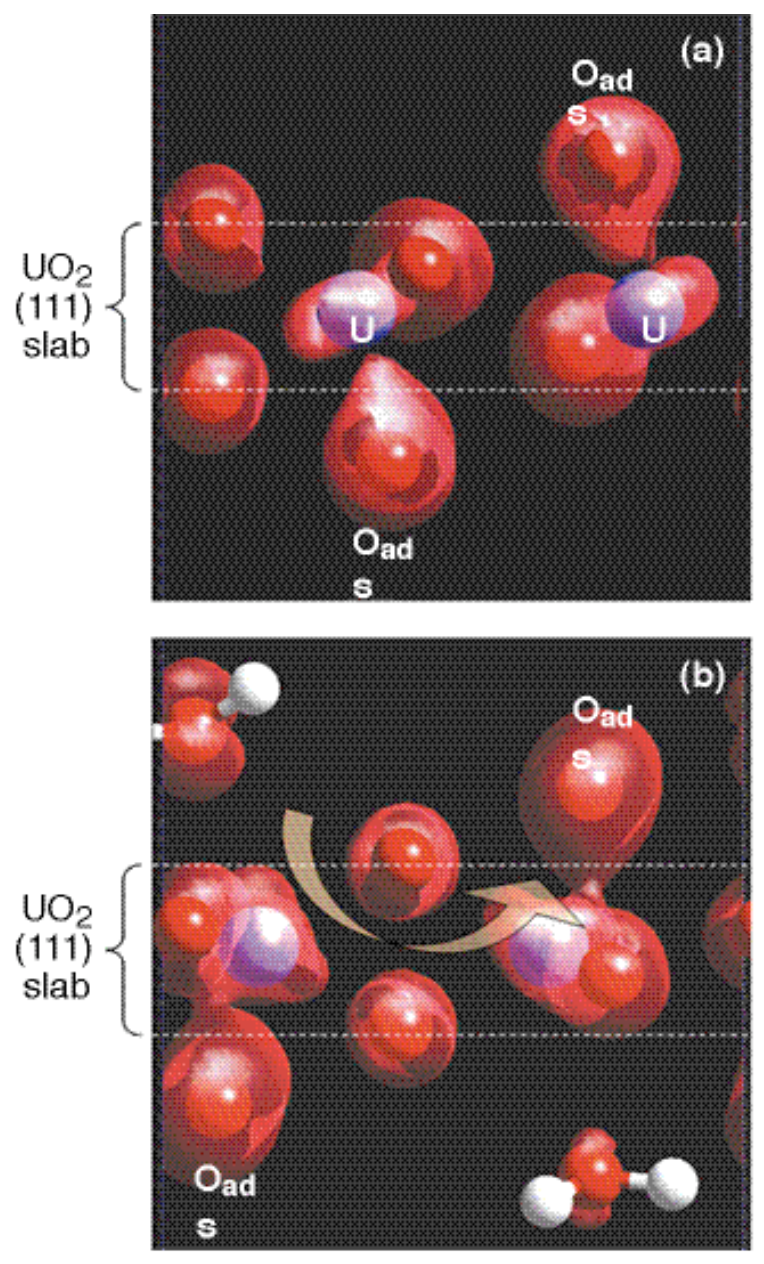

Figure 2. In the oxygen-only adsorption case (a), the balloon-like features surrounding each atom represent the valence-band density of atoms, and a small tail-like feature stemming off one of the adsorbing oxygen atoms indicates that there is some interaction (increase in electron density) between it and a uranium in the slab. In (b), we see the valence band electron density for a $\mathrm{UO}_{2}$ (III) surface, with both oxygen and water interacting with surface atoms.

\section{Recent Publications}

Skomurski, F.N., R.C. Ewing, A.L. Rohl, J.D. Gale, and Udo Becker, Quantum mechanical versus empirical potential modeling of $\mathrm{UO}_{2}$ surface energies: (111) (110) and (100). American Mineralogist (submitted), 2005.

Utsunomiya, S., and R.C. Ewing, Fate of the epsilon phase in the Oklo natural reactors. Radiochimica Acta (in press), 2005.

Utsunomiya, S., and R.C. Ewing, Radiation-induced decomposition of $\mathrm{U}(\mathrm{VI})$ phases to nanocrystals of $\mathrm{UO}_{2}$. Earth and Planetary Science Letters (in press), 2005. 


\title{
Direct Determination of the Thermodynamic Properties of Uranyl Minerals Important for the Performance of the Proposed Geological Repository at Yucca Mountain
}

\author{
Jeremy B. Fein, Peter C. Burns', and Alexandra Navrotsky² \\ IUniversity of Notre Dame | 2University of California, Davis
}

\section{Research Objectives}

The objective of this study is to determine the thermodynamic properties of a broad range of environmentally important uranyl mineral phases using solubility and calorimetric measurements, producing an internally consistent dataset that is useful in modeling spent nuclear fuel (SNF) alteration and uranium (U) mobility behavior in near-surface environments.

We are using solubility and calorimetry measurements in order to provide rigorous constraints on the Gibbs free energies of formation, enthalpies of formation, and standard entropies for these solids. Solubilities of representative members of the uranyl oxide hydrates, uranyl silicates, and uranyl carbonates are being measured, both for the end-member phases as well as for selected phases containing a range of substituted neptunium $(\mathrm{Np})$ within the crystal structure.

\section{Approach}

In the experimental program, we are synthesizing and measuring the solubility of a wide range of uranyl mineral phases. In order to improve the accuracy and precision of the thermodynamic interpretation of the data, solubility measurements are being conducted primarily under the low $\mathrm{pH}$ conditions at which $\mathrm{UO}_{2}^{+2}$ ion is the dominant aqueous uranyl species. The solubility experiments are being conducted as a function of $\mathrm{pH}$, ionic strength, and temperature, and will yield Gibbs free energies of formation for the phases of interest. Solubility measurements conducted as a function of $\mathrm{Np}$ content of the uranyl minerals will enable us to extract solid-phase activity-coefficient parameters to use in thermodynamic models that quantify the effect of the $\mathrm{Np}$ on uranyl mineral stabilities and solubilities. The calorimetric data will enable determination of the enthalpies of formation for these phases, so that together the standard entropies can be determined as well.

Successful extraction of thermodynamic data from solubility measurements requires a range of measurements or controls on the experimental systems: (1) rigorous demonstration of equilibrium reversal; (2) measurements of the equilibrium $\mathrm{pH}$ and the total equilibrium concentrations of all mineral-forming cations in the system; (3) ionic strength control or measurement; and (4) determination that secondary mineral phases do not form during experimentation. In each batch solubility experiment, a synthesized uranyl mineral powder is placed in contact with a fixed-ionic-strength solution, and the $\mathrm{pH}$ of the suspension is adjusted to a desired value using minute volumes of concentrated perchloric acid or sodium hydroxide solution. Ionic strength is buffered using the inert electrolyte $\mathrm{NaClO}_{4}$. Perchlorate concentrations are maintained low enough to prevent the formation of uranyl perchlorate phases. Because of complexities in the aqueous speciation of the uranyl ion above $\mathrm{pH} 5$, and to speed the attainment of equilibrium in the experimental systems, all experiments will be conducted between pH 2 and 5 .

In the second phase of this project, we will also determine the effect of Np substitution in these uranyl-phase structures on the solubility of selected phases. Each uranyl phase of interest will be synthesized with variable concentrations of $\mathrm{Np}$, following similar procedures used by Burns et al. (2004). The extent of Np incorporation will be determined by whole-phase acid dissolution of each phase of interest, and $\mathrm{Np}$ analysis by inductively coupled plasma mass spectrometry (ICP-MS). The Np concentration of aqueous samples from the solubility experiments will also be analyzed by ICP-MS. Experimental systems will be controlled so that the approach to equilibrium is either from undersaturation or from oversaturation, thereby providing necessary and rigorous constraints on the equilibrium conditions.

High-temperature oxide-melt-solution calorimetry uses a Calvet-type high-temperature custom-built calorimeter, details of which are given elsewhere (Navrotsky, 1977; 1997). Solution enthalpies for each sample are measured by dropping $\sim 5 \mathrm{mg}$ pressed pellets of material from room temperature, $298 \mathrm{~K}$, into the molten oxide solvent, $3 \mathrm{Na}_{2} \mathrm{O}$ $4 \mathrm{MoO}_{3}$, at calorimetric temperature, $976 \mathrm{~K}$. Earlier experiments for $\mathrm{UO}_{3}$ confirmed that $\mathrm{U}^{6+}$ is the stable oxidation state of $\mathrm{U}$ dissolved at low concentrations in $3 \mathrm{Na}_{2} \mathrm{O} \cdot 4 \mathrm{MoO}_{3}$ at $976 \mathrm{~K}$ under experimental conditions (Helean et al., 2003). The calorimeter is calibrated using the heat content of $\alpha-\mathrm{Al}_{2} \mathrm{O}_{3}$. It is flushed continuously with $\mathrm{O}_{2}$ throughout the experiments to ensure an oxidizing atmosphere. Prior to the calorimetric experiments, complete dissolution in the solvent at calorimetric condi- 
tions is established in a furnace at $976 \mathrm{~K}$. A large and rapidly generated endothermic enthalpy of drop solution for each phase, return of the calorimetric signal to its baseline value, and a solvent color change from white to yellow indicates that uranyl minerals dissolve fully in the melt. The evolution of water occurs quickly but not too vigorously. The high density of the sample assures that the pellets drop quickly and sink in the solvent, so that the sample does not float on the surface of the melt. Calorimetry is straightforward and problem free. The well-characterized samples used for solubility experiments are also being used for calorimetry.

\section{Accomplishments}

This research project has been under way for only a few months, but we have made significant progress. We have perfected synthesis techniques for three uranyl oxide hydrates (schoepite $\left[\left(\mathrm{UO}_{2}\right)_{8} \mathrm{O}_{2}(\mathrm{OH})_{12}\right]\left(\mathrm{H}_{2} \mathrm{O}\right)_{12}$, metaschoepite $\mathrm{UO}_{3}\left(\mathrm{H}_{2} \mathrm{O}\right)_{2}$, and becquerelite $\mathrm{Ca}\left[\left(\mathrm{UO}_{2}\right)_{3} \mathrm{O}_{2}(\mathrm{OH})_{3}\right]_{2}\left(\mathrm{H}_{2} \mathrm{O}\right)_{8}$ ), two uranyl silicates (soddyite $\left(\mathrm{UO}_{2}\right)_{2}\left(\mathrm{SiO}_{4}\right)\left(\mathrm{H}_{2} \mathrm{O}\right)_{2}$ and uranophane $\left.\mathrm{Ca}\left[\left(\mathrm{UO}_{2}\right)\left(\mathrm{SiO}_{3} \mathrm{OH}\right)\right]_{2}\left(\mathrm{H}_{2} \mathrm{O}\right)_{5}\right)$, and a uranyl carbonate (rutherfordine $\mathrm{UO}_{2} \mathrm{CO}_{3}$ ). In addition, solubility and calorimetry measurements have begun on several of these phases. Preliminary solubility measurements indicate that solubility reversals can be measured and equilibrium attained over the course of 10-20 days, depending on $\mathrm{pH}$ and the uranyl phase present.

Currently, there is uncertainty in the thermochemical parameters of uranyl minerals to support development of models for radionuclide mobility in the subsurface. The experiments in this study will be valuable as direct indica- tions of the concentration of $U$ and other elements in solution, in equilibrium with environmentally important uranyl mineral phases. In addition and perhaps more importantly, the experiments will yield an internally consistent dataset of the thermodynamic properties for a wide range of uranyl minerals of proposed repository and general environmental interest.

\section{References}

Burns, P.C., K.M. Deely, and S. Skanthakumar, Neptunium incorporation into uranyl compounds that form as alteration products of spent nuclear fuel: Implications for geologic repository performance. Radiochimica Acta, 92, 151-159, 2004.

Helean, K.B, A. Navrotsky, E.R.Vance, M.L. Carter, B. Ebbinghaus, O. Krikorian, J. Lian, L.M. Wang, and J.G. Catalano, Enthalpies of formation of Ce-pyrochlore, $\mathrm{Ca}_{0.93} \mathrm{Ce}_{1.00} \mathrm{Ti}_{2.035} \mathrm{O}_{7.00}$, U-pyrochlore, $\mathrm{Ca}_{1.46} \mathrm{U}^{4+}{ }_{0.23} \mathrm{U}^{6+}{ }_{0.46} \mathrm{Ti}_{1.85} \mathrm{O}_{7.00}$ and $\mathrm{Gd}$-pyrochlore, $\mathrm{Gd}_{2} \mathrm{Ti}_{2} \mathrm{O}_{7}$ : Three materials relevant to the proposed waste form for excess weapons plutonium. Journal of Nuclear Materials, 303, 226-239, 2002.

Navrotsky, A., Recent progress and new directions in high T calorimetry. Physics and Chemistry of Minerals, 2, 89-104, 1977.

Navrotsky, A., Progress and new directions in high T calorimetry revisited. Phys. Chem. Minerals, 24, 222-241, 1997. 


\title{
Chemical and Coordination Structure of Radionuclides in Spent Nuclear Fuel and Its Alteration Products: Understanding Release Pathways
}

\author{
Jeffrey A. Fortner, A. Jeremy Kropf, and James C. Cunnane
}

Argonne National Laboratory (ANL)

\section{Research Objectives}

Present and future nuclear fuel cycles will rely upon controlling the complex chemistry of trace fission products and transuranium actinides. Knowledge of the chemical states of such radionuclides in spent nuclear fuel (SNF) and related materials provides a first line of understanding that may benefit waste disposal, fuel reprocessing, transmutation/recovery, and remediation of sites from weapons-related activities. Few techniques have proven more effective than $\mathrm{x}$-ray absorption spectroscopy (XAS) for determining oxidation states and structural environments of elements in solids. This project investigates the solid state chemistry of radioactive fission products (e.g., technetium $[\mathrm{Tc}]$ ) and activation products (neptunium [Np], plutonium [Pu]) in commercial SNF by using advanced XAS techniques, often developed by our own researchers. The objective is to provide definitive information about the crystal chemistry and partitioning of these key

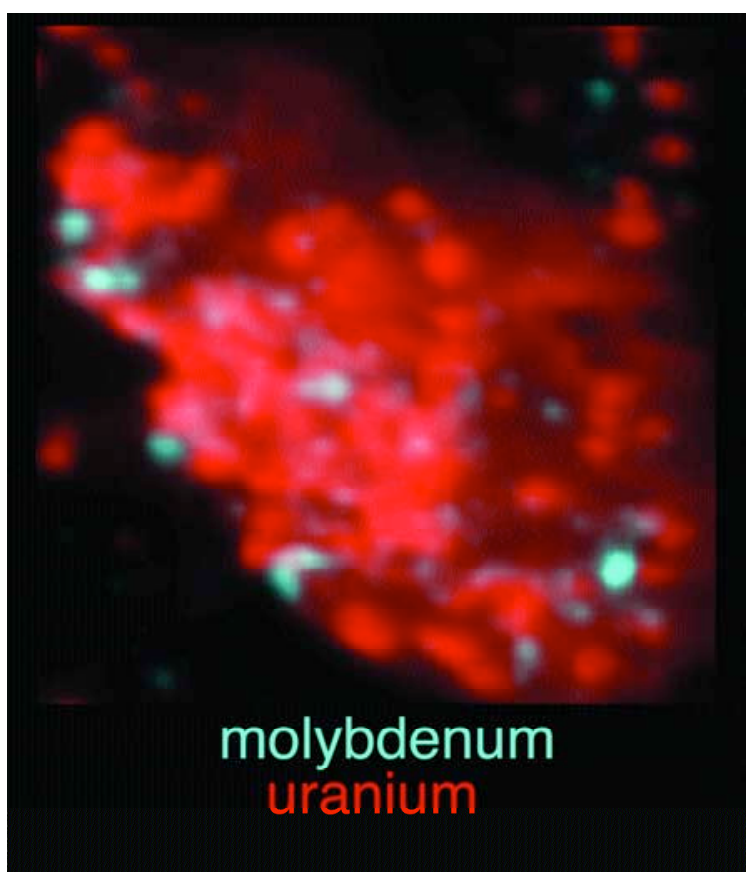

Figure I. X-ray map showing the inhomogeneous distribution of uranium (red) and molybdenum (blue) in SNF that has been partially corroded by exposure to water for extended periods at high temperature. The scale is $\sim 300$ micron field of view.

radionuclides between grain boundary, fuel/cladding gap, and intragranular locations within the SNF, and to determine the impact of these phenomena on release behavior during SNF corrosion. We will also address possible sequestration of these radionuclides in more stable minority phases (e.g., exsolved, metallic "epsilon" particles) and secondary alteration phases. By strengthening the science underlying models developed to predict the long-term performance of SNF in the proposed repository, we hope to provide insight that is expected to benefit both modeling and design considerations for waste disposal in a geologic repository.

\section{Approach}

Using a novel "bent-Laue analyzer" detection scheme that we helped develop, detailed XAS information from trace elements in specimens of SNF and its alteration-phase materials has been obtained. By analyzing XAS extended fine structure (EXAFS) data from a particular absorption edge, we can determine the local environment of a specific atomic species, including distances to near-neighbors, types and numbers of neighboring atoms, and details of the radial distribution function. The energy of the absorption threshold and near-edge absorption features also can be used to obtain information about the charge state of the central atom and the site symmetry. Several XAS measurements from SNF were performed at the Materials Research Collaborative Access Team (MR-CAT) insertion device beamline, located in the Advanced Photon Source (APS), a third-generation $\mathrm{x}$-ray synchrotron source located at Argonne National Laboratory. The brightness of the APS in the high-energy $x$-ray regimes makes it ideal for investigating radionuclide systems, which have relatively highenergy absorption edges, and which must be carefully encapsulated for radiological safety.

\section{Accomplishments}

We have achieved unprecedented spectral energy resolution for XAS, which has allowed us to measure detailed information from trace elements in a SNF U oxide matrix. Our developments in x-ray focusing and sample positioning make the technique operate as an $\mathrm{x}$-ray microscope, providing spectral detail in two spatial dimensions. The unique XAS instrumentation and techniques allow simultaneous 
element mapping by $x$-ray microscopy (Figure 1) and XAS/EXAFS (Figure 2). These are the first such studies of SNF.

These XAS and EXAFS data have allowed, for the first time, direct observation of oxidation state, coordination environment, spatial distribution, and site symmetry of Tc, Mo, $\mathrm{Np}$, and $\mathrm{Pu}$ within SNF and its alteration products. In addition to providing a better understanding of radionuclide release from corroding waste in the proposed Yucca Mountain repository, these advances are expected to find applications in understanding fission product behavior in advanced fuel cycles (e.g., fission-product behavior in nuclear fuels operating at high temperatures).

\section{Related Publications and Further Reading}

Fortner, J.A., A.J. Kropf, R.J. Finch, and J.C. Cunnane, Technetium and molybdenum in oxide spent nuclear fuel: Impact on release estimates. In: Scientific Basis for Nuclear Waste Management XXVIII, John M. Hanchar, Simcha Stroes-Gascoyne, and Lauren Browning, eds., Mater. Res. Soc. Symp. Proc. 824, 2004, Paper CC2.11, 2004.

Fortner, J.A., R.J. Finch, A.J. Kropf, and J.C. Cunnane, Reevaluating neptunium in uranyl alteration phases from corroded spent fuel. Nuclear Technology, 148 (2) 174-180, November 2004.

Fortner, J.A., A.J. Kropf, R.J. Finch, C.J. Mertz, J.L. Jerden, M.G. Goldberg, and J.C. Cunnane, Analysis of trace elements in commercial spent nuclear fuel using $\mathrm{x}$-ray absorption spectroscopy. In: Global 2003, ANS Proceedings, 2003.

Kropf, A.J., J.A. Fortner, R.J. Finch, J.C. Cunnane, and C. Karanfil, A bent silicon crystal in the Laue geometry to resolve $\mathrm{x}$-ray fluorescence for $\mathrm{x}$-ray absorption spectroscopy. Physica Scripta, T115, 998-1000, 2005. 


\title{
An In Situ Spectroelectrochemical Study of Neptunium (Np) Redox, Dissolution, and Precipitation Behavior at the Corroding Spent Nuclear Fuel/Alteration Phase Interface
}

\author{
Artem Guelis', Jeremy Kropf', Christopher Johnson', Jeffrey Fortner', and Petr Vanysek² \\ 'Argonne National Laboratory (ANL) | 2Northern Illinois University
}

\section{Research Objectives}

The objective of this project is to examine the oxidative dissolution of $\mathrm{Np}(\mathrm{IV})$ and the reductive precipitation of aqueous $\mathrm{Np}(\mathrm{V})$ species at $\mathrm{U}_{(1-\mathrm{x})} \mathrm{Np}_{\mathrm{x}} \mathrm{O}_{2}[0 \leq \mathrm{x}<0.1]$ and other surfaces under applied oxidation-potential conditions relevant to the range of corrosion potentials expected for the surface of corroding spent $\mathrm{UO}_{2}$ fuels in air-saturated solutions (i.e., at applied potentials near the fuel's corrosion potential).

\section{Approach}

The planned work will include the following steps: (1) identify the applied potential ranges for congruent and incongruent release of $\mathrm{Np}(\mathrm{V})$ and $\mathrm{U}(\mathrm{VI})$ from $\mathrm{U}_{(1-\mathrm{x})} \mathrm{Np}_{\mathrm{x}} \mathrm{O}_{2}$ surfaces, (2) determine the applied potential range for reductive precipitation of $\mathrm{Np}(\mathrm{V})$ onto $\mathrm{U}_{(1-\mathrm{x})} \mathrm{Np}_{\mathrm{x}} \mathrm{O}_{2}[0 \leq \mathrm{x}<$ 0.1 and inert (e.g., $\mathrm{Pt}$, carbon, or pyrolytic graphite) electrode surfaces, (3) design electrochemical cells suitable for performing the $\mathrm{Np}$ oxidative dissolution and reductive

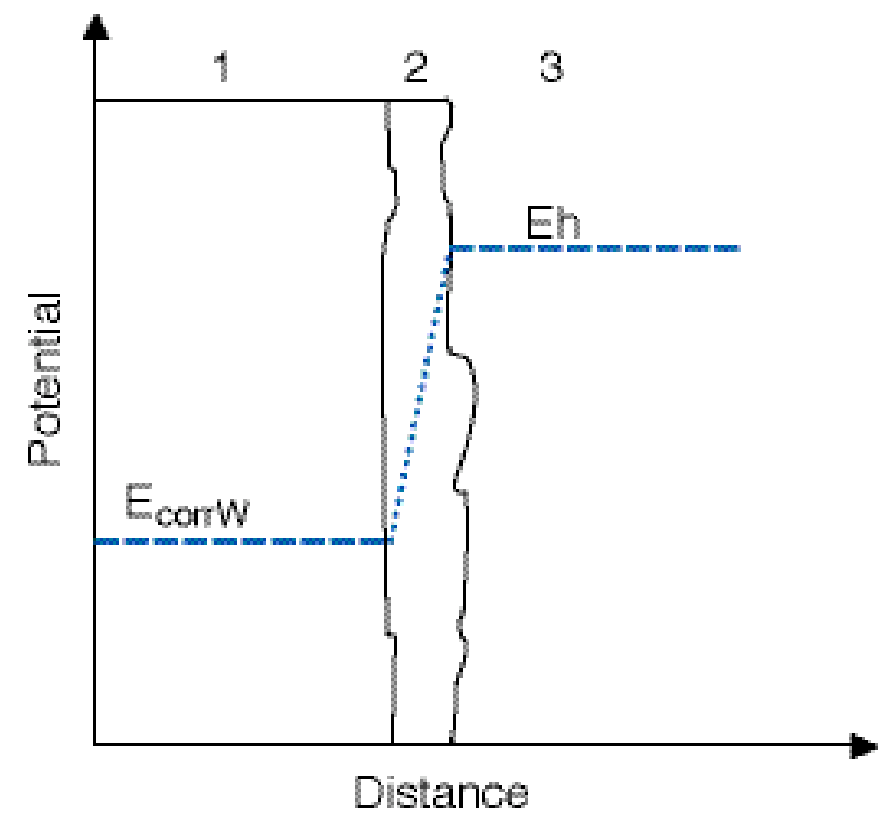

Figure I. Qualitative illustration of the variation of the oxidation potential profile at and near the corroding fuel surface precipitation measurements in situ at ANL's Advanced Photon Source (APS), Materials Research-Collaborative Access Team (MR-CAT) beamline hutch, and (4) use a bent Laue analyzer, as needed to select trace $\mathrm{Np}$ fluorescence in the presence of $U$ for conducting $x$-ray absorption near edge structure (XANES) and extended $x$-ray absorption fine structure (EXAFS) analyses of solution species and precipitated solids. The possible effects of the $\mathrm{x}$-ray beam on promoting reduction of $\mathrm{Np}(\mathrm{V})$ solids will be examined by doing time-resolved spectroscopy to identify changes that occur with irradiation time.

Figure 1 illustrates salient features and processes that are considered here for the fuel matrix corrosion and the initial part of the reaction path for $\mathrm{Np}$. The $\mathrm{Np}$ release path starts at the corroding fuel surface and progresses through the alteration phase rind to the "bulk solution." It also qualitatively illustrates the relevant potentials (see dashed line) that Np will "see" for reactions occurring at the surface of the fuel (1), in the alteration product rind layer (2), and in the bulk solution (3).

In spent $\mathrm{UO}_{2}$ fuels, $\mathrm{Np}$ is expected to be present as a solid solution of $\mathrm{NpO}_{2}$ in the $\mathrm{UO}_{2}$ fluorite structure with which it is compatible. $\mathrm{Np}$ can be released from the $\mathrm{UO}_{2}$ when the matrix degrades by oxidative dissolution. Available data indicate that the standard potential for the $\mathrm{UO}_{2}{ }^{2+} / \mathrm{U}^{4+}$ is significantly lower than the standard potential for the $\mathrm{NpO}_{2}{ }^{+} / \mathrm{Np}^{4+}$ couple and indicate that reduction of $\mathrm{Np}(\mathrm{V})$ by $\mathrm{U}(\mathrm{IV})$ as the fuel corrodes is thermodynamically favored, as shown by the following reaction:

$2 \mathrm{NpO}_{2}{ }^{+}+\mathrm{U}^{4+}+4 \mathrm{H}^{+}=2 \mathrm{~Np}^{4+}+\mathrm{UO}_{2}{ }^{2+}+2 \mathrm{H}_{2} \mathrm{O} \quad \mathrm{E}=0.405$ to $0.469 \mathrm{~V}$

This indicates that while the fuel is corroding, it is capable of reducing dissolved $N p(V)$ to $N p(I V)$ at the surface of the residual fuel.

Although the above arguments indicate that reduction of $\mathrm{Np}(\mathrm{V})$ by $\mathrm{U}(\mathrm{IV})$ is favored thermodynamically, the redox kinetics of $\mathrm{Np}$ under the corrosion conditions at the corroding fuel surface are uncertain. Measured corrosion potentials (Ecorr) for spent $\mathrm{UO}_{2}$ fuels in aerated, near-neutral $\mathrm{pH}$ solutions depend on many factors, but are generally in the range of about 300 to $600 \mathrm{mV}$ SHE. These data indicate that the fuel's corrosion potential (see Figure 1) 
may be lower than the standard potential for the anodic dissolution of $\mathrm{Np}(\mathrm{IV})$ in the fuel matrix. This indicates that oxidation of $\mathrm{Np}(\mathrm{IV})$ in the fuel's lattice may not occur under the pertinent potential conditions at the fuel's surface. In short, the oxidative dissolution behavior of $\mathrm{Np}$ at the corroding fuel surface remains uncertain. Reaction paths for Np mobilization should take into account the behavior of $\mathrm{Np}$ at the corroding fuel surface. In the immediate vicinity of the fuel surface, the redox and nucleation behavior is likely to be influenced by the corroding fuel's matrix. The behavior under the redox conditions at and near the corroding surface, and how the crystal lattice structures at the corroding surface promote/enhance nucleation of $\mathrm{NpO}_{2}$ and $\mathrm{Np}_{2} \mathrm{O}_{5}$, will be investigated in this project.

\section{Accomplishments}

Funding was received at ANL and the task was initiated in August 2005. Various designs for the spectroelectrochemical cell are being considered. 


\title{
Natural Sequestration of Radionuclides In Volcanic Tuff
}

\author{
Jonathan Icenhower', Edgar Buck', Eric Pierce', Dawn Wellman', and Andreas Lüttge²
}

IPacific Northwest National Laboratory (PNNL) | 2Rice University

\section{Research Objectives}

Our principal objective is to quantitatively determine the mobility of radionuclides released during corrosion of commercial spent nuclear fuel (SNF) to the near-field volcanic tuffs. Aqueous solutions with chemical compositions similar to those of Yucca Mountain pore waters will react with SNF analog material $\left(\mathrm{UO}_{2}\right)$ underlain by crushed tuff in a hydraulically unsaturated column experiment designed to replicate repository conditions. We will study secondary-phase growth on the $\mathrm{UO}_{2}$ surface and in the tuff, as well as element mobility through the tuff, in order to increase mechanistic and predictive understanding of radionuclide behavior. These data can be used to establish source term parameters to underpin increasingly realistic models of radionuclide migration and retention over the very long time frames relevant to a geological repository for SNF.
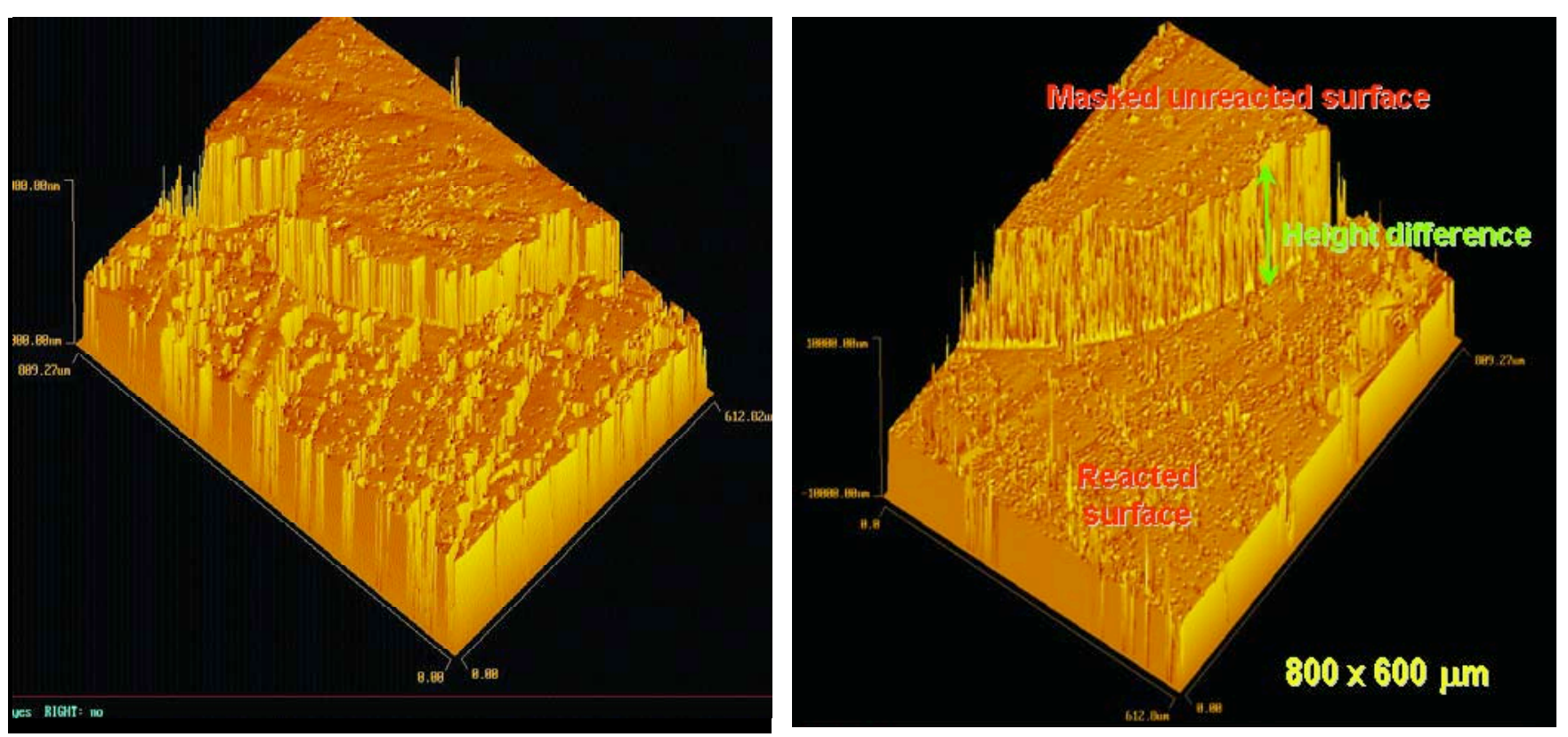

Figure I. Example of an image generated by vertical scanning interferometry (VSI) on a borosilicate glass specimen subjected to a dissolution test. A protective temperature-resistant mask was placed on a spot on the surface of the glass prior to the test. Following termination of the test, the mask was removed and the protected surface acts as the reference surface to quantify the surface retreat on the exposed glass surface. The height difference can be converted into an apparent dissolution rate.

The experimental and analytical methods that will be used to obtain the key set of data revolve around three techniques, two of which (PUF column and VSI) have not been used with SNF or its analog, $\mathrm{UO}_{2}$. These methods are described below.

1. The cornerstone of this experimental program is PNNL's pressurized unsaturated flow (PUF) system. The PUF system is a column experiment wherein geochemical reactions take place under hydraulically unsaturated conditions relevant to the disposal environment. A computerized interface controls variables such as temperature, solution flow rate, $\mathrm{pH}$, redox state, $\mathrm{CO}_{2}$ partial pressure, and water saturation state (partial to full). The column will be set up with layers of crushed $\mathrm{UO}_{2}$ and volcanic tuff. Aqueous solutions, with realistic chemical compositions and doped with the radionuclides (or their analogs) of interest, 
will be transferred to the column at a metered rate. As the solution comes in contact with the solids in the column, the chemistry of the solution will progressively change as dissolution/precipitation reactions occur. We anticipate that a sequence of secondary minerals, some of which may sequester radionuclides of interest, will precipitate on the surface of the $\mathrm{UO}_{2}$ grains. The chemically altered solution will then contact the volcanic tuff, resulting in further secondary mineral formation. The characterization of these secondary phases will be accomplished with the analytical techniques described below.

2. A suite of in situ and ex situ analytical devices will characterize the secondary-phase assemblage formed during interaction of the solution and the column solids ( $\mathrm{UO}_{2}$ and volcanic tuff). The PUF column can be fashioned from transparent materials, which would enable laser-Raman techniques to identify phases growing in situ. In addition, the PUF column can be disassembled following termination of the experiment, and the materials can be subjected to x-ray diffraction (XRD), scanning electron microscopy (SEM), and transmission electron microscopy (TEM) analyses. Additional chemical analyses will be undertaken using electron energy loss spectroscopy (EELS), which can detect very low concentrations of actinide elements harbored in nanometer-size secondary uranyl minerals.
3. Complete characterization of precipitation/dissolution reactions will be resolved using a new technique called vertical scanning interferometry (VSI). This technique can be used to quantify dissolution/precipitation reactions on the $\mathrm{UO}_{2}$ and volcanic tuff surfaces and provides a vital link between experimentation and predictive models. The VSI technique uses white light interferometry to detect very small changes in vertical distances (presently, nanometer scale) over the course of an experiment. The VSI method measures the difference in height between an unreacted reference surface and a surface subjected to dissolution (Figure 1) in chemically complex solutions. The height difference can then be translated into rate data and, coupled with images acquired over large areas on the specimen surface, will lead to dissolution/precipitation models.

\section{Accomplishments}

Transport and reaction mechanisms from $\mathrm{UO}_{2}$ into volcanic tuff that affect selected radioactive elements will be determined in detail. If it can be shown that important radioactive elements are less mobile than presently assumed, and that aqueous corrosion of SNF (presently assumed to be at the forward rate of reaction) is far slower than current models imply, more realistic source term and attenuation values can be utilized in proposed repository performance assessments. 


\section{Surface Charge and Radionuclide Adsorption Characteristics of $\mathrm{U}(\mathrm{IV}, \mathrm{VI})$ Oxyhydroxides at $25-150^{\circ} \mathrm{C}$}

David J. Wesolowski', Donald A. Palmer', Laetitia Delmau', Lawrence M. Anovitz', and Michael L. Machesky²

'Oak Ridge National Laboratory (ORNL) | 2llinois State Water Survey

\section{Research Objectives}

We will determine, in $\mathrm{NaCl}$ and/or $\mathrm{NaCF}_{3} \mathrm{SO}_{3}$ brines from 25 to $150^{\circ} \mathrm{C}$ : (a) the $\mathrm{pH}$ and temperature dependences of the proton-induced surface charge density of depleted $\mathrm{UO}_{2}$ (uraninite) and a representative $\mathrm{U}(\mathrm{VI})$ alteration phase $\left(\mathrm{UO}_{2}\right)_{8} \mathrm{O}_{2}(\mathrm{OH})_{12}\left(\mathrm{H}_{2} \mathrm{O}\right)_{12}$ (schoepite); (b) the $\mathrm{pH}$ of zero net surface charge (pHpzc) of these phases; and (c) new solubility data on these phases using direct sampling and in situ $\mathrm{pH}$ monitoring. We will then conduct protonrelease and direct sampling studies of the sorption of multivalent analogue cations and anions on these phases for charge types and ionic radii representative of primary source term radionuclides. This information will be used to develop surface site complexation models to describe ion adsorption under near-field repository conditions. These models will be tested for their relevance to radionuclide adsorption by comparing them with the results of batch adsorption studies of trace quantities of the actual radionuclides of interest $\left(238,235,234,233 \mathrm{U},{ }^{237} \mathrm{~Np},{ }^{239} \mathrm{Pu}\right.$,

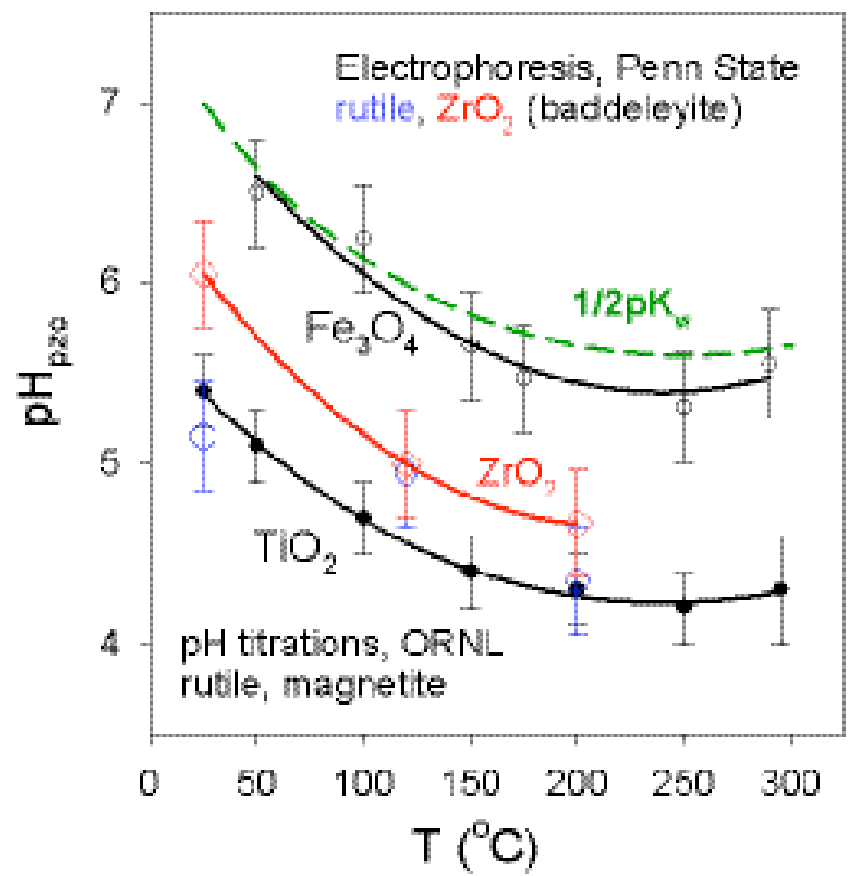

Figure I. The $\mathrm{pH}_{\mathrm{pzc}}$ of several metal oxides as a function of temperature, compared with the neutral $\mathrm{pH}$ of water $(\mathrm{I} / 2 \mathrm{pKw})$
${ }^{241} \mathrm{Am},{ }^{129} \mathrm{I},{ }^{99} \mathrm{Tc},{ }^{79} \mathrm{Se},{ }^{36} \mathrm{Cl}$ ) on these model oxide phases at selected temperatures. Batch adsorption studies will also be conducted on actual spent nuclear fuel (SNF) samples to gauge the relevance of our pure-oxide-phases studies.

\section{Approach}

We and our collaborators have pioneered experimental investigations of metal oxide solubility, surface charging, and $\mathrm{pH}$-dependent ion adsorption at temperatures ranging from 10 to $>250^{\circ} \mathrm{C}$, using our unique high-temperature $\mathrm{pH}$-measurement and electrophoresis systems. Figure 1 shows all published data on the temperature dependence of the $\mathrm{pH}$ of zero net surface charge $\left(\mathrm{pH}_{\mathrm{pzc}}\right)$ for metal oxides above $95^{\circ} \mathrm{C}$ (Wesolowski et al., 2000; Machesky et al., 2001; Zhou et al., 2003; Fedkin et al., 2003). Oxide surfaces are positively charged at $\mathrm{pH}^{\prime}$ s below the $\mathrm{pH}_{\mathrm{pzc}^{\prime}}$ and negatively charged at higher $\mathrm{pH}$. This charge accumulation attracts ions of opposite sign, which adsorb on the

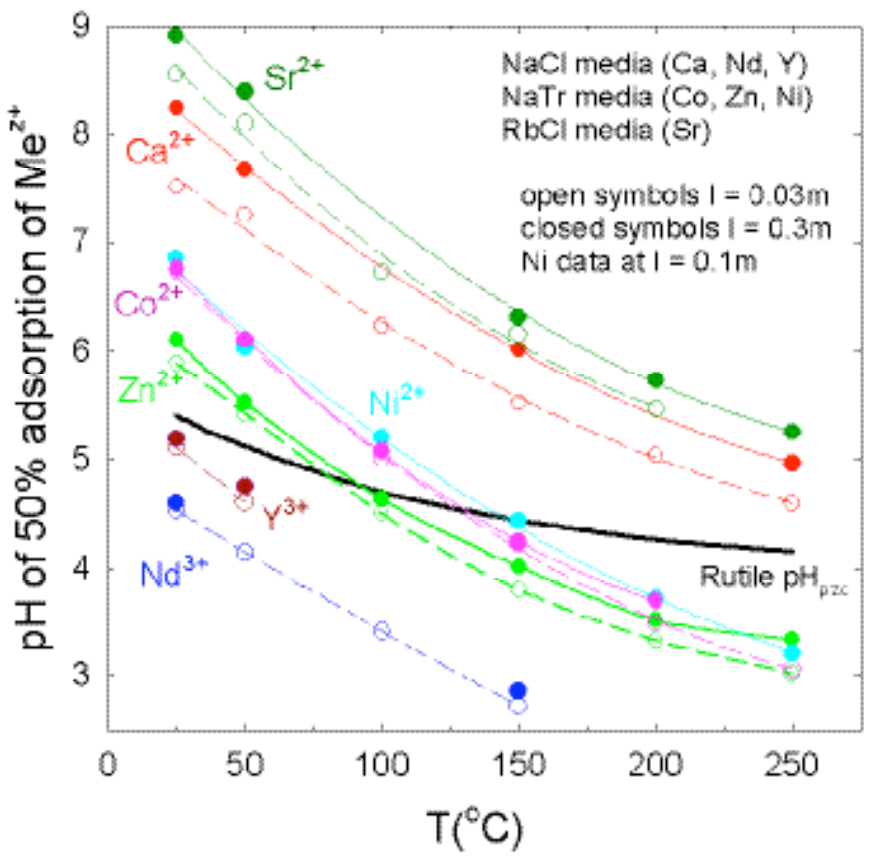

Figure 2. The $\mathrm{pH}$ at which $50 \%$ of a trace concentration (initially $0.00 \mathrm{I}$ molal) of the indicated metal cation is adsorbed on the surfaces of rutile powders suspended in aqueous solutions of $\mathrm{NaCl}, \mathrm{RbCl}$, or $\mathrm{NaCF}_{3} \mathrm{SO}_{3}(\mathrm{NaTr})$ at ionic strengths of $0.03-0.3$ molal. 
surface. Figure 2 shows the temperature dependence of the $\mathrm{pH}$ at which $50 \%$ of a trace level for various cations are adsorbed on the rutile $\left(\alpha-\mathrm{TiO}_{2}\right)$ surface during $\mathrm{pH}$ titrations of solutions containing a suspension of the mineral powder, and the indicated cation in a much higher concentration of background 1:1 electrolyte ( $\mathrm{NaCl}$, etc.). The lower the $\mathrm{pH}$ of $50 \%$ adsorption, the stronger the adsorption affinity of the cation. The $\mathrm{pH}_{\mathrm{pzc}}$ of rutile is shown for reference. Large alkaline earth cations such as $\mathrm{Sr}^{2+}$ and $\mathrm{Ca}^{2+}$ are weakly attracted, and only achieve $50 \%$ adsorption at $\mathrm{pH}^{\prime} \mathrm{s}$ well above the $\mathrm{pH}_{\mathrm{pzc}}$. However, small divalent $\left(\mathrm{Zn}^{2+}, \mathrm{Co}^{2+}, \mathrm{Ni}^{2+}\right)$ and all trivalent cations achieve $50 \%$ adsorption at $\mathrm{pH}^{\prime}$ s at or even below the $\mathrm{pH}_{\mathrm{pzc}}$. We have also developed thermodynamically rigorous surface complexation models (cf. Ridley et al., 2004) that quantitatively predict the equilibrium adsorption constants of protons, monovalent anions, and mono-, di-, and trivalent cations on metal oxide surfaces to high temperatures. These experimental and modeling approaches will enable useful investigation of the sorptive properties of $U$ oxide phases at the elevated temperatures expected in the nearfield environment at Yucca Mountain.

\section{Accomplishments}

This is a new project, and results to date have focused on the establishment of an experimental test plan and procedures for conducting the experiments.

Figure 1 indicates that $\mathrm{pH}_{\mathrm{pzc}}$ values of the metal oxides studied to date exhibit a temperature dependence approximately parallel to the neutral $\mathrm{pH}$ of water $(1 / 2 \mathrm{pKw})$. We expect the $U$ oxides to behave similarly, though few data are available and only at room temperature.

Furthermore, we expect the U(IV and VI) oxide surfaces to exhibit a range of sorption affinities for various radionuclide and analog ions that are functions of the ion charge, radius, and atomic structure. It is clear from Figure 2 that small, highly charged cations are very strongly adsorbed on metal oxide surfaces, particularly at the near-neutral $\mathrm{pH}^{\prime}$ s likely to prevail under proposed repository conditions. Thus, for some radionuclides released during alteration, the $\mathrm{U}$ oxides that make up the bulk of the SNF may prove to be strong absorbers, inhibiting release of the radionuclides to the external environment.

\section{Related Publications}

Fedkin, M.V., X.Y. Zhou, J.D. Kubicki, A.V. Bandura, S.N. Lvov, M.L. Machesky, and D.J. Wesolowski, High temperature microelectrophoresis studies of the rutile/aqueous solution interface. Langmuir, 19, 3797-3804, 2003.

Machesky, M.L., D.J. Wesolowski, D.A. Palmer, and M.K. Ridley, On the temperature dependence of intrinsic surface protonation equilibrium constants: An extension of the revised MUSIC model. J. Colloid Interface Sci., 239, 314-327, 2001.

Ridley, M.K., M.L. Machesky, D.J. Wesolowski, and D.A. Palmer, Surface complexation of neodymium at the rutile-water interface: A potentiometric and modeling study in $\mathrm{NaCl}$ media to $250^{\circ} \mathrm{C}$. Geochim. Cosmochim. Acta, 69, 63-81, 2004.

Wesolowski, D.J., M.L. Machesky, D.A. Palmer, and L.M. Anovitz, Magnetite surface charge studies to $290^{\circ} \mathrm{C}$ from in situ pH titrations. Chemical Geology 167, 193-229, 2000.

Zhou, X.Y., X.J. Wei, M.V. Fedkin, K.H. Strass, and S.N. Lvov, Zetameter for microelectrophoresis studies of the oxide/water interface at temperatures up to $200^{\circ} \mathrm{C}$. Rev. Scientific Instru. 74, 2501-2506, 2005. 


\title{
WASTE FORM-WASTE PACKAGE INTERACTIONS IN THE NeAR FiELD
}

\author{
Waste Package Corrosion Studies Using Small Mockup Experiments \\ Patrick V. Brady, B. Elizabeth Anderson, and Katheryn B. Helean, Sandia National \\ Laboratories (SNL) \\ In-Package Sequestration of Radionuclides at Yucca Mountain: Neptunium \\ Surface Complexation Subtask \\ James Jerden, Argonne National Laboratory (ANL) \\ Uptake of Technetium (Tc) by Iron-Based Materials \\ Kenneth Krupka, Chris Brown, Michelle Valenta, H. Todd Schaef, and Bruce Arey, \\ Pacific Northwest National Laboratory (PNNL)
}


This page intentionally left blank. 


\section{Waste Package Corrosion Studies Using Small Mockup Experiments}

Patrick V. Brady, B. Elizabeth Anderson, and Katheryn B. Helean

Sandia National Laboratories (SNL)

\section{Research Objectives}

The corrosion of spent nuclear fuel (SNF) and subsequent mobilization of radionuclides is an important concern in a geologic repository, particularly if conditions are oxidizing. Corroding A516 steel may offset these transport processes within the proposed waste packages at the proposed Yucca Mountain repository by retaining radionuclides, creating locally reducing conditions, and reducing porosity. Ferrous iron, $\mathrm{Fe}^{2+}$, has been shown to reduce $\mathrm{UO}_{2}{ }^{2+}$ to $\mathrm{UO}_{2}$ (s) (O'Loughlin et al., 2003), and some ferrous iron-bearing ion-exchange materials adsorb radionuclides and heavy metals (Navratil, 1989). High electron availability leads to the reduction and subsequent immobilization of problematic dissolved species such as $\mathrm{TcO}_{4}{ }^{-}$, $\mathrm{NpO}_{2}{ }^{+}$, and $\mathrm{UO}_{2}{ }^{2+}$, and can also inhibit corrosion of SNF. Finally, the more water occluded, the bulkier the corrosion products, and the less porosity available for water and radionuclide transport. The focus of this study is on the nature of Yucca Mountain-relevent steel-corrosion products and their effects on local redox state, porosity, and radionuclide transport.

\section{Approach}

Six small-scale $(\sim 1: 40)$ waste package mockups were constructed using 316 stainless steel, the same material as the proposed Yucca Mountain waste packages. Each waste package mockup contains 25 strips $(1 \times 10 \times 0.2 \mathrm{~cm})$ of certified A-516 carbon steel, scaled by surface area to resemble the proposed repository waste packages. A simulated Yucca Mountain pore water (YMPW) was injected into the mockups at a rate of $200 \mu \mathrm{L} /$ day, five days a week, using a needle syringe. The YMPW consists of $50 \mathrm{mg} / \mathrm{L}$ silica as sodium metasilicate (and thus, $38.3 \mathrm{mg} / \mathrm{L} \mathrm{Na}$ ), enough hydrochloric acid to lower the $\mathrm{pH}$ to 7.6, and an excess of powdered calcite. The solution was allowed to equilibrate open to the atmosphere for 5 days, filtered, and allowed to equilibrate with the atmosphere for an additional 5 days. The final $\mathrm{pH}$ stabilized at 7.5.

Characterization of corrosion products was by x-ray powder diffraction (XRD) and, where appropriate, scanning electron microscopy (SEM) and transmission electron

microscopy (TEM). Ferrous iron was measured in the solids using a standard $\mathrm{K}_{2} \mathrm{Cr}_{2} \mathrm{O}_{7}$ titration technique (Sandia ASTM D 3872-86) and in liquids using colorimetry. Effluents will also be analyzed periodically using inductively coupled plasma mass spectrometry (ICP-MS).

\section{Accomplishments}

Although the generally poor crystallinity of the corrosion products precludes reliable quantitative analysis by XRD, major and minor phases were identifiable in the scoping study after 30 and 90 days. Magnetite, $\mathrm{Fe}_{3} \mathrm{O}_{4}$, possibly along with the structurally identical, but fully oxidized, maghemite, was the major corrosion phase present after both 30 and 90 days. Titration showed that $4 \%$ of the corroded iron present was $\mathrm{FeO}$, corresponding to $12 \mathrm{wt} \%$ $\mathrm{Fe}_{3} \mathrm{O}_{4}$. Hematite, $\mathrm{Fe}_{2} \mathrm{O}_{3}$, was identified as a minor phase in both cases, and after 90 days a diffraction peak corresponding to a d-spacing of $12.87 \AA$ was also evident in x-ray data from the solids. (All other diffraction peaks corresponded to either magnetite or hematite.) This peak may indicate an unknown solid; however, this phase could not be identified from a single diffraction peak.

SEM was used to characterize a polished cross section of the 90-day corroded steel. A backscattered electron micrograph shows oxidation "blisters" pock-marking the steel surface and clear zones that can be described as anodic (oxidizing) and cathodic (reducing). Energy dispersive spectroscopy (EDS) indicates that $\mathrm{Cl}$ is preferentially incorporated into a "fibrous" phase, and micrographs suggest a layered structure.

The presence of reduced iron in magnetite in waste package mockup studies suggests not only that radionuclidesorbing minerals will be present in Yucca Mountain waste packages, but also that the abundance of reduced iron will cause locally reducing conditions. Ongoing experiments with $\mathrm{UO}_{2}$ and XPS studies will provide further insight into the effects of A516 steel corrosion products and radionuclide transport. This study suggests that steel and its corrosion products may retard transport of $U$ and other radionuclides in Yucca Mountain waste packages and the environment. 


\section{References}

Navratil, J. D., Ion-exchange technology in spent fuelreprocessing. Journal of Nuclear Science and Technology, 26, 8, 735-743, 1989.

O'Loughlin, E., S.D. Kelly, R.E. Cook, R. Csenscsits, and K.M. Kemner, Reduction of uranium(VI) by mixed iron(II)/iron(III) hydroxide (green rust): Formation of $\mathrm{UO}_{2}$ nanoparticles. Environmental Science and Technology, 37, 721-727, 2003. 


\section{In-Package Sequestration of Radionuclides at Yucca Mountain: Neptunium Surface Complexation Subtask}

James Jerden

Argonne National Laboratory (ANL)

\section{Research Objectives}

This subtask of the Source Term In-Package Sequestration Project has three main objectives: (1) to quantify the distribution of neptunium $(\mathrm{Np})$ between metal oxide corrosion products (i.e., those that form from corroding waste package materials) and aqueous solutions as a function of $\mathrm{pH}$, ionic strength, sorbent/sorbate ratio, reaction time (aging), and solution composition; (2) to use synchrotron based $x$ ray absorption and fluorescence techniques to obtain molecular-scale information (e.g., local coordination environment, oxidation state) on how $\mathrm{Np}$ is bound to mineral surfaces; and (3) to quantify the reversibility of radionuclide sorption onto relevant mineral substrates.

Reich et. al. Radiochim. Acta 88 (2000)

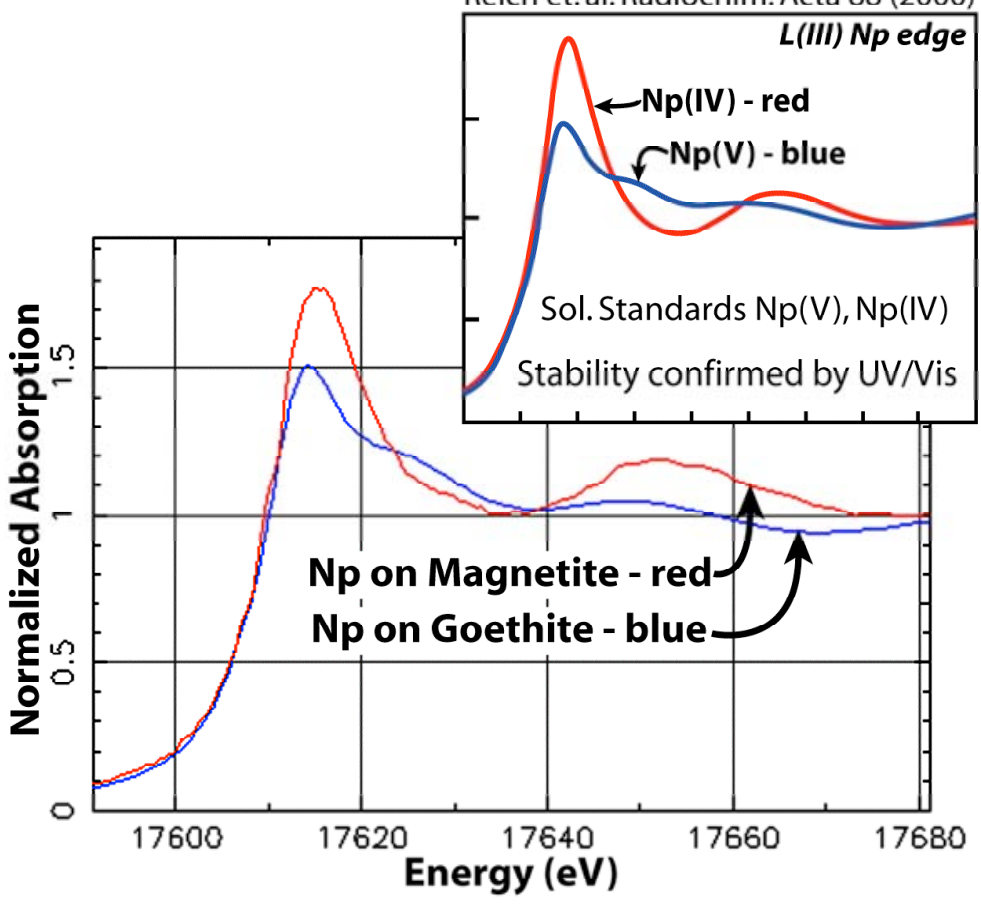

Figure I. X-ray absorption spectra for neptunium adsorbed to goethite (blue) and magnetite (red). Our data are shown in the bottom plot. The upper plot shows reference spectra distinguishing between neptunium redox states. Comparison of our data with the reference spectra show that neptunium adsorbed to goethite is $\mathrm{Np}(\mathrm{V})$ and neptunium on the magnetite is $\mathrm{Np}(\mathrm{IV})$. Neptunium was $\mathrm{Np}(\mathrm{V})$ in all starting solutions.

\section{Approach}

We are performing batch adsorption experiments in which $\mathrm{Np}$-bearing solutions are reacted with goethite $(\alpha-\mathrm{FeOOH})$ and magnetite $\left(\mathrm{Fe}_{3} \mathrm{O}_{4}\right)$. These iron oxides are anticipated to be important corrosion phases within a breached waste package. The variables for the batch tests include $\mathrm{pH}$, ionic strength, sorbent/sorbate ratio, reaction time (aging), and solution chemistry. We are also testing how uranium (U) may compete with $\mathrm{Np}$ for adsorption sites by performing experiments in which $\mathrm{Np}$ and $\mathrm{U}$ are both present as sorbates. Concentrations of $\mathrm{Np}$ and $\mathrm{U}$ in solution are measured before and after a given reaction interval, using inductively coupled plasma mass spectrometry or highresolution gamma counting. Selected reacted sorbent samples are analyzed by $x$-ray absorption spectroscopy to determine the oxidation state and molecular speciation of adsorbed $\mathrm{Np}$. The x-ray absorption data are collected at ANL's Advanced Photon Source Sector 10, MR-CAT beam-line.

\section{Accomplishments}

Solution data from the batch tests have been used to establish the $\mathrm{pH}$ adsorption edge of $\mathrm{Np}$ and $\mathrm{U}$ on goethite in a calcium-bearing sodium silicate solution (simulated Yucca Mountain pore fluid). The results indicate that $\mathrm{Np}$ uptake on goethite reaches $95 \%$ at a $\mathrm{pH}$ of approximately 7 and begins to decrease at $\mathrm{pH}$ values greater than 8.5 (for $1 \mathrm{~g} / \mathrm{L}$ of sorbent and a starting concentration of $10^{-5.5}$ molal neptunium). $U$ uptake on goethite reaches $95 \%$ at a $\mathrm{pH}$ of 5 and also begins to decrease at $\mathrm{pH}$ values greater than 8.5 (again for $1 \mathrm{~g} / \mathrm{L}$ of sorbent and a starting concentration of $10^{-5.5}$ molal U). These observations have important implications for the competition of $U$ and $\mathrm{Np}$ for surface adsorption sites at low sorbent/sorbate ratios. $\mathrm{Np}$ and $\mathrm{U}$ uptake on magnetite show similar trends with respect to $\mathrm{pH}$, but have slightly lower uptakes overall.

We have also successfully analyzed selected sorbent samples from the batch tests by $\mathrm{x}$-ray absorption spectroscopy to determine the oxidation state and coordination environment of $\mathrm{Np}$ 
adsorbed to goethite and magnetite. Results from these analyses indicate that $\mathrm{Np}$ complexes with the goethite surface as $\mathrm{Np}(\mathrm{V})$ and with the magnetite surface as $\mathrm{Np}(\mathrm{IV})$ (Figure 1). Np in the starting solutions for all of our tests is $\mathrm{Np}(\mathrm{V})$ (confirmed by x-ray absorption spectroscopy). The $\mathrm{Np}$ adsorbed to goethite shows a $\mathrm{Np}-\mathrm{O}$ bond length of $1.86 \AA$, which is representative of the $\mathrm{Np}-\mathrm{O}$ axial bond in the neptunyl(V) complex. The $\mathrm{Np}$ on goethite also shows a $\mathrm{Np}-\mathrm{O}$ bond length of $2.45 \AA$, which is interpreted as the distance to equatorial oxygens perpendicular to the linear neptunyl(V) ion. $\mathrm{Np}$ adsorbed to magnetite shows a $\mathrm{Np}-\mathrm{O}$ bond length of $2.38 \AA$ and Np-Fe bond length of $3.46 \AA$. While the molecular geometry of this $\mathrm{Np}$ surface complex is still under investigation, the observation of an $\mathrm{Np}-\mathrm{Fe}$ interaction is important because it indicates that $\mathrm{Np}$ is bound to the Fe oxide surface as an inner sphere complex. This has important implications for the reversibility of $\mathrm{Np}$ sorption (i.e., the presence of an inner sphere complex indicates that the $\mathrm{Np}$ is "tightly" bound to the sorbent surface).

Our results indicate that under certain conditions, $\mathrm{Np}$ will be sequestered by waste package corrosion products as tightly bound (not readily desorbed) inner-sphere complexes. Furthermore, the reduction of $\mathrm{Np}$ on magnetite could potentially catalyze the precipitation of the relatively insoluble $\mathrm{Np}$ solid, $\mathrm{NpO}_{2}$. Most importantly, these results may provide a mechanistic basis for modeling the surface complexation of $\mathrm{Np}$ with key corrosion products. 


\section{Uptake of Technetium (Tc) by Iron-Based Materials}

Kenneth Krupka, Chris Brown, Michelle Valenta, H. Todd Schaef, and Bruce Arey

Pacific Northwest National Laboratory (PNNL)

\section{Research Objectives}

This work focuses on characterizing the surface-mediated, heterogeneous reduction/sorption reactions that will affect the sequestration of ${ }^{99} \mathrm{Tc}$ by iron $(\mathrm{Fe})$ oxide/hydroxide solids that precipitate during corrosion of Fe-based materials, such as A516 carbon steel used in the fuel basket of the waste package design.

\section{Approach}

Batch reaction experiments were used to examine the sorption of dissolved perrhenate, as a surrogate for pertechnetate, on corrosion products of A516 carbon steel coupons reacted with synthetic groundwater or dilute water. Test vials were sacrificed and sampled at various time points, and the resulting solutions were analyzed for $\mathrm{pH}$, major cations, and some trace metals by inductively coupled plasma-atomic emission spectroscopy. Other trace metals and rhenium (Re) were analyzed by inductively coupled plasma-mass spectrometry. Bulk x-ray diffraction (XRD) and scanning electron microscopy (SEM), in conjunction with energy dispersive spectroscopy (EDS), were used to characterize the unreacted and corroded steel coupons and Fe corrosion products, as well as to determine the extent of sorbed Re.

\section{Accomplishments}

Analyses of solution samples from the Re uptake experiments indicated that the concentrations of dissolved $R e$, calcium (Ca), and silicon ( $\mathrm{Si}$ ) in both solution matrices decreased as a function of time. After 109 days, the concentration of dissolved Re in the simulated groundwater matrix was reduced by approximately $26 \%$; the dilute water matrix experienced a 99\% decrease in dissolved Re over the same time period. Additionally, the concentration of dissolved $\mathrm{Si}$ in all solution samples was less than the analytical detection limit.

Bulk XRD results for the corroded steel coupons showed that the corrosion products consisted primarily of maghemite $\left(\gamma \mathrm{Fe}_{2} \mathrm{O}_{3}\right)$, lepidocrocite $[\gamma \mathrm{FeO}(\mathrm{OH})]$, and goethite $[\alpha \mathrm{FeO}(\mathrm{OH})]$. Magnetite $\left(\mathrm{Fe}_{3} \mathrm{O}_{4}\right)$ was also identified on coupons reacted for 109 days in the perrhenatespiked synthetic groundwater. The relative proportions of these Fe oxide/hydroxide phases differed slightly for different experimental conditions, such as reaction time and solution matrix. XRD analysis of corrosion products in the steel-coupon samples did not identify any solids containing $\mathrm{Re}, \mathrm{Ca}$, or Si.

Analyses of the corroded steel coupons by SEM/EDS indicated that the corrosion products on the steel coupons reacted in both solution matrices consisted of morphologically complex assemblages of Fe oxide/hydroxide solids (Figure 1). Analyses by $\mu$ XRD are currently being used to identify the specific Fe oxide/hydroxide phases that form the different morphologies of these precipitates. EDS analyses of the corroded coupons indicated that Re was only present with the corrosion products for samples spiked with the highest dissolved perrhenate concentration used for these experiments $(1.0 \mathrm{mmol} / \mathrm{L})$. Because the reacted coupons were rinsed several times with their respective Re-free starting solutions prior to storage and SEM/EDS analysis, Re associated with the corrosion products is currently assumed to be co-precipitated with the corrosion products, rather than surface adsorbed.

Results of these studies showed that Re was removed from solution during corrosion of the A-516 steel coupons in both solutions tested. Surface-mediated sorption and/or reduction of Re onto/with the Fe oxide/hydroxide corrosion products resulted in as much as a $99 \%$ decrease in the dissolved Re concentration for the dilute water matrix. Regardless of the mechanism responsible for the observed removal of Re from solution, results of our studies using Re as an analogue for ${ }^{99} \mathrm{Tc}$ suggest that ${ }^{99} \mathrm{Tc}$ would also be sorbed and/or reduced with the steel corrosion products, and that the inventory of ${ }^{99} \mathrm{Tc}$ released from breached waste packages would be lower than what is now conservatively estimated.

The Pacific Northwest National Laboratory is operated by Battelle for the U.S. Department of Energy under Contract No. DE-AC05-76RLO 1830. 

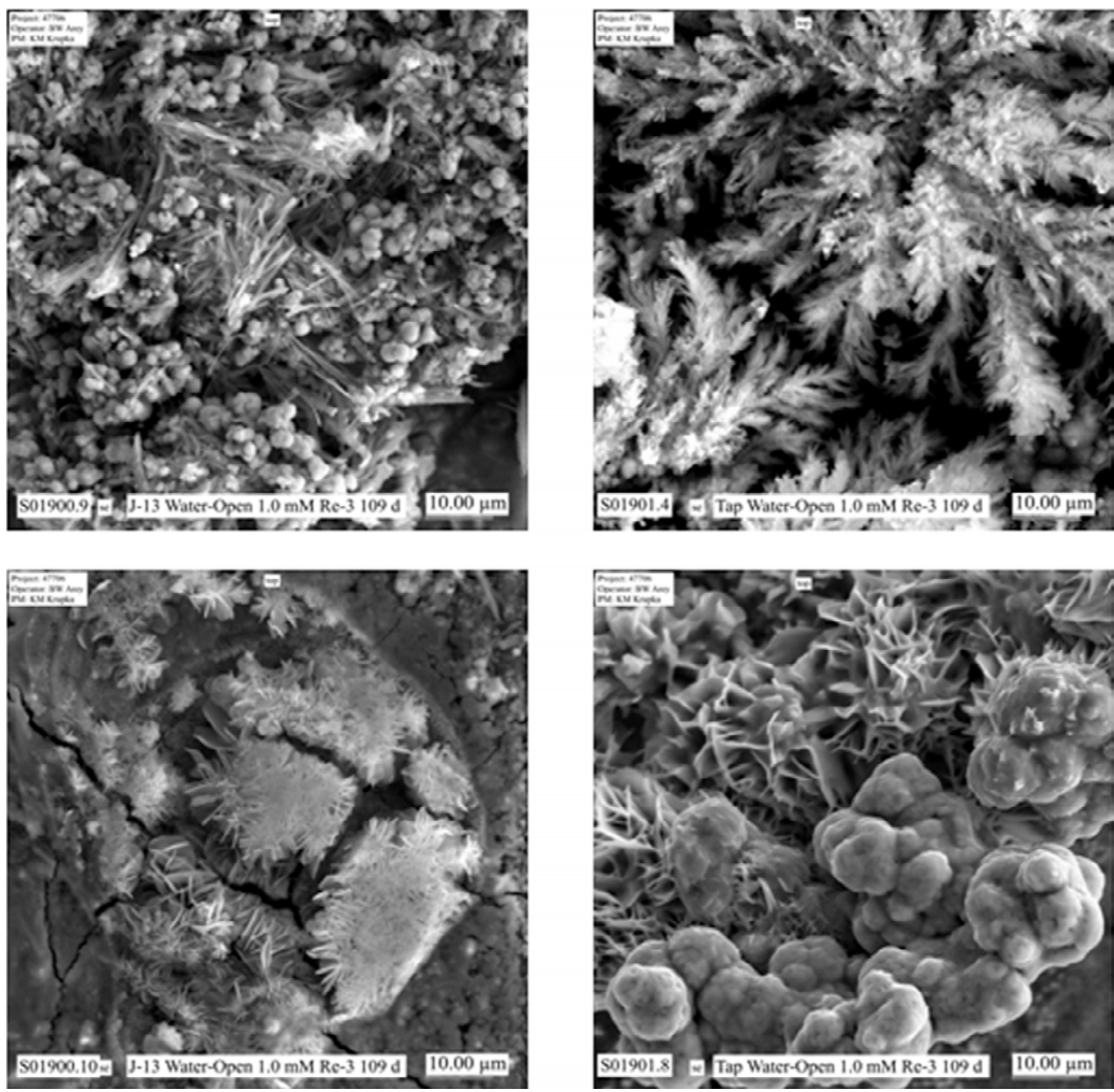

Figure I. SEM micrographs of typical corrosion products that formed after 109 days on the A-516 carbon steel coupons reacted in I.0-mmol/L $\mathrm{ReO}_{4}$--spiked J-I3 (left column) and dilute waters (right column) 


\section{INTEGRATION OF IN-PACKAGE CHEMICAL AND PHYSICAL PROCESSES}

Neptunium Incorporation into the $\mathbf{U}^{6+}$ Alteration Phases of Spent Nuclear Fuel and Neptunium Sorption onto Oxide Phases Udo Becker and Lindsay C. Shuller, University of Michigan

A Model for Radionuclide Release from Commercial Spent Nuclear Fuel Carl I. Steefel, John Apps, Nic Spycher, and Eric Sonnenthal, Lawrence Berkeley National Laboratory (LBNL) 
This page intentionally left blank. 


\section{Neptunium Incorporation into the $\mathrm{U}^{6+}$ Alteration Phases of Spent Nuclear Fuel and Neptunium Sorption onto Oxide Phases}

Udo Becker and Lindsay C. Shuller

University of Michigan

\section{Research Objectives}

The objectives of this work are to: (1) determine the incorporation mechanism of neptunium $(\mathrm{Np})$ into $\mathrm{U}^{6+}$ alteration phases of spent nuclear fuel (SNF) and (2) determine the mechanism of $\mathrm{Np}$-sorption onto iron (Fe)-oxide surfaces.

With respect to the first objective, past experimental work on $\mathrm{Np}$ incorporation into $\mathrm{U}^{6+}$ alteration phases is inconsistent. A thorough understanding of the incorporation mechanisms requires an understanding of the energetics of the possible substitution mechanisms in different $\mathrm{U}^{6+}$ structure types. We ask four central questions: What is the energy of substitution? What is the mechanism of substitution (e.g., $\mathrm{Np}^{5+}+\mathrm{OH}-\leftrightarrow \mathrm{U}^{6+}+\mathrm{O}^{2-}$ )? What is the thermodynamic limit of $\mathrm{Np}$ incorporation into $\mathrm{U}^{6+}$ alteration phases? What is the long-term stability of $\mathrm{U}^{6+}$ alteration phases with and without Np incorporation?

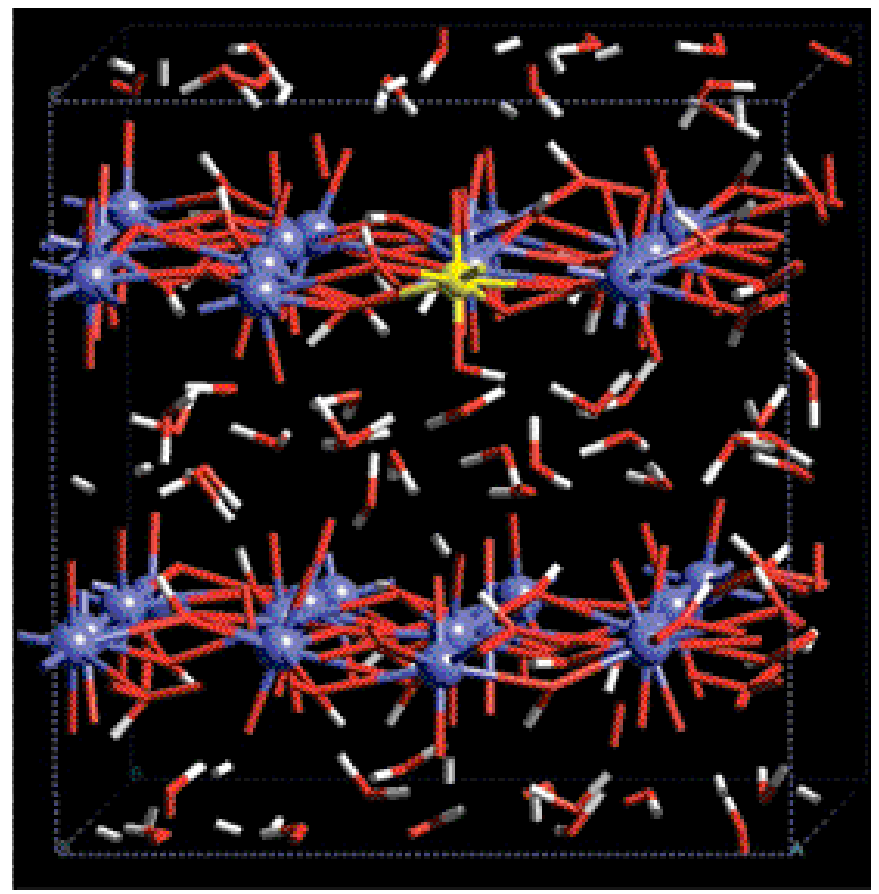

Figure I. Model for $\mathrm{Np}$ coupled substitution into schoepite. In this model, $\mathrm{Np}^{5+}$ and a bonded $\mathrm{OH}^{-}$(below the yellow $\mathrm{Np}$ ) replace a $\mathrm{U}^{6+}$ (blue) and $\mathrm{O}^{2-}$ (red) in the same coordination sphere. The composition of $\mathrm{H}$ atoms is one possible low-energy configuration.
Sorption of Np onto Fe oxide surfaces is a viable mechanism that will inhibit the release of $\mathrm{Np}$ into the near-field of a repository. Iron oxide minerals are among the most important potential $\mathrm{Np}$ adsorbers, because they are commonly found within close proximity to high-level waste material. The state of $\mathrm{Np}$, whether $\mathrm{Np}$ or $\mathrm{NpO}_{2}{ }^{+}$, upon sorption, as well as the oxidation state, $\mathrm{Np}(\mathrm{IV})$ or $\mathrm{Np}(\mathrm{V})$, can control the adsorption energy, kinetics, and mechanism. Definitive quantitative data on adsorption energies and surface site dependence, as well as the role of temperature, humidity, and background electrolytes on the above phenomena, are still required for a better understanding of the fate of $\mathrm{Np}$.

\section{Approach}

To elucidate the fate of $\mathrm{Np}$ during the corrosion of SNF under oxidizing conditions, we have three related subprojects involving quantum mechanical calculations and in situ observations of adsorption experiments.

\section{Quantum mechanical and empirical force-field calculations of} $N p$ incorporation into different $\mathrm{U}^{6+}$ alteration phases:

Quantum mechanical and empirical potential calculations will clarify the mechanism of (coupled) substitution of $\mathrm{Np}$ into $\mathrm{U}^{6+}$ containing minerals (Figure 1 ). In addition, we will evaluate the thermodynamics of $(\mathrm{Np}(\mathrm{V}), \mathrm{U}(\mathrm{VI}))$ oxide and hydroxide solid solutions from Monte Carlo calculations that are based on the quantum mechanical results. This information is important for evaluating how much $\mathrm{Np}$ can be incorporated into $\mathrm{U}^{6+}$ alteration phases and the long-term stability of these solid solutions (Skomurski and Shuller et al., 2005).

2. Quantum mechanical calculations on the thermodynamics of $\mathrm{Np}$ adsorption on Fe-oxide phases: The stability of Np adsorbates on these oxide phases and the mechanisms of stabilization as a function of redox processes are instrumental for determining corroded phases as a potential "trap" for $\mathrm{Np}$. These calculations will help us to understand the thermodynamics of $\mathrm{Np}$ adsorption, the potential to form $\mathrm{Np}$ oxy-hydroxide clusters on oxides (Figure 2), and the potential incorporation mechanisms into oxide minerals. 
3. In situ scanning probe microscopy observations of Np adsorp tion on oxide phases at different redox potentials: In our laboratory, we have the opportunity to test the mechanism of adsorption as a function of electrochemical potential at the atomic scale. In situ observations of $\mathrm{Np}$ adsorption to $\mathrm{Fe}$ oxide surfaces will be performed as a function of the redox potential and the solution chemistry. These experiments enable testing of the findings from our quantum mechanical calculations. In addition, the strongest adsorption sites can be identified, and site-dependent adsorption and desorption kinetics can be determined.

In summary, the calculations, in combination with atomicscale observations, are the ideal tool for determining reaction mechanisms and energies, and they also allow for the separation of processes governed by different environmental parameters.

\section{Accomplishments}

We are still at the very beginning of our research, since funding of this project has just started. To perform molecular simulations on crystal structures that will determine the incorporation energetics, we must know the positions of all atoms in a given structure. We are in the process of developing a potential set applicable to a number of $\mathrm{U}^{6+}$ alteration phases (e.g., studtite and other uranyl oxyhydroxides), especially to specifically mimic the structural and physical properties of $\mathrm{OH}^{-}, \mathrm{H}_{2} \mathrm{O}$, and peroxyl groups in these structures. The fitting process will be based on the quantum mechanical calculations, resulting from the limited availability of $\mathrm{H}$ position data from experimental structure determinations. The program used to fit the empirical potential is GULP. Meanwhile, the studtite crystal structure, including the hydrogen lattice positions, has been optimized with quantum mechanical calculations using the CASTEP program. Ultimately, this work will provide a strong theoretical basis for understanding experimental results that indicate that some radionuclides, such as $\mathrm{Np}$, may be incorporated into the $\mathrm{U}(\mathrm{VI})$ phases.

The crystal structure for studtite was determined by Burns et al. (2003) by using x-ray diffraction (XRD); however, determining $\mathrm{H}$ positions in the presence of heavy atoms using only XRD data is inherently difficult. Our calculations for the structure of studtite indicate that the $\mathrm{H}$ posi-

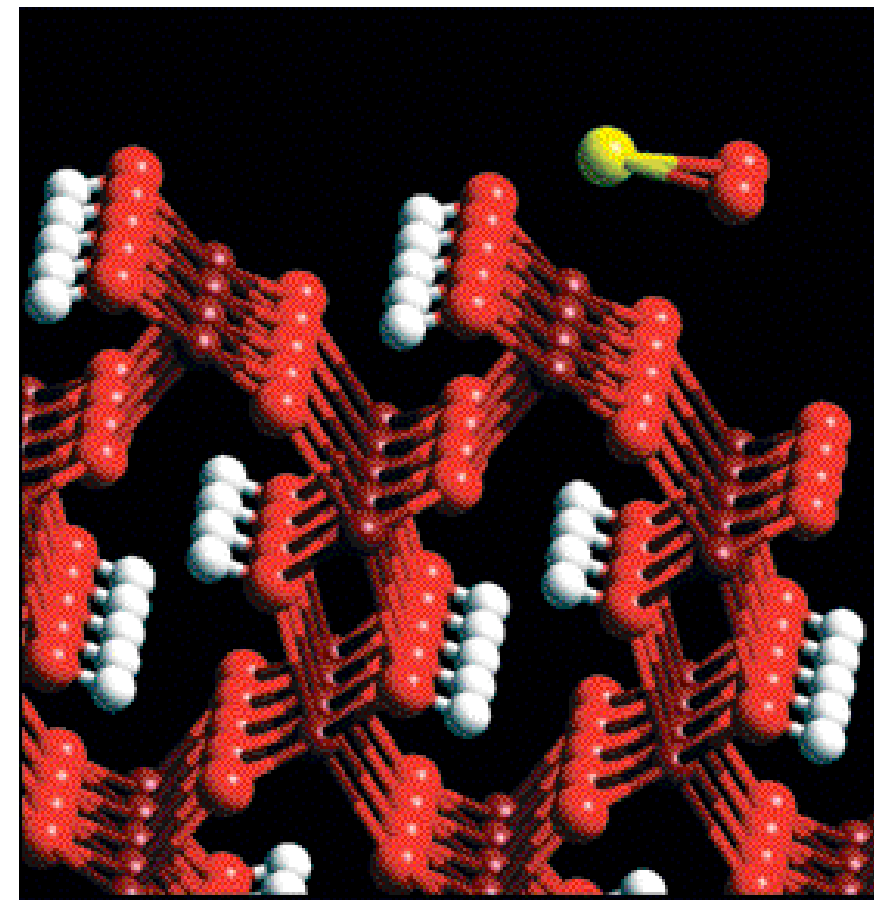

Figure 2. Model for $\mathrm{NpO}_{2}{ }^{+}$adsorption onto a step site on a goethite (0I0) surface. For better graphical representation, the goethite surface is unrelaxed. The negative local charge of the surface at the adsorption site bends the $O$ atoms of the neptunyl molecule away from the step. Water (in preliminary MD runs) around the adsorption site reorients the neptunyl and extends the bond length within the neptunyl and from the $\mathrm{Np}$ to the closest $\mathrm{O}$ on the step (here: I. $8 \AA$ ). This represents the desorption tendency in the presence of water.

tions of $\mathrm{H}_{2} \mathrm{O}$ coordinated to $\mathrm{U}$ are closer to the (101) plane than reported by Burns et al. (2003).

\section{References}

Burns, P.C., and K.A. Hughes, Studtite

$\left[\left(\mathrm{UO}_{2}\right)\left(\mathrm{O}_{2}\right)\left(\mathrm{H}_{2} \mathrm{O}\right)_{2}\right]\left(\mathrm{H}_{2} \mathrm{O}\right)_{2}$ : The first structure of a peroxide mineral. American Mineralogist, 88, 1165-1168, 2003.

Skomurski, F.A., L.C. Shuller, R.C. Ewing, and U. Becker, Surface and Interface Science Workshop, Argonne National Laboratory. Abstract, September 8-9, 2005. 


\section{A Model for Radionuclide Release from Commercial Spent Nuclear Fuel}

Carl I. Steefel, John Apps, Nic Spycher, and Eric Sonnenthal

Lawrence Berkeley National Laboratory (LBNL)

\section{Research Objectives}

The technical goal of the project is to develop a comprehensive conceptual and numerical model describing the degradation of irradiated uranium (U) oxide when exposed to seepage and condensate water. The model will incorporate the partial oxidation and dissolution of $U$ oxide, the precipitation of alteration products, the solid solution substitution and/or adsorption of other actinides (e.g., Np, Pu, and Am) during precipitation of the secondary uranyl phases, radionuclide decay, alpha particle and gamma radiation on aqueous phase radiolysis, gaseous $\mathrm{O}_{2}$ and $\mathrm{CO}_{2}$ fluxes, and transport through cracks of differing size in the commercial spent nuclear fuel (SNF). The project will be coordinated with separate Office of Science and Technology and International investigations defining the near-field and in-drift chemical environment.

The goals are to consider the processes listed above in:

1. Developing an SNF degradation model that takes into account the transport and chemical processes affecting seepage water as it migrates into a single crack in the SNF. Initially, this model will treat redox processes through whole cell reactions. However, a "galvanic cell" model for waste form degradation will be incorporated in future model updates, explicitly accounting for electron fluxes.

2. Developing a drift/near field-scale model for waste form degradation and release that couples THC processes occurring in the near field and indrift environment (gas transport, evaporation of seepage water, flow in the invert) with those occurring inside a breached waste package. This coupled approach will permit treatment of fluxes into and out of the waste package, thus providing a more realistic description of the total environment within which SNF degradation occurs.

\section{Approach}

The technical approach reflects current conceptualizations of hypothetical waste package failures, as illustrated in Figure 1. Ingress of groundwater or condensate will occur (Figure 1a), and contact SNF through cladding cracks (Figure 1b). SNF corrosion will then occur along intergran- ular boundaries and discontinuities (Figure 1c). The initial emphasis is on development of conceptual models of key processes in a comprehensive numerical model for SNF degradation and uranyl phase alteration. Tasks include:

- Evaluation of the thermodynamic properties of secondary U phases. This task will consist primarily of a comprehensive literature review and critical evaluation of thermochemical data, with the aim of developing an internally consistent thermodynamic database as a function of temperature that can be used by TOUGHREACT, a reactive transport simulation code for thermal-hydrological-chemical processes.

- Characterization of nucleation and phase growth from supersaturated solutions, accounting for interfacial free energies. The key to this task will be to develop a kinetic model capable of predicting the temporal sequence of metastable and eventual stable phases following the general kinetic approach outlined by Steefel and Van Cappellen (1990).

- Development of appropriate solid solution models for the uranyl and uranous phases.

- Incorporation of radionuclide decay chains for reactive species into TOUGHREACT. Capabilities for otherwise conservative species already exist. This will also include heat production as a result of radioactive decay.

- Inclusion of radiolytic species and their thermodynamic properties in the TOUGHREACT thermodynamic database. The formation of aqueous radiolytic species and free radicals under defined radiation fluxes has been studied extensively, and the thermodynamic parameters, homogeneous rate constants, and associated activation energies are generally well characterized.

- Inclusion of homogeneous reaction-rate constants in the TOUGHREACT database and testing of current TOUGHREACT capabilities for kinetically controlled homogeneous reactions in the aqueous phase. Although reactions involving radiolytic species are sufficiently fast to be ignored, radiolytic products of dissolved $\mathrm{HCO}_{3}{ }^{-}$and $\mathrm{SO}_{4}{ }^{2-}$ may persist and cause significant deviations in redox equilibrium or steady-state conditions. Of particu- 
lar relevance will be the role of hydrogen peroxide in reducing $\mathrm{PuO}_{2}{ }^{+}$and $\mathrm{NpO}_{2}{ }^{+}$to the IV state and their substitution in secondary uranyl phases.

- Development of a 1-D dual continuum and a 2-D discrete fracture TOUGHREACT model to simulate aqueous phase attack on $\mathrm{UO}_{2}$ and precipitation of secondary phases.

- Development of a galvanic cell model, including electron transport, for waste form degradation and precipitation of secondary phases. This model will more realistically describe the spatial distribution of reaction products than a generalized, whole cell redox approach.

- Development of a near-field/drift-scale 2-D dual continuum model for THC processes that incorporates waste form degradation inside a breached package. This model will be capable of handling transport and chemical reactions taking place within the near-field environment, inside the drift (including gas-aqueous phase exchange and evaporation) and the invert, in addition to SNF degradation processes within the package.

Model development will be responsive to ongoing separate experimental and theoretical studies, and will be modified based on experimental results from other projects.

The resulting models will be closely integrated with nearfield and in-drift THC process models, with the ultimate goal of making near-quantitative predictions of radionuclide transport and fate in the proposed repository environment.

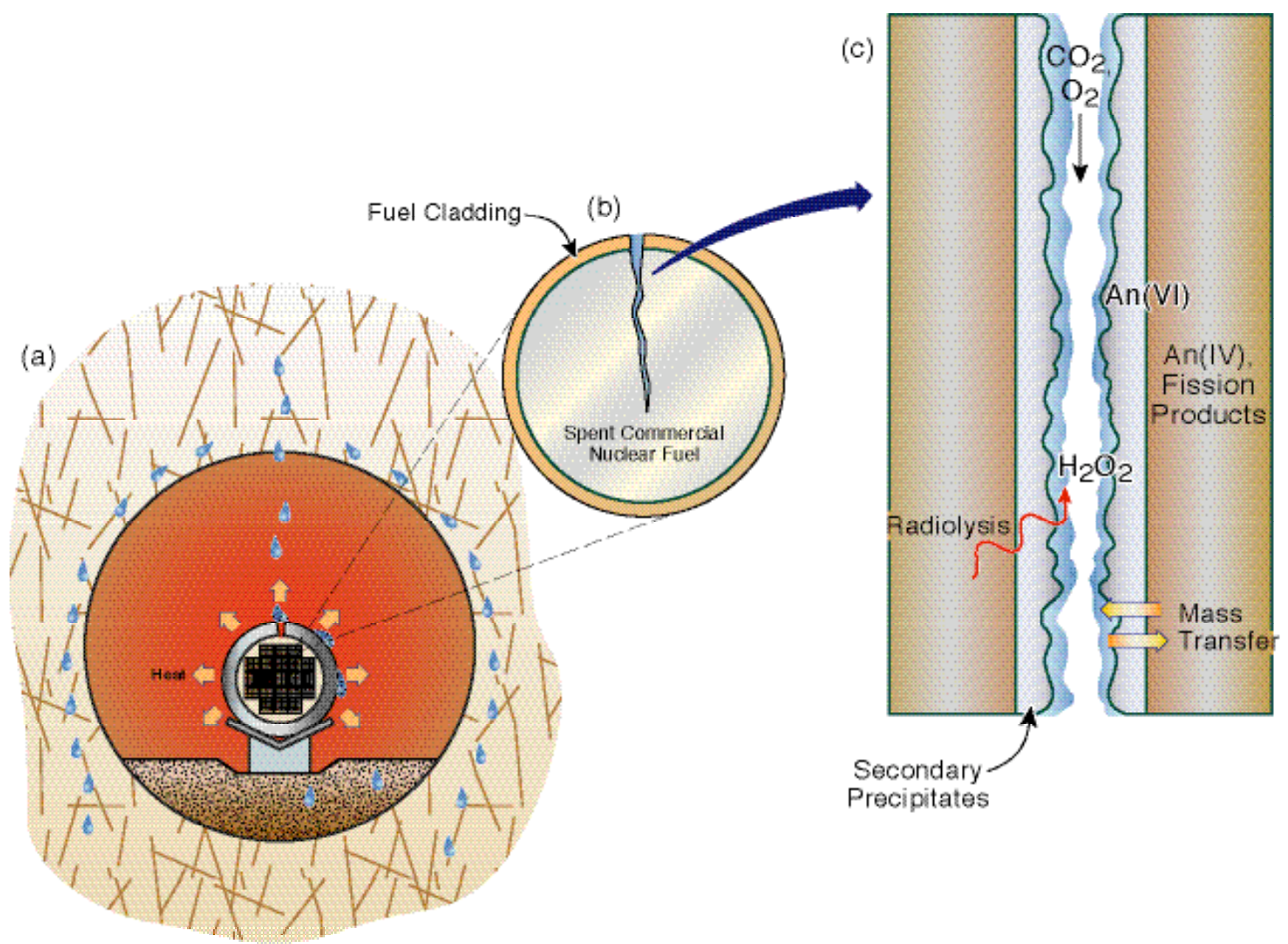

Figure I. (a) In-drift physical and chemical processes influence the in-package environment in the event of a breach of the waste package; (b) a breach of the fuel cladding allows ingress of seepage water and reactive gases (especially $\mathrm{O}_{2}$ and $\mathrm{CO}_{2}$ ), (c) leading potentially to corrosion of the spent nuclear fuel. 


\section{Accomplishments}

The project began in September 2005. To date, project leaders have attended the Source Term workshop at Argonne National Laboratory and laid preliminary plans to collaborate with other principal investigators.

Current source term models used for the YMP License Application do not include all chemical processes known to be relevant to the retention and migration of critical radionuclides, potentially making the current models overly conservative. The aim of this study is to integrate such chemical processes into a more comprehensive and realistic model that can more confidently predict radionuclide behaviors over the very long time frames relevant to a geologic repository.

\section{References}

Steefel, C.I., and P. Van Cappellen, A new kinetic approach to modeling water-rock interaction: The role of nucleation, precursors, and Ostwald ripening. Geochimica et Cosmochimica Acta, 54, 2657-2677, 1990. 


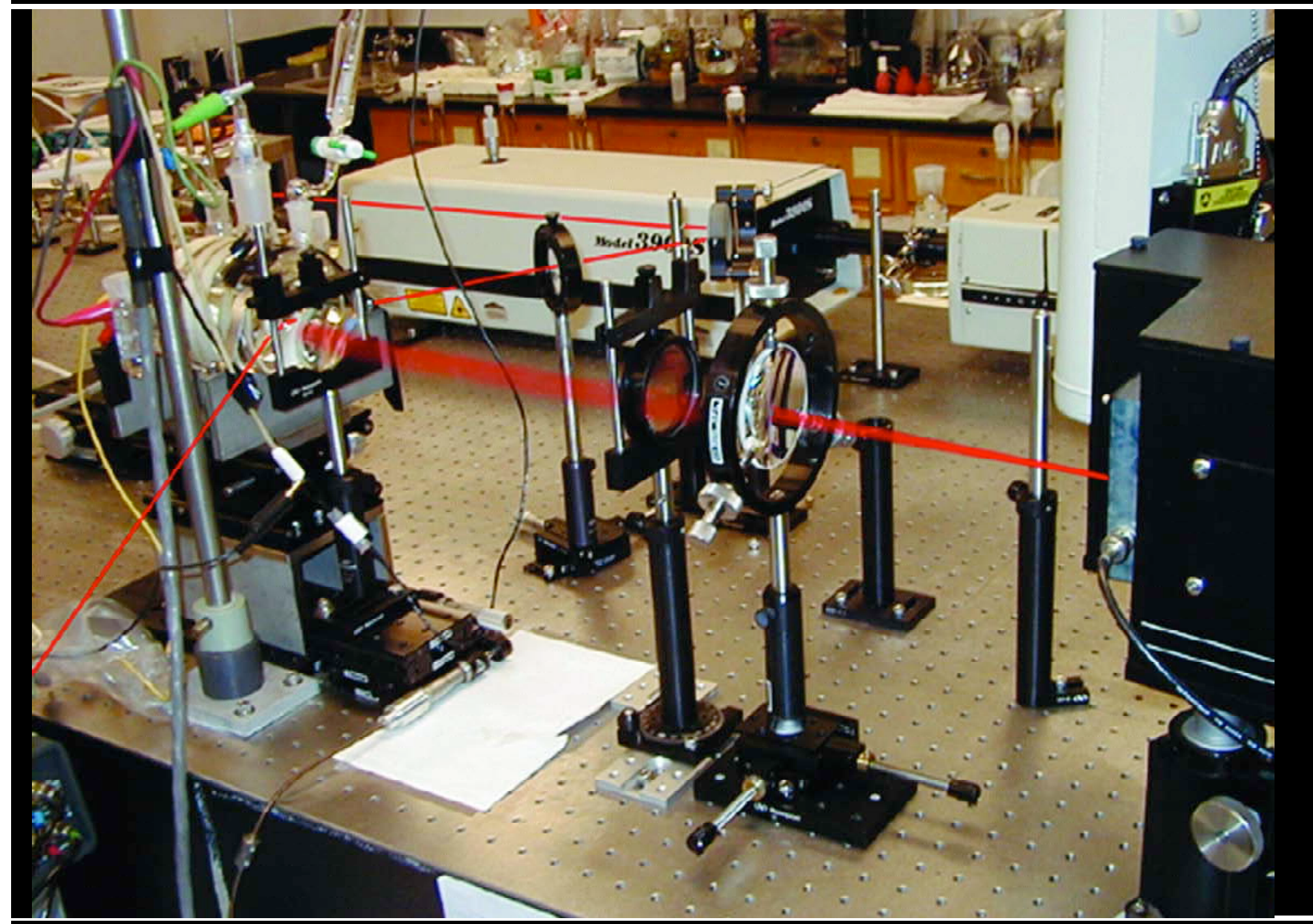

Surface Enhanced Raman Spectroscopy (SERS) for insitu

analysis of the corrosion protection (passive) film on Ni-Cr-Mo alloys 


\section{MATERIALS PERFORMANCE THRUST}

Joe H. Payer, Director, Materials Performance Thrust

\author{
Case Western Reserve University
}

Contact: 216.368.4218 | joe.payer@case.edu

\section{B a ckground}

The Yucca Mountain site was recommended by the President to be a geological repository for commercial spent nuclear fuel and high-level radioactive waste. The site was then selected by Congress and signed into law by the President. The multi-barrier approach was adopted for assessing and predicting system behavior, including both natural barriers and engineered barriers. A major component of the long-term strategy for safe disposal of nuclear waste is first, to completely isolate the radionuclides in waste packages for long times, and then, to greatly retard the egress and transport of radionuclides from penetrated packages.
The goal of the Materials Performance Thrust program is to further enhance the understanding of the role of engineered barriers in waste isolation. In addition, the thrust will explore technical enhancements and seek to offer improvements in materials cost and reliability.

\section{Opportunities for Performance and Technical Advances}

The materials used for isolating waste in the proposed repository are an important component of the overall approach to the design of the repository system. The proposed emplacement drift is shown in Figure 1.

Opportunities exist to enhance the understanding of material performance and to probe technical enhancements. These enhancements may include optimizing the performance of waste packages and drip shields for increased reliability and cost effectiveness.

Corrosion is a primary determinant of waste package performance at the proposed Yucca Mountain repository and will control the delay time for radionuclide transport from the waste package. Intact waste packages fully contain and isolate radionuclides at the proposed repository. Corrosion is the most likely degradation process that will determine when packages will be penetrated and the shape, size, and distribution of those penetrations. This thrust program strives for increased scientific understanding, enhanced

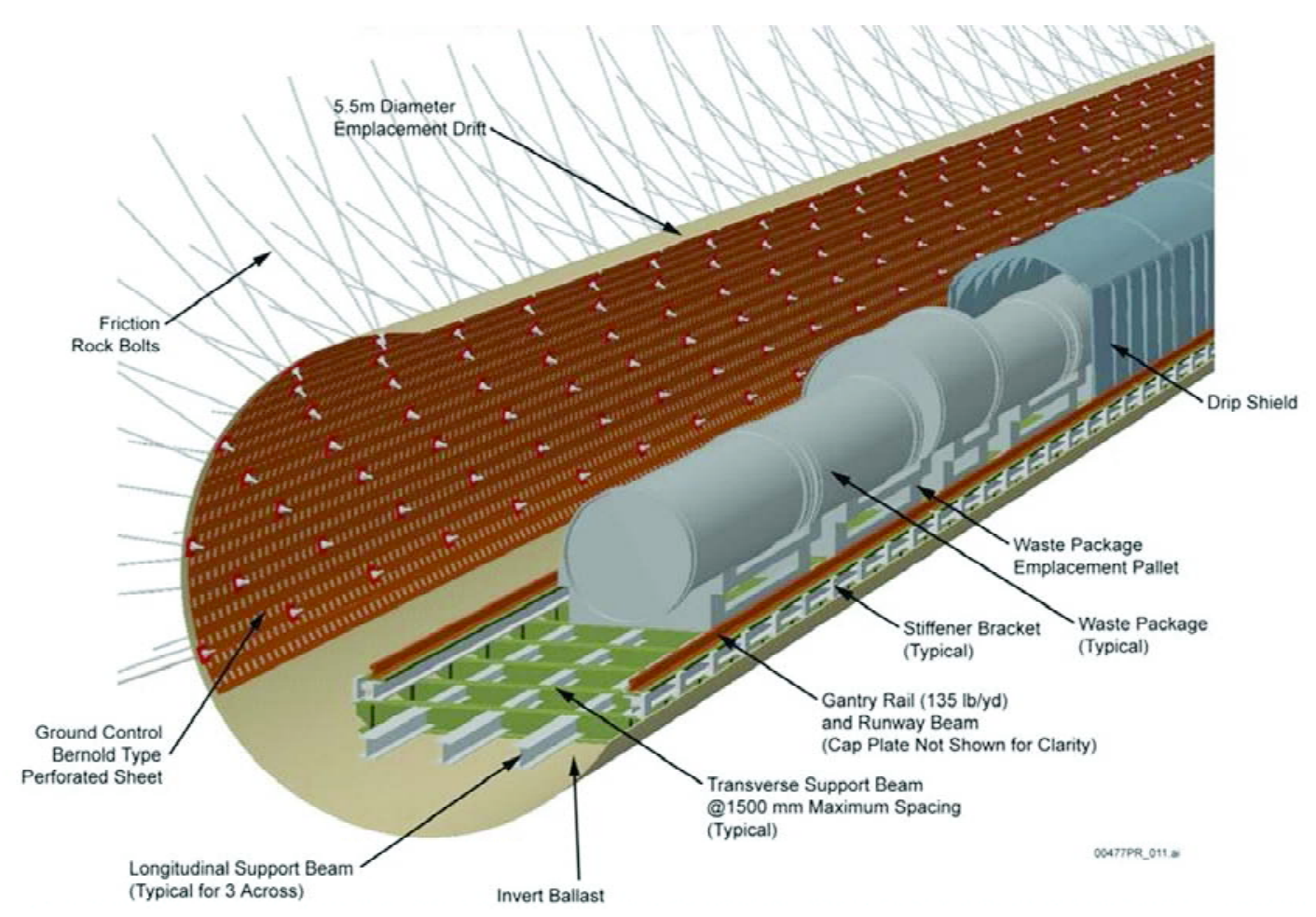

Figure I. The proposed emplacement drift with waste packages and drip shield 
process models, and advanced technologies for long-term corrosion performance.

Thus, corrosion resistance is important to the long-term performance of waste packages. The waste packages are manufactured from highly corrosion-resistant metals, and the surface of these metals is protected by the formation of a self-healing, passive layer. The metals for waste packages and drip shields have excellent corrosion resistance over a wide range of aqueous solution compositions and temperatures. Based upon previous measurements of corrosion rates of passive metals, if the passive film remains stable, the waste packages can remain intact with no penetrations resulting from corrosion for durations of tens of thousands and even hundreds of thousands of years.

\section{Approach}

Materials optimization is realized through a coordinated p rogram of targeted, applied research projects. The program comprises directed technical goals and thrusts. A team of leading scientists/engineers from major universities, national laboratories, and other participants is working together to meet the program objectives. This group brings expertise and specialized facilities in important disciplines, including corrosion science, materials science, electrochemistry, physical chemistry, and geochemistry. The team is organized among collaborative technical thrusts focused on important topics:

- Long-term behavior of protective, passive films

- Composition and properties of moisture in contact with metal surfaces

- Rate of penetration and extent of corrosion damage over extremely long times.

Each technical thrust has a set of coordinated projects. As the program evolves, there will be additional technical thrusts, and the collaborative effort will be expanded to include other participants. The Materials Performance Thrust is coordinated with the Yucca Mountain Project through cooperative projects, technical exchanges, and program reviews.

\section{Targeted Technical Thrusts}

There are currently three multi-investigator projects within the Materials Performance Thrust. Each of these is a coordinated set of collaborative efforts.

\section{Corrosion of Metal Surfaces Covered with Particulate and Deposits}

The waste packages are supported in air, and they will never be fully immersed in water. Rather, the metal surfaces may be covered with dust, particulate, and moisture from the surrounding rock and humidity. This technical thrust examines corrosion in thin moisture films and layers of particulate and deposits. (See pp. 57-72 for an overview and the individual projects.)

\section{Evolution of Corrosion Damage by Localized Corrosion}

Understanding of localized corrosion processes, and particularly crevice corrosion, is a high priority. This technical thrust examines the rate of penetration and extent of corrosion damage by factors that determine localized corrosion over extremely long times. (See pp. 73-96 for an overview and the individual projects.)

\section{Evolution of Moisture Environment on Metal Surfaces}

The corrosion performance of a metal is determined by the inherent corrosion resistance of the metal and the corrosivity of the environment to which the metal is exposed. The amount, distribution, and chemical composition of the moisture on waste packages are important. (See pp. 97-115 for an overview and the individual projects.)

In addition to the multi-investigator projects, there are bridging projects that coordinate and integrate processmodeling activities in the Materials Performance Thrust to those in the Natural Barriers Thrust and the Source Term Thrust. The Materials Performance Thrust has been an incubator for work that transitioned to full development projects in the Office of Science and Technology and Internatonal (OST\&I) Advanced Technologies Thrust, e.g., advanced welding techniques and high-performance amorphous metal coatings.

\section{Materials Performance Thrust Program Team}

A team of experts from universities was formed under a DOE/OST\&I Corrosion Cooperative (CorrCoOp), and they work closely with scientists and engineers at several national laboratories and other participants. The CorrCoOp is based at Case Western Reserve University and includes investigators at Arizona State, Ohio State, Pennsylvania State, University of California-Berkeley, University of Minnesota, University of Toronto, University of Western Ontario and University of Virginia. National 


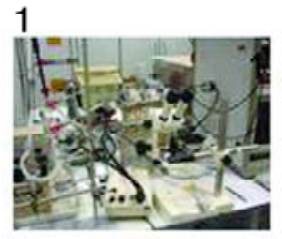

5
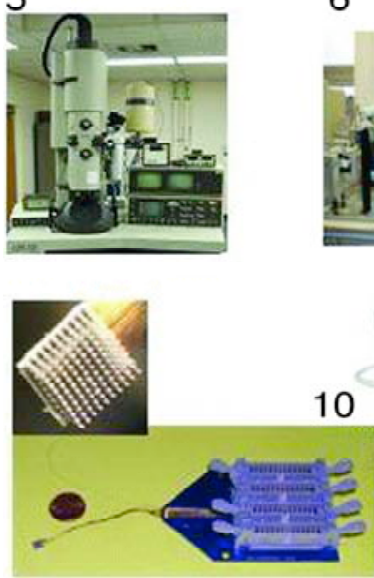

2

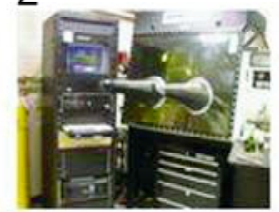

6

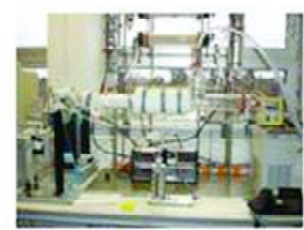

3

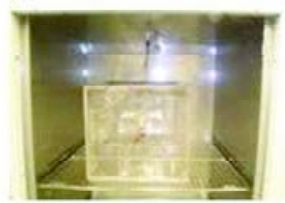

7

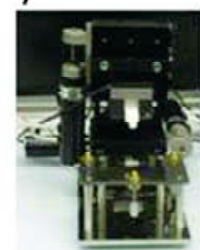

4

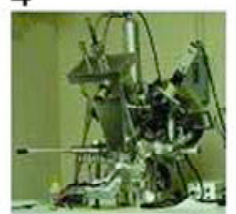

8

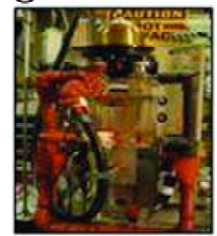

1. Kelvin Probe and Scanning Kelvin Probe

2. Laser-directed powder deposition for graded Ni-Cr-Mo compositions

3. Experimental apparatus for thin-layer electrochemical studies of stability of corrosion sites

4. X-ray Photo-Electron Spectrometry

5. 200KV Transmission Electron Microscope

6. Salt Particle Deposition System

7. Scanning Electrochemical Microscope

8. Thermogravimetric Analysis System at LLNL

9. Electrochemical Quartz Crystal Microbalance

10. Microelectrode Array

Figure 2. A sampling of the specialized capabilities and facilities in the Materials Performance Thrust

laboratory participants include Argonne (ANL), Lawrence Livermore (LLNL), Oak Ridge (ORNL), Pacific Northwest (PNNL), and Lawrence Berkeley (LBNL). Other participants include the Atomic Energy of Canada Limited (AECL).

The Director of the Materials Performance Thrust is Dr. Joe H. Payer at Case Western Reserve University. He is supported by an executive committee, a technology/research committee comprised of all program principal investigators, an external review panel, and several international affiliates.

The investigators in the Materials Performance Thrust bring expertise and specialized facilities in important disciplines, including corrosion science, materials science, electrochemistry, physical chemistry, and geochemistry. A sampling of the specialized capabilities and facilities is shown in Figure 2.

\section{Programmatic Milestones}

The Materials Performance Thrust was established as the Corrosion Thrust in FY2004 and renamed in FY2005 to reflect a broader materials perspective and technical scope. The thrust was initiated by the identification and grouping of start-up projects from the OST\&I project portfolio. Two major program milestones are:
- Corrosion Cooperative established June 1, 2004

- Defense Advanced Research Projects Agency (DARPA)/DOE High Performance Corrosion Resistant Metals project transferred from the Materials Performance Thrust to Advanced Technologies in FY2005.

The former started the major, multi-university effort to address key technical areas for corrosion of waste packages and other engineered structures. The latter illustrates an effective transition from science-based development to engineering-based technology implementation.

During the fiscal year, progress and directions of thrust projects were presented at meetings of the principal investigators. The thrust was critically reviewed and received meritorious evaluations by a thrust External Review Panel and an OST\&I Programmatic Evaluation Panel.

\section{Acknowledgments}

This work is supported by the Director, Office of Civilian Radioactive Waste Management, Office of Science and Technology and International, of the U.S. Department of Energy. The interactions among investigators in the OST\&I Materials Performance Thrust are appreciated and gratefully acknowledged. 
This page intentionally left blank. 


\section{CORROSION OF METAL SURFACES COVERED WITH PARTICULATE AND DEPOSITS}

\section{Overview}

Kinetics of the Cathodic Reduction of Oxygen on Passive Metals David W. Shoesmith, University of Western Ontario

Oxygen Electro-Reduction on Passive Metals in Particulate and Deposited Layers

Dominic Gervasio, Arizona State University

Corrosion Cells Beneath Thin Films, Particulate, and Deposited Layers Joe H. Payer, Case Western Reserve University

Electrochemical Measurements of Corrosion under Thin Brine Layers Gerald S. Frankel and Rudolph G. Buchheit, Ohio State University

\section{Mechanism of Mixed-Ion Effects on Corrosion in Thin Films} Roger C. Newman, University of Toronto

Effect of Environmental Variables on the Structure and Composition of Passive Films

Thomas M. Devine, University of California, Berkeley 
This page intentionally left blank. 


\section{Corrosion of Metal Surfaces Covered with Particulate and Deposits}

\section{OVERVIEW}

The objective of this multi-investigator effort is to determine the corrosion behavior of corrosion-resistant metal surfaces that are covered by thin layers of moisture and moist particulate and deposits. Advanced analytical and computational methods for corrosion processes in thin films, particulates, and deposits are developed. Inputs are generated for advanced, next-generation models and alternate conceptual models, based on less conservative assumptions. Enhanced scientific understanding of chemical, electrochemical, and corrosion processes is provided.

Targeted thrust objective: Develop technical basis and demonstrate the reduction in passive corrosion rate with time. There is a potential to extend predicted waste package life by 100 to 1,000 times compared to that with a time-constant rate.

Highly corrosion-resistant materials are selected for the waste packages and drip shields for the proposed Yucca Mountain repository, i.e., Alloy 22, a nickel-chromiummolybdenum (Ni-Cr-Mo) alloy, and titanium (Ti), respec- tively. Both Alloy 22 and Ti have high corrosion resistance in oxidizing environments that are of interest for the proposed repository. These alloys depend upon the formation and the tenacity of a passive film, i.e., a thin oxide on the metal surface, for their corrosion resistance. Measured corrosion rates for passive metals decrease with time to (on the order of) 0.1 to 0.01 micrometer per year. At these rates, it takes 10,000 to 100,000 years to penetrate $1 \mathrm{~mm}$ of metal, and the Alloy 22 outer layer of the waste packages is on the order of $20 \mathrm{~mm}$ thick. Thus, accounting for the reduction in passive corrosion rates is important to life prediction.

Targeted thrust objective: Identify corrosion processes for metal covered with particulate and deposits. Where corrosion is based on fully immersed solutions and not corrosion in moist layers of dust/particulate, this treatment is consevative in many cases.

In the proposed repository, metal surfaces will be dry (no

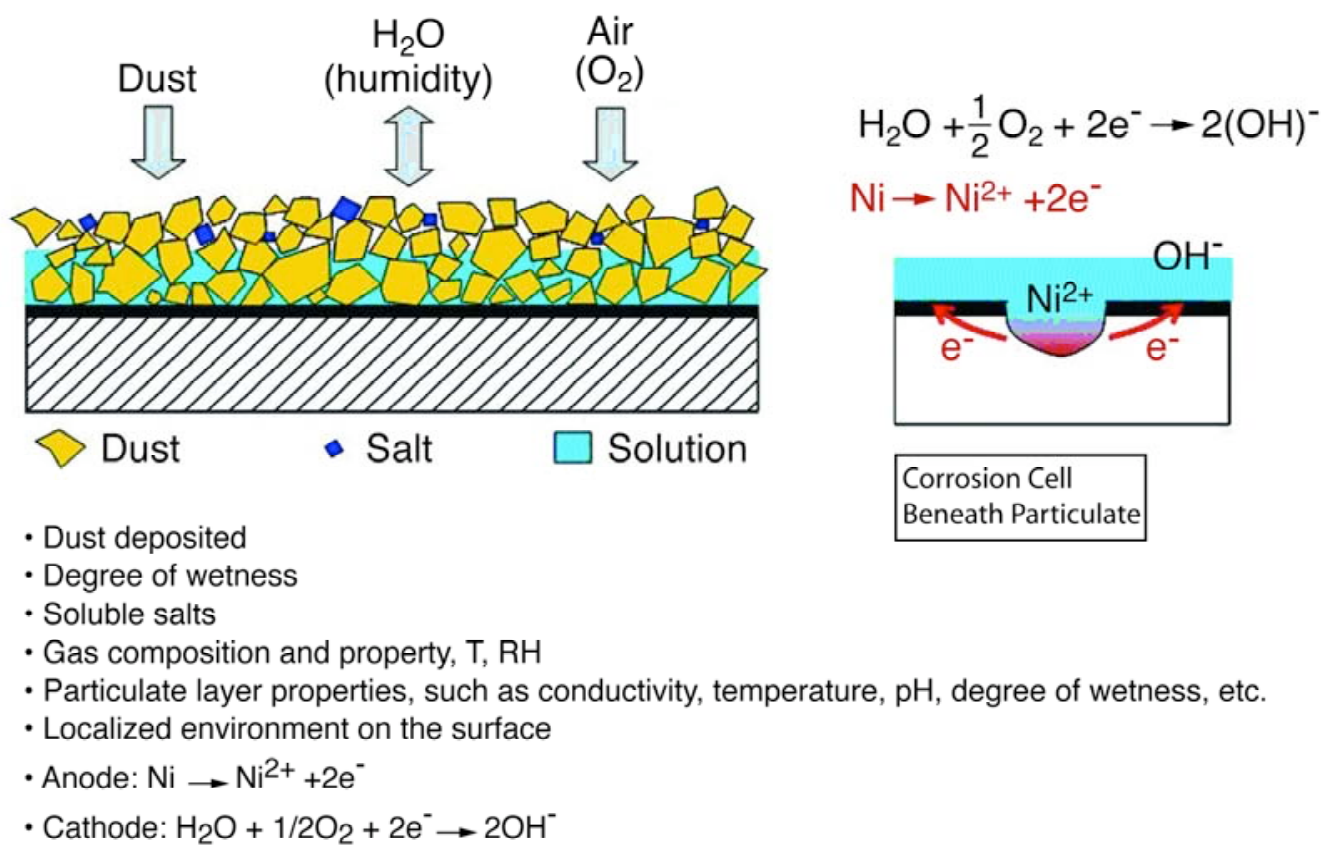

Figure I. Schematic diagram of moisture in a particulate layer on a metal surface and identification of important parameters that affect corrosion of the metal 
corrosion) or exposed to thin layers of moisture and moist particulates or deposits. The waste packages are placed on support pallets and sit in air at atmospheric pressure. No feasible scenario exists that would lead to waste packages being fully immersed in water. There is a limited amount of water moving through the rock, and there is a limited amount of salts and minerals available to deposit on the packages. Ambient waters in the mountain are dilute; however, those ambient waters can be modified and become concentrated by the thermal-hydrological-chemical processes. The sources of water that can contact metal surfaces in the proposed repository are deliquescence, condensation, and drips or seepage. Deliquescence is determined by the amount and composition of soluble salts in the particulate layers, the relative humidity, and temperature. Drips and seepage of water from the drift walls onto the metal surfaces are possible after the thermal barrier period ends, i.e., when the drift wall has cooled to below the boiling point of water. Metals will be exposed to thin layers of moisture and moist particles in deposits of dust and particulate.
The approach is to meet the objectives through a coordinated set of projects. A schematic diagram of corrosion in thin layers of particulate and a list of important parameters that affect corrosion are presented in Figure 1.

\section{Technical Milestones: Corrosion of metal surfaces cov- ered with particulate and deposits}

- Organize to develop and analyze changes in passive corrosion rate with time.

- Identify the key role of oxygen-reduction rates on corrosion and passivity.

- Initiate a coordinated set of computational modeling and experimental projects.

- Develop and implement specialized experimental methods to examine corrosion and electrochemistry in thin layers of particulate and moisture.

- Initiate work to determine the relationships between passive film structure and composition with corrosion resistance of Ni-Cr-Mo alloys.

- Elucidate the controlling corrosion processes in thin films, particulate, and deposits. 


\section{Kinetics of the Cathodic Reduction of Oxygen on Passive Metals}

David W. Shoesmith

University of Western Ontario

\section{Research Objectives}

The primary goal of this project is the elucidation of the mechanism and kinetics of the cathodic reduction of oxygen on nickel-chromium-molybdenum (tungsten) (Ni-Cr$\mathrm{Mo}(\mathrm{W})$ ) alloys. The accumulation of damage can be controlled either anodically (i.e., by the oxidative dissolution of the alloy components) or cathodically (i.e., by oxygen reduction). A clear definition of which of these two possible reactions is rate controlling, and a quantitative specification of the reaction kinetics, is important to the conceptual and numerical development of a corrosion model.

\section{Approach}

Experiments are being conducted at rotating disc electrodes (RDEs), since oxygen transport in the aqueous environment to the reacting surface of the alloy could exert a control that would (partially) mask the fundamental interfacial kinetics of the oxygen reduction reaction. The use of RDEs allows the control and quantification of transport effects.

Since the $\mathrm{O}_{2}$ reduction reaction will occur on the surface of the thin passive oxide, which covers all except the creviced area of the alloy surface, we are investigating how the

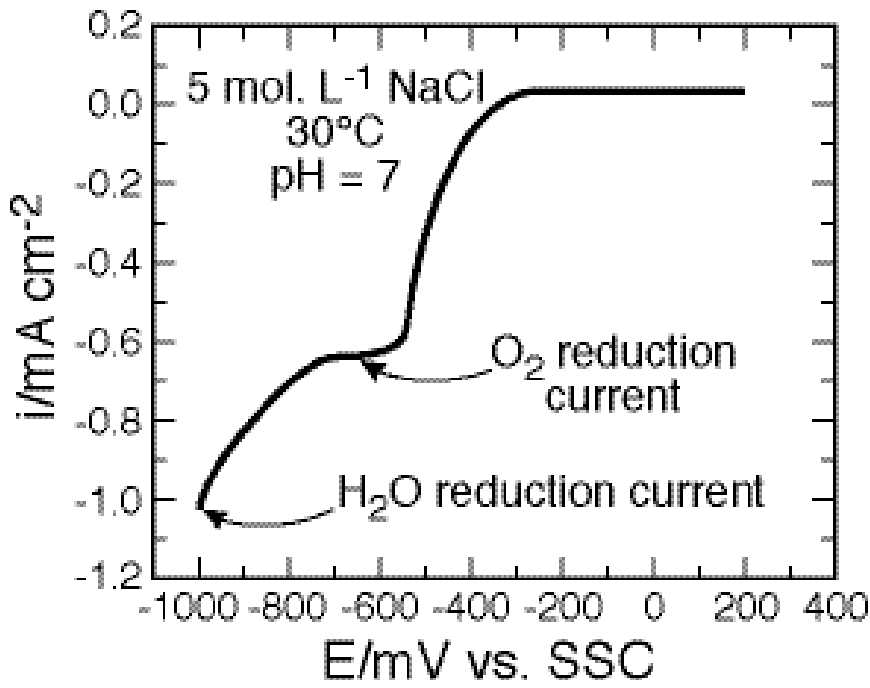

Figure I. A polarization scan for Alloy 22 showing a limiting oxygen reduction current on a rotating disk electrode at $23.5 \mathrm{~Hz}$. SSC is $\mathrm{Ag} / \mathrm{AgCl}$ reference electrode. composition and electrical properties of this layer influence the electrochemical currents for this reaction. Electrochemical impedance spectroscopy (EIS) is used to measure film conductivities, which will control the transfer of current from the alloy, through the oxide, to oxygen. The oxide conductivity is directly related to its composition and determined by the nature and concentration of oxidation states for the metal cations in the oxide. Thus, we will apply techniques such as $\mathrm{x}$-ray photoelectron spectroscopy (XPS) and time of flight secondary ion mass spectrometry (TOFSIMS) to determine the chemical composition and the distribution of metallic cations in the oxide. Changes in the oxide are determined for a range of redox and exposure conditions. The two primary parameters influencing the corrosiveness of the environment are chloride concentration and temperature, and the tests are done in concentrated solutions $\left(5 \mathrm{~mol} . \mathrm{L}^{-1} \mathrm{NaCl}\right)$ over the temperature range $25^{\circ} \mathrm{C}$ to $120^{\circ} \mathrm{C}$.

\section{Accomplishments}

For the 5 mol. $\mathrm{L}^{-1} \mathrm{NaCl}, 25^{\circ} \mathrm{C} \leq \mathrm{T} \leq 70^{\circ} \mathrm{C}$ conditions, the properties of the oxide film are the primary determinants of oxygen reduction kinetics. Since these properties could be controlled by pre-exposure to atmospheric conditions, it was necessary to develop an electrochemical protocol to obtain a reproducible surface condition. This has been achieved using a cathodic reduction treatment. A polarization scan for Alloy 22 at $30^{\circ} \mathrm{C}$ is shown in Figure 1.

Subsequently, we have measured $\mathrm{O}_{2}$ reduction currents as a function of pre-oxidation of the alloy at a series of potentials in the region where the passive oxide film is stable. The potential region studied was $-600 \mathrm{mV}$ to $+600 \mathrm{mV}$ (vs. $\mathrm{Ag} / \mathrm{AgCl}$ ) and covers the range within which an aerated solution would pose the corrosion potential under natural corrosion conditions. Experiments were conducted at $30^{\circ} \mathrm{C}$, $50^{\circ} \mathrm{C}$, and $70^{\circ} \mathrm{C}$, and show that oxygen-reduction currents are observable on the oxide present at $-600 \mathrm{mV}$, but that these currents are eliminated as the potential of oxide formation is increased. The effect of 60-minute oxidation of Alloy 22 at various potentials is shown in Figure 2. For the two lowest temperatures, no significant $\mathrm{O}_{2}$ reduction current was observed for a potential greater than $-200 \mathrm{mV}$. A similar elimination of the $\mathrm{O}_{2}$ reduction current with increasing potential was observed at $70^{\circ} \mathrm{C}$, except that 
when oxides were grown at potentials greater than $+400 \mathrm{mV}$, the $\mathrm{O}_{2}$ reduction current was revived. Hystereses in the $\mathrm{O}_{2}$ reduction currents indicated that the reaction was accompanied by transitions in the oxidation states in the oxide film, especially at $70^{\circ} \mathrm{C}$.

EIS measurements to measure film properties were conducted over the same range at temperatures (to date) of $30^{\circ} \mathrm{C}, 40^{\circ} \mathrm{C}, 50^{\circ} \mathrm{C}$, and $60^{\circ} \mathrm{C}$. The spectra obtained were fitted to an equivalent circuit previously determined to be appropriate for the oxide film on these alloys and consistent with the mixed conduction model (MCM) for defect transport in passive films (Bojinov et al., 2000). The resistance of the oxide films was found to increase markedly (by 2 to 3 orders of magnitude) over the potential range for which the $\mathrm{O}_{2}$ reduction current was eliminated $(-600 \mathrm{mV}$ to $-200 \mathrm{mV})$. No significant differences in film impedances were observed with temperature.

The impedance results are consistent with the predictions of the MCM for passive films and confirm that the establishment of a positive corrosion potential under natural corrosion conditions will lead to improvements in quality of the passive films on these alloys. The disappearance of the $\mathrm{O}_{2}$ reduction current with increasing potential of film growth is consistent with the large increase in film resistance measured in the impedance experiments. This confirms that the electrical properties of the oxide are paramount in determining $\mathrm{O}_{2}$ reduction kinetics. The revival of the $\mathrm{O}_{2}$ reduction at positive potentials at $70^{\circ} \mathrm{C}$ indicates a

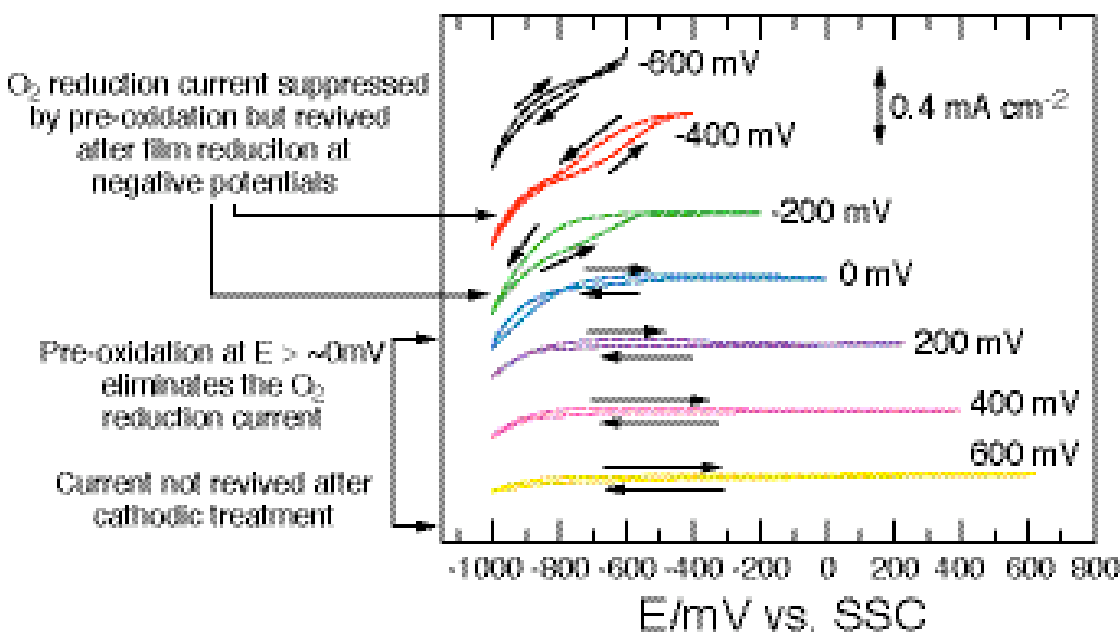

Figure 2. Influence of 60 minutes oxidation of Alloy 22 at various potentials on the $\mathrm{O}_{2}$ reduction current at $30^{\circ} \mathrm{C}$. Curves are offset on current axis. SSC is $\mathrm{Ag} / \mathrm{AgCl}$ reference electrode.

narrowing of the passive oxide region at higher temperatures as a consequence of redox transformations $\left(\mathrm{M}^{\mathrm{n}+} \leftrightarrow\right.$ $\mathrm{M}^{\left.(\mathrm{n}+1)^{+}\right)}$in the oxide film. The nature of these changes should be revealed by planned surface analyses using XPS and TOFSIMS.

\section{References}

Bojinov, M. G. Fabricus, P. Laitinen, K. Mäkelä, T. Saario, and G. Sundholm, Coupling between ionic defect structure and electronic conduction in passive films on iron, chromium and iron-chromium alloys, Electrochimica Acta, 45, 2029-2048, 2000. 


\section{Oxygen Electro-Reduction on Passive Metals in Particulate and Deposited Layers}

Dominic Gervasio

Arizona State University

\section{Research Objectives}

The objective is to determine the corrosion behavior of corrosion-resistant metals that are covered by thin layers of moisture and moist particulate and deposits. This work is intended to develop advanced analytical and computational methods for corrosion processes in thin films, particulate, and deposits to produce advanced, next-generation conceptual models with significantly reduced uncertainty; and provide integrated scientific understanding of the chemical, electrochemical, and corrosion processes.

\section{Approach}

The approach is to experimentally study the oxygen $\left(\mathrm{O}_{2}\right)$ electro-reduction or other cathodic redox reactions in thin layers of moisture and layers of moist particulate and deposits on metal surfaces. The $\mathrm{O}_{2}$ reduction is of particular interest (although other redox reactions may also contribute) as the source of cathodic current at the metal surface that can sustain pitting, crevice corrosion, stress corro- sion cracking, and galvanic action. The alloy surfaces are studied in brine and with submonolayer and thicker coverage of particles. A series of experiments is conducted to investigate oxygen reduction on fresh and aged nickel (Ni) alloy surface as a function of saturated and unsaturated particulate, chemical composition of moisture and particulate, temperature, and relative humidity. Results are important inputs to the determination of the onset and extent of cathodic stifling of corrosion processes. These experiments provide input to modeling of corrosion of the $\mathrm{Ni}$ alloy, and the results provide a basis for model validation.

Two experimental apparatuses are constructed and used in this project: (a) a Rotating Ring-Disk Electrode (RRDE) shown in Figure 1 and (b) an Electrochemical Fourier Transform Infrared Reflectance Surface Spectroscope (Echem-FTIR), shown in Figure 2. The techniques measure $\mathrm{O}_{2}$ reduction, oxide growth, and possibly other redox reactions on passive metal as a function of potential and current. The research plan is to:
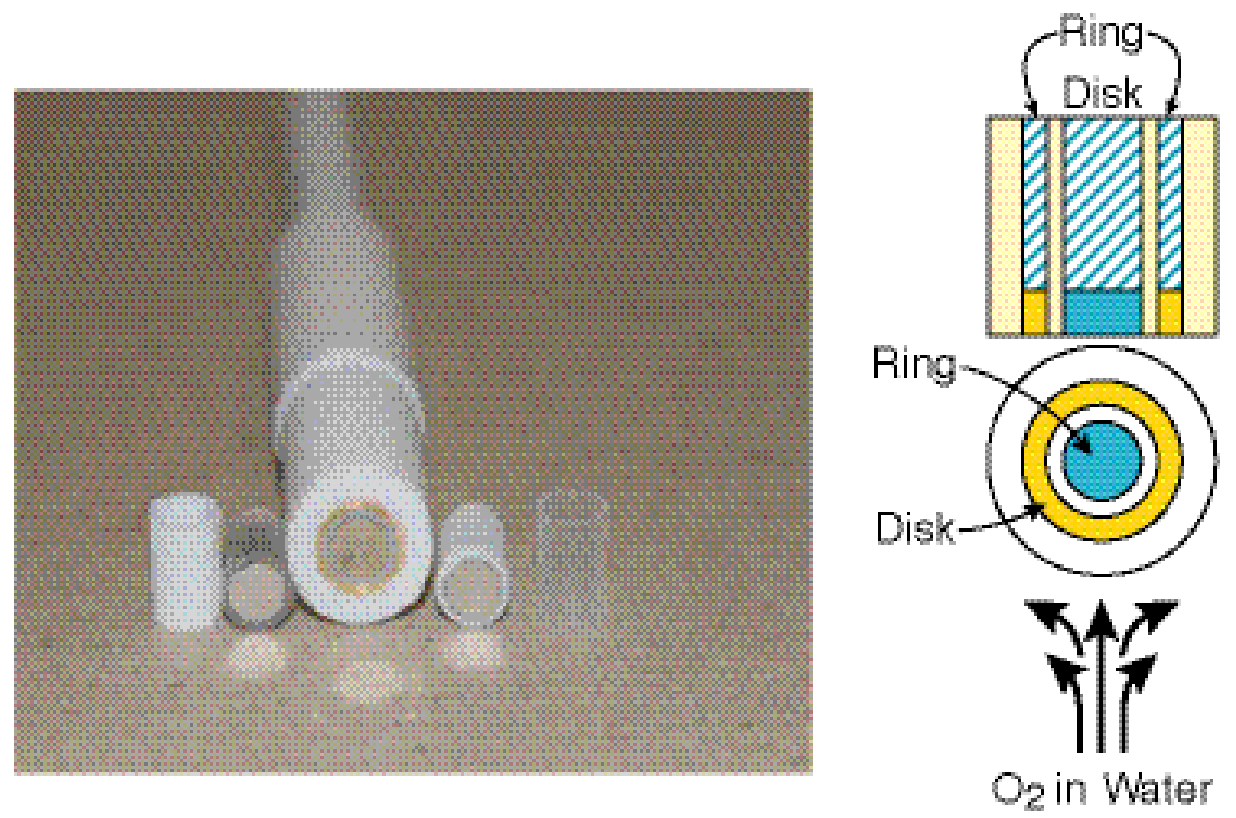

Figure I. Nickel alloy C276 for voltammetry (left); in a rotating nickel alloy disk and gold ring electrode; and a schematic diagram of ring-disk electrode showing convection streamlines that form when the electrode is rotated 

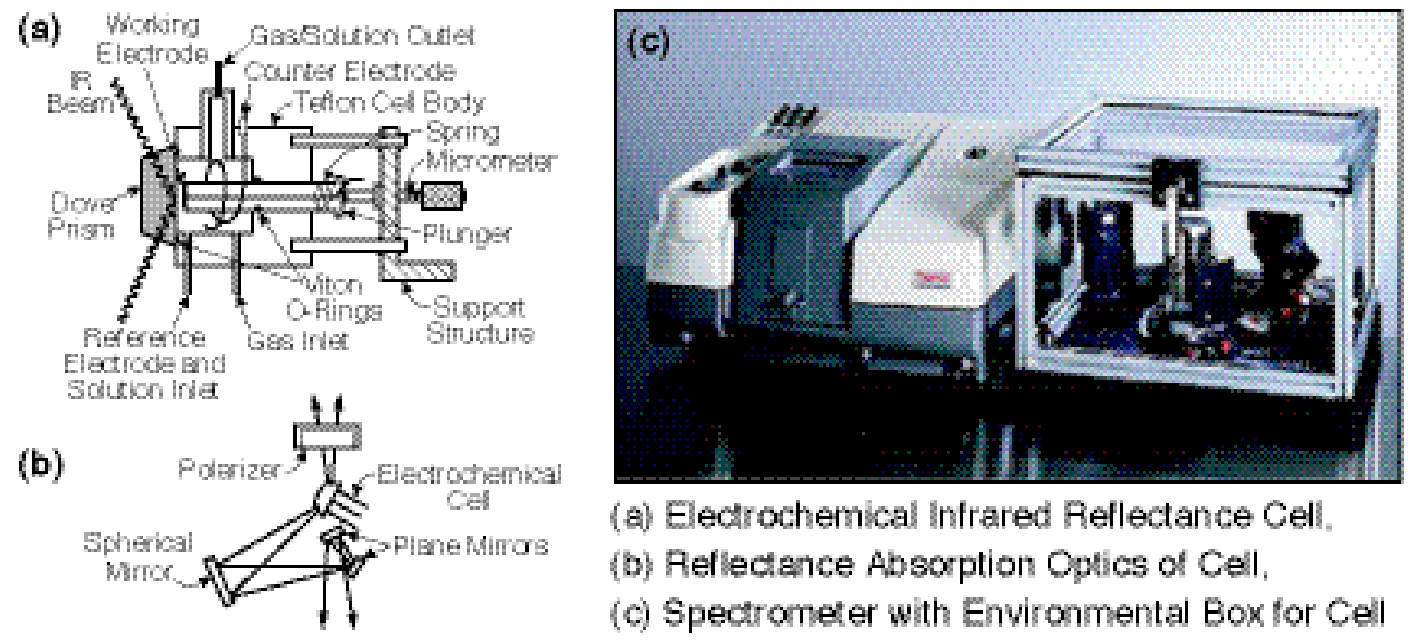

Figure 2. The Electrochemical Fourier Transform Infrared (Echem-FTIR) reflectance surface spectroscopy method is a powerful tool for characterizing the alloyace.

- $\quad$ Measure $\mathrm{O}_{2}$ reduction on freshly abraded and aged surfaces in brine.

- Characterize effects of exposure with time, temperature, and polarization.

- Characterize the effect of particulate layers on the alloy surface and $\mathrm{O}_{2}$ electro-reduction.

- Characterize $\mathrm{O}_{2}$ reduction and other redox reactions on the alloy surface with thick particulate coverage.

- Examine the affects of mechanical damage to the passive film by freshly abrading a line along the diameter of a disk of passive surface.

\section{Accomplishments}

We obtained the voltammograms (I/V curves) of freshly abraded C276 nickel-chromium-molybdenum (Ni-Cr-Mo) alloy and clean smooth platinum $(\mathrm{Pt})$ in still brine, which were equilibrated with either an inert atmosphere (nitrogen $-\mathrm{N}$ ) or with $\mathrm{O}_{2}$ atmosphere. The voltammogram for $\mathrm{Pt}$ in oxygen-containing brine shows a pronounced oxygen-reduction current not seen when the $\mathrm{Pt}$ is in brine equilibrated with $\mathrm{N}$ - whereas the voltammograms for C276 alloy in brine with either $\mathrm{O}_{2}$ or $\mathrm{N}$ are symmetrical about the $\mathrm{x}$-axis, and this is taken to show that $\mathrm{C} 276$ electrode does not show noticeable oxygen reduction current. The voltammogram of the C276 alloy in $5 \mathrm{M}$ aqueous $\mathrm{NaCl}$ brine in air was determined. Once again, there is no noticeable $\mathrm{O}_{2}$ reduction current.

Oxygen reduction is the most likely cathodic process that will sustain anodic corrosion of a metal in air. $\mathrm{O}_{2}$ reduction current is therefore related to the rate of metal corrosion. The lack of noticeable $\mathrm{O}_{2}$ reduction in the voltammogram for C276 Ni alloy in still solution is a qualitative indicator of the corrosion resistance of C276 and similar alloys (e.g., Alloy 22). Voltammograms are measured for the Ni alloys under forced convection, using a rotating disk electrode to obtain a quantitative measure of $\mathrm{O}_{2}$ reduction, because this is needed as an input for models of the corrosion and expected lifetime of the Ni alloys. These polarization measurements are being repeated as a function of solution composition and conditions (chloride concentration, particulates, $\mathrm{pH}$, temperature, abrasion, aging after abrasion) to find the situations that favor or disfavor $\mathrm{O}_{2}$ reduction on $\mathrm{Ni}$ alloy, as input to models of $\mathrm{Ni}$ alloy under likely environmental exposures for bulk metal and in crevices and pits.

\section{References}

Gervasio, D., and J.H. Payer, The kinetics of the oxygen reduction reactions on steel in alkaline solution. Journal of Electrochemical Society Ex. Abs. No. 1337, Orlando, FL, in Proceedings of the Electrochemical Society, Oct. 2003 (in press). Full paper to be submitted to J. Electrochem. Soc.

Payer, J.H., B. Trautman, and D. Gervasio, Methods to determine the role of electrochemical reduction products on coating disbonding from cathodically protected steel. In: Polymeric Materials Science and Engineering, 68, D.R. Bauer, ed., American Chemical Society, Washington, DC), pp. 109-110, 1993. 


\section{Corrosion Cells Beneath Thin Films, Particulate, and Deposited Layers}

Joe H. Payer, Pallavi Pharkya, and Xi Shan

Case Western Reserve University

\section{Research Objectives}

The objective is to examine the behavior of macro- and micro-corrosion cells in experiments on passive metals covered by thin layers of moisture, particulate, and deposits. The operation of corrosion cells beneath thin films, particulate, and deposited layers can vary significantly from the behavior observed in fully immersed conditions. Corrosion of active metals, e.g., iron and zinc, in thin layers of moisture that pertain to atmospheric corrosion has been studied extensively; however, the behavior of passive metals in thin layers of moisture may be further elucidated. The results will provide input to the modeling efforts to describe the behavior. The focus is on the postinitiation stages of the corrosion cells to gain insight on the propagation and potential stifling processes that will affect corrosion-damage evolution over time.

\section{Approach}

A series of experiments is conducted to investigate geometric effects, saturated and unsaturated particulate, chemical composition of moisture and particulate, temperature, and relative humidity. The experiments are closely coupled to numerical modeling of corrosion cells. The current distribution in thin layers of moisture and layers of moist particulate and deposits on metal surfaces are measured experimentally. Of particular interest is the flow of current representative of corrosion scenarios at the metal surface during pitting, crevice corrosion, stress corrosion cracking, and galvanic action. A range of layer thickness on metal surfaces is examined, i.e., from thin layers of absorbed moisture, to single particulate layers, to multiple particulate layers of $1 \mathrm{~cm}$ thickness and greater. Two morphologies of corrosion are examined: micro-cells at isolated spots (pits) and macro-cells of corrosion damage representative of scrapes and scratches. The multiplate cell shown in Figure 1 is used to examine current distribution in a macro-cell.
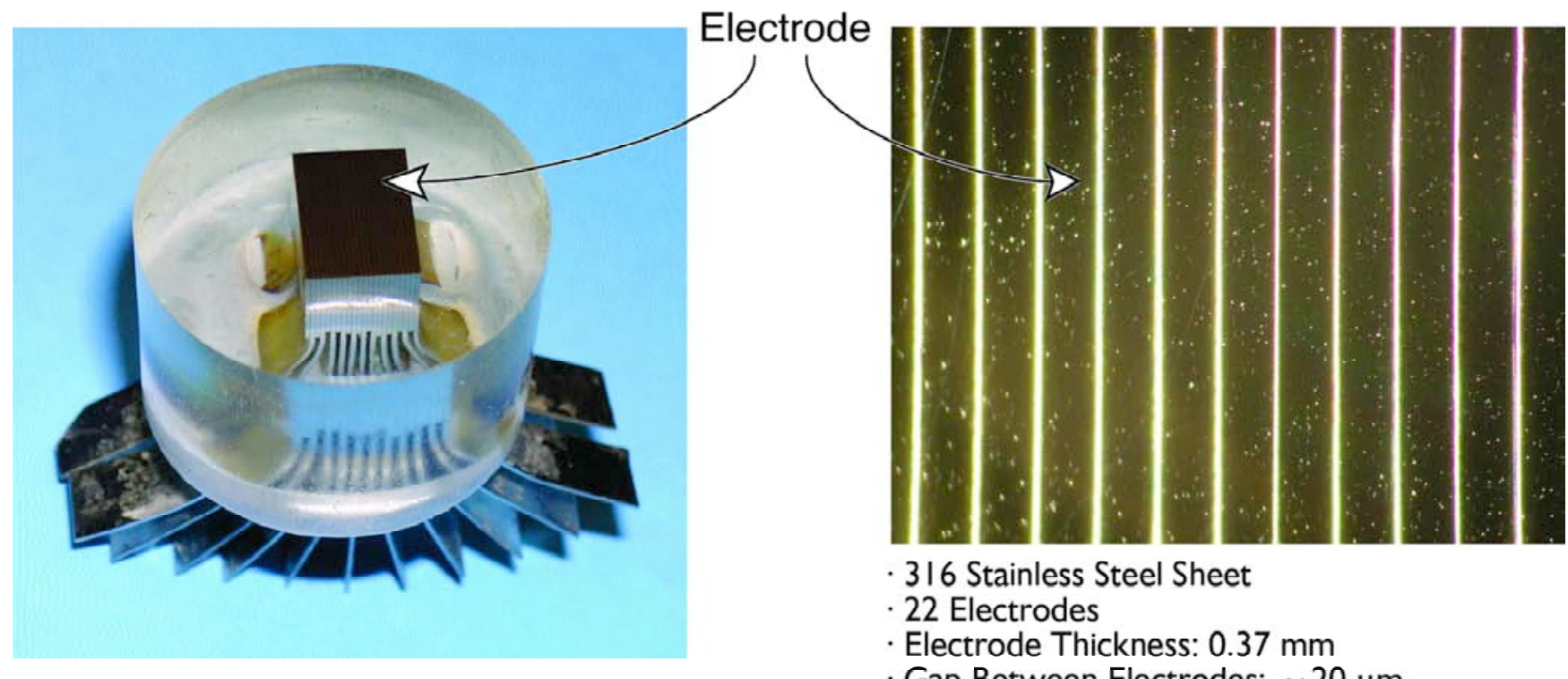

- 316 Stainless Steel Sheet

- 22 Electrodes

- Electrode Thickness: $0.37 \mathrm{~mm}$

- Gap Between Electrodes: $20 \mu \mathrm{m}$

Figure I. The multiplate cell for current distribution in a macro-cell 


\section{Accomplishments}

Work is under way on the following tasks:

Task 1: Develop procedures to initiate and monitor corrosion cells under controlled conditions of solution composition, layer thickness, and particulate properties.

Task 2: Simulate and monitor macro-cell conditions.

Task 3: Simulate and monitor micro-cell conditions.

Task 4: Integrate results with modeling efforts, and conduct experiments to test the validity and applicability of models.

Procedures for the controlled creation and monitoring of repassivation are developed. The macro-cell corrosion is examined by a scratch and repassivation method. The passive film that protects the metal is removed locally by scratching the specimen with a hard, pointed scribe. The amount of damage and repassivation behavior is examined by monitoring the anodic current from the specimen and by post-test surface examination. The corrosion current decreases rapidly after the metal is scratched when repassivation is favored. A slowly decreasing or level current response indicates greater corrosion damage. More damage was observed in the more corrosive solution.
Micro-cell corrosion sites are initiated using artificial pit configurations created by more active metal embedded in corrosion-resistant metals, and by the application of aggressive chemical species in local areas on the metal surface. Corrosion cells will be simulated by the polarization of isolated wire "anodes" within a corrosion-resistant specimen. Sensors and probes developed in the Corrosion CoOp projects, other probes, and conventional methods determine the corrosion cell response over time. Scanning Electrochemical Microscopy will be used to determine electrochemical behavior and the properties of the thin layer environment at the cell anode and the surrounding area.

The waste packages are manufactured from highly corrosion-resistant metals, and the surface of these metals is protected by the formation of a self-healing, passive layer. The waste packages are supported in air, and they will never be fully immersed in water; rather, the metal surfaces may be covered with dust, particulate, and moisture from the surrounding rock and humidity. This project examines corrosion in thin moisture films and layers of particulate and deposits. Results are important inputs to determining the onset and extent of cathodic stifling of corrosion processes. Inputs are generated for advanced, next-generation models and alternate conceptual models based on less conservative assumptions. Enhanced scientific understanding of the chemical, electrochemical, and corrosion processes is provided. 


\section{Electrochemical Measurements of Corrosion under Thin Brine Layers}

Gerald S. Frankel and Rudolph G. Buchheit

Ohio State University

\section{Research Objectives}

The objective is to make electrochemical measurements on corrosion-resistant alloys under layers representative of dust, particulate, and adsorbed moisture (from monolayers to millimeters in thickness); and characterize the relationship between the physical characteristics of the layers and the electrochemical behavior of the alloys.

\section{Approach}

Simulation of Thin Brine Layers. Development of an effective method to simulate the thin brine layers is important, and a range of techniques is examined to fabricate the particulate layer. A controlled temperature and humidity chamber will be constructed for forming and stabilizing thin electrolyte layers on electrode arrays.

Electrochemical Measurements. A major challenge in making electrochemical measurements in thin electrolyte layers is the incorporation of a viable reference electrode with the ability to provide spatial resolution of the potential. In this task, Kelvin Probe and Scanning Kelvin Probe techniques

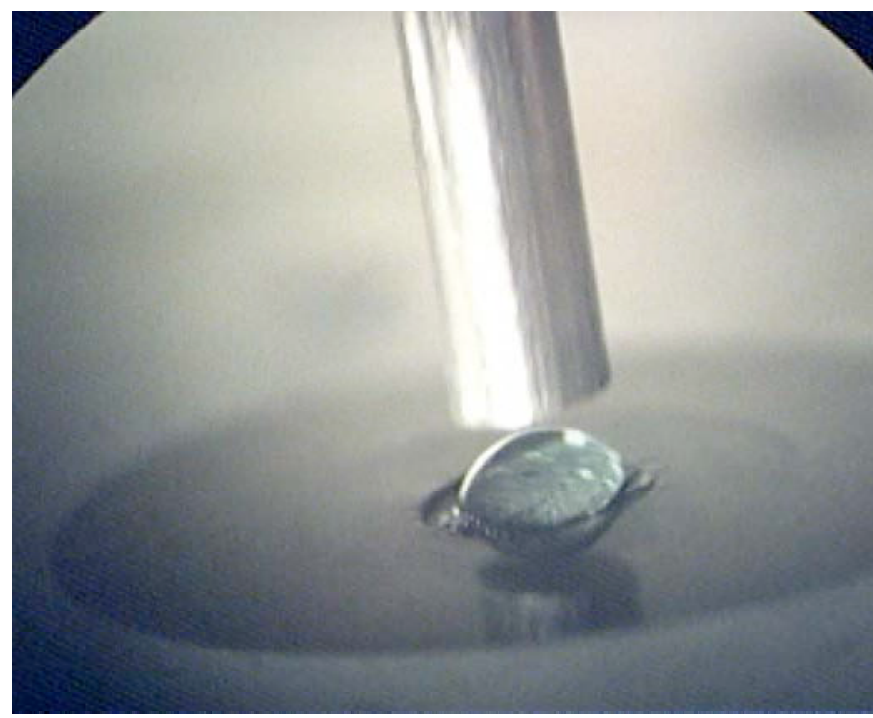

Figure I. Video image from thin film electrolyte pitting experiment. The I mm diameter Kelvin Probe is vibrated above the sample. The original electrolyte layer thickness was about $50 \mu \mathrm{m}$, and a droplet about $\mathrm{Imm}$ in radius formed after pitting initiated as a result of water uptake from the humid air. are be utilized to make electrochemical measurements in the thin layers. The Kelvin Probe provides a noncontact measurement of potential.

Multi-Electrode Arrays. Wires of corrosion-resistant alloys with diameters ranging from tenths of millimeters to a few millimeters will be imbedded with periodic spacing into inert substrates. This structure results in a regular planar array of electrodes for environmental exposure and electrochemical testing. In thin layer electrolytes, the Scanning Kelvin Probe technique is used to simultaneously measure the potentials of the array elements. A configuration that simulates a localized corrosion cell is an array of multiple Alloy 22 wires with a central electrode of a more-susceptible material, such as type 316 stainless steel.

\section{Accomplishments}

Thin Silica Layers. A number of approaches have been taken to develop the artificial particulate brine layers to be used as models for dust and rock deposits. We have settled on electrophoretic deposition to make hydrophobic silica layers of controllable thickness in the range of 10-80 $\mu \mathrm{m}$. The films are homogeneous and composed of silica spheres about $350 \mathrm{~nm}$ in diameter. Because of the pore space, water wets the layers. Electrochemical measurements have been made on silica-coated stainless steel, in bulk electrolytes and limiting current density, for oxygen reduction decreased with increasing silica film thickness of a silica layer. Breakdown potential tends to increase with film thickness, possibly because pit growth under thicker layers is inhibited. Atmospheric corrosion experiments have also been performed using a Luggin capillary in the sample mount, the end of which was next to and co-planar with the flat sample surface. Pit initiation and propagation during drying and evaporative concentration of the electrolyte is sensed by a change in the open circuit potential (OCP). The OCP transient for a silica-coated sample showed slower decay compared with the uncoated sample after pitting corrosion initiated, which could indicate that the silica layer retards pit growth.

Kelvin Probe Measurements. A Kelvin Probe apparatus was modified to perform as a potentiostat, allowing electrochemical measurements under thin electrolyte layers. The limiting current density for oxygen reduction was deter- 
mined from cathodic polarization curves as a function of layer thickness. Anodic polarization measurements indicate that the breakdown potential under thin layers might be slightly higher than in bulk solutions, but no strong dependence on solution layer thickness was found. One interesting observation was that after pitting initiated under the thin electrolyte layer, the volume of the electrolyte layer increased rapidly, eventually becoming hundreds of times larger than the original volume of the electrolyte before the test (Figure 2). As pitting progressed and cations dissolved rapidly into the thin film electrolyte, the concentration of the electrolyte was no longer in equilibrium with the $95 \% \mathrm{RH}$ in the chamber, and water was taken from the air into the electrolyte. This happened quickly, over a period of minutes. An implication of this case is that a thin electrolyte layer did not exert an inhibiting influence on localized corrosion growth once initiated. In fact, the thin layer took up moisture from the air and became a bulk electrolyte drop.
Multi-Electrode Arrays. A one-dimensional array has been constructed for characterizing the effect of solution and particulate layer thickness on the potential and current distributions developed on Alloy 22 associated with a locally corroding site.

This work has shown that it is possible to model thin dust layers using electrophoretically deposited silica layers. Electrochemical measurements under thin layers have been made using a Kelvin Probe and an in-plane Luggin capillary.

\section{Acknowledgments}

The support of one principal investigator (Frankel) by the Alexander von Humboldt Foundation, during his sabbatical stay in Germany, is gratefully acknowledged. Part of this work was conducted and partially supported at the Max Planck Institute for Iron Research (MPIE) in Dusseldorf, Germany. 


\section{Mechanism of Mixed-Ion Effects on Corrosion in Thin Films}

Roger C. Newman, Chris Healey, and Anatolie Carcea

University of Toronto

\section{Research Objectives}

The objective is to measure and to understand how the thickness of a moist particulate layer, containing mixed aggressive and inhibiting salts, affects localized corrosion kinetics. A further objective is to determine whether nonchloride anionic inhibitors, especially nitrate, are as effective in thin layers and deposits as they are in bulk solutions, and to understand any associated depletion mechanisms.

\section{Approach}

Localized corrosion of nickel-chromium-molybdenum (Ni-Cr-Mo) alloys in thin, moist deposit layers is different from that in bulk solutions. Micro-electrode studies in thin layers and deposits are being used to monitor growth of corrosion sites and simultaneously to monitor the properties of the thin electrolyte layer. We use small electrodes embedded in resin to carry out dc and ac electrochemistry in thin layers exposed to controlled humidity. Initially, we are using a microelectrode of $\mathrm{Ni}-\mathrm{Cr}-(\mathrm{Mo})$ alloy wire, mounted in resin, to grow a cylindrical localized corrosion cavity. Since we are dealing with relatively thick moist layers compared with conventional atmospheric corrosion, mass and current transport may be relatively easy. Yet, because of the limited supply of inhibiting anions such as nitrate, inhibition may be lost, leading to

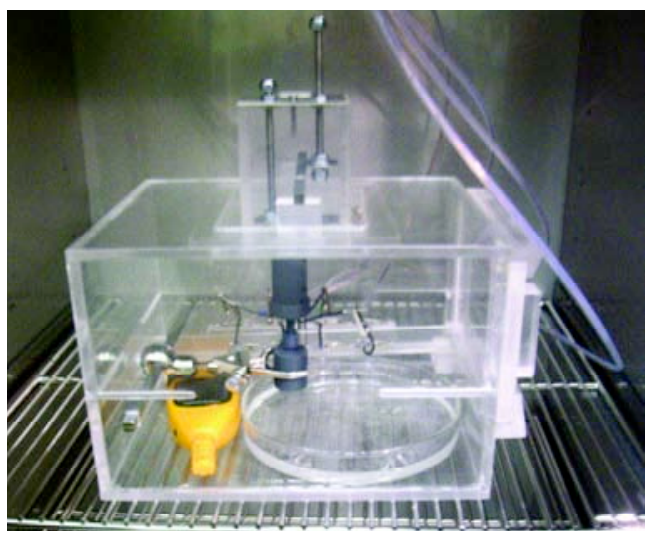

Figure I. Humidity chamber in the oven showing electrode assembly, meter, and tray of solution used for humidity control stable propagation of localized corrosion. By examining this scenario, basic scientific information on thin-layer corrosion is obtained as input to models of corrosion damage.

\section{Accomplishments}

A humidity chamber has been constructed (Figure 1) that enables thin layers of salt plus silica particulate to be hydrated to different levels. It is placed in an oven, generally at $60^{\circ} \mathrm{C}$ in initial work. The $125 \mu \mathrm{m}$ diameter working electrode, initially $\mathrm{Ni}-22 \mathrm{Cr}$, is in the center of a resin mount with two concentric ring electrodes of silver (Ag) (which can be chloridized) and one of platinum (Pt). Layer thicknesses are $0.1-1.0 \mathrm{~mm}$. The silica/salt mixture can be applied dry or, preferably, prewetted. An important observation was that localized corrosion cavities could be grown in $200 \mu \mathrm{m}$ thick layers of the particulate mixture, and at very high rates, not much lower than in a bulk liquid environment. Analysis shows that the radial nature of the current flow and the small size of the working electrode disk minimize the infrared potential drop in the solution layer to a minimal degree; thus, informative kinetic studies can be done. Figure 2 shows a set of cyclic polarization curves obtained with this system. The propa-

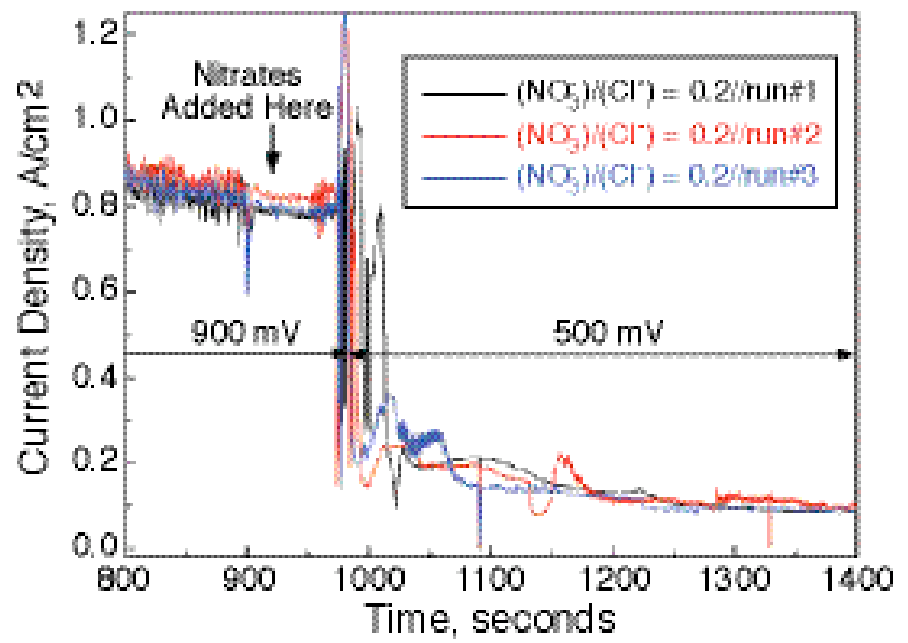

Figure 2. Cyclic polarization curves on $\mathrm{Ni}-22 \mathrm{Cr}$ in $250 \mu \mathrm{m}$ thick layers of $\mathrm{SiO}_{2} / \mathrm{NaCl}$ mixture with different silica-to-salt ratios at $60^{\circ} \mathrm{C}$ and $75 \% \mathrm{RH}$ (scan rate of $3 \mathrm{mV} / \mathrm{s}$ ) 
gation rates reach $1 \mathrm{~A} / \mathrm{cm}^{2}$, similar to bulk solutions. Differences in repassivation potential appear as a function of layer composition and (in other work not shown) humidity.

A system for nitrate spray-inoculation of particulate layers has been developed, so that studies can be done similar to those that are in progress using bulk solutions in another project.

There is a need to understand at a more fundamental level the localized corrosion of passive metals like Alloy 22 (and even stainless steels) in thin electrolyte layers. By using a particular arrangement of electrodes, in conjunction with a well-defined corrosion cavity, we are able to obtain the same kind of rigorous electrochemical kinetic information that was previously only available in bulk solutions. This will enable us to identify important dependencies that may await those trying to extend traditional corrosion studies to thin-layer systems. In particular, we will know whether it is possible for nitrate to lose its inhibiting effect in thin layers, and there may be other unanticipated depletion or enrichment effects that we can currently only surmise-for example, nitrate may become reduced, volatile, etc. The fate of chloride (especially insofar as it may exist as $\mathrm{HCl}$ ) may also be counterintuitive. 


\section{Effect of Environmental Variables on the Structure and Composition of Passive Films}

Thomas M. Devine, Zeuyuan Zhang, and Marcela Miyagusuku

University of California, Berkeley

\section{Research Objectives}

This project is an in situ investigation of the identities and properties of the passive films formed on Alloy 22 in aqueous solutions. The objectives are to determine structure, composition, electrochemical, and electronic properties of the thin (about $2 \mathrm{~nm}$ at $25^{\circ} \mathrm{C}$ ) protective, passive films on nickel-chromium-molybdenum (Ni-Cr-Mo) alloys where these films are responsible for the corrosion resistance of the alloys. Pure metals (Ni, Cr, Mo, tungsten [W], iron $[\mathrm{Fe}])$ that make up alloys were also examined.

\section{Approach}

When passive films are removed from aqueous solutions, structure and properties can change. To avoid this, the present study uses five in situ techniques to examine passive films in a series of solutions: (1) near-neutral $\mathrm{pH}$ typical of many engineering applications of passive alloys; (2)

highly corrosive acids $(0.001 \mathrm{M}-12 \mathrm{M} \mathrm{HCl})$ found inside pits and crevices that damage the passive metals; (3) neutral and acidic solutions with nitrate and sulfate ions, which may inhibit localized corrosion by chloride.

Identical experiments are conducted on Ni-Cr-Mo alloys and on the elements that are the major components of corrosion-resistant alloys. Temperature accelerates uniform and localized corrosion, so tests are conducted at $20^{\circ}-25^{\circ} \mathrm{C}$ and $90^{\circ} \mathrm{C}$.

\section{Accomplishments}

Cyclic polarization (CyP), electrochemical impedance spectroscopy (EIS), Mott-Schottky analyses (M-S), surfaceenhanced Raman spectroscopy (SERS), and electrochemical-quartz-crystal-microbalance measurements (EQCM) have been conducted on Alloy 22 and chromium in $0.1 \mathrm{M}$ $\mathrm{HCl}$. Testing in $1 \mathrm{M} \mathrm{HCl}$ and $6 \mathrm{M} \mathrm{HCl}$ has begun.

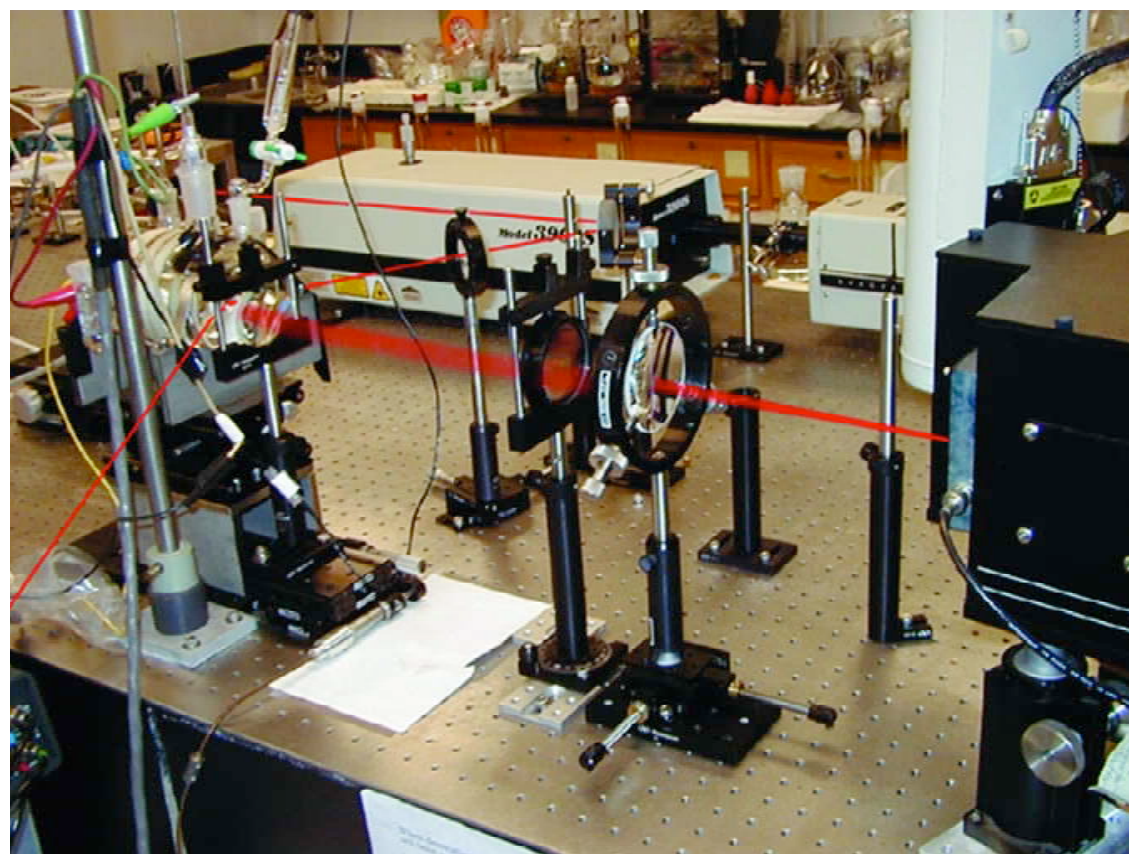

Figure I. Surface Enhanced Raman Spectroscopy (SERS) - The electrochemical cell containing the sample under investigation (e.g., Alloy 22) by SERS is on the left side of photograph. Light from the Ti-Sapphire Laser (large, white box in center-top of photograph) is represented by sharp, red line and is focused onto sample inside the electrochemical cell. Raman scattered radiation collected from the sample is represented by the wide, diffuse beam of red light.
The surface-enhanced Raman spectroscopy (SERS) experiment is demonstrated in Figure 1. Figure 2 shows the first in situ identification of the passive film of Alloy 22. The passive film on Alloy 22 is almost identical to that on $\mathrm{Cr}$, and the spectrum does not match that of any known oxide, hydroxide, or oxyhydroxide of $\mathrm{Cr}$.

The SER spectra show that the Cr-like passive film does not change its identity throughout the passive range of potential, but that at high potentials an outer layer forms. The thickness of the passive film was measured $(0.8 \mathrm{~nm}-1.8 \mathrm{~nm})$ throughout the passive region by EIS, which also identified ion migration as the rate-determining step in film growth, and showed that the passive film slows down, but does not stop, the rate of $\mathrm{H}^{+}$reduction. Additionally, EQCM established that metal dissolution occurs during film growth and that transpassivity causes film dissolution by oxidation of $\mathrm{Cr}$ (III) to soluble $\mathrm{Cr}(\mathrm{VI})$. 


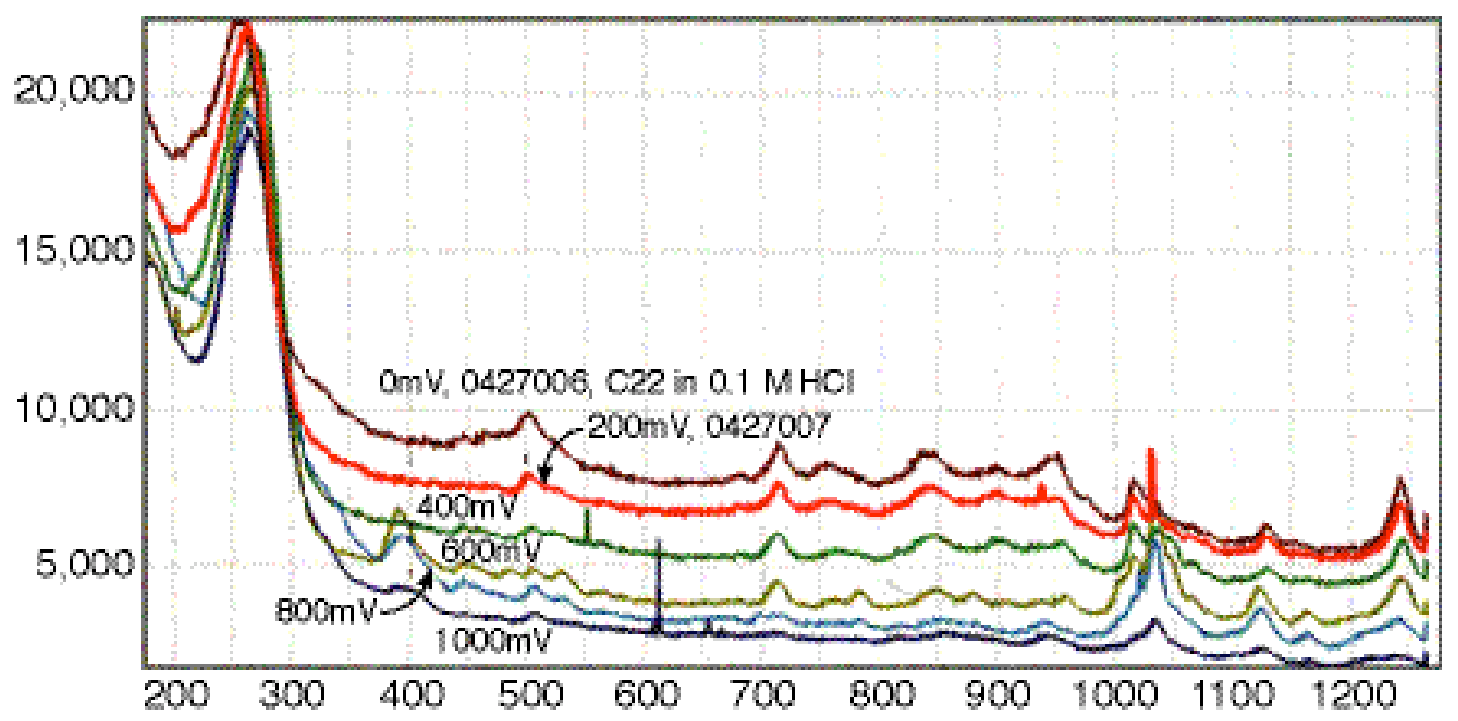

Figure 2. SERS of passive film formed on Alloy 22 in $0.1 \mathrm{M} \mathrm{HCl}$ at potentials of $0 \mathrm{~V}, 0.2 \mathrm{~V}, 0.4 \mathrm{~V}, 0.6 \mathrm{~V}, 0.8 \mathrm{~V}, \mathrm{I} .0 \mathrm{~V}$ vs. SCE. Each peak is related to a specific vibrational mode of the passive film. Collectively, the peaks serve as a fingerprint of the passive film and indicate that the passive film is nearly identical to the passive film of chromium. The spectrum changes if the sample is removed from the aqueous solution, and this indicates the benefit of the in situ method.

From M-S, the passive film on Alloy 22 exhibits n-type conductivity, with a flat band potential of $-0.1 \mathrm{~V}$, and a carrier density of approximately $10^{21} / \mathrm{cm}^{3}$. Potentials above $0.5 \mathrm{~V}$ cause significant band bending, which produces an inversion layer at the passive film's surface and p-type conductivity.

Our results provide the first comprehensive, in situ identification of the properties of passive films on Alloy 22 and $\mathrm{Cr}$. Knowledge of the exact structure and composition of the passive film is important for modeling of the long-term corrosion rates of passive metals. SERS has obtained in situ the fingerprints of Alloy 22's and Cr's passive films, and they do not match those of known Cr compounds. Improved models would consider these new structures to calculate their Raman spectra for comparison with the measured, in situ SER spectra.

Overall, our results demonstrate the enhanced understanding of passive films and corrosion provided by multiple in situ tests. The combination of SERS, EQCM, CyP, and EIS indicates that a Cr-rich passive film, nearly identical to Cr's passive film, forms on Alloy 22 and has a structure unlike those of known compounds of $\mathrm{Cr}$, and this film inhibits uniform corrosion by slowing down the rate of ion transport through the passive film.
Other results relate to the mechanism of localized corrosion:

1. The sum of EIS and M-S results show that electron transport through passive films is fast enough to support high rates of reduction of $\mathrm{H}^{+}$inside a crevice/pit. This has implications regarding the requirement for significant reduction of oxygen outside the crevice/pit and on the propagation, growth, and stifling of localized corrosion.

2. The combination of EQCM and EIS indicates metal dissolution accompanies passive film growth. Metal dissolution causes acidification of pit and crevice solutions, which is a necessary step for localized corrosion.

3. SERS and EIS indicate the identity and thickness of the passive film changes with concentration of $\mathrm{HCl}$. Consequently, models of pitting and crevice corrosion should reflect the synergism between the passive film structure and properties and the corrosion rates inside pits and crevices. 


\section{EVOLUTION OF CORROSION DAMAGE BY LOCALIZED CORROSION}

\section{Overview}

Crevice-Corrosion Electrochemistry and Propagation Behavior John R. Scully, University of Virginia

Modeling of Critical Chemistry for Crevice Corrosion Robert G. Kelly, University of Virginia

Experimental Determination of the Evolution of Crevice-Corrosion Damage David W. Shoesmith, University of Western Ontario

\section{Coupled Crevice Tests for Initiation, Propagation, and Arrest} of Crevice Corrosion

Brian Ikeda, Atomic Energy of Canada Limited

\section{Localized Corrosion Stability in the Presence of Non-Chloride Anions} Roger C. Newman, University of Toronto

Metallurgical Effects on Localized Corrosion of Ni-Cr-Mo Alloys Gerald S. Frankel and Rudolph G. Buchheit, Ohio State University

Effect of Crevice Former on Corrosion-Damage Propagation Joe H. Payer and Uziel Landau, Case Western Reserve University

\section{Combinatorial Chemistry Approaches for Alloy Composition} and Corrosion Behavior

Rudolph G. Buchheit and Gerald S. Frankel, Ohio State University

Prediction of the Time Evolution of Localized Corrosion Damage

Digby D. Macdonald, Pennsylvania State University

Data Mining of Experimental Localized Corrosion Data

Mirna Urquidi-Macdonald, Pennsylvania State University 
This page intentionally left blank. 


\section{Evolution of Corrosion Damage by Localized Corrosion}

\section{OVERVIEW}

Increased understanding of the processes that control localized corrosion, particularly crevice corrosion, is a high priority. This targeted multi-investigator technical thrust examines the rate of penetration and extent of corrosion damage by localized corrosion over extremely long times. Advanced analytical and computational methods for the time evolution of crevice-corrosion damage are developed. The requirements for the initiation and propagation of localized corrosion are determined. In addition, there is a focus on the phenomena and processes that can result in a reduction in the rate of penetration or the complete arrest of crevice corrosion. If this targeted thrust's objectives are met, it may allow a more realistic treatment of localized corrosion processes in future repository performance modeling. Adapting the results of this work should allow less conservative, more traceable, and more transparent treatment of the processes being addressed.

Targeted thrust objective: Develop and analyze a logic-tree approach for the damage to waste packages by localized corro sion. The logic-tree approach provides a clear and transparent treatment to account for contributing factors.
Targeted thrust objective: Develop technical basis and demonstrate processes that slow penetration rates by localized corrosion. Where these processes pertain, the amount of damage would be greatly reduced.

Targeted thrust objective: Demonstrate factors that limit the initiation of localized corrosion. It is likely that localized corro sion will not occur under many conditions, because necessary crevices and supporting conditions are not always available on the waste packages and other engineered components.

Corrosion is a primary determinant of waste package performance and will control the delay time for the onset of radionuclide transport from the waste package. In addition, corrosion will determine when packages are penetrated and the shape, size, and distribution of those penetrations.

The evolution of crevice-corrosion damage is determined by the initiation, propagation, stifling, and arrest stages of localized corrosion. Crevice corrosion is affected by the crevice geometry and properties of the crevice former. For waste packages, metal surfaces can be covered with dust and particulate. The particulate, scale, and deposits can

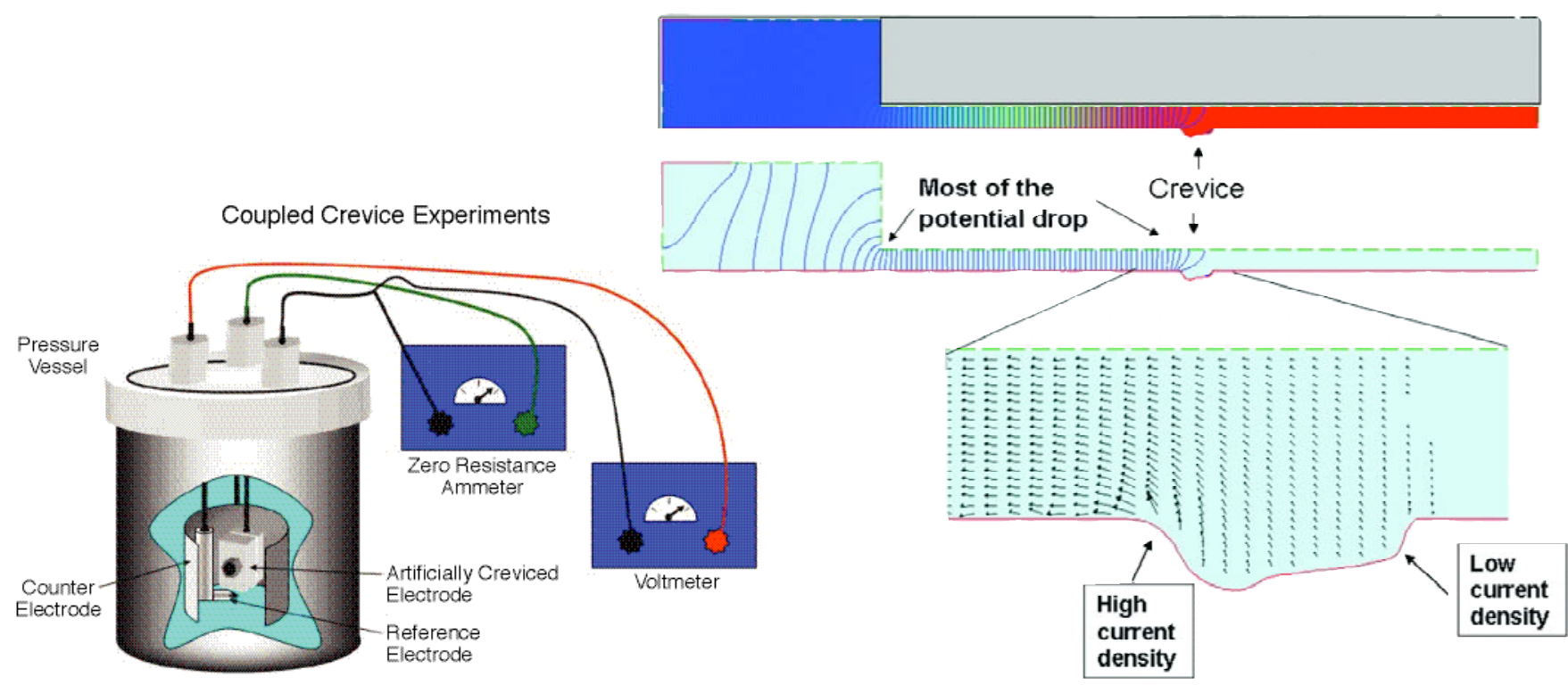

Figure I. The coupled crevice apparatus is an insitu technique to monitor the initiation, propagation, and arrest of crevice corrosion in high-temperature solutions (see lkeda, AECL)

Figure 2. Analytical model for the evolution of the profile of crevice-corrosion damage indicates greater lateral growth than penetration of the metal (see Landau, Case Western) 
form from dust, minerals from waters, and corrosion products. An important issue is how effective particulate layers and deposits are as crevice formers compared to metal/metal crevices on waste packages and polymer/metal crevices used in laboratory tests. Chemical, electrochemical, and metallurgical factors control the formation and evolution of the crevice chemistry. For crevice corrosion to persist, critical crevice chemistry must be formed and maintained. These and other crucial issues are addressed by the projects in this technical thrust area.

The approach is to meet the objectives through a coordinated set of projects. Examples of the experimental methods and analytical modeling in this area are shown in Figures 1 and 2.

\section{Technical Milestones: Evolution of corrosion damage by localized corrosion}

- Organize to develop and analyze a logic-tree approach for the damage by localized corrosion.

- Identify the key role of the interrelationship between anodic and cathodic processes in the determination of crevice-corrosion behavior.

- Initiate a coordinated set of computational modeling and experimental projects.

- Develop and implement specialized experimental methods for crevice-corrosion initiation, propagation, and arrest.

- Initiate work to determine the relationships between metallurgy (corrosion resistance of metals) and water chemistry (corrosivity of the environment) for Ni-Cr-Mo alloys and less corrosionresistant metals in high-temperature, multi-species waters.

- Establish a framework and process for the incorporation of findings into advanced methods for the prediction of time evolution of localized corrosion damage.

- Apply data mining techniques (cluster analysis, neural networks, wavelet and fuzzy representations) to establish relationships among metallurgical and environmental conditions that govern localized corrosion. 


\section{Crevice-Corrosion Electrochemistry and Propagation Behavior}

John R. Scully, Florent Bocher, and Francisco Presuel-Moreno

University of Virginia

\section{Research Objectives}

The objective of this project is to understand the impact of electrochemical driving forces (e.g., applied potential), physical and geometric conditions (e.g., temperature and crevice gap/depth), and unconventional crevice-former properties (e.g., semi-permeability and reactivity) on the susceptibility of nickel-chromium-molybdenum (Ni-Cr$\mathrm{Mo}$ ) alloys to crevice corrosion. The relationships are sought between properties associated with the crevice anode material, in conjunction with the properties of the crevice former, that together control the development, maintenance, and dilution of critical crevice solution. Understanding of these phenomena will significantly enhance the understanding and prediction of how crevicecorrosion damage evolves.

\section{Approach}

Electrochemical properties of Ni-Cr-Mo alloys behaving as isolated anodes in crevice solutions effect initiation, stabilization, propagation, repassivation, and stifling phenomena. A variety of alloy compositions are studied, with an infinite cathode area simulated by using a potentiostat and remote counter electrodes. One specific objective is to characterize $\mathrm{Ni}-\mathrm{Cr}-\mathrm{Mo}-\mathrm{Fe}$ alloy corrosion electrochemistry focusing on active dissolution properties relevant to isolated anodes, as a function of well-controlled artificial acidchloride crevice solutions. These solutions are typical for crevice-corrosion sites. The effects of metal alloy composition on conditions for depassivation and activation, as well as active corrosion rates, are determined, and critical crevice chemistries are defined. Subsequent modeling studies can help determine whether these electrochemical conditions can be met in realistic crevices. Data from isolated anodes are free of artifacts and geometric effects, and thus can serve as inputs to modeling studies.

Electrode arrays are also used in rescaled crevices. Electrode arrays consist of close-packed coupled electrodes capable of obtaining local electrochemical information. Increased understanding is sought for the combinations of environmental, geometric, and material properties that enable crevice stabilization versus repassivation.

Experiments using close-packed arrays simulating a pla-

nar electrode extend our studies from isolated anodes and enable determination of local as opposed to global electrochemical properties at specific sites in crevices. Arrays will also be used to examine the electrochemical properties of crevice anodes when confronted and mediated by finite cathode areas. These studies will elucidate the crevice dissolution properties and the resultant crevice chemistries associated with anodic crevices as affected by cathode limitations. In addition, unconventional crevice formers such as reactive and semi-permeable to either gas and/or selective ion will be investigated. The overall objective is to elucidate the anode material properties, and the physical, electrochemical, and environmental conditions, that favor stabilization (i.e., the continued steady propagation) of the crevice-corrosion rate compared to those conditions that promote crevice-corrosion stifling and repassivation of corrosion processes.

\section{Accomplishments}

A database of electrochemical polarization behavior of model Ni-22Cr-XMo $(X=0,3,6,9$, and 13) in $\mathrm{HCl}$ solution of diff e rent concentration and at diff e rent temperature $s$ has been established. These data provide boundary conditions used to derive scaling laws that define the rescaled $c$ revice geometry used for the array experiments. An electrode-array assembly is shown in Figure 1. Half of the array is covered with a crevice former. The current evolution of each wire can be monitored. A comparison of a fully anodic array at $100 \mathrm{mV}_{\mathrm{SCE}}$ and an anodic crevice (also at $100 \mathrm{mV}_{\mathrm{SCE}}$ ) against the case of a proximate cathode is shown in Figure 2. The proximate cathode inhibits the spreading of crevice corrosion under the crevice former.

This work has produced an understanding of the electrochemical behavior of Ni-22Cr-XMo alloys in different environmental conditions. The array studies enable the stabilization and planar evolution of crevices to be studied under crevice conditions more relevant to thin film conditions than conducted in past studies. By comparing an anodic crevice coupled to a proximate cathode, the conclusion is that the proximate cathode (equivalent to thin film electrolyte on the metal surface) will greatly inhibit the initiation and spreading of crevice corrosion. 


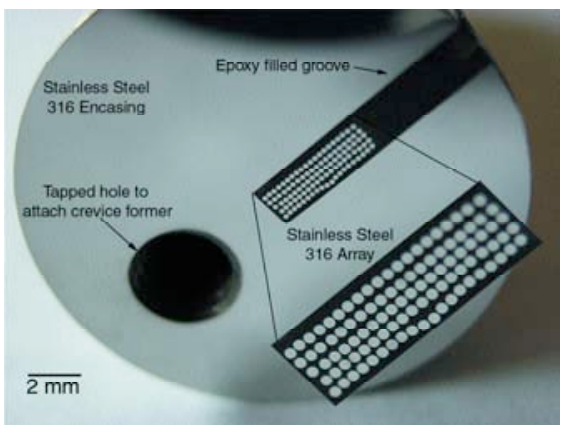

Figure I. A $5 * 20$ electrode array assembly of closepacked, coupled, wire electrodes

\section{Related Publications}

Kehler, B.A., and J.R. Scully, Role of metastable pitting in crevices on crevice stabilization in Alloys 625 and 22. Corrosion Journal, 61, 665-685, July 2005.

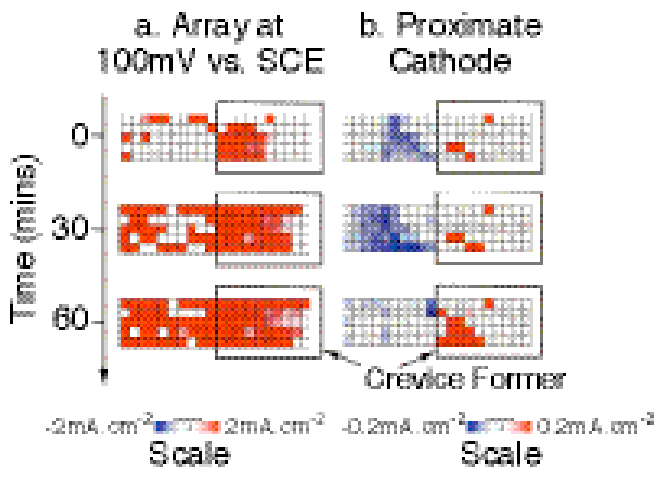

Figure 2 . The evolution of the current with time on an array partly covered with a crevice former (not to scale). Every square represents one electrode, red is anodic current and blue is cathodic, scales are shown for both series: (a) anodically polarized array at $100 \mathrm{mV}_{\mathrm{SCE}}$, (b) proximate cathode with anodic crevice, outside wires at $-400 \mathrm{mV}_{\mathrm{SCE}}$ and inside wires at $-100 \mathrm{mV}_{\mathrm{SCE}}$. SCE is saturated calomel electrode. 


\title{
Modeling of Critical Chemistry for Crevice Corrosion
}

\author{
R.G. Kelly, A.J. Hodges, and F. Presuel-Moreno \\ University of Virginia
}

\section{Research Objectives}

A primary goal of this work is to establish a stronger scientific basis for the calculation of the stability of crevicecorrosion propagation for corrosion-resistant alloys (i.e., stainless steels, nickel-chromium-molybdenum-iron [NiCr-Mo-Fe] alloys) under atmospheric exposure conditions. Of particular interest is the current demanded by a localized corrosion site as a function of crevice geometry, temperature, alloy composition, relative humidity (RH), and external solution layer composition.

An additional goal is to quantify crevice-corrosion damage of these alloys as a function of relevant variables. Quantification of crevice corrosion is traditionally very challenging because of the local nature of the damage. Mass-loss measurements are not well suited because the

corrosion damage is integrated over the entire exposed surface, and most electrochemical approaches do not provide information on the spatial distribution of the damage. These factors limit the validation of computational models for crevice-corrosion damage and make interpretations of the effects of relevant variables on crevice-corrosion damage qualitative.

\section{Approach}

A previously developed crevice-corrosion computational code is leveraged by extending it to the alloys of interest. This extension was accomplished by adding the species relevant for $\mathrm{Ni}-\mathrm{Cr}-\mathrm{Mo}-\mathrm{Fe}$ alloys as well as the species present in the solution layer outside the crevice. Because of the extensive literature available on its localized corrosion site conditions, stainless steel alloy 316L was used for the scop-

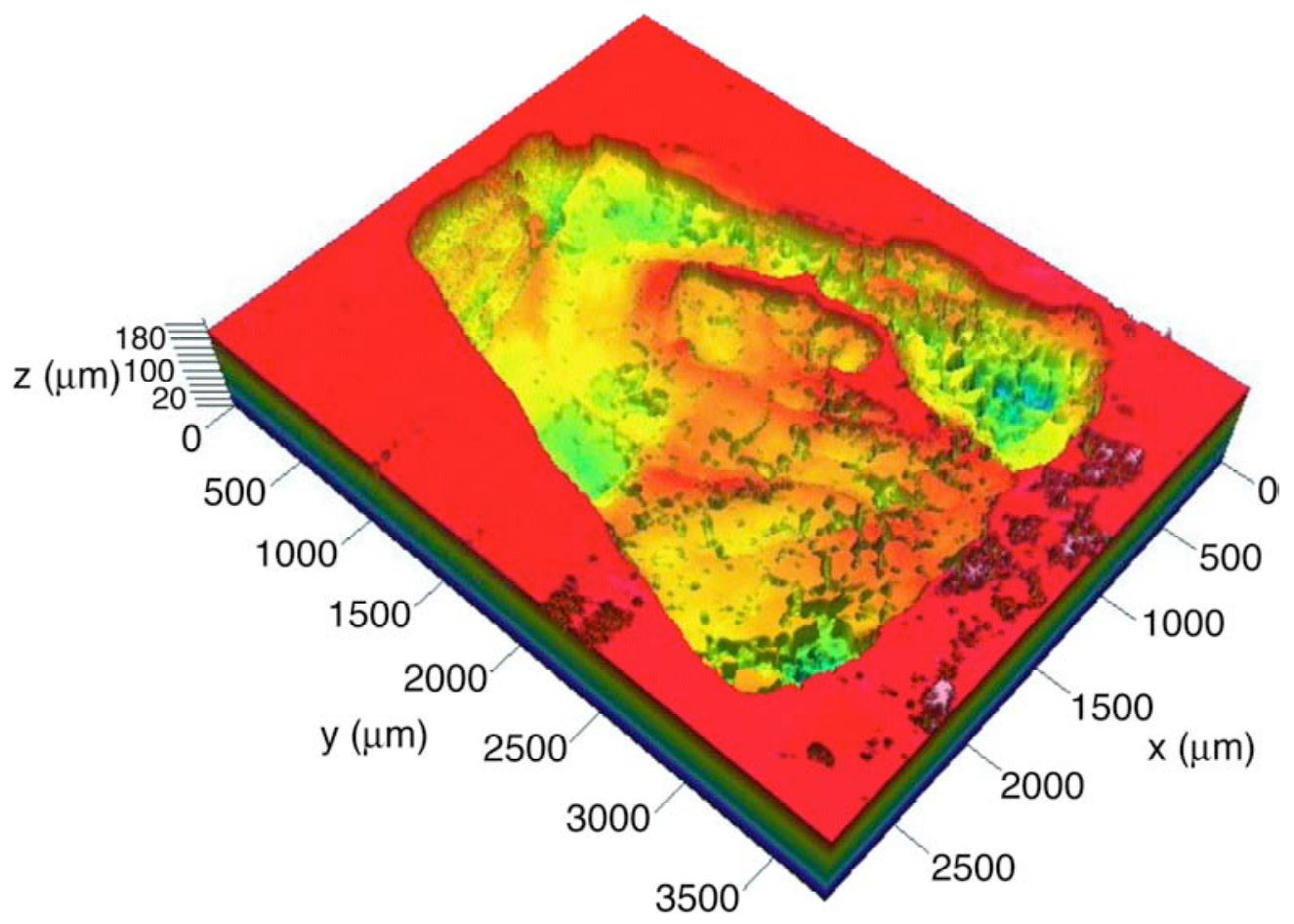

Figure I. A 3-D map of crevice-corrosion damage on an alloy C-22 specimen after a laboratory crevice corrosion test conducted at LLNL. Image obtained by confocal laser scanning microscopy. 
ing work on computations of relevance to the stifling of localized corrosion. Electrochemical kinetics were extracted from the literature. A range of crevice gap heights was studied, because this geometric factor is considered to be of primary importance in determining crevice stability. The calculations determined the current needed by a crevice with a constant chemistry and a given set of electrochemical kinetics. These results were compared to the current delivery capabilities of the external cathodes studied in a related project. The maximum gap size for a stable crevice was determined as that gap for which the required current was less than or equal to the maximum current available by the external cathode.

To complement the computational modeling, confocal laser scanning microscopy (CLSM) provides the capability to quantitatively map the surface topography of corroded samples. Three-dimensional maps of corrosion damage were generated, as shown in Figure 1, for creviced samples of Alloy 22 that had been corroded at the Lawrence Livermore National Laboratory. Determinations of the total volume loss, maximum depth of attack, and the morphology (general dissolution, intergranular attack) were made for crevices that included base metal and/or welded material.

\section{Accomplishments}

Modeling has highlighted the importance of an external cathode's ability to supply sufficient current in allowing stable crevice corrosion to occur under thin electrolyte layer conditions. Using the electrochemical data extracted from the literature for Type 316L stainless steel, only crevices with gaps of three microns or less would be supported by the cathodic current available from the most capable external surface studied in a related project. In addition, the value of the repassivation potential was found to have dramatic effects on the size of the crevice gap that could be stabilized, with an increase of $50 \mathrm{mV}$ leading to a decrease in the maximum gap of more than an order of magnitude. Thus, higher repassivation potentials make crevice stabilization much more difficult.

The CLSM studies demonstrated the ability of this measurement method to quantify crevice-corrosion damage with high resolution in all three spatial dimensions. These data are being analyzed both statistically (i.e., distributions of damage) and using reduced parameter sets (i.e., total corroded volume).

The methodology for evaluating the current demand of a localized corrosion site, and its relation to the capability of external, thin-electrolyte layer cathodes, provides a new means of determining parameters of importance in establishing stable localized corrosion sites under atmospheric conditions. These insights can be used to guide experimental work aimed at establishing more precisely the values of the important parameters, thus enabling more accurate prediction of corrosion susceptibility as well as alloy design.

The ability of the CLSM to quantify arevice-corrosion damage will enable more accurate validation of corrosion-damage models, as well as provide quantitative descriptions of how important parameters (e.g., crevice gap, potential, alloy composition) affect the evolution of corrosion damage. 


\section{Experimental Determination of the Evolution of Crevice- Corrosion Damage}

David W. Shoesmith and Jamie Nöel

University of Western Ontario

\section{Research Objectives}

The objective is to measure the damage functions that can be used either to develop models for damage accumulation by crevice corrosion in nickel-chromium-molybdenum (tungsten) (Ni-Cr-Mo(W)) alloys or to validate alternative models. The key deliverable will be a series of direct measurements of the time-dependence of the depth and distribution of corroded sites within well-defined creviced areas. A major focus of this project is the experimental identification of those alloy features that determine the propagation, stifling/repassivation, and re-initiation processes of crevice corrosion.

\section{Approach}

A range of electrochemical and surface analytical techniques are used to accelerate and/or monitor the progress of crevice corrosion. In particular, a galvanic coupling technique that simulates crevice corrosion in the absence of any applied electrochemical driving force is used. The current and potential signals associated with crevice propagation can be monitored directly to provide a real-time measurement of the accumulation rate of corrosion damage. The evolution of these parameters with time and temperature indicate whether the tendency in crevice behavior is towards stifling/repassivation or continued propagation.

Since these alloys are designed to be resistant to localized corrosion processes, aggressive environments (presently, 5 mol. $\mathrm{L}^{-1} \mathrm{NaCl}$ ) are used, and experiments are conducted at high temperatures $\left(70^{\circ} \mathrm{C}\right.$ to $\left.120^{\circ} \mathrm{C}\right)$. The morphology of damage distribution is measured by profilometry and confocal laser microscopy. Secondary ion mass spectrometry (SIMS) and other surface analytical techniques are used to determine changes in surface composition on metallographic cross sections cut through crevice-corroded specimens.

\section{Accomplishments}

Experiments with Alloy 22 have had no success in initiating crevice corrosion without an initial electrochemical stimulus, despite attempts at temperatures up to $200^{\circ} \mathrm{C}$. However, crevices have been successfully initiated using both constant potential and constant current stimuli. Crevices initiated under constant potential conditions (200 $\mathrm{mV}$ at $120^{\circ} \mathrm{C}$ ) subsequently propagated very rapidly, with crevice currents approaching $100 \mathrm{~mA}$. In these experiments, the crevice continued to propagate until a shallow depth of the whole creviced area had been dissolved and then repassivation occurred. These experiments are not a real representation of crevice-corrosion conditions, since unlimited current is available electronically to maintain the propagation process. Nevertheless, the results suggest that providing a sufficiently large cathodic stimulus can be maintained (i.e., an unlimited supply of very aggressive oxidants under natural corrosion conditions), propagation can proceed rapidly in the exposure environment used (5 mol.L ${ }^{-1} \mathrm{NaCl}$ at $120^{\circ} \mathrm{C}$ ).

Subsequently, we have switched to initiating corrosion using a constant current stimulus. While gentler than the constant potential approach, this method still constitutes an extremely unlikely scenario under natural corrosion conditions. Initiation involves application of a constant current $\left(\sim 200 / 300 \mu \mathrm{A} / \mathrm{cm}^{2}\right)$ and an excursion of the crevice potential to positive values $(>400 \mathrm{mV} \mathrm{Ag} / \mathrm{AgCl})$ unlikely under natural corrosion conditions. However, despite the artificiality of the initiation process, we can, once initiated, switch to galvanic control and monitor the propagation current under natural corrosion conditions.

Our results show a number of important features:

- Crevice initiation appears to occur at a small number of sites (one and possibly two). This behavior is distinctly different from some other materials (e.g., titanium alloys) on which a series of initiations (some metastable and rapidly followed by repassivation) are observed.

- Once initiated, corrosion appears to propagate at a constant rate (between 1 and $7 \mu \mathrm{A}$ ) at $120^{\circ} \mathrm{C}$ in 5 mol.L $\mathrm{L}^{-1} \mathrm{NaCl}$. The maximum propagation period observed to date is 18 days at $\sim 1 \mu \mathrm{A}$, after which the experiment was terminated.

- Damage appears to be shallow and confined to a single area on the periphery of the crevice. Depths of penetration remain to be measured.

- SIMs experiments on cross sections of crevice-corroded specimens show no incongruity in the alloy 
composition at the corroded surface; i.e., the alloying elements were dissolved in proportion to their concentration in the alloy.

The initiation process of crevice corrosion on Alloy 22 is very difficult. However, once initiated, using applied electrochemical stimulus, crevice corrosion was observed to propagate, albeit at a very slow rate $(1$ to $7 \mu \mathrm{A})$ in 5 mol. $\mathrm{L}^{-1} \mathrm{NaCl}$ at $120^{\circ} \mathrm{C}$. Based on these results, under aggressive conditions and forced initiation, the only repassivation driving force we have identified is the drop in temperature upon concluding an experiment. Further work will continue to examine the initiation, propagation, and repassivation processes. 


\section{Coupled Crevice Tests for Initiation, Propagation, and Arrest of Crevice Corrosion}

Brian M. Ikeda and C.D. Litke

Atomic Energy of Canada Limited

\section{Research Objectives}

The objective is to investigate the role of the cathodic reaction on the initiation, propagation, and cessation of crevice corrosion under nearly natural corroding conditions; and to develop an understanding of the processes driving crevice corrosion. The corrosion behavior of an alloy that is more susceptible to crevice corrosion is compared to that of a more resistant high nickel-chromium-molybdenum (Ni-Cr-Mo) material, e.g., Alloy 22. The data obtained from this project will contribute to the development of advanced process models for the evolution of damage by crevice corrosion, and will provide data for verifying the predictions of advanced process models being developed to predict long-term localized corrosion-damage functions. These results complement other experimental and computational tasks in this technical thrust for Evolution of Localized Damage by Crevice Corrosion.

\section{Approach}

The galvanic coupling technique is suitable for monitoring the corrosion current and potential under nearly natural crevice-corrosion conditions. The crevice-corrosion reaction is coupled to a cathodic reaction that occurs on an isolated surface outside the crevice. The occurrence of crevice corrosion can be monitored by measuring the current flow between the creviced electrode and a cathode (Figure 1). The active or passive state of the corrosion reaction can be determined by measuring both the current and potential of the system. These experimental conditions simulate the large cathode-small anode conditions normally encountered for crevice-corrosion situations. However, should initiation prove difficult for a given set of experimental parameters, other electrochemical methods can be used to start the crevice-corrosion reaction. Once a stable crevice environment is established, the artificial stimulation can be replaced by a galvanic coupling measurement to follow the natural progress of propagation and cessation processes.

The susceptibility to start or stop a damaging crevice reaction, and the corrosion rate, is affected by the size (effective area) of, and efficiency (kinetics) at, the cathode. These effects can be examined by varying the cathodic area (blocking), the anodic area, or both; by changing the

\section{Coupled Crevice Experiments}

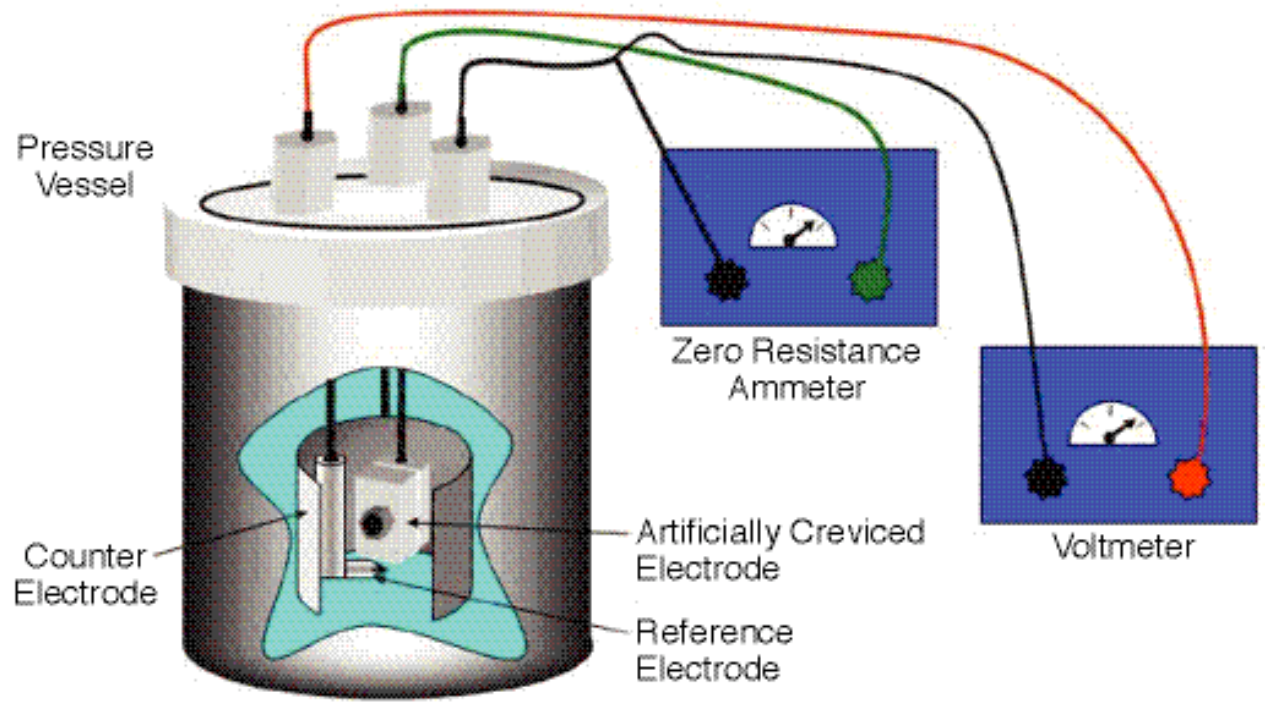

Figure I. Schematic of the experimental arrangement for a coupled crevice experiment with the electrodes and instrumentation 
counter electrode surface condition (e.g., oxide layer thickness); or by introducing environmental interactions (e.g., silicate precipitation).

Coupled crevice experiments are performed in a pressure vessel containing an air atmosphere and a $\mathrm{NaCl}$ solution, at temperatures up to $\sim 130^{\circ} \mathrm{C}$. The creviced electrode is formed by sandwiching a polytetrafluoroethylene (PTFE) sheet between two metal coupons. A nut-and-bolt assembly is used to hold the crevice together at a specified initial tightness. The corrosion potential of a planar metal specimen immersed in the solution is measured to indicate the corrosivity of the bulk environment.

The initial reference solution is a $0.5 \mathrm{~mol} \cdot \mathrm{L}^{-1} \mathrm{NaCl}$ (nearsea-water chloride concentration). The effect of varying the chloride concentration and adding groundwater constituents will be examined. Temperature can be varied to determine the effect of temperature on the corrosion rate and the repassivation or cessation of the crevice-corrosion reaction.

\section{Accomplishments}

Qualified materials have been procured and their chemistry verified. The experimental apparatus and instrumentation have been established for measuring the low coupled currents anticipated for crevice corrosion of high nickel alloys. Previous testing of Inconel 625 has shown this material to be resistant to sustained crevice corrosion in solutions of 0.5 to $2 \mathrm{~mol} / \mathrm{L} \mathrm{NaCl}$ at $130^{\circ} \mathrm{C}$. The small amount of corrosion is consistent with both the small coupled-current measured $(<10 \mu \mathrm{A})$ throughout the exposure period and the small difference between the coupled and planar electrode potential values.

A preliminary experiment has been performed in which a small constant current was applied to an Inconel 625 creviced electrode for 24 hours and then removed. The creviced electrode was then coupled to the cathode, and the coupled current was followed. This experiment demonstrated the methodology, but the conditions were not sufficiently aggressive as to create a stable crevice-corrosion reaction.

These experiments demonstrate that high Ni-based alloys have good resistance to crevice corrosion at temperatures higher than anticipated for pure, concentrated $\mathrm{NaCl}$ solutions. Strongly aggressive conditions may be required to generate a stable crevice environment conducive to sustained corrosion in $\mathrm{NaCl}$.

\section{References}

Nöel, J.J., D.W. Shoesmith, and B.M. Ikeda, Crevice corrosion of alpha titanium alloys. NACE 2001, Topical Research Symposium Proceedings, Houston, TX, 2000.

Bailey, M.G., B.M. Ikeda, M.J. Quinn, and D.W. Shoesmith, Crevice corrosion behaviour of titanium Grades-2 and 12 in hot aqueous chloride solution - The effect of chloride concentration. AECL-10971, COG-95-279, 1996. 


\section{Localized Corrosion Stability in the Presence of Non-Chloride Anions}

Roger C. Newman, David D. He, and Anatolie Carcea

University of Toronto

\section{Research Objectives}

This project will generate fundamental data and scientific understanding for the localized corrosion kinetics of nickel-chromium-molybdenum (Ni-Cr-Mo) alloys in the presence of non-chloride anions, especially nitrate. The research will identify factors that may lead to reduced inhibition efficiency in bulk solutions and will provide basic underlying mechanistic information required by other projects. In particular, it will support related research dealing with thin, moist particulate layers.

\section{Approach}

Electrochemical studies using the artificial pit or pencil electrode technique have enabled the exposure of a constant surface area of metal that is undergoing localized dissolution. The conditions have covered the following range of relevant variables: temperature $75-90^{\circ} \mathrm{C}$, Mo content 0-13 wt. \%, nitrate-to-chloride molar ratio 0-0.5. Special alloys prepared by the U.S. DOE Ames Laboratory have

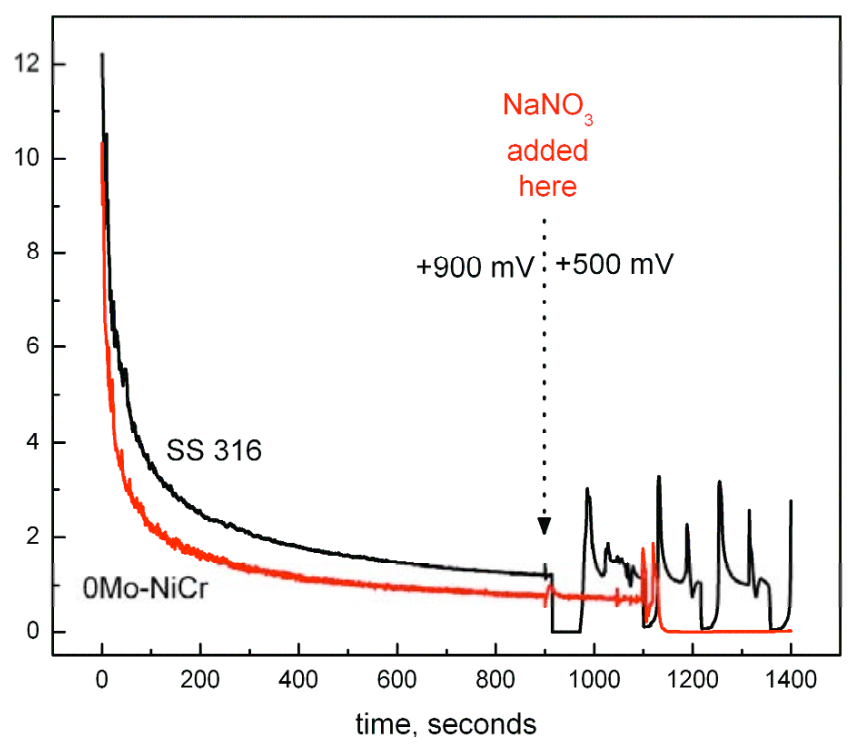

Figure I. Growth of artificial pits on $316 \mathrm{SS}$ and molybdenum-free $\mathrm{Ni}-22 \mathrm{Cr}$ (OMo-NiCr) in I $\mathrm{M} \mathrm{NaCl}$ with $0.05 \mathrm{M} \mathrm{NaNO}_{3}$ injected just after the vertical line, showing oscillation and repassivation been used throughout, in the form of $125 \mu \mathrm{m}$ or $250 \mu \mathrm{m}$ wires. Typically, a cavity is grown to a chosen depth, and then the propagation kinetics as a function of the potential and the local chemistry are measured. Nitrate or another inhibiting ion is inoculated into the bulk solution, and its transport into the cavity is observed by monitoring its effect on the current. If the cavity is not repassivated by the inhibitor addition, the potential is further varied or more inoculations are made, and further kinetic information is thus gained. The experiments are supported by appropriate modeling.

\section{Accomplishments}

Initial work tested the hypothesis of Newman and Ajjawi (1986): that the peculiar localized corrosion behavior of stainless steel in the presence of nitrate was associated with a redox reaction of $\mathrm{NO}_{3}{ }^{-}$with ferrous ions - thus, $\mathrm{Ni}$ $\mathrm{Cr}$ alloys may not show the effect. This proved to be so with $0.1 \mathrm{M} \mathrm{NaCl}$ and low nitrate levels: propagating cavities in Ni-22Cr did not passivate anodically. However, increasing the nitrate-to-chloride ratio to 0.5 produced a similar or even stronger effect on Ni-22Cr (Figure 1). Further work focused on the more practically relevant behavior at low potentials. Backscan experiments showed that $\mathrm{NiCr}$ alloys have lower limiting current density (proportional to the product of solubility and diffusivity in the cavity) than stainless steel. Progressive ennoblement of the repassivation potential with Mo content (the 13\% Mo alloy did not activate completely) was observed, and actual dissolution kinetics were measured for all alloys in the nearly saturated cavity solution.

When nitrate was injected, the behavior was different with and without Mo. Whereas the binary Ni-22Cr showed no detectable nitrate-inhibiting effect at low potentials, the presence of nitrate reproducibly caused a partial repassivation of the $6 \%$ and $9 \%$ Mo alloys, and the adoption of a new, much lower limiting current density (Figure 2). The mechanism for this is under investigation.

This research is generating high-quality kinetic data that are universally applicable to localized corrosion cavities of any geometry on Ni base alloys. The significance with respect to Alloy 22 is that we can observe, in a graduated fashion, the beneficial effect of alloyed Mo in the presence 


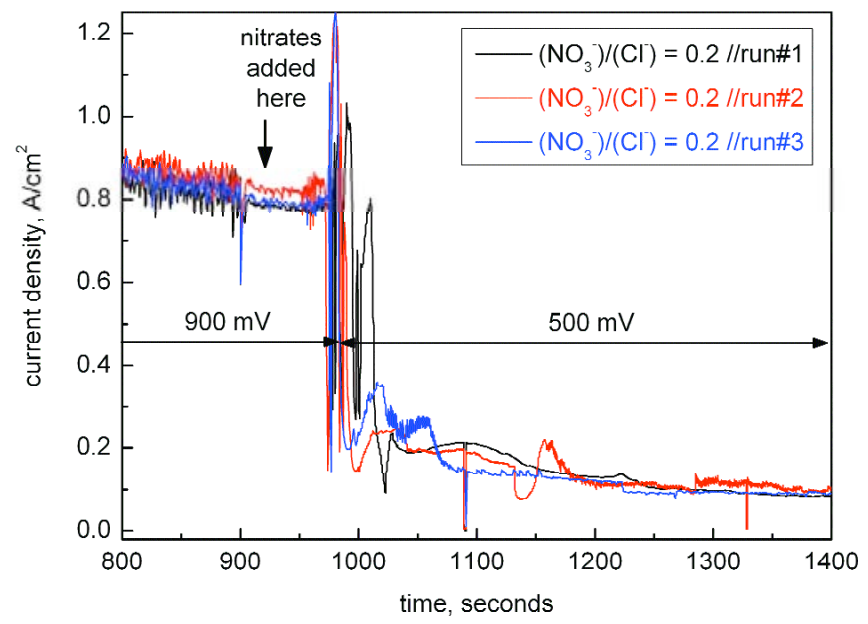

Figure 2. Repassivation effect of nitrate on the $6 \% \mathrm{Mo} \mathrm{NiCr}$ alloy $(6 \mathrm{Mo}-22 \mathrm{NiCr})$ in $0.1 \mathrm{M} \mathrm{NaCl}$ of nitrate at varying levels. The real kinetic data for the dissolving surface provide a firm basis for validation of whether localized corrosion propagates indefinitely in an alloy with less Mo than Alloy 22. In that case, we can say that Alloy 22 will resist that environment (for a particular cavity geometry). Scientifically, the research is also generating fundamental information on the mechanism of the Mo effect on localized corrosion.

\section{References}

Newman, R.C, and M.A.A. Ajjawi, A microelectrode study of the nitrate effect on pitting of stainless steels. Corros. Sci., 26, 1057, 1986. 


\section{Metallurgical Effects on Localized Corrosion of Ni-Cr-Mo Alloys}

Gerald S. Frankel and Rudolph G. Buchheit

Ohio State University

\section{Research Objectives}

This project will study several metallurgical aspects such as changes produced by welding and long-term aging, and the effects of alloying within the allowable ranges of composition according to the standard material specifications. In some experiments, a wider range of composition will be investigated.

\section{Approach}

There will be two primary approaches taken in this project. The first approach will study the behavior of creviced samples of Alloy 22 and similar materials at high temperatures and in aggressive electrolytes. This work will be performed on bulk samples to investigate the effects of weld- ing, long-term aging, and composition variation. The second approach will study the behavior of thin film metal samples deposited onto inert substrates. A wider range of composition will be investigated with this approach.

\section{Bulk Samples}

The effects of welding will be examined through studies on samples treated to physically simulate welding, not by studying actual welded samples, whose properties could depend on the details of the welding process. There are two microstructural zones in fusion welds: the fusion zone (FZ), which had been molten and then resolidified, and the heat affected zone (HAZ), which had never been melted, but was altered in some way by the welding process. The FZ is simulated in an electric arc melter by striking an arc

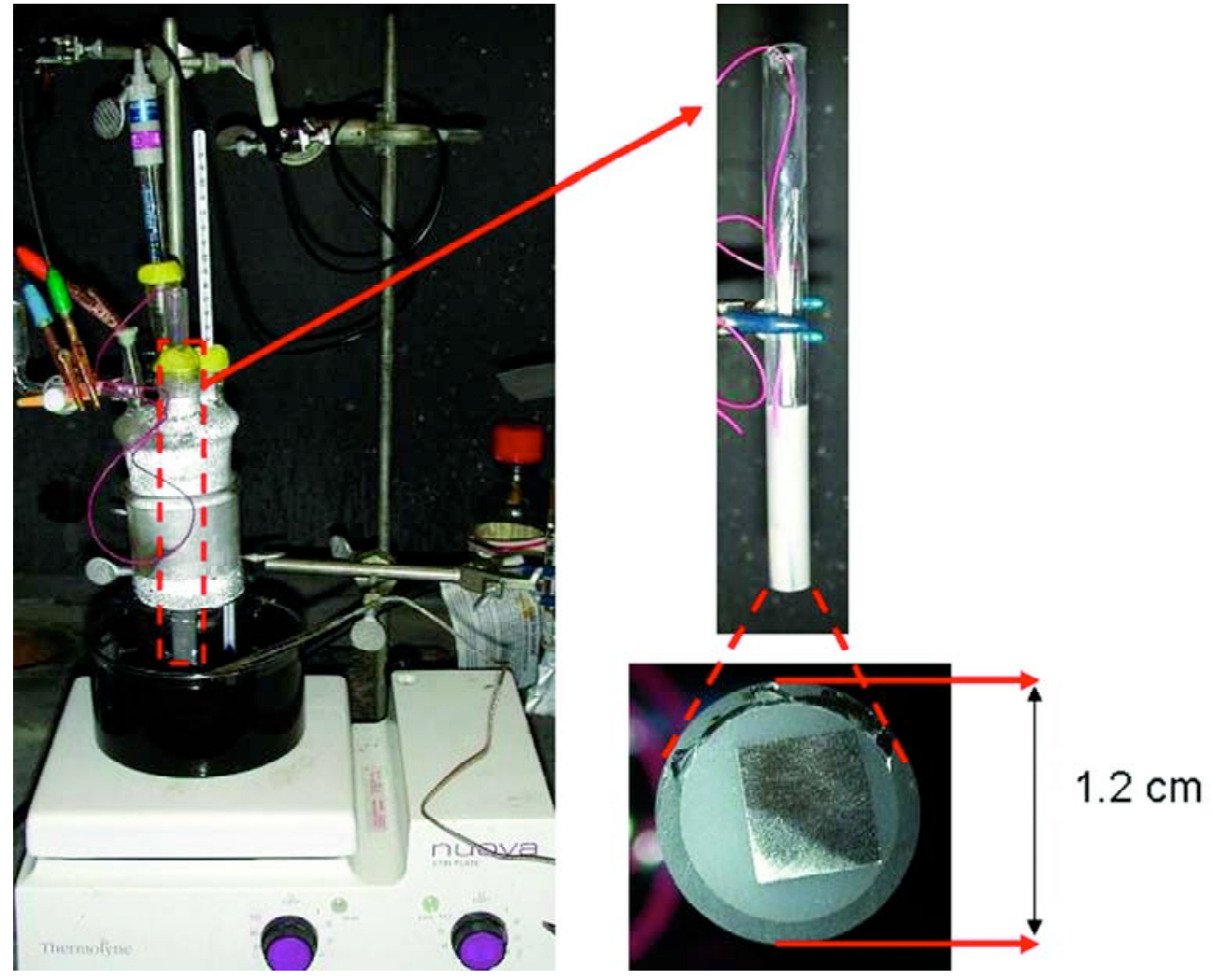

Figure I. The test setup for electrochemical polarization tests 
to a plate sample. Such samples are tested in the as-melted condition and also in the annealed condition. The HAZ is simulated using a Gleeble tool, which provides similar thermal-mechanical conditions as found during welding. The Gleeble also has a mechanical control system that can simulate the constraints found during welding.

Aged samples are prepared by heat treatment. Samples with varying composition within the alloy specification will be prepared by electric arc melting of mixtures of pure materials to form buttons of varying composition. We will also work with vendors to identify Alloy 22 stock that has different compositions, based on chemical analysis.

\section{Thin Film Samples}

Another approach will utilize thin films deposited by sputter deposition onto inert substrates using a transparent crevice former to stimulate localized attack. Growth of crevice attack under the crevice former will be documented with video imaging. The small sample thickness will simulate the behavior of Alloy 22 crevice attack, which stays shallow and does not propagate to great depths. The kinetics will be assessed as a function of controlled sample potential.

The thin film crevice geometry will facilitate the analysis of the corrosion product. Localized corrosion reactions usually result in the formation of nonprotective corrosion product, which can nonetheless play an important role in the process by, for instance, altering transport. Samples will be analyzed by scanning electron microscopy/energy dispersive spectroscopy (SEM/EDS) upon disassembly of the cell.

\section{Accomplishments}

Thin films of 304L were polarized at a fixed potential of 1 $\mathrm{V}_{\mathrm{SCE}}$ in $5 \mathrm{M} \mathrm{NaCl}$. A $130 \mathrm{~nm}$ thick film did not exhibit attack at this potential, but 200 and $470 \mathrm{~nm}$ films exhibited localized 2-D pitting corrosion in the crevice region away from the edge of the hole, which could be observed through the transparent crevice former. The rate of perimeter increase was determined for these samples. As with uncreviced thin film pits, the perimeter increased linearly with time. The rate of increase for the $200 \mathrm{~nm}$ film was found to be about 4 times smaller than for the $470 \mathrm{~nm}$ film, which is different from what had been observed for uncreviced thin films, where the local current density increases as the film thickness decreases.

Baseline anodic and cathodic polarization responses for Alloy 22 in $5 \mathrm{M} \mathrm{NaCl}$ plus $1 \mathrm{M} \mathrm{KNO}_{3}$ solutions have been carried out, at temperatures ranging from 25 to $90^{\circ} \mathrm{C}$. Post-test examinations suggest that sample mounting procedures and cell fixturing has been developed to significantly limit crevice corrosion during slow-scan polarization measurements in hot, concentrated brine-like solutions.

The results of these studies on thin metal films are useful input to crevice-corrosion models, and provide the dissolution kinetics as a function of solution composition, pit depth, and crevice position. 


\section{Effect of Crevice Former on Corrosion Damage Propagation}

Joe H. Payer, Uziel Landau, Xi Shan, and Arun S. Agarwal

Case Western Reserve University

\section{Research Objectives}

A necessary condition for crevice corrosion is that a crevice former must create a restricted geometry on the metal surface. Crevice corrosion is affected by the crevice geometry and properties of the crevice former. For waste packages, metal surfaces can be covered with particulate, scale, and deposits that can form from dust, minerals from waters, and corrosion products. An important issue is how effective particulate layers and deposits are as crevice formers compared to metal/metal crevices on waste packages and polymer/metal crevices used in laboratory tests. The objective of this project is to determine the effect of the crevice former on the type and rate in localized corrosiondamage propagation.

\section{Approach}

Our approach consists of a combination of experimental measurements of localized corrosion with various crevice formers, and analytical computations of the crevice damage profile as a function of crevice geometry, environment, and corrosion resistance of the metal. Standard crevice-corrosion test methods are modified by (a) the use of metal, polymer, and ceramic materials as crevice formers and (b) the variation in size and shape of the crevices.

\section{Accomplishments}

To make head-to-head comparisons, crevice-corrosion tests are run with different crevice formers on each metal speci-

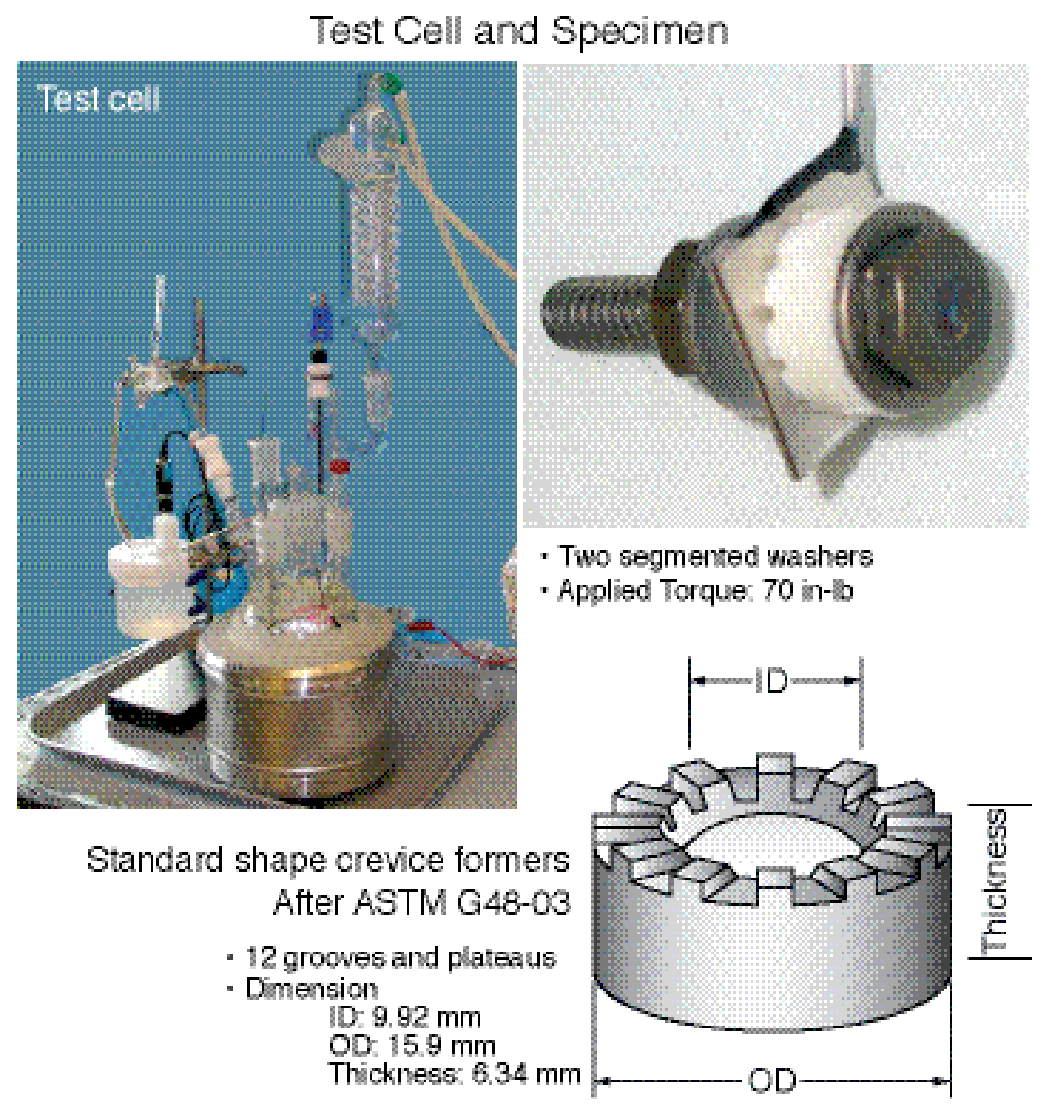

Figure I. The test cell and crevice assemblies for crevice-corrosion tests 
men in the same exposure. The test cell and crevice former assemblies are shown in Figure 1. The crevice-corrosion damage is monitored throughout the test by corrosion current measurements, and post-test examination documents the depth and distribution of corrosion damage. A series of tests are run to establish the test protocols. Tests to date have used 316L stainless steel to examine crevice-former effects on a metal that is highly susceptible to localized corrosion. Later tests will use more corrosion-resistant nickel-chromium-molybdenum (Ni-Cr-Mo) alloys.

Significant differences in the extent of damage are shown in Figure 2. The polymer/metal crevice resulted in more damage (deeper and over a wider area) than the damage from a ceramic/metal crevice (shallower).

The profile of damage from crevice corrosion is determined by modeling the corroding area within the crevice. The damage propagates from an initiation site within the crevice. For the scenario shown in Figure 3, the crevice damage extended more rapidly toward the crevice mouth than into the metal (penetration). When the crevice mouth opened beyond a critical level, the crevice repassivated and corrosion stopped, owing to dilution of the critical crevice chemistry.

This project addresses factors that may limit the initiation of localized corrosion and also slow or stop the continued propagation of corrosion. The Total System Performance Assessment treatment presumes crevices and supporting processes are always available, and once initiated, crevice corrosion proceeds at a constant rate. The findings are an important contribution to the determination of the penetration rate and extent of corrosion damage by localized corrosion over extremely long times, and dilution of the critical crevice solution within the crevice.

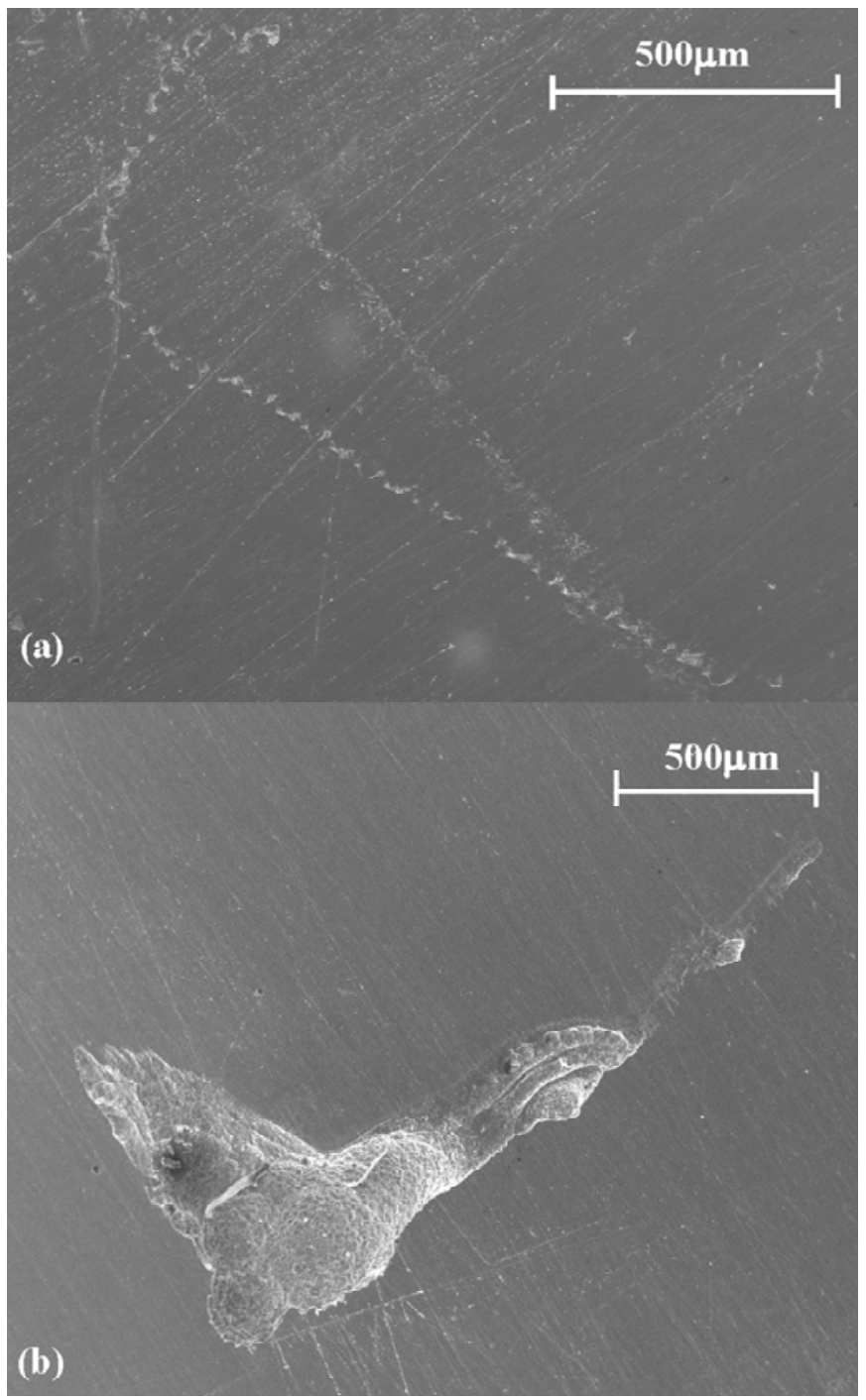

Figure 2. Comparison of corrosion damage (a) beneath a ceramic/metal crevice and (b) beneath a polymer/metal crevice (more severe) on 316 stainless steel in $0.5 \mathrm{M} \mathrm{NaCl}$ at room temperature polarized to $0.1 \mathrm{~V}_{\mathrm{SCE}}$

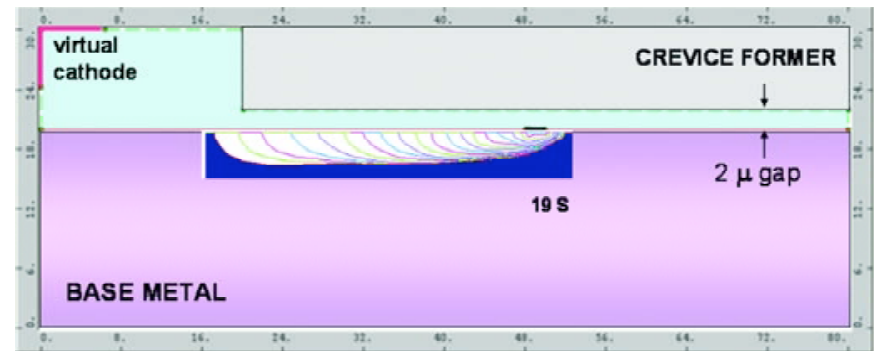

Figure 3. An illustration of crevice repassivation and damage arrest (corrosion stopped) by widening of the crevice mouth and dilution of the critical crevice solution within the crevice 


\title{
Combinatorial Chemistry Approaches for Alloy Composition and Corrosion Behavior
}

\author{
Rudolph G. Buchheit and Gerald S. Frankel
}

Ohio State University

\section{Research Objectives}

The objective of this task is to develop and apply combinatorial chemistry approaches to characterize the effect of nickel-chromium-molybdenum-tungsten(niobium) (Ni-Cr$\mathrm{Mo}-\mathrm{W}(\mathrm{Nb})$ alloy chemistry on the corrosion behavior in high temperature, multi-ionic species brines. In addition to the highly corrosion-resistant Ni-Cr-Mo alloys, less-corrosion-resistant alloys are examined for comparison. The general approach is based on the use of a potentiostat capable of simultaneously measuring up to 100 independent channels of current on a segmented working electrode operated in an otherwise conventional three-electrode configuration. Alloy composition will be varied systematically across specially prepared arrays comprised of millimeter to submillimeter-diameter electrodes, to develop relationships between alloy composition and electrochemical behavior in selected environments characteristic of crevices and thin electrolyte layers.

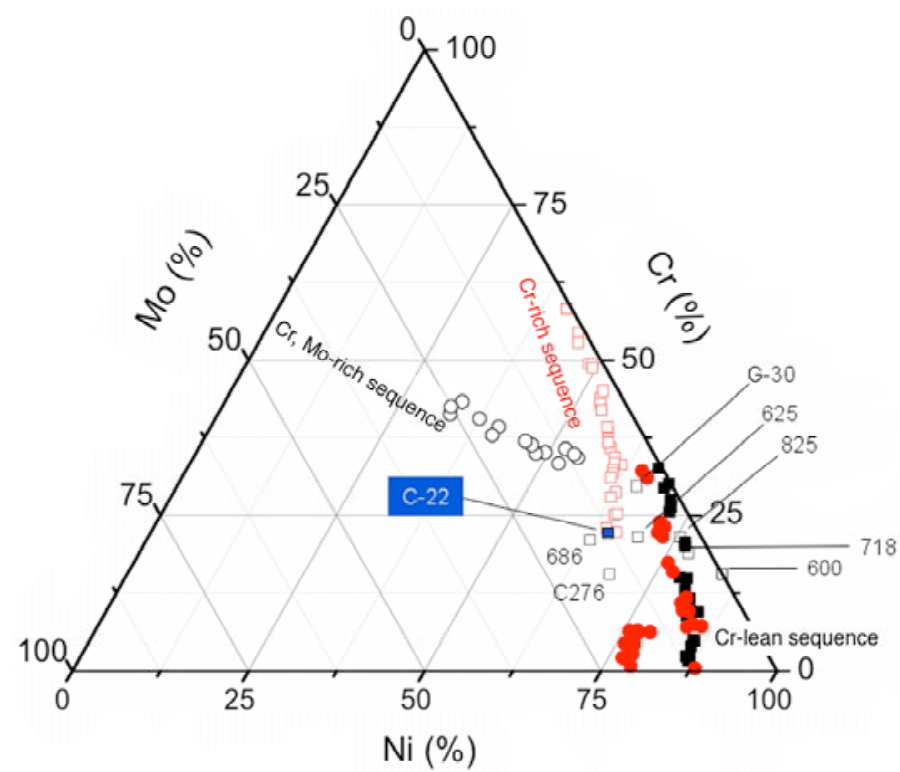

Figure I. Ni-Cr-Mo composition diagram showing the alloys fabricated for this study so far. Several commercial alloys are located on the diagram according to their $\mathrm{Ni}, \mathrm{Cr}$, and Mo contents.

\section{Approach}

Alloy samples for this study have been fabricated using a directed laser deposition process, i.e., Laser Engineered Net Shaping (LENSTM). This method allows us to rapidly fabricate samples covering a range of compositions for electrochemical characterization. Alloys were prepared with composition surrounding that of Ni-22Cr-14Mo (Alloy 22). The effects of iron and tungsten additions to selected Ni-Cr-Mo alloys will be studied separately.

Electrochemical characterization carried out so far has focused on characterizing the dependence of anodic and cathodic polarization responses on alloy composition. Upcoming studies are aimed at characterizing the metastable-to-stable pit transition and the evolution of surface film chemistry and its effect on electrochemical reactivity of Ni-Cr-Mo-based alloys.

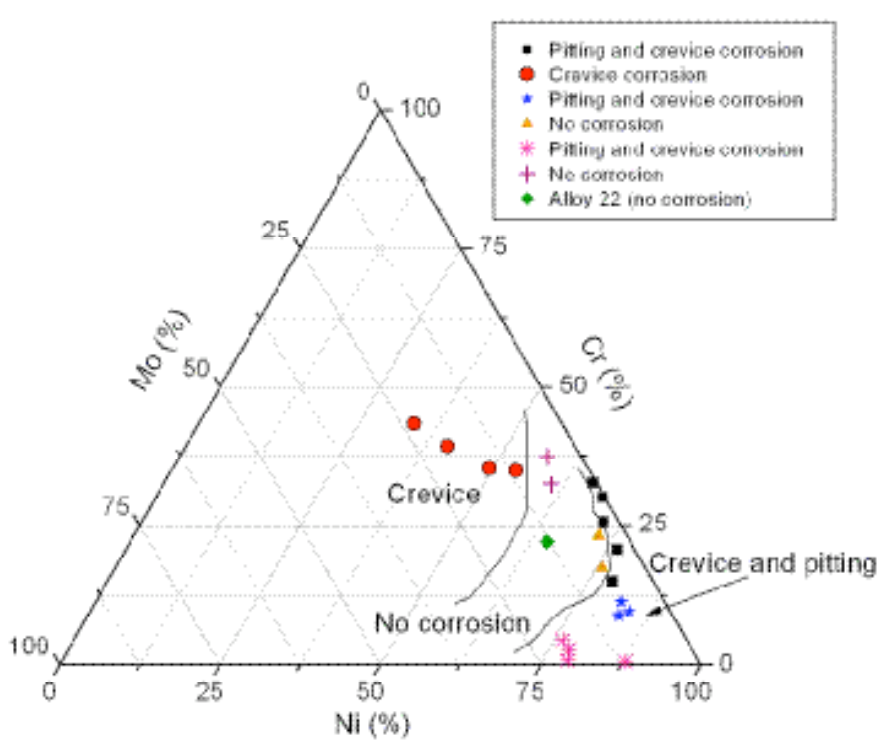

Figure 2. Localized corrosion tendencies mapped on the Ni-Cr-Mo composition diagram 


\section{Accomplishments}

Over one hundred unique Ni-Cr-Mo alloys have been prepared for electrochemical testing along three main compositional sequences, shown in the ternary composition diagram in Figure 1. These are a "Cr-rich sequence" with alloy compositions ranging from $\mathrm{Ni}-22 \mathrm{Cr}-14 \mathrm{Mo}$ to $\mathrm{Ni}$ $60 \mathrm{Cr}$, a "Cr-lean sequence" ranging from Ni-22Cr-14Mo to $\mathrm{Ni}-25 \mathrm{Mo}$, and a "Cr, Mo-rich sequence" ranging from Ni$22 \mathrm{Cr}-14 \mathrm{Mo}$ to $\mathrm{Ni}-45 \mathrm{Cr}-25 \mathrm{Mo}$.

In our initial survey of electrochemical behavior, anodic and cathodic polarization curves have been measured in $5 \mathrm{M} \mathrm{NaCl}$ plus $1 \mathrm{M} \mathrm{NaNO}_{3}$ at $60^{\circ} \mathrm{C}$. Post-test examination allows determination of the form of corrosion induced, e.g., crevice corrosion, pitting corrosion, or no corrosion. Examination of polarization curves allows for a more quantitative characterization of electrochemical kinetics and reaction control.

Alloys along the Cr-rich and Cr-lean sequence exhibited passive behavior, but there is a sharp increase in the resistance to pitting as $\mathrm{Cr}$ content increases from 11 to $15 \mathrm{wt}$ \%. $\mathrm{Cr}$-rich and Cr-lean sequence alloys with Mo contents under $3 \mathrm{wt}$.\% demonstrate a susceptibility to crevice corrosion. The presence of Mo in concentrations greater than about $3 \%$ in alloys with more than $12 \mathrm{wt} . \% \mathrm{Cr}$ reduces the tendency for crevice corrosion. In fact, no localized corrosion was observed in alloys of this type in these experiments. Alloys with high Mo-to-Cr ratios (Mo > $15 \mathrm{wt} . \%, \mathrm{Cr}$ $<5 \mathrm{wt} . \%$ ) are spontaneously passive under free corrosion conditions. With anodic polarization, passivity quickly breaks down in two steps, perhaps because of crevice corrosion and pitting onset. A black, nonprotective, Mo-rich film is observed on the sample surface at the conclusion of the experiment. Alloys richer in $\mathrm{Cr}$ and Mo than Alloy 22 in the $\mathrm{Cr}$, Mo-rich sequence are susceptible to crevice corrosion, but have not shown evidence of pitting. Beyond this observation, these alloys have not demonstrated regular trends in their corrosion behavior because they are two-phase. Figure 2 summarizes results collected to date on film formation and localized corrosion tendencies as a function of alloy composition.

The intent of this study is to reveal essential relationships between alloy composition and electrochemical behavior that affect localized corrosion-damage accumulation in the $\mathrm{Ni}-\mathrm{Cr}-\mathrm{Mo}$ alloy system. The data show where critical areas for detailed mechanistic study of localized corrosion phenomena should be focused and can provide important fundamental information for those pursuing mechanistic and phenomenological modeling of localized corrosion. 


\title{
Prediction of the Time Evolution of Localized Corrosion Damage
}

\author{
Digby D. Macdonald, Shaofeng Yang, and George R. Engelhardt (Consultant)
}

Pennsylvania State University

\section{Research Objectives}

The purpose of this project is to identify the crucial electrochemical processes and parameters affecting localized corrosion; to use basic theories to build models for calculating these parameters; to use electrochemical measurements to substantiate and improve the corrosion models; and eventually to predict the service life of metal waste packages from a limited number of measurements carried out over laboratory time.

\section{Approach}

Both theoretical and experimental activities are under way to address the objectives of this project. A Point Defect Model (PDM) has been expanded to quantify the impact of species in the environment on passivity breakdown and the accumulation of pitting damage. This is done on the basis of competitive adsorption of deleterious species, such as $\mathrm{Cl}^{-}$, and inhibitors, like $\mathrm{NO}_{3}{ }^{-}$into surface oxygen vacancies. The inhibitors act by blocking the extraction of cations, and hence the production of surface cation vacancies, by the aggressive anion. The modified PDM has been inserted into Damage Function Analysis (DFA) for predicting the accumulation of localized corrosion damage caused by pitting corrosion. Predicted damage functions for Alloy 22 in saturated $\mathrm{NaCl}$ solution $(6.2 \mathrm{~m})$ at $\mathrm{pH}=7$ and $\mathrm{T}=100^{\circ} \mathrm{C}$ for $1,000,5,000$, and 10,000 years for three different delayed repassivation constants are shown in Figure 1 (Macdonald et al., 2001). Significant progress in developing models for predicting prompt and delayed repassivation kinetics has been made. Prompt repassivation kinetics determines the probability of metastable pits transitioning into stable pits, while delayed repassivation kinetics determines the extent to which damage may accrue. A crucial parameter is the delayed repassivation rate constant, $\gamma$; the greater the value of $\gamma$, the lower the total amount of damage, because only living pits can contribute to the accumulation of damage.

Figure I. Predicted damage functions for Alloy 22 after I,000, 5,000, and 10,000 years of exposure to saturated brine $\left(\mathrm{a}_{\mathrm{Cl}}=6.2\right)$ at $\mathrm{pH}=7.0$ and $\mathrm{T}=100^{\circ} \mathrm{C}$, as a function of the delayed repassivation constant, $\gamma$. The corrosion current density is $0.1 \mu \mathrm{A} / \mathrm{cm}^{2}$, and total possible number of stable pits was assumed to be $5,000 / \mathrm{cm}^{2}$. Note that the initial impact of increasing $\gamma$ is to change the shape of the damage function, such that deeper pits become less favored, but at sufficiently high $\gamma$, no pit extends beyond the first depth increment.
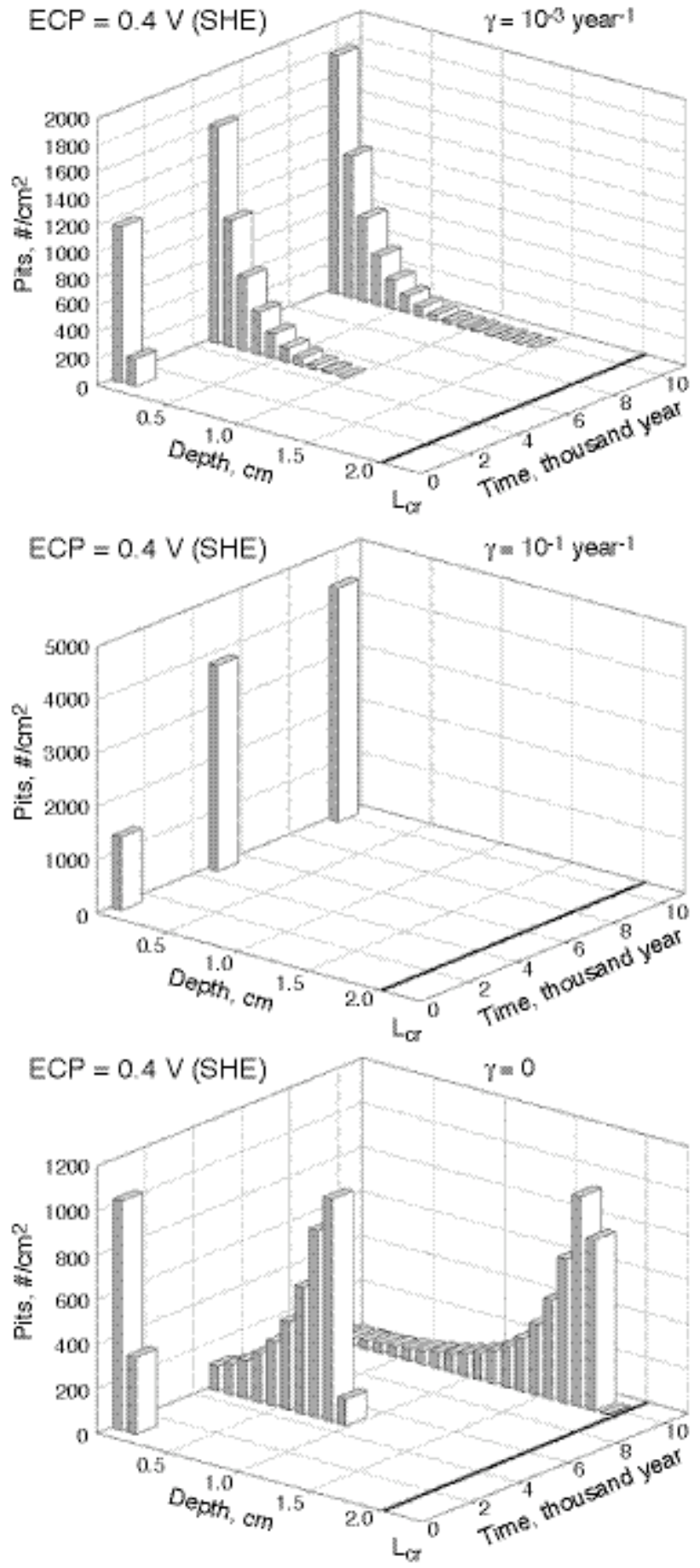
The PDM has now been developed to the extent that the damage can be accurately predicted, provided that the value of the delayed repassivation constant, $\gamma$, is known. Figure 1 demonstrates that $\gamma$ has a huge impact on the development of damage and that an effective localized corrosion-control strategy might be to modify the alloy or the environment, to increase the value of $\gamma$.

Stainless steel alloy 316 is used in our initial experiments to examine dependencies for a less corrosion-resistant alloy. The treatment is then extended to account for the greater corrosion resistance or the more corrosion-resistant nickel-chromium-molybdenum alloy.

The critical breakdown potential, $\mathrm{V}_{\mathrm{C}}$, has been measured for 316 stainless steel as a function of voltage sweep rate (v), $\left[\mathrm{Cl}^{-}\right]$, and $\mathrm{pH}$. A linear relation between $\mathrm{V}_{\mathrm{C}}$ and $v^{1 / 2}$, as predicted by the PDM, is observed, and the slope yields a concentration of condensed vacancies at the metal/film interface that is in excellent agreement with predictions from the geometry of the interface. Finally, pitting in the presence of $\mathrm{NO}_{3}{ }^{-}$has been systematically studied. The influence of $\mathrm{NO}_{3}-$ on $\mathrm{V}_{\mathrm{C}}$ is in agreement with the PDM as modified for competitive adsorption. Thus, the PDM predicts a linear relationship between $\mathrm{V}_{\mathrm{C}}$ and $\log \left[\mathrm{Cl}^{-}\right]$with the slope being independent of $\mathrm{NO}_{3}{ }^{-}$. Although the shift of $\mathrm{V}_{\mathrm{C}}$ in the positive direction is quite modest (only a few tens of $\mathrm{mV}$ ), $\mathrm{V}_{\mathrm{C}}$ appears in an exponential in the induction time expression from the PDM. This results in a much longer induction time for passivity breakdown.

\section{Accomplishments}

1. Extended the PDM to account for the inhibition of passivity breakdown by oxy-anions, such as $\mathrm{NO}_{3}{ }^{-}$.

2. Experimentally quantified nitrate inhibition of passivity breakdown on 316 stainless steel and showed that the predictions of the PDM are in accord with the experimental findings.

3. Extended DFA for the prediction of localized (pitting) corrosion damage in prototypical high-level nuclear waste environments.

4. Developed the theory for delayed repassivation in terms of pit-pit interaction.

We now have a formal theoretical basis for the beneficial effect of the presence of nitrate ion in the proposed repository environment, with regard to passivity breakdown and the accumulation of pitting corrosion damage.

Experiments have shown that the PDM provides an accurate description of passivity breakdown. The scan-rate dependence of the breakdown voltage, which yields the critical concentration of condensed cation vacancies, is in excellent agreement with that calculated from geometric arguments. The theory for delayed repassivation has been essentially completed.

\section{References}

Macdonald, D.D., G.R. Engelhardt, P. Jayaweera, N. Priyantha, and A. Davydov, The deterministic prediction of localized corrosion damage to Alloy 22 HLNW canisters. Proceedings of the International Workshop on Predicted Long Term Corrosion Behavior in Nuclear Waste Systems (Commissariat a l'Energie Atomique and Pennsylvania State University), pp. 103-117, Cadarache, France, Nov. 26-29, 2001. 


\section{Data Mining of Experimental Localized Corrosion Data}

Mirna Urquidi-Macdonald and Kamrun Nahar

Pennsylvania State University

\section{Research Objectives}

The objective is the mining of existing experimental corrosion databases on metals/alloys, including Alloy 22. Data mining allows the extraction of knowledge from historical data and prediction of outcomes of future situations by finding relationships and patterns existing in data. Our objective is to establish the conditions under which certain parameter sets (e.g., $\mathrm{pH}$, temperature, time of exposure, electrolyte composition, metal composition, metallographic characteristics) greatly impact the alloy's electrochemical potentials and corrosion rates (e.g., pitting, crack, and crevice growth rates). As part of this project, we will demonstrate the predictive capabilities of data mining by using data available for alloy materials to predict their performance and compare our predictions to the prediction of the Point Defect Model.

\section{Approach}

The approach involves: (1) data reprocessing that includes data filtering (for bias information), data transformation (to accentuate certain data features), and data normalization (to give all variables the same order of importance); (2) representation of the data in multiple ways to look for different types of clusters; (3) cluster hierarchy and cluster analysis using self-organizing maps (SOM) and self-organizing tree algorithm (SOTA) techniques. We are establishing a methodology for data representation and analysis that can be used as a complementary tool in the laboratory to avoid the costly, time-consuming capture of additional data.

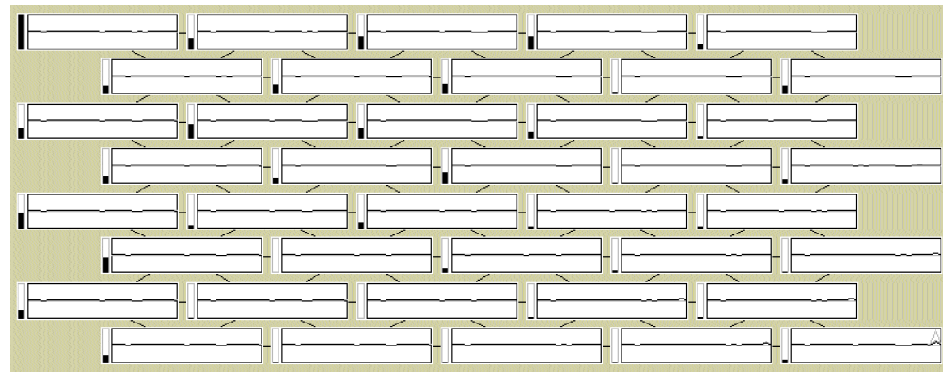

Figure I. A five-by- eight cell Kohonen-map for 766 samples of Ni-alloy. Each cell contains a bar to the left and a block containing a 2-D plot. Each pattern corresponds to a vector of 29 parameters of metal/environment, duration of experiment, and corrosion damage.

\section{Accomplishments}

We performed cluster analysis of nickel (Ni) alloys and carbon and alloy steel data obtained from the National Institute of Standards and Technology (NIST) (Trim et al., 1988; Sturrock and Bogaerts, 1997) in different environments and temperatures, to develop patterns in the data with respect to general corrosion rate and to predict the evolution of corrosion properties of an alloy as a function of material composition, time, and operating environment (e.g., evolution can go from a "high" corrosion rate cluster to a "low" corrosion rate cluster). We transformed the alloy/environment data into input vectors of size 29 that contain alloy composition, electrolyte environment (assigned as an arbitrary number), temperature, duration of the experiment, logarithm of duration, rate of corrosion, and the logarithm of the rate. A 2-D Kohonen map and the corresponding SOTA tree for 766 samples of Ni-alloy, generated using a publicly available program in BioInformatics (http://gepas.bioinfo.cnio.es), are shown in Figures 1 and 2, respectively. Each cell can be occupied by similar input vectors containing the information of metal alloys, environment, and corrosion rate. The SOTA of depth 7 in Figure 2 allows us to visualize and categorize the whole data set in two main families, i.e., of high corrosion rate and low corrosion rate, and several subfamilies with medium rates. Based on the knowledge of the environment-evolution at the proposed Yucca Mountain repository, the corrosion rates of Alloy 22 with time can be predicted using the trained Kohonen map.

Historical data on alloy composition and different environments helped to create 2-D Kohonen maps, where clusters representing a given alloy/environment can be indicated as a point on the map. The vectors have size 29 , and they cluster on the map by "similarities"; clusters represent alloys/environments with "high" to "low" corrosion rates. This type of study can be performed with as many data points as are available. Then, the specific environment of interest can be tested, and its location on the map will indicate the corrosion rate corresponding to the given environment. Evolutionary path on the Kohonen maps from "low" to "medium" corrosion rates (or others) can be 
used to predict corrosion behavior into the far future of the alloy of interest for changing environments.

\section{References}

Sturrock, C.P., and W.F. Bogaerts, Classification and prediction of the corrosion behavior of nickel-containing alloys from field test data, ASTM STP 1311, Computerization and Networking of Materials Databases, Fifth Volume; Tsukuba; Japan, pp. 144-157, 1995. 1997 ASTM, 100 Barr Harbor Drive, West Conshohocken, PA 19428-2959, 1997.

Trim, J.D., D.B. Anderson, and G.J. Laverty, The NACE NBS Corrosion Data Program. Key Eng. Mater., 20-28 (2), 1781-1784, 1988; 10th International Congress on Metallic Corrosion. Vol. II, Madras, India, 1987.
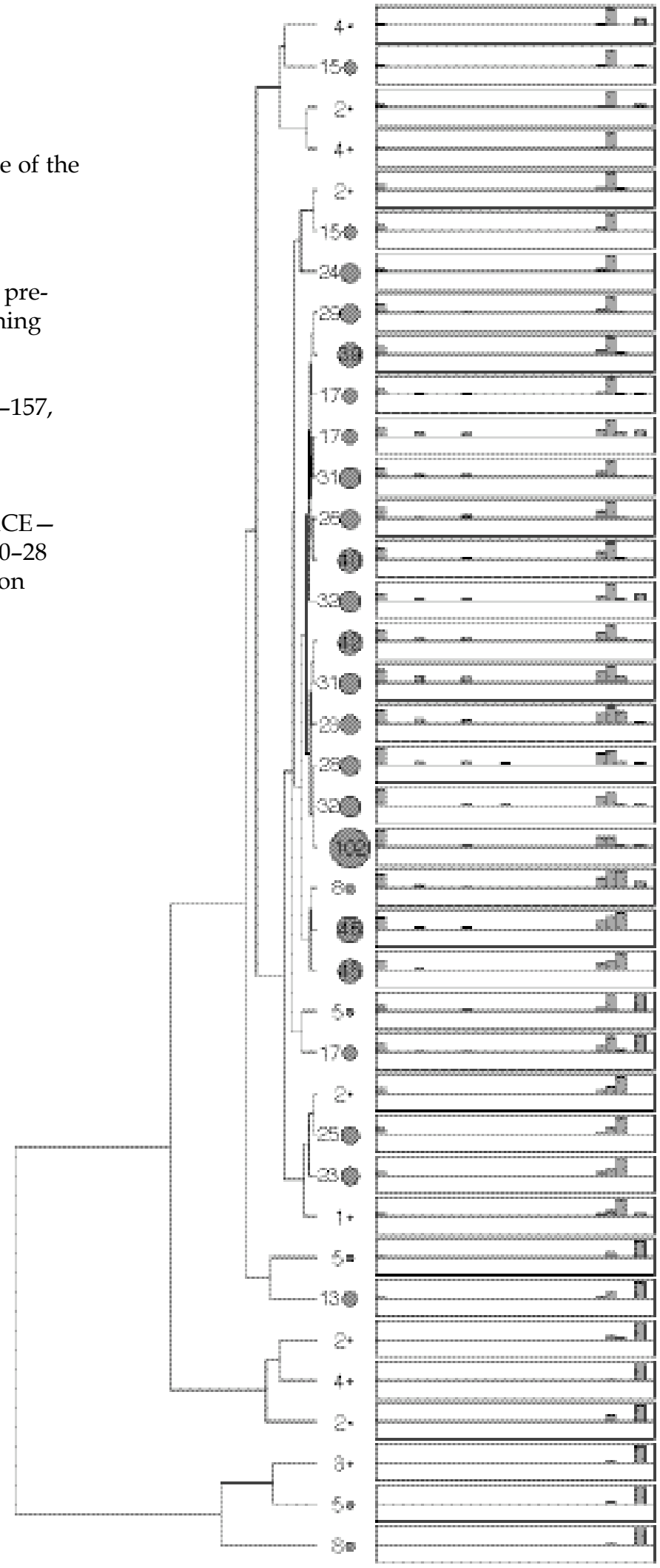


\section{EVOLUTION OF MOISTURE ENVIRONMENT ON METAL SURFACES}

Overview

Thin Solution Layer Properties and Their Effect on Corrosion Robert G. Kelly, University of Virginia

Modeling and Measurement of Current Distribution in Particulate and Deposited Layers

Uziel Landau and Joe H. Payer, Case Western Reserve University

Microelectronic and MEMS Devices for Solution Properties and Corrosion Evaluations

C.C. Liu and Joe H. Payer, Case Western Reserve University

Optical Probes and Sensors to Determine Concentration Distributions in Thin Films on Reactive Surfaces

William H. Smyrl, University of Minnesota

High-Temperature, Multi-Species Solution Properties and Behavior David R. Cole, Donald Palmer, Lawrence N. Anovitz, Pascale Bénézeth, Miroslaw S. Gruszkiewicz, Lee R. Riciputi, and David J. Wesolowski, Oak Ridge National Laboratory (ORNL); George Engelhardt. OLI Systems; and Digby D. Macdonald, Pennsylvania State University

Coupling Thermal-Hydrological-Chemical Models to Process Models on Waste Packages

N. Spycher, G. Zhang, C. Steefel, E. Sonnenthal, and Z. Zhang, Lawrence Berkeley National Laboratory

Integration of Materials Performance Process Models with Those in the Natural Barriers and Source Term Thrusts

Bo Bodvarsson, Lawrence Berkeley National Laboratory; and Mark Peters, Argonne National Laboratory 
This page intentionally left blank. 


\section{Evolution of Moisture Environment}

\section{on Metal Surfaces}

\section{OVERVIEW}

The corrosion performance of a metal is determined by the inherent corrosion resistance of the metal and the corrosivity of the environment to which the metal is exposed. The amount, distribution, and chemical composition of the moisture on waste packages are important. The objective of this multi-investigator effort is to determine the properties of thin layers of moisture, moist particulates, and deposits that will affect the corrosion performance of metals. Advanced analytical and computational methods for the evolution of the environment on metal surfaces are developed. Scientific understanding is enhanced for moisture formation, chemistry, and evolution with time and for the properties of thin layers of particulates and deposits on metal surfaces.

Targeted thrust objective: Develop and demonstrate evolu tion of the environment (moisture) on the waste package surface and other engineered components. Current model addresses dust/moisture and corrosion, but in a limited way based on lim ited understanding. This work is designed to enhance that understanding and allow more realism in the modeling.

Key issues for corrosion behavior and long-term performance are determination of the presence of moisture on metal surfaces, the corrosive properties of the moisture, and the corrosion resistance of materials in these environments. Thin layers of electrolyte, particulates, and deposits are the conditions of interest for the analysis of corrosion of waste packages. A special feature of the proposed Yucca Mountain repository is the extremely long time frame of interest. Thus, the time evolution of the environment in contact with waste package surfaces, and the time evolution of corrosion damage that may result, are of primary interest in determining expected performance.

In the proposed repository, moisture can form on the metal surfaces by deliquescence and condensation processes as the waste packages cool from high temperatures after the heat-up period. A thermal barrier prevents drips and seepage into the drifts as long as the drift wall is hotter than the boiling point of water. After the thermal barrier period, an additional source of moisture on the metal surfaces is drips or seepage from the rock formation onto waste packages.

It is well accepted that dry metals, without the presence of an aqueous phase, do not corrode at an appreciable rate.
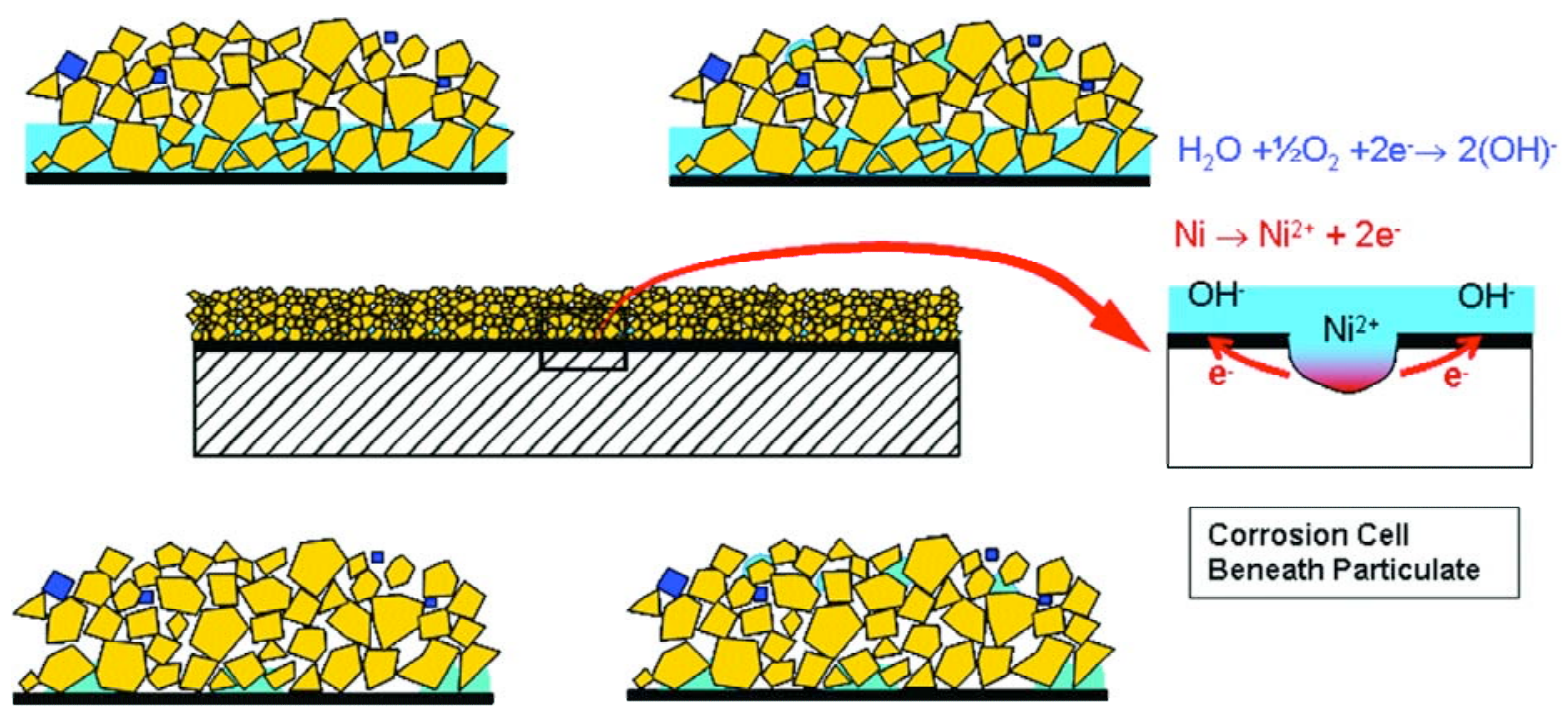

$\mathrm{Ni} \rightarrow \mathrm{Ni}^{2+}+2 \mathrm{e}^{-}$
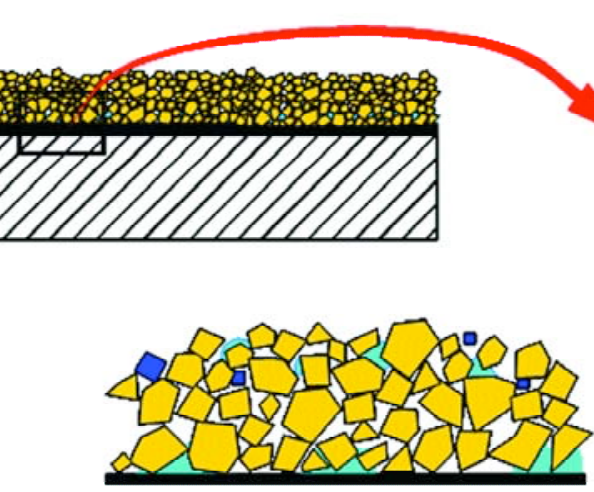

Corrosion Cell

Beneath Particulate

Figure I. Several scenarios for the distribution of moisture within a layer of particulate are illustrated. 
Furthermore, full immersion in waters will not occur under any realistic scenario. Therefore, corrosion in thin layers of electrolyte, particulate, and deposits are the conditions of interest. These thin layers with their associated moisture provide a potentially significant aqueous environment to support electrochemical dissolution. Anodes, cathodes, and the electrochemical corrosion cell can operate in a thin moisture layer. However, the factors that determine the onset of corrosion and the subsequent degree of damage can vary significantly in thin layers compared to fully immersed conditions.

The approach is to meet the objective through a coordinated set of projects. Figure 1 shows several scenarios for the distribution of moisture within a layer of particulates.

\section{Technical Milestones: Evolution of moisture} environment on metal surfaces

- Initiate a coordinated experimental and computational effort to examine corrosion current distributions in moist particulate layers on metal surfaces.

- Organize a multi-investigator team for the properties and behavior of high-temperature, multispecies solutions.

- Combine expertise and specialized facilities in geochemistry, corrosion, electrochemistry, and materials science.

- Establish a framework and process for incorporation of findings into advanced methods for the Prediction of Time Evolution of Localized Corrosion Damage.

- Develop and apply advanced analytical methods and sensors to determine the properties of layers of moisture and particulate on metal surfaces. 


\section{Thin Solution Layer Properties and Their Effect on Corrosion}

R. G. Kelly, F. Cui, and F. Preseul-Moreno

University of Virginia

\section{Research Objectives}

The goal of this study was to investigate the ability of a wetted metal surface of limited area to support an active localized corrosion site via the production of cathodic current. Studies of cathodic control of localized corrosionresistant alloys are sparse, and studies considering thin electrolyte layers are nonexistent. Quantification of the total current that a wetted surface could deliver under a given set of conditions provides a scientific basis for analyses of both the maximum rate and the stability of localized corrosion. These results will be coupled with complementary calculations of the requirements of localized corrosion sites for current to remain stable.

\section{Approach}

The potential and current distributions on wetted metal surfaces were computationally modeled, considering the effects of relevant kinetic and physiochemical parameters such as water layer thickness, solution conductivity, and electrochemical kinetics. The finite-element-based model used (Figure 1) was specifically designed for solution layers of

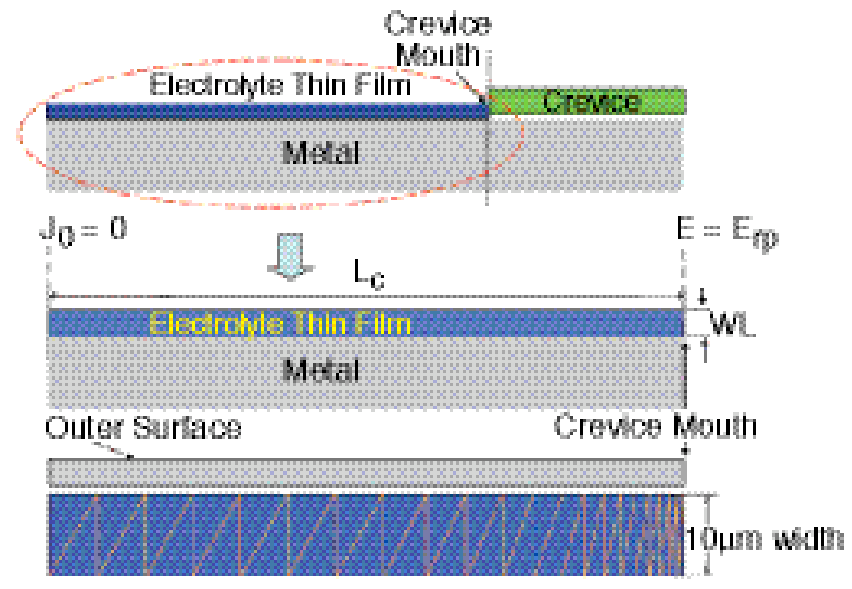

Figure I. Schematic of the system modeled: (a) a typical crevice-corrosion system for atmospheric exposure; (b) the separated cathode modeled, where WL is water layer thickness and Lc is the length of the cathode. It is assumed that the flux at the end of the cathode was $0\left(J_{o}=0\right)$; (c) mesh used to represent the cathode surface.

restricted geometry. The scoping calculations considered stainless steel alloy 316L, because of the substantial database on electrochemical kinetics available on this metal. The parameters of interest were water layer thickness, solution conductivity (coupled to solution composition), electrode kinetics, and size of cathode. The relative impact of these variables, as well as any synergistic interactions over the reasonable range of values, was determined by applying a factorial design to the computational modeling matrix.

\section{Accomplishments}

The matrix of calculations demonstrated that all three main parameters of interest, water layer thickness, cathode size, and solution conductivity, have significant impact on the total cathodic current that can be sustained by a wetted surface. In addition, two-way interactions were found to be significant. The strongest factor was the size of the cathode, with the water layer thickness being less important than either the solution conductivity or the interaction terms involving cathode size and solution conductivity. Figure 2 shows a saturation of the total cathodic current that was observed as the cathode size increased. Linear regression had a limited ability to capture the computation results, demonstrating that traditional, simple scaling laws cannot be applied to predicting the stability of localized corrosion in thin electrolyte films.

The distributed resistance between a localized corrosion site and positions on the wetted cathode, and the nonlinear interfacial kinetics, make accurate estimates of the effects of important variables on current output ability (using simple Mixed Potential Theory or nondimensionalized methods) only qualitative at best. Numerical modeling has shown the importance of several physical parameters on the total net cathodic current $\mathrm{I}_{\text {net }}$ that a wetted cathode can supply. In addition, linear regression approaches to the model results only give a fair representation of the effects of these variables, implying that more subtle interactions are involved. The three most important variables for current output are the size of the cathode, the solution conductivity, and the interaction of these two variables. Note that the three most important effects do not involve the thickness of the electrolyte layer on the surface; this is a nonintuitive observation. The observation 
of a saturation of current output with increasing cathode size has important implications for the design of relevant experiments, as well as for the long-term stability of localized corrosion sites. The modeling described here can be used to guide experimental systems for the study of localized corrosion under atmospheric exposure, so they are not unintentionally influenced by the size of the cathode. In terms of long-term stability of localized corrosion sites under such conditions, the modeling here provides limits on the combination of site size and intensity that can be supported by a cathode.

\section{Related Publication}

Cui, F., F.J. Preseul-Moreno, and R.G. Kelly, Effects of cathodic kinetics on the stability of localized corrosion in thin electrolyte films. Corrosion Science (in press), May, 2005 (invited).

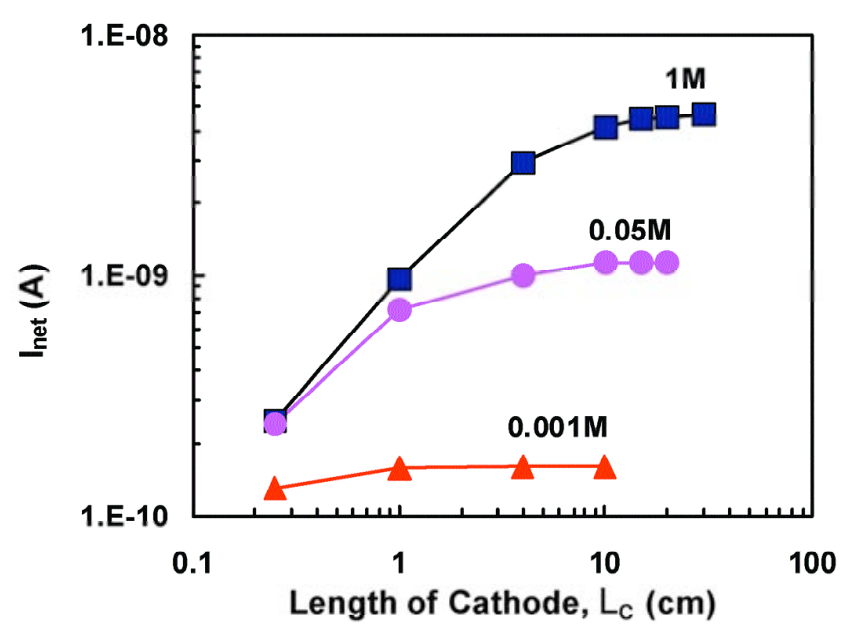

Figure 2. Total net cathodic current $\mathrm{I}_{\text {net }}$ saturates as the length of the cathode increased to a critical value. The length of cathode at which saturation occurs depends highly on conductivity $\left(\mathrm{Cl}^{-}\right)$. 


\section{Modeling and Measurement of Current Distribution in Particulate and Deposited Layers}

Uziel Landau, Arun Agarwal, Xi Shan, and Joe H. Payer

Case Western Reserve University

\section{Research Objectives}

The objective is to model and measure the current flow patterns and distribution in thin layers of moisture and layers of moist particulates and deposits on metal surfaces. Of particular interest is the flow of current representative of corrosion scenarios at the metal surface: pitting, crevice corrosion, stress corrosion cracking, and galvanic action. Layer thicknesses range from monolayer coverage to thicker particulate layers. Results provide important inputs to determining the extent of cathodic stifling of corrosion processes.

\section{Approach}

The project examines geometric effects, saturated and unsaturated particulate layers, chemical composition of moisture and particulates, temperature, and relative humidity. Modeling and experiments are closely coupled to determine current flow and potential distribution. The experiments provide direct measurements and a basis for model validation. The model treatment starts with macroscopic, bulk properties of the moisture layers and then moves to consideration of microscopic effects of particulate and heterogeneous distribution of moisture. A number of multiple-electrode, segmented cells and sensing probes are used in the experiments.

\section{Accomplishments}

An initial parametric study on the effect of moisture-layer macroscopic properties was completed. Quantitative limitations on the cathode current capacity were determined

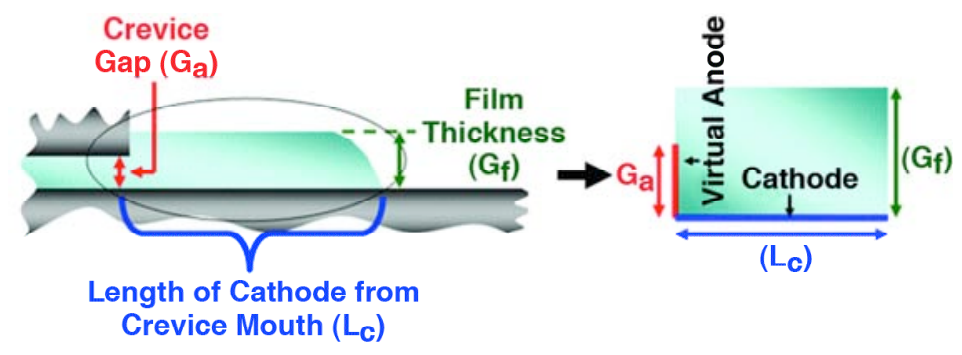

Figure I. Model of macro-scale (2-D) parameters on current distribution: (a) schematic diagram of the crevice and electrolyte film; (b) the decoupled, cathodic region in the model for conductivity, cathode length, layer thickness, and crevice gap, spatial variation of $\mathrm{pH}$, mass transport of oxygen, oxygen reduction kinetics, and particulates. In addition to the geometric and bulk conductivity effects, the cathode capacity is quite sensitive to the oxygen-reduction kinetics on the passive metal. A decoupled cathode model is employed to simulate the current and potential distributions on the cathode with respect to a virtual anode maintained at the crevice gap, as shown in Figure 1.

Microscopic effects of particulate in the moisture layer are being examined to include 3-D effects of fine particles and microcurrent distributions. Figure 2 shows a 3-D simulation result obtained for a uniform distribution of cubic particles on a cathode surface of 90 microns in length. Arrows indicate the direction of the current, and the length is proportional to the magnitude of the current. The effects of volume fraction, surface coverage, and particle size and shape are determined. An analysis is under way to develop scaling factors and to determine the relative effects of volume (ohmic) and surface (interfacial kinetics) properties.

Current distributions were measured using a multi-plate, segmented cell, and the results correlate well with the analytical calculations. An isolated electrode cell is being fabricated for further measurements in these solution layers.

The corrosion performance of a metal is determined by the inherent corrosion resistance of the metal and the corrosivity of the environment. One overall objective is to determine the properties of thin layers of moisture, moist particulates, and deposits that will affect corrosion. This work determines the conditions under which corrosion is limited or stopped completely, because of constraints on the cathodic currents necessary to support localized corrosion. 


\section{References}

Agarwal, A.S., U. Landau, and J.H. Payer, Modeling of cathode current capacity to sustain localized crevice corrosion. To be submitted.

Agarwal, A.S., U. Landau, X. Shan, and J.H. Payer, Modeling the cathodic region in crevice corrosion under a thin electrolyte film including particulates. Abstract for 208th Electrochemical Society Meeting, October 16, 2005.

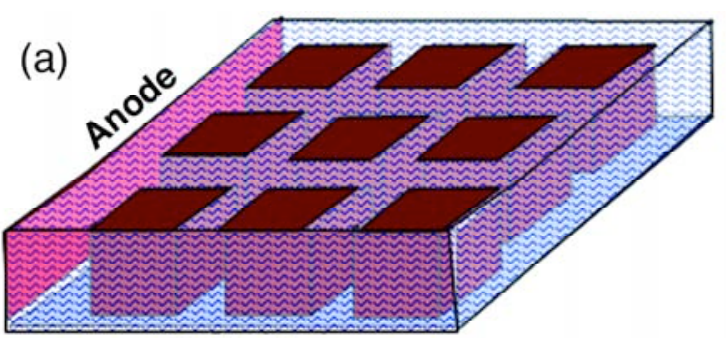

Cathode
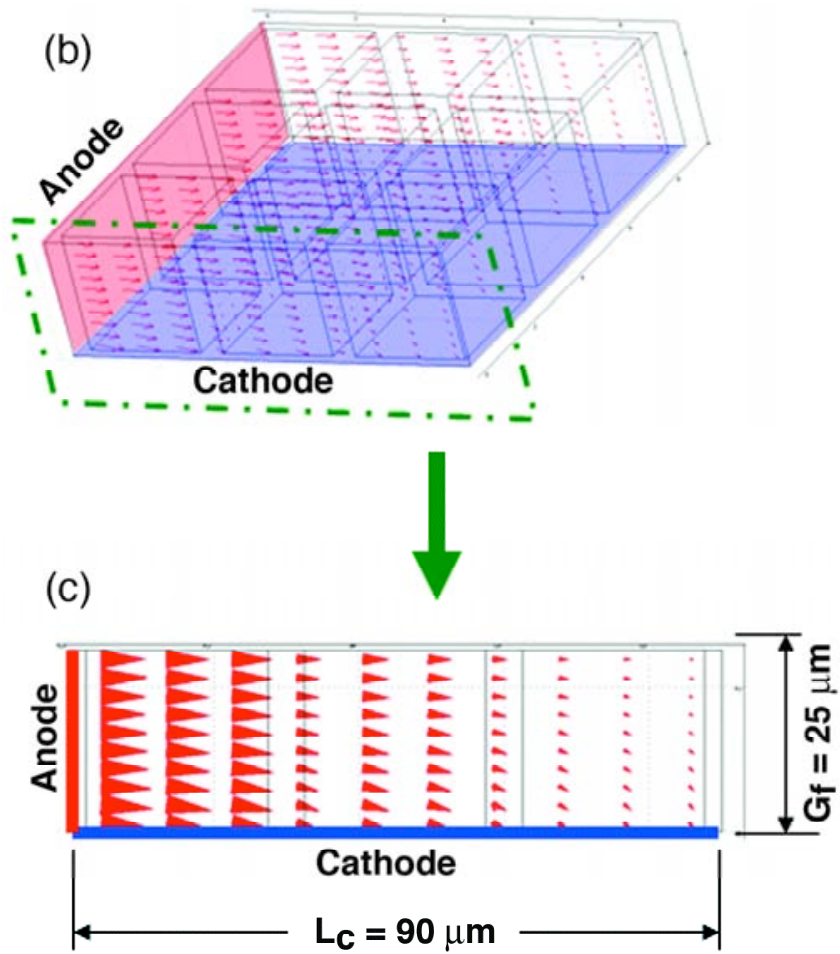

Figure 2. Macro-scale (3-D) simulation results for the particulate model for specific simulation factors below: (a) schematic diagram of the cathode with uniform particle distribution; (b) arrows indicating direction and magnitude of current flow; and, (c) 2-D projection of current distribution. Simulation parameters used: io $=10^{-9} \mathrm{~A} / \mathrm{cm}^{2}, \mathrm{k}=1.21 \mathrm{mS} / \mathrm{cm}, \mathrm{EO}, \mathrm{C}=0.19 \mathrm{~V}_{\mathrm{NHE}}, \mathrm{ERP}=-0.31 \mathrm{~V}_{\mathrm{NHE}}$, $\mathrm{LC}=0.009 \mathrm{~cm}, \mathrm{G}_{\mathrm{f}}=25 \mu \mathrm{m}$. NHE is normal hydrogen electrode. 


\section{Microelectronic and MEMS Devices for Solution Properties and Corrosion Evaluations}

Chung-Chiun Liu, Joe H. Payer, Jinsong Yu, and Laurie Dudik

Case Western Reserve University

\section{Research Objectives}

The objective is to design, fabricate, and apply sensors to measure important environmental parameters that affect corrosion of metals covered by thin layers of electrolyte and layers of particulate or deposits. The sensor measurements include temperature, solution conductivity, $\mathrm{pH}$, and oxidizing potential. Data from these sensors will supplement the information from electrochemical tests. The sensors will be used individually and in multisensor arrays.

\section{Approach}

Individual microsensors for solution conductivity, $\mathrm{pH}$, oxidizing potential, and oxygen concentration are developed and demonstrated for use with simulated or real corrosion cells. The operational principles of these microsensors are electrochemical, and the fabrication processes of these microsensors employ silicon-based microfabrication techniques. This includes both thin and thick film metallization processes, photo-lithographic reduction, photo-resist patterning, and chemical etching, as well as screen printing techniques.

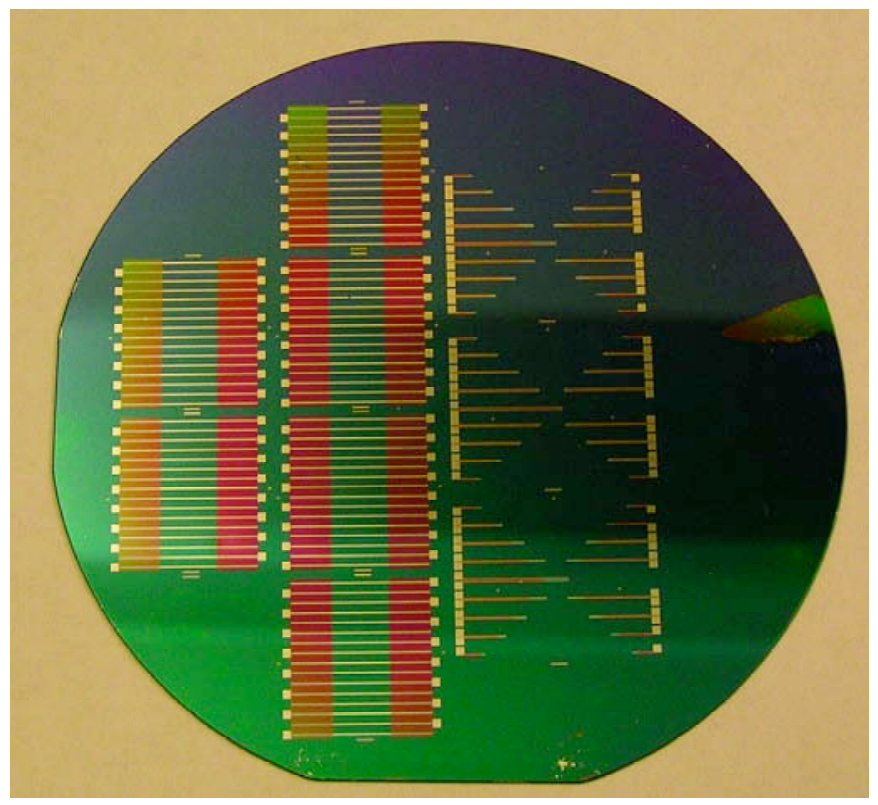

The sensing procedures are designed to avoid and minimize influences of the corrosion crevice solutions.

Measurements with the $\mathrm{pH}$ and oxidizing potential sensors do not influence the solutions. High-frequency (1000 $\mathrm{Hz}$ ) alternating current is used for conductivity measurements to avoid changing the solution. Oxygen measurements use small electrodes and are done rapidly.

\section{Accomplishments}

The four types of microsensors have been successfully fabricated. This includes the design, the fabrication of the masks, the metallization processing, and the patterning steps for both the thin and thick film processes.

For the conductivity sensors, silicon is used as the substrate, and thin film metallization processing is used in the fabrication of the sensors. Figure 1 shows a group of conductivity sensors fabricated on a silicon wafer. Sensors with different gap sizes and exposed sensor lengths are fabricated. Table 1 shows the sensor dimensions. The oxygen sensor has a three-electrode configuration: working, counter, and reference electrodes. Both the working and the counter electrodes are platinum, with the reference electrode $\mathrm{Ag} / \mathrm{AgCl}$. A thick film metallization process is used in the fabrication of this sensor. The platinum and reference electrode of this sensor are used to measure oxidizing potential. The solid state $\mathrm{pH}$ sensor employs a metal-metal oxide electrode. In this study, Pd-PdO is used along with a silversilver chloride reference electrode. Thick film processes are used to produce the sensor prototypes.

The thin film conductivity sensor employs a two-electrode

Table I. Sensor dimensions over a range of lengths Conductivity Sensor

Gap between electrodes $(\mu \mathrm{m}) \quad 30,50,100$

Electrode width $(\mu \mathrm{m}) \quad 100$

Tip width $(\mu \mathrm{m})$

2,000 $250,500,1,000,1,500$,

Electrode length $(\mu \mathrm{m})$

17,490 (left) 17,470 (right)

Figure I. Conductivity sensors fabricated on a silicon wafer 


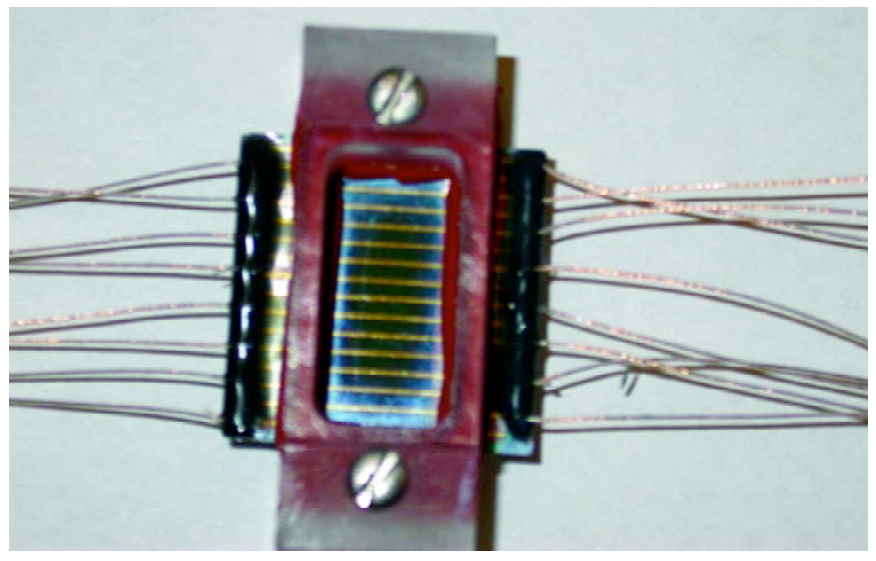

Figure 2. A diced and wired conductivity sensor mounted in a test fixture

structure and an AC impedance method to measure conductivity/resistivity. As shown in Figure 2, the sensor is mounted in a test fixture and covered with a thin layer of electrolyte and particulate. Sensor dimensions were varied to assess the conductivity over a range of lengths, as shown in Table 1.

The conductivity sensor was evaluated for particulate layers comprised of 3-micron $\mathrm{Al}_{2} \mathrm{O}_{3}$ particulate saturated with $\mathrm{NaCl}$ solutions. Measurements were made by an $\mathrm{AC}$ impedance technique. Illustrative results are shown in Figure 3.

Testing chambers for these sensors for the evaluation of solution properties are designed and constructed to provide a controlled environment for evaluation of the microsensors. Both potentiometric and chrono-amperometric measurement techniques are used in this study. Oxygen sensors of three different sensing-element gap sizes are

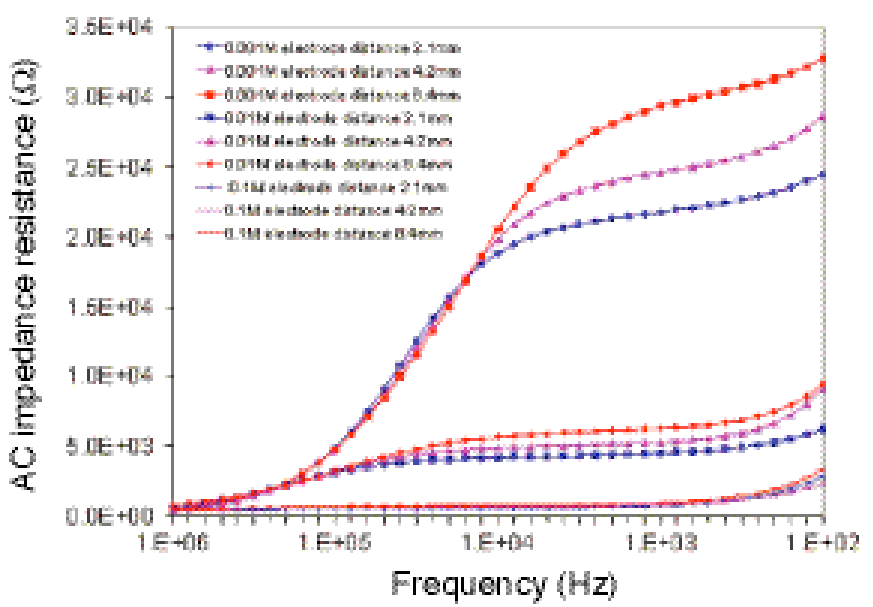

Figure 3. Solution resistance measurements for an $8 \mathrm{~mm}$ thick layer comprised of $3 \mu \mathrm{m} \mathrm{Al} \mathrm{O}_{3}$ particulate saturated with $\mathrm{NaCl}$ of $0.001 \mathrm{M}, 0.0 \mathrm{I} \mathrm{M}$, and $0.1 \mathrm{M}$ concentrations. AC impedance measurements were made over a broad frequency range. Frequency on the order of $1,000 \mathrm{~Hz}$ is useful for the resistance / conductivity measurements.

used. For the solid state $\mathrm{pH}$ sensors, two sizes of the threeelectrode configurations are fabricated. Preliminary evaluations of these sensors within the testing chambers have been carried out, and the sensors have performed well.

Sensors to measure important solution layer properties are powerful tools for generating a database of properties needed in the models for current distributions and corrosion behavior in particulate layers. The sensors developed will be provided to other projects within the OST\&I Materials Performance Thrust for monitoring the particulate layer during corrosion tests. 


\section{Optical Probes and Sensors to Determine Concentration Distributions in Thin Films on Reactive Surfaces}

William H. Smyrl

University of Minnesota

\section{Research Objectives}

This research is intended to reveal the reaction distributions on heterogeneous, reactive metal surfaces. Our previous work has revealed the current/potential distributions on galvanically coupled surfaces, including those under thin films of electrolytes. Fluorescent dyes were used to explore the chemistry and distribution of reaction products on and near reactive inclusions. Our goal is to design fluorescent multiprobe sensors capable of monitoring $\mathrm{pH}$, oxygen partial pressure, specific metal ions, and temperature at and near reactive (corroding) surfaces.

\section{Approach}

Fluorescence techniques are powerful tools to measure physico-chemical conditions $(\mathrm{pH}$, gas concentration) and analyte species in situ. We have adapted some of these methods to monitor localized corrosion on aluminum alloys with a submicrometric spatial resolution.

Fluorescent probe techniques are emphasized for mapping and chemical characterization in the laboratory and in the field. These studies will utilize films, patches, derivatized optical fibers, and nanospheres. Films and derivatized optical fibers results are described here.

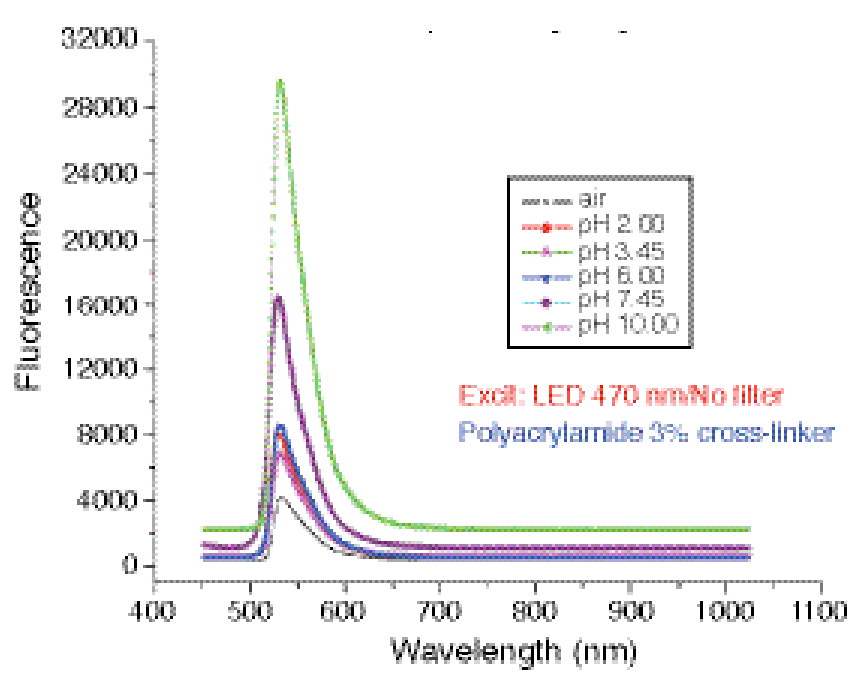

Figure I. Fluorescence intensity versus $\mathrm{pH}$ for a derivatized optical fiber (DOF) immersed in solution

\section{Accomplishments}

\section{Optical Fiber Sensors for pH Monitoring and Measurement}

Because of their very small size, fiber optic $\mathrm{pH}$ sensors are very attractive for measurements in thin films of electrolytes on a metal surface. Since only optical measurements are used for the sensors, this eliminates any electrical noise problems that can plague miniature electrochemical sensors in the field. Our $\mathrm{pH}$ sensor is based on fluorescein immobilized in photo-polymerized acrylamide gel. The useful $\mathrm{pH}$ range of fluorescein is between 4.5 and 8 . The photo-polymerization procedure allows precise deposition of the host polymer at the distal end of the fiber only. The objective is a fiber optic $\mathrm{pH}$ sensor with no dye leakage and stable collecting properties.

The fabrication process consists of several steps: (1) fiber cleaving, (2) cleaning, (3) silanizing, (4) drying, and (5) photo-polymerization of acrylamide gel with fluorescein incorporated. We have confirmed that the process is reproducible, the polymer host is attached only to the end of the optical fiber, and the attachment is quite robust. In this way, a derivatized optical fiber (DOF) is fabricated for $\mathrm{pH}$

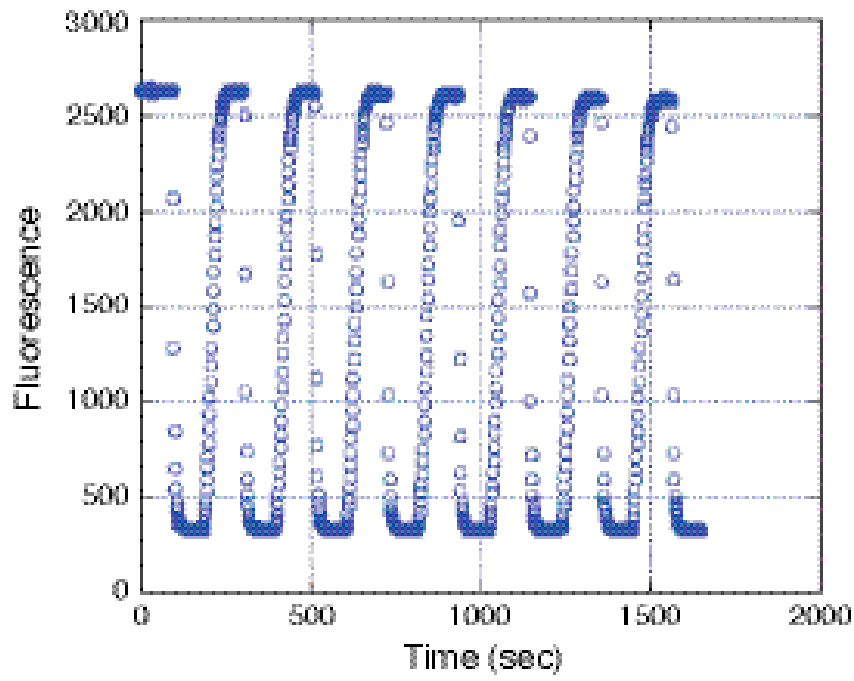

Figure 2. Fluorescence observed from a PDMS film (molecular doped with $\mathrm{Ru}(\mathrm{Phen})$ ) cycled between 100\% nitrogen (high) and 100\% oxygen (low) 
sensing. Results generated with multimode fibers in preliminary testing have been favored because of the ease of manipulation. The smaller single mode fibers will be used in future measurements in thin films because of their small size. Figure 1 shows the fluorescence intensity versus $\mathrm{pH}$ for a DOF immersed in solution. A $470 \mathrm{~nm}$ Panasonic blue light emitting diode was used as excitation source. The sensor response time was not measured, but appeared to be extremely fast $(<1$ second).

\section{Oxygen Sensors and Monitors Utilizing Fluorescent Films}

There are numerous descriptions in the literature of fluorescent-based oxygen sensing devices. These devices work well in a laboratory-controlled environment, but are too fragile for field use. We have developed fabrication methods for assembling poly(dimethylsiloxane) (PDMS) membranes doped with fluorescent dyes. The dye was incorporated into a sol-gel solid and ground to a powder to add to PDMS. The dynamic range of the sol-gel powder alone was high, on the order of 70\%. The dynamic range is about $30 \%$ when the powder is embedded in a PDMS film (i.e., sol-gel doped PDMS), but the method is difficult to make reproducible with embedded powder particles. This led to the development of the second doping procedure. In the second method, $\mathrm{Ru}$ (Phen) (Ru (1-10 phenanthroline) ${ }_{3} \mathrm{CL}_{2}$ ) has been incorporated as a molecular dopant in PDMS. PDMS films are swelled by exposure to triethylamine and immersed in methylene chloride- $\mathrm{Ru}(\mathrm{Phen})$ solution. Excess solution is removed, and the film is allowed to shrink to the original volume by slowly evaporating triethylamine overnight. This process is repeated several times to achieve the final doped state (i.e., molecular doping). In Figure 2, there is a plot of the fluorescence observed from a PDMS film (molecular doped with $\mathrm{Ru}(\mathrm{Phen})$ ) cycled between $100 \%$ nitrogen (high) and $100 \%$ oxygen (low). The measurement is shown over several cycles. It is apparent that the response time is fast (a few seconds), and the final states are reproducible for both $100 \%$ nitrogen and $100 \%$ oxygen.

A pH sensor was fabricated with a useful range between 4.5 and 8 . We have successfully fabricated oxygen sensing films for PDMS/Ru(Phen) systems. Several experiments are planned for monitoring oxygen depletion around corroding sites in a thin electrolyte film. In addition, we expect to adapt the molecular doping procedure to fabrication of DOF for oxygen sensing. 


\section{High-Temperature, Multi-Species Solution Properties and Behavior}

David R. Cole', Donald A. Palmer', Lawrence N. Anovitz', Mostafa Fayek', Miroslaw S. Gruszkiewicz', Lee R. Riciputi', David J. Wesolowski ${ }^{1}$, George Engelhardt ${ }^{2}$, and Digby D. Macdonald ${ }^{3}$

IOak Ridge National Laboratory (ORNL) | 2OLI Systems Inc. | 3Pennsylvania State University

\section{Project Objectives}

The objective of this project is to develop a basic scientific understanding of the chemistry of multi-component solutions within the immediate environment of clean and particulate-covered, metal-alloy surfaces and their effects on the evolution of localized corrosion processes. This objective incorporates various experimental methods integrated with computer modeling by OLI Systems, Inc. The chemistry of critical solutions required for sustained crevice-corrosion damage is also examined.

\section{Approach}

The approach in the initial phase was to take advantage of unique experimental techniques developed at ORNL: (1) to conduct scoping experiments utilizing the ORNL high-temperature humidity chamber, which allows measurement of the mass of solutions (and hence their compositions) within the vessel as a function of temperature, solution composition, and relative humidity; (2) to quantify liquid/vapor interactions as a function of temperature, solution composition, prevailing humidity, and time; (3) to measure the $\mathrm{pH}$ of solutions as a prime indicator of hydrolysis, adsorption/desorption, and precipitation equilibria as a function of temperature, solution composition, the effect of tuff/dust particulates, and time; (4) to interrogate the liquid/particulate/alloy interface using secondary ion mass spectrometry (SIMS) and other techniques to track the movement of atoms to and from the bulk alloy through the corrosion layer to the surface liquid film, with and without tuff or dust present; and (5) to incorporate the experimental results into the OLI Systems MSE computer model database to enhance our understanding of the corrosion evolutionary path of the system. A new subtask is under development to use spectroscopic and in situ $\mathrm{pH}$ methods to determine the speciation and thermodynamic stability of metal ions in active crevices on alloy surfaces as a function of temperature, solution composition, and acidity.

\section{Accomplishments}

Our accomplishments are organized below according to the subtasks outlined in the previous section. One fundamental accomplishment was the establishment of the ORNL Quality Assurance Plan, which was audited and approved during Fiscal Year 2005. This allowed us to work under the ORNL QA umbrella beginning in March 2005, although some prior scoping experiments were performed in Subtasks (1)-(3).

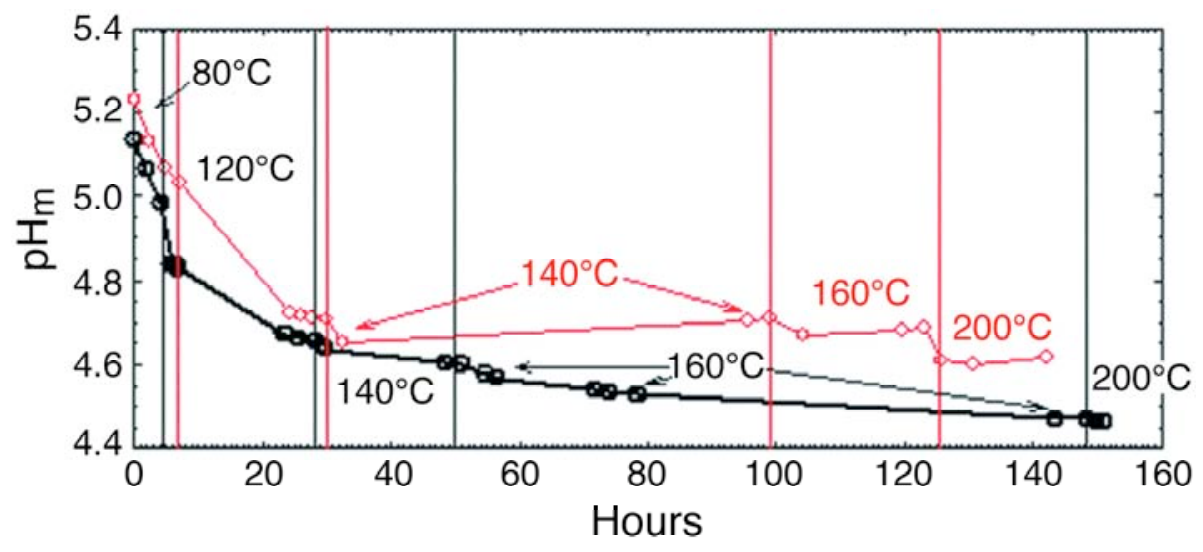

Figure I. The $\mathrm{pHm}=-\log \mathrm{IO}[\mathrm{H}+]$ in molal concentration units as a function of time and temperature in an $\mathrm{NaCl}-\mathrm{CaCl}_{2}$ brine. Because $\mathrm{HCl}$ is slightly volatile under these conditions, the two curves (red and black) are believed to bracket the true $\mathrm{pH}_{\mathrm{m}}$ of the experimental solution. 
(1) Soluble salts such as $\mathrm{NaNO}_{3}, \mathrm{KNO}_{3}, \mathrm{NaCl}$, and $\mathrm{KCl}$ can deliquesce and form concentrated brines, and dilute aqueous solutions coming into contact with hot alloy surfaces will tend to evaporate, both forming concentrated liquid films depending on relative humidity, temperature, and composition. Mixed salts usually deliquesce at significantly lower humidities than the pure components. A scoping experiment was carried out at $140^{\circ} \mathrm{C}$ on 14 solutions, including $\mathrm{Na}^{+}, \mathrm{K}^{+}, \mathrm{Ca}^{2+}$, and $\mathrm{Mg}^{2+}$ cations with $\mathrm{Cl}^{-}$and $\mathrm{NO}_{3}{ }^{-}$anions, using the ORNL isopiestic facility. This method provided definitive data on solution properties as well as the deliquescence point of the dry mixture as a function of the relative humidity. The solubility limits of the individual components of the mixed solutions were also determined as a function of relative humidity. Evaporation was continued until the mixtures reached their individual constant compositions, whereupon all the remaining water evaporated at a constant relative humidity. These results were successfully modeled with OLI's MSE code in most cases. In cases such as those involving nitrates, however, the predictability was considerably outside the experimental uncertainty, and this indicates the benefit of gathering additional solution data for these systems.

(2) Experiments utilizing two ORNL corrosion-resistant volatility apparatus were performed at 60,110 , and $160^{\circ} \mathrm{C}$ to quantify the partitioning of $\mathrm{HF}, \mathrm{HCl}$, $\mathrm{HNO}_{3}$, and $\mathrm{H}_{2} \mathrm{SO}_{4}$ from liquid solutions to the vapor phase. These acids are known to be far more volatile than their sodium, potassium, etc., salts, such that they represent the only significant anionic species in the vapor phase at these temperatures. To be able to predict the transport of anions from liquid films on hot waste package surfaces, it is essential to control the $\mathrm{pH}$ of the liquid phase in these experiments. This was achieved using the $\mathrm{pH}$ buffer $\mathrm{HSO}_{4}{ }^{-} / \mathrm{SO}_{4}{ }^{2-}$. Data garnered to date clearly establish that the volatility of these acids is in the order $\mathrm{HF}>>\mathrm{HCl}>\mathrm{HNO}_{3}>>$ $\mathrm{H}_{2} \mathrm{SO}_{4}$. Because these results are being obtained over a narrow range of composition, it will be necessary to utilize the OLI MSE code to determine the activity coefficients in these mixed solutions as a function of temperature. Thus, thermodynamic partitioning coefficients are determined for each anionic species over a wide range of concentration. Most of these partitioning coefficients are not currently available within the OLI database, and the results will be used to ultimately upgrade the database.

(3) In the scoping phase of this subtask, $\mathrm{pH}$-monitoring experiments were completed using two complex brines in the system $\mathrm{Ca}^{2+}-\mathrm{Mg}^{2+}-\mathrm{Na}^{+}-\mathrm{K}^{+}-\mathrm{F}^{-}-$ $\mathrm{Cl}^{-}-\mathrm{SO}_{4}{ }^{2-}$. The $\mathrm{pH}$ was continuously monitored for up to 8 days as temperature was raised to 80,120 , 140,160 , and $200^{\circ} \mathrm{C}$ in ORNL's high-temperature, hydrogen-electrode cell. Additional long-termed experiments monitored the $\mathrm{pH}$-change with time in $\mathrm{NaCl}-\mathrm{CaCl}_{2}$ solutions over the same temperature range (Figure 1). Precipitates of fluorite, $\mathrm{CaF}_{2}$, and the mixed salt kogarkoite, $\mathrm{Na}_{3} \mathrm{SO}_{4} \mathrm{~F}$, were observed in the more complex brines. There are no reliable thermodynamic data available for kogarkoite, which is not included in the EQ3/6 or OLI MSE databases. Subsequently, three experiments following the ORNL QA procedures were conducted to define the solubility of kogarkoite in $\mathrm{Na}^{+}-\mathrm{F}^{-}-\mathrm{Cl}^{-}-\mathrm{SO}_{4}{ }^{2-}$ brines over a range of ionic strengths at $80,120,140,160$, and $200^{\circ} \mathrm{C}$. These results will be used to extract thermodynamic equilibrium constants for the solubility reaction $\mathrm{Na}_{3} \mathrm{SO}_{4} \mathrm{~F} \leftrightarrow 3 \mathrm{Na}^{+}+\mathrm{SO}_{4}{ }^{2-}+\mathrm{F}^{-}$from 25 to $200^{\circ} \mathrm{C}$, using activity coefficients obtained from both the EQ3/ 6 and OLI Systems databases. Since the thermodynamic properties of all of the ions studied are well known in water over this temperature range, we will extract the thermodynamic properties of kogarkoite from derivatives of the temperature function that will be used to fit the solubility equilibrium constants.

The ability to monitor the $\mathrm{pH}$ of aqueous mixedelectrolyte brines and brine-solid interactions over long periods of time (days to weeks) at elevated temperatures adds an important constraint in testing and augmenting computer models of the evolution of brine compositions of interest. We have demonstrated that either acidic or basic conditions can be generated, depending on the initial brine composition. The solid-phase kogarkoite $\left(\mathrm{Na}_{3} \mathrm{SO}_{4} \mathrm{~F}\right)$ was identified, and this phase may be important in controlling the fluoride and sulfate levels in concentrated brines at elevated temperatures. Systematic sampling of a variety of mixed brines in equilibrium with this and other solid phases, over a range of temperatures and total salinities, can be used to test activity coefficient 


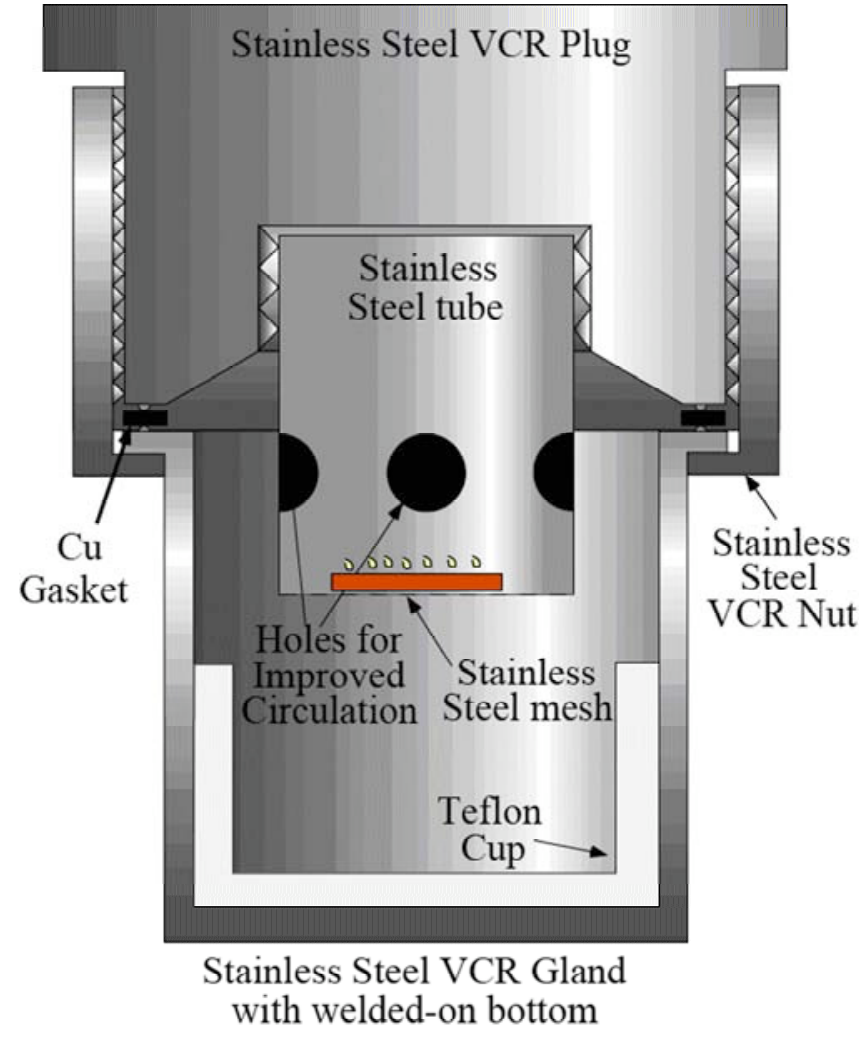

Figure 2. Schematic of prototype humidity reaction cell based on prior studies of water diffusion into glass. Vessel material can be made from Alloy 22 instead of stainless steel. The metal coupons (red) with or without tuff particles (in yellow) can be suspended in the vapor phase on a wire mesh.

models and derive the thermodynamic properties of the solids.

(4) This subtask was deferred during the first year. However, we did procure Alloy 22 and C-276 sheets, and QA procedures were established for cutting and stamping them into usable segments. We also acquired 14 ground Yucca Mountain tuff samples, which had been previously characterized by Z. Peterman of the U.S. Geologic Survey. Scanning-electron microscopy (SEM) and x-ray diffraction (XRD) studies have been initiated on these tuff samples. In addition, an independent study was completed on the effects of variable relative humidity on diffusion of water into glass at temperatures below $150^{\circ} \mathrm{C}$, which led to the development of cells (see Figure 2) and techniques needed as prototypes for forthcoming work on metal-solution-tuff interactions.
(5) A comprehensive literature search was completed by OLI, providing detailed and quantitative information relevant to the overall brine chemistry and evolution of environments for the proposed Yucca Mountain repository. The chemical compositions covered by this survey include: $\mathrm{Na}^{+}, \mathrm{K}^{+}, \mathrm{H}^{+}, \mathrm{Ca}^{2+}$, $\mathrm{Mg}^{2+}, \mathrm{Cl}^{-}, \mathrm{F}^{-}, \mathrm{NO}_{3}{ }^{-}, \mathrm{OH}^{-}, \mathrm{SO}_{4}{ }^{2-}, \mathrm{CO}_{3}{ }^{2-} / \mathrm{HCO}_{3}{ }^{-}$, and $\mathrm{SiO}_{2}$. In addition, the work performed at OLI during this period included extracting data from the collected papers and preparation of spreadsheets, indexing the spreadsheets and chemical systems, and preparing a reference list for the preexisting data.

The OLI subtask has and will provide the platform on which much of our experimental data will be treated and applied to defining the evolution of environment and corrosion studies. The results of Subtasks (1) through (3), and the future subtask involving aqueous crevice chemistry, will enhance the OLI database and in some cases provide a test bed for their predictive calculations of the corrosion evolutionary path.

\section{Related Publications}

Palmer, D., L. Anovitz, D. Cole, M. Fayek, M. Gruszkiewicz, L. Riciputi, D. Wesolowski, and L. Wilson, Experimental approaches to predict the behavior of liquid films. Proceedings of the 15th annual Goldschmidt Conference, Idaho; Geochimica et Cosmochimica Acta, 69, A413, 2005.

\section{Acknowledgments}

Support is provided to ORNL through the U.S. Department of Energy Contract No. DE-AC05-00OR22725. 
This page intentionally left blank. 


\title{
Coupling Thermal-Hydrological-Chemical Models to Process Models on Waste Packages
}

\author{
N. Spycher, G. Zhang, C. Steefel, E. Sonnenthal, and Z. Zheng \\ Lawrence Berkeley National Laboratory (LBNL)
}

\section{Research Objectives}

The safety case for the proposed repository at Yucca Mountain depends greatly on the integrity of the engineered barrier system, especially the waste packages. Therefore, the potential appearance of corrosive fluids in emplacement drifts and subsequent corrosion of waste packages is a key concern for long-term repository performance. The current proposed repository design will lead to boiling conditions around emplacement drifts for hundreds of years, as a result of heat released from waste packages through radioactive decay. The high temperature at ambient atmospheric pressure will lead to evaporation of pore waters potentially seeping into emplacement drifts, and the formation of various brines that could have elevated boiling temperatures. Salt-bearing mineral dust accumulated on top of waste packages could also wet upon seepage, or deliquesce at elevated temperatures.

These processes could potentially produce corrosive brines at temperatures significantly higher than the boiling point of pure water.

The objective of this ongoing study is, therefore, (1) to develop a quantitative model of coupled thermal, hydrological, and chemical (THC) processes potentially leading to brine formation on top of waste packages and/or a drip shield, and (2) to dynamically integrate such a model into both the larger-scale models of processes within and around waste emplacement drifts, and into the smallerscale waste package corrosion models (Figure 1). As such, the main goal of this study is to provide a link between the THC processes defining the in-drift chemical environment (evaluated within the Natural Barriers Thrust) and those affecting waste package corrosion (evaluated within this Materials Performance Thrust) and fuel degradation (evaluated in the Source Term Thrust).

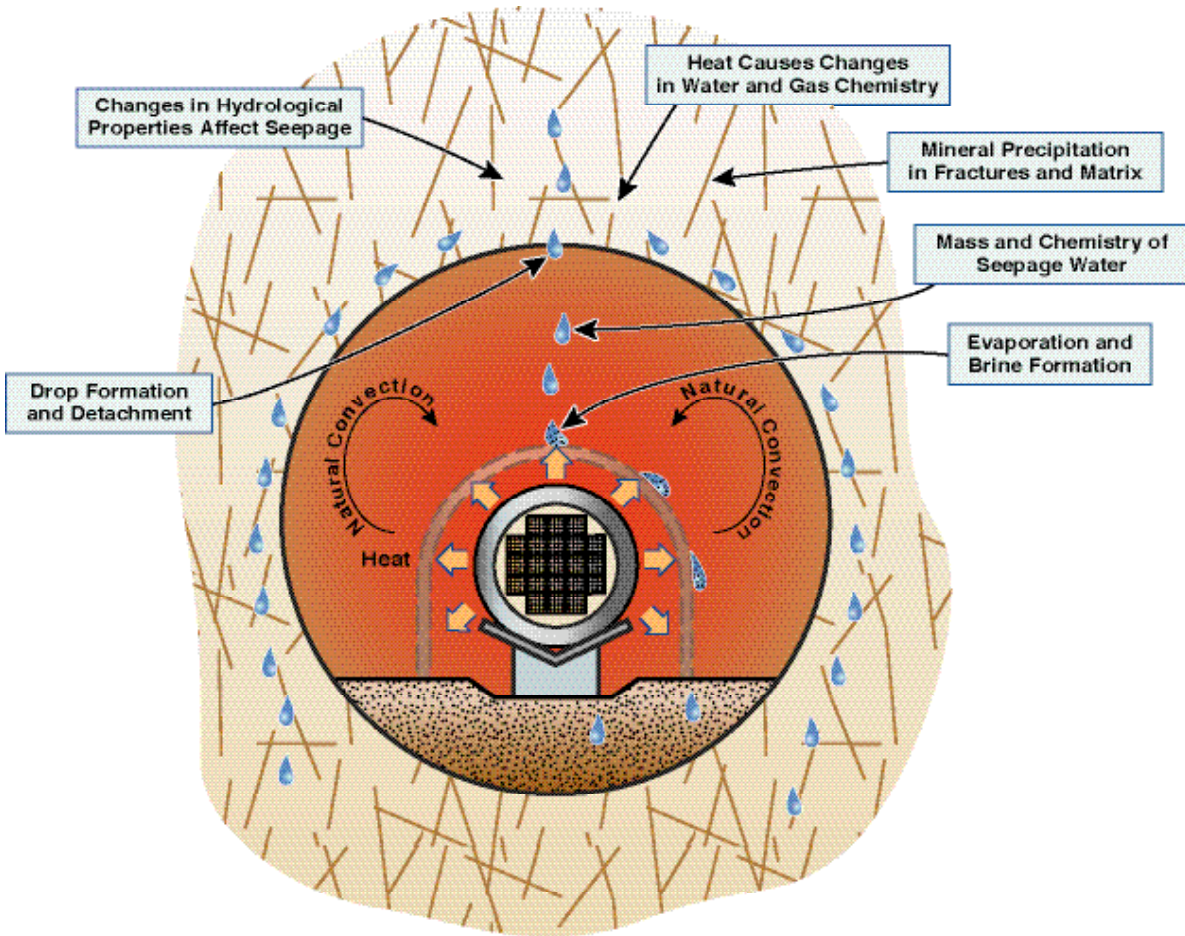

Figure I. Conceptualization of brine formation resulting from water seepage or dust deliquescence above waste packages. Note that salt re-precipitation after deliquescence may occur because of the precipitation of secondary salts with a higher deliquescence relative humidity than the initial assemblage.

\section{Approach}

The TOUGHREACT reactive transport simulator is currently being used for modeling drift-scale and mountain-scale coupled THC processes at Yucca Mountain. This simulator is also being used to integrate THC processes in and around waste emplacement drifts, and to simulate spent fuel degradation as part of other ongoing OST\&I projects described in this report. For full integration with these projects, process models are being implemented into this simulator to allow the modeling of evaporative concentration to very high ionic strength, modeling of boiling point elevation caused by dissolved salts, modeling of boiling/evaporation to dryness, and modeling of salt deliquescence. These process models are being tested against experimental data and refined as necessary to reasonably reproduce these data. The full simulator, integrated with 
simulations of near-field and in-drift THC processes, will then be used to simulate brine formation and salt deliquescence on waste packages and other engineered systems in waste emplacement drifts, providing inputs and boundary conditions for corrosion and source term degradation models.

\section{Accomplishments}

To allow the simulation of chemical reactions in concentrated solutions, a Pitzer ion-interaction model was implemented into the TOUGHREACT reactive transport simulator. The calculation of activity coefficients was verified against measured activity coefficients, osmotic coefficients, and salts solubilities reported in the literature. Boiling point elevation (vapor pressure lowering) caused by dissolved salts was implemented directly through the water activity computed with the Pitzer ion-interaction model. In addition, computer routines are being developed to allow efficient calculation of the deliquescence relative humidity for multiple-salt assemblages, and the determination of salt precipitation sequence and amounts upon evapora- tion/boiling to dry or near-dry conditions, for application to numerical grids containing several thousand nodes. Such routines enable us to compute, for example, the quantity and composition of brine formed, and the amount of water absorbed by deliquescence of natural dust sitting on waste packages, over a range of relative humidity values (Figure 2).

Until now, modeling brine chemical evolution as a function of evaporation, as well as salt deliquescence, was restricted to reaction-path simulations that made use of simpler computer codes that could not capture multiphase reactive transport. The present study allows integration of such computations in complex reactive-transport simulations involving the flow of water, water vapor, other important gases such as $\mathrm{CO}_{2}$, and trace gases like $\mathrm{HCl}$ and other acid gases, which all play a role in the evolution of the chemical environment in waste emplacement drifts. The close integration of this modeling effort with other modeling activities related to in-drift seepage, near-field and in-drift THC processes, corrosion, and spent fuel degradation will ultimately enable us to predict radionuclide fate and transport from one comprehensive model, rather than separate, mostly uncoupled submodels, as done in previous studies.

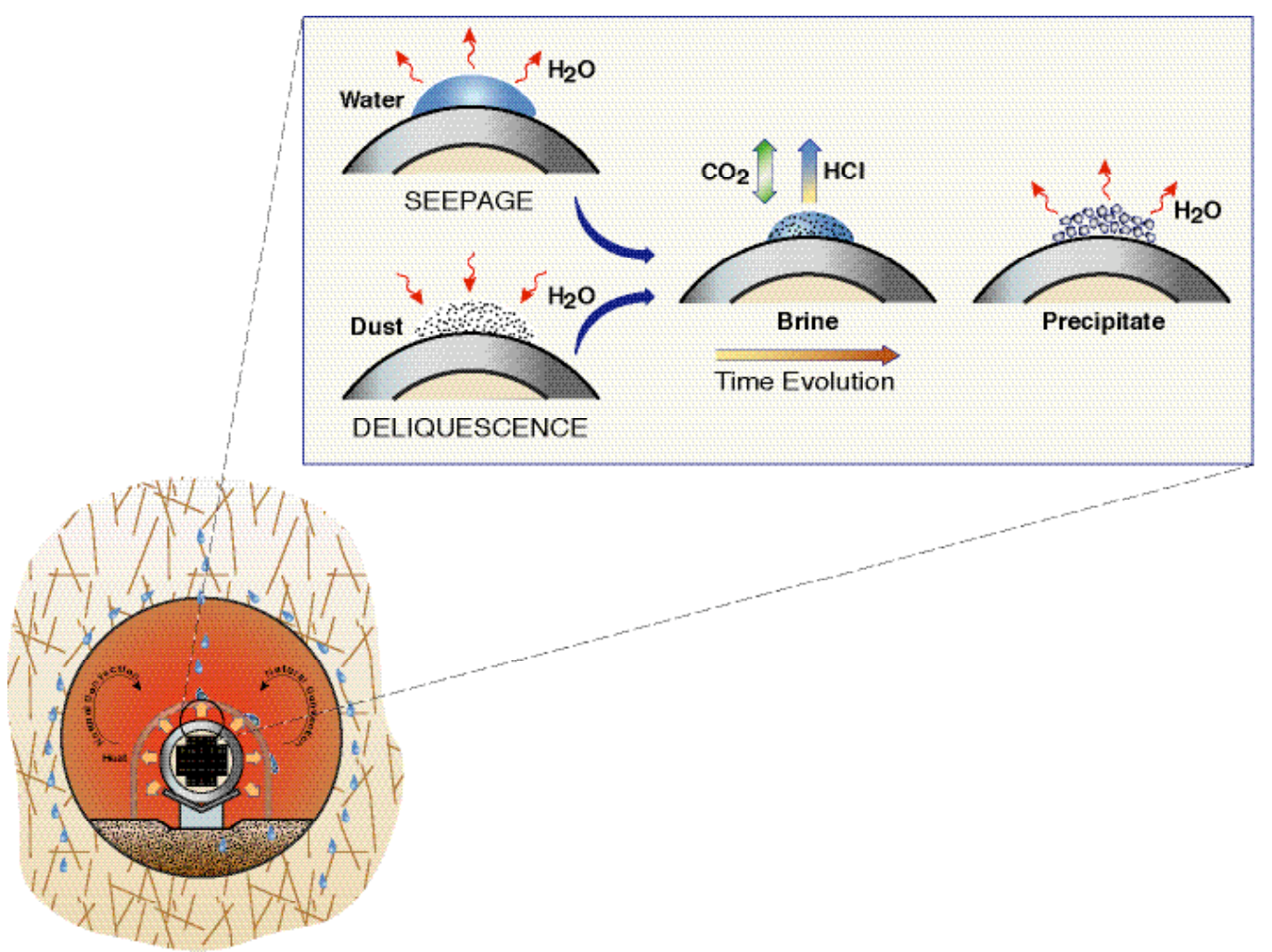

Figure 2. Calculated amounts of absorbed water and brine formed by the deliquescence of atmospheric dust accumulated on waste packages, as a function of relative humidity (example case with $16 \mathrm{mg}$ dust per $\mathrm{cm}^{2}$ ) 


\section{Integration of Materials Performance Process Models with Those in Natural Barriers and Source Term Thrusts}

Bo Bodvarsson', Mark Peters ${ }^{2}$, and Joe H. Payer ${ }^{3}$

'Lawrence Berkeley National Laboratory (LBNL) | ${ }^{2}$ Argonne National Laboratory (ANL) | ${ }^{3}$ Case Western Reserve University

\section{Research Objectives}

In addition to the multi-investigator projects organized to address important technical thrusts, there are bridging projects that coordinate and integrate process modeling activities in the Materials Performance Thrust to those in the Natural Barriers Thrust and Source Term Thrust. The objectives of the projects at LBNL and ANL are to identify opportunities for synergism and to cross-fertilize the modeling efforts in the Natural Barriers Thrust and the Source Term Thrust with the modeling efforts within the Materials Performance Thrust. The goal is to enhance the linkage and flow of information and modeling methodologies among the thrusts.

\section{Approach}

The objective is addressed through the formation of work groups among principal investigators carrying out and using the results of the modeling tasks. These groups correspond to share information and meet periodically to describe modeling status, approaches, data availability and needs, model inputs and outputs, and methodologies. The sessions are organized to identify gaps, overlaps, and opportunities.

\section{Accomplishments}

Representatives from each of the three thrusts have met as work groups on:
- Modeling of the Evolution of Localized Corrosion Damage

- Modeling of the Evolution of the Environment on Metal Surfaces.

A critical review of modeling approaches, strategies, and status relevant to the OST\&I Thrusts is planned for completion in the next fiscal year.

In FY2005, advantage was taken of a special opportunity to support a collaborative/ educational effort. Under the direction of and in collaboration with Christopher Johnson at Argonne National Laboratory, Marion Houlière explored the use of x-ray synchro tron radiation to interrogate the nature of passive film on Alloy 22. Methods included x-ray absorption spectroscopy (XAS) and x-ray diffraction and scattering experiments. Ms. Houlière, a student at Ecole Nationale Supérieure des Mines de Paris, participated in a technical exchange and internship at ANL.

Process models address the rock/geology near-field environment around and in the drifts; on the metal surfaces of waste packages and other engineered barrier components; and within waste packages related to spent fuel, other waste forms, and internals. The scale of interest ranges from mountain scale (10's of meters); to drift/waste packages/clad fuel rods scale (meter/centimeters); to pores/fractures in rock, passive films, and radionuclide scale (microns/nanometers). This endeavor strives for integration among those efforts. 


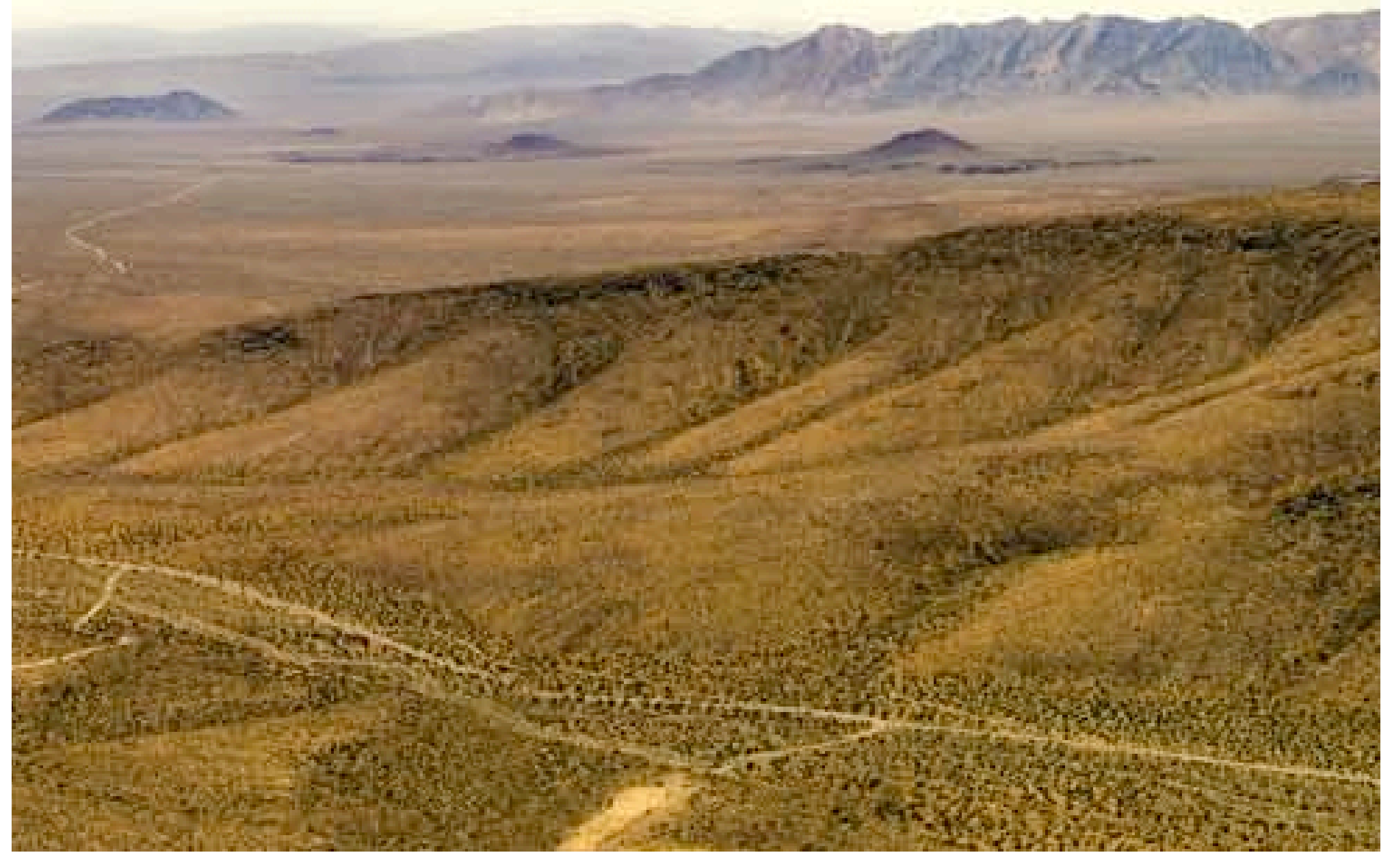




\section{RADIONUCLIDE}

\section{GETTERS}

THRUST

Hong-Nian Jow' (Director), Robert C. Moore' (Co-Director), and Shas Mattigod ${ }^{2}$ (Co-Director), Radionuclide Getters Thrust

ISandia National Laboratories (SNL)

2Pacific Northwest National Laboratory (PNNL)

Contact: Hong-Nian Jow | 505.284.4819 | hjow@sandia.gov

The proposed Yucca Mountain repository, located in southern Nevada, is to be the first facility in the U.S. for the permanent disposal of high-level radioactive waste and spent nuclear fuels (SNF). Total System Performance Assessment (TSPA) has indicated that among the major radionuclides contributing to potential dose are neptunium $(\mathrm{Np})$, technetium (Tc), and iodine (I). These three radionuclides are highly mobile in the environment. Sequestering these radionuclides within the proposed repository horizon is a priority for the Yucca Mountain Project (YMP). Developing radionuclide sorbents, or "getters," is the focus of this thrust area. The ultimate goal of this research is to prescribe a recipe and placement recommendation for getters that could enhance radionuclide containment within the proposed repository.

The development of radionuclide getters was a collaborative effort between Sandia National Laboratories (SNL), Pacific Northwest National Laboratory (PNNL), and Virginia Polytechnic and State University (Virginia Tech). The radionuclide getters program was initiated in the third quarter of FY2004. The objective of this program is to develop new materials that can scavenge and sequester $\mathrm{Np}$, Tc, and I under the conditions anticipated at the proposed Yucca Mountain repository. Ideally, getters will withstand the initial heat pulse, radiation fields, and contact with groundwater, the composition of which is expected to vary as repository conditions evolve over time.

In FY2005, the focus of the getter thrust area is to investigate various natural minerals that have shown promising characteristics for sequestering radionuclides and incorporating these natural minerals into synthesized compounds to increase interaction surfaces (i.e., increase surface areato-volume ratio) and enhance their selectivity for sequestering specifically targeted radionuclides: $\mathrm{Np}, \mathrm{Tc}$, and I. During the last decade, research and development of synthesized nanoporous materials have shown promising applications in various industries as highly effective absorbents. One of the key research approaches in the getters thrust area is to leverage the experience in the synthesis of nanoporous materials to investigate their potential applications in sequestering selected radionuclides by engineering synthesis technologies.

Absorber development focused on the use of nanoporous and mesoporous compounds. SNL researched the synthesis of nanoporous oxides coated with inorganic functional groups selective for radionuclide binding. PNNL efforts focused on the use of nanoporous phosphate materials as inherently functional radionuclide absorber materials.

Virginia Tech investigated the use of manganese oxides as absorbers.

Additionally, conventional hydrotalcites offer a number of compositional variations that may provide the needed selectivity and capacity to allow these materials to function as effective anion absorbers. The applied research of hydrotalcites focused on manipulating the interlayer spacing and charge distributions in the hydroxide layers as a means of obtaining $\mathrm{TcO}_{4}^{-}, \mathrm{I}^{-}$, and $\mathrm{IO}_{3}{ }^{-}$selective absorbers. Past studies have demonstrated that a number of novel hydroxide and oxide systems (Bi-Al-Zn-Mg-Zr-La-Cu$\mathrm{OH}^{-}, \mathrm{O}_{2}^{-}, \mathrm{H}_{2} \mathrm{O}$ ) have a particular affinity for scavenging I and to a lesser extent $\mathrm{TcO}_{4}$ - in groundwater systems.

Apatite is a mineral known to strongly sorb many radionuclides. Apatite can be synthesized with a nanoporous structure with a high surface area. In past work at SNL, the effectiveness of apatite for sorption of $\mathrm{Np}$ was demonstrated through batch and column experiments. This research focused on apatite and modified apatites to determine their sorption capacity for radionuclides under conditions relevant to the proposed Yucca Mountain repository.

Principal investigators (PIs) from SNL, PNNL, and Virginia Tech lead different projects for investigating various promising natural minerals and synthesizing different engineered materials, as described below:

Dr. Jun Liu: synthesis of nanoporous oxide materials coated with functional inorganic compounds (bismuth [Bi] hydroxide) in order to effectively absorb Tc and I anions.

Dr. Shas Mattigod: development of nanoporous titanium (Ti) and zirconium (Zr) phosphate materials for sequestering Tc and $\mathrm{Np}$.

Dr. Shas Mattigod and Glen Fryxell: development and testing of nanoporous tin (Sn) phosphate materials structurally tailored to enhance selective sequestration of Tc and $\mathrm{Np}$. 


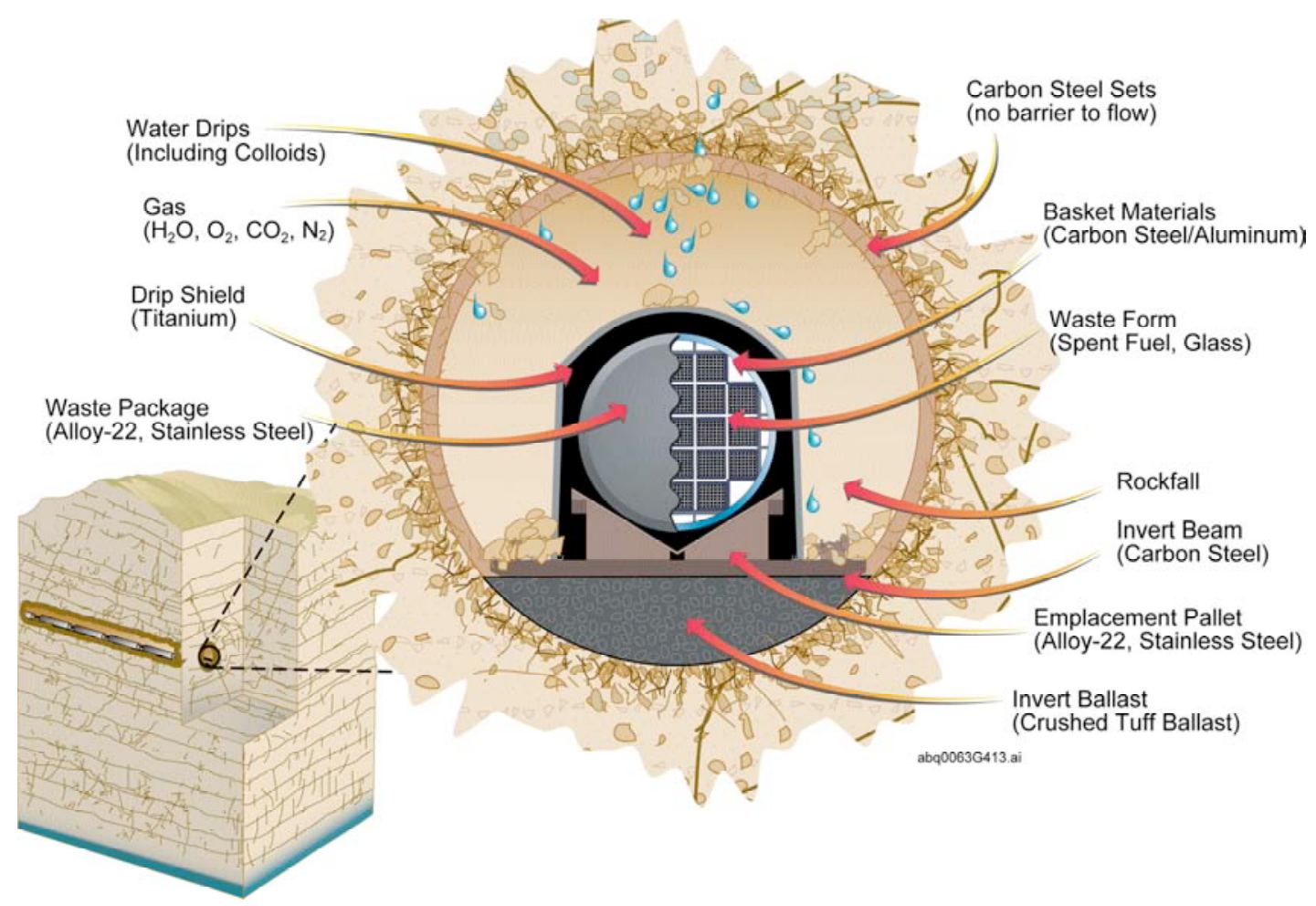

Figure I. Diagram indicating the potential placement of the getter material in relation to the waste package

Dr. Yifeng Wang: synthesis of a diverse range of layers of double hydroxide (LDH) materials to effectively absorb Tc and I anions.

Dr. Robert C. Moore and Dr. Katheryn Helean: investigation of the use of apatite-like natural minerals doped with aliovalent cations, including iron $(\mathrm{Fe})$, copper $(\mathrm{Cu})$, and manganese $(\mathrm{Mn})$ to sequester Tc.

Dr. Jim Krumhansl: synthesis and investigation of natural minerals for sequestering I anions and developing a test matrix of various simulated proposed-repository fluid compositions to be used by the getter PI team.

Dr. Robert C. Moore and Dr. Ranko Bontchev: development and synthesis of Bi-based oxides (BiOX) to sequester Tc and I anions.

Dr. Mike Hochella: investigation of the use of naturally occurring Mn oxides as a potential getter for anionic radionuclides.

Several getter thrust area team meetings were held among all PIs to share research results and communicate successes of research findings during FY2005. For example, successful findings by one PI- of promising characteristics of Bi hydroxide compounds for sequestering anionic compounds-led other PIs to investigate the synthesis of Bi compounds into different nanoporous materials.
A getters workshop was held on November 18-19, 2004, sponsored by the Office of Science and Technology and International (OST\&I) and DOE's Office of Basic Energy Sciences (BES). The purposes of the workshop were: (1) to review current research and technology efforts for sequestering radionuclides, with a focus on $\mathrm{Np}, \mathrm{Tc}$, and I; and (2) to cover issues concerning the proposed repository environment and the getter characteristics required for potential placement into the proposed repository. The workshop report is planned for publication later in calendar year 2005.

In the following pages (pp. 121-139), the major accomplishments for FY2005 are summarized by each PI. Listed below are highlights of the accomplishments made by the radionuclide getter thrust area:

- Enhanced Tc sorption by using Bi hydroxides to coat nanoporous silica surfaces.

- Nanoporous phosphate materials with $\mathrm{Ti}, \mathrm{Zr}$, and Sn have been successfully synthesized and shown to have promising sequestering characteristics for Tc and Np.

- Mechanistic studies have concluded that a significant portion of Tc is absorbed to the surfaces of layered double hydroxide (LDH) materials. 
- Fe-doped hydroxyapatite has shown strong sorption of Tc in solution batch experiments.

- Several Bi hydroxide compounds are successful at sequestering iodate, iodide, perrhenate (pertechnetate surrogate), and pertechnetate.

- Hydrotalcites (LDH-based materials) are successful at sequestering both iodide and iodate in batch sorption tests.

- Sheet and tunnel structured manganese oxides are found to be getters for anionic radionuclide species.

\section{Acknowledgments}

\section{Sandia National Laboratories Acknowledgment}

Sandia is a multiprogram laboratory operated by Sandia Corporation, a Lockheed Martin Company, for the USDOE's National Nuclear Security Administration under Contract No. DE-AC04-94AL85000.

\section{Pacific Northwest National Laboratory Acknowledgment}

This work was supported by the Office of Civilian Radioactive Waste Management and Pacific Northwest National Laboratory, managed by Battelle Memorial Institute for US-DOE under Contract No. DE-AC06-76RLO 1830.

\section{Virginia Polytechnic and State University Acknowledgment}

The research at Virginia Tech was conducted in the Department of Geosciences, College of Science, and was funded by a generous grant from Sandia National Laboratories. Supplemental funding was provided by DOE Grant No. DE-FG02-02ER15326 and National Science Foundation Grant No. EAR-01-03053. 
This page intentionally left blank. 
Development of Coated Mesoporous and Small Spherical Technetium and lodine Sorbents

Jun Liu, Yifeng Wang, Qisheng Huo, and Huizhen Gao, Sandia National Laboratories $(\mathrm{SNL})$

Development and Testing of Nanoporous Sorbents for Technetium, Neptunium, and lodine

Shas V. Mattigod, Dawn M. Wellman, Glen E. Fryxell, X. Shari Li, Andrea R. Courtney,

Kent E. Parker, and Wassana Yantasee, Pacific Northwest National Laboratory (PNNL)

New Nanoporous Phosphate-Based Getter Materials: Design, Synthesis, and Testing

Shas V. Mattigod, Dawn M. Wellman, Glen E. Fryxell, and Kent E. Parker, Pacific Northwest National Laboratory (PNNL)

Optimization of Layer Double Hydroxides and Related Materials Yifeng Wang and Huizhen Gao, Sandia National Laboratories (SNL)

Hydroxyapatite for Technetium Sequestration

Katheryn B. Helean, Sandia National Laboratories (SNL)

\section{lodine Getter Development}

James L. Krumhansl, Jason D. Pless, and J. Benjamin Chwirka, Sandia National Laboratories (SNL)

BiOX-Based Solid Radionuclide Getters

Ranko P. Bontchev, Sandia National Laboratories (SNL)

Exploring the Use of Manganese Oxides as Anionic Getters

Michael Hochella and Heike Pieper, Virginia Polytechnic and State University 
This page intentionally left blank. 


\section{Development of Coated Mesoporous and Small Spherical Technetium and lodine Sorbents}

Jun Liu, Yifeng Wang, Qisheng Huo, and Huizhen Gao

Sandia National Laboratories (SNL)

\section{Research Objectives}

Our objective is to develop stable, efficient, inorganically functionalized nanoporous radionuclide getter materials.

\section{Approach}

The general approach is focused on the synthesis of nanoporous oxide materials as a backbone, and then coating the structures with functional inorganic ligands in order to effectively adsorb radionuclides-specifically, coating bismuth $(\mathrm{Bi})$ hydroxide on mesoporous silica. In this research, four methods have been tested to make mesoporous Bi with or without silica: (1) hydrolyzing Bi nitrate and depositing on synthesized mesoporous silica; (2) formation of a Bi and silica alkoxide monolith with controlled hydrolysis and controlled calcinations; (3) immobilization of a strong organic ligand (8-hydroxyquinoline) on mesoporous silica, then complexed with $\mathrm{Bi}$ hydroxide; (4) direct formation of self-assembled nanostructured Bi (hydro)oxide with surfactant addition. All

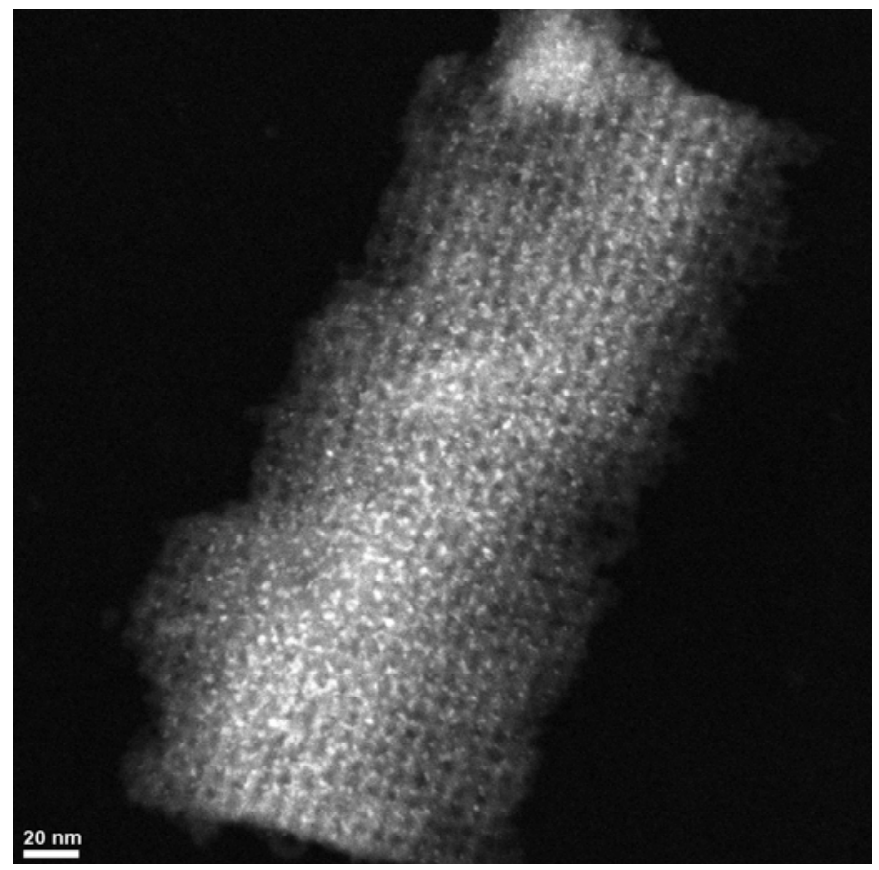

synthesized materials have been subjected to a technetium (Tc) adsorption screening test. The activities of Tc were measured by a liquid scintillation instrument and converted to mass concentration. The distribution of Tc in the solid phase and liquid phase were calculated to obtain the partition coefficient $\left(\mathrm{K}_{\mathrm{d}}\right)$ values.

\section{Accomplishments}

We synthesized four types (methods) of designed Bi composites and conducted Tc screening tests. In Method 1, we synthesized mesoporous silica with nonionic block copolymer (TEOS/F108) and hydrolyzed Bi nitrate, and deposited on mesoporous silica (precipitation-deposition). This synthesis route resulted in a two-phase composite. The $\mathrm{K}_{\mathrm{d}}$ values of Tc adsorption range from 6 to 100's, with increasing $\mathrm{Bi}$ content in the composite (the $\mathrm{Si}$-to-Bi ratio ranges from 0.1 to 0.4 ). Our test results found that pure $\mathrm{Bi}(\mathrm{OH})_{3}$ has a $\mathrm{K}_{\mathrm{d}}$ of $12,000 \mathrm{~mL} / \mathrm{g}$. For Method 2, the chemical route was to hydrolyze silica alkoxide and Bi alkoxide-e.g., $\mathrm{Bi}\left(\mathrm{OCH}_{2} \mathrm{CH}_{2} \mathrm{OCH}_{3}\right)_{3}-$ at the same rate to form monolithic gel, i.e., reducing the Bi alkoxide hydrolyzing rate by forming a complex with acetylacetone (Aa) at the Bi-to-Aa molar ratio of 1:1. We successfully obtained the Si-Bi composite without phase separation (Figure 1). However, the $\mathrm{K}_{\mathrm{d}}$ value of this material is very low because of the low $\mathrm{Bi} / \mathrm{Si}$ ratio (1/50). In Method 3, we coated mesoporous silica with hydroxyquinoline bridged by azonized aminophenyltrimethysilane, then further complexed with $\mathrm{Bi}\left(\mathrm{Bi}\left(\mathrm{NO}_{3}\right)_{3}\right.$. In Method 4, we formed silica oxide mesoporous crystals. The Bi alkoxide (e.g., $\mathrm{Bi}\left(\mathrm{OOC}_{7} \mathrm{H}_{5}\right)_{3}$ was hydrolyzed with acetylacetone controlling and copolymer P123 as the surfactant. An x-ray diffraction (XRD) spectrum shows the synthesized material to be a nanostructure Bi-oxide crystal (Figure 2; note the peak at around one $2 \theta$ and the crystallinity at the high-angle range). Neither material shows significant Tc adsorption capacity.

The Bi materials investigated in this task have been shown to selectively adsorb and sequester pertechnetate, thus potentially decreasing the mobility of this anionic radionuclide in the event that a waste package is breached at the proposed Yucca Mountain repository. The adsorption of Tc

Figure I. Monolithic self-assembled $\mathrm{Bi}$ oxide and silica oxide 
$\left(\mathrm{TcO}_{4}^{-}\right)$by Bi compounds is highly dependent on the structure. Neither Bi oxide nor Bi salt can adsorb Tc. The layered Bi hydroxide is the optimal choice. Our study has developed a method for forming a monolithic composite of two compounds by controlled hydrolysis. A synthesis route for mesoporous crystals, such as Bi oxide in our study, can be selfassembled from its alkoxide precursor. The development of these methods will help future research in finding new nanomaterials and their potential applications, as well as in understanding the mechanism of $\mathrm{Bi} / \mathrm{Tc}$ adsorption and the synthesis of ordered layered Bi hydroxide.

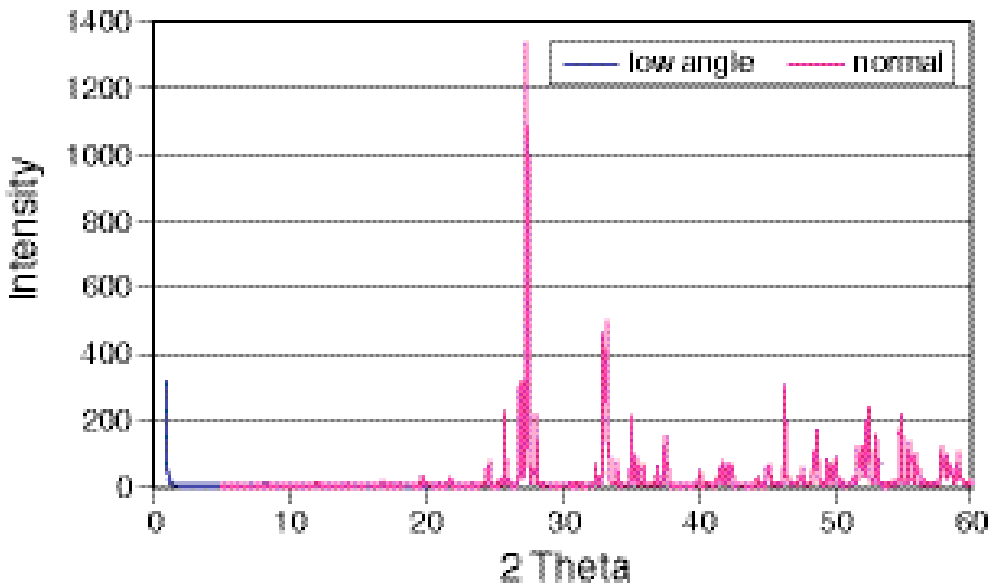

Figure 2. XRD spectrum of self-assembled Bi-oxide showing the low-angle peak 


\section{Development and Testing of Nanoporous Sorbents for Technetium, Neptunium, and lodine}

Shas V. Mattigod, Dawn M. Wellman, Glen E. Fryxell, X. Shari Li, Andrea R. Courtney, Kent E. Parker, and Wassana Yantasee Pacific Northwest National Laboratory (PNNL)

\section{Research Objectives}

The objectives of this work are to develop nanoporous titanium (Ti) and zirconium (Zr) phosphate materials. The materials will be employed as getter materials to sequester radionuclides that may leach from spent nuclear fuel and vitrified waste forms.

\section{Approach}

We conducted a series of template synthesis experiments using various cationic, anionic, and nonionic surfactants such as hexa/octadecyl-trimethylammonium halides, sodium dodecyl sulfate, Pluronic P123, and Tergitol 15-S-9. The reactants consisted of metal salts, alkoxides, phosphoric acid, and its salts. Typically, the syntheses were carried out at $40-75^{\circ} \mathrm{C}$, and the resulting products were filtered, washed with water, dried at $75^{\circ} \mathrm{C}$ for 24 hours, and calcined at temperatures ranging from $150-500^{\circ} \mathrm{C}$ in air for $\sim 5$ hours to remove the template. The effectiveness of template removal was also tested by using a solvent extraction technique. The resulting nanoporous phosphates were characterized by using x-ray diffraction (XRD), Fourier transform infrared spectroscopy (FTIR), transmission electron microscopy (TEM), and $31 \mathrm{P}$ nuclear magnetic resonance (MAS-NMR).

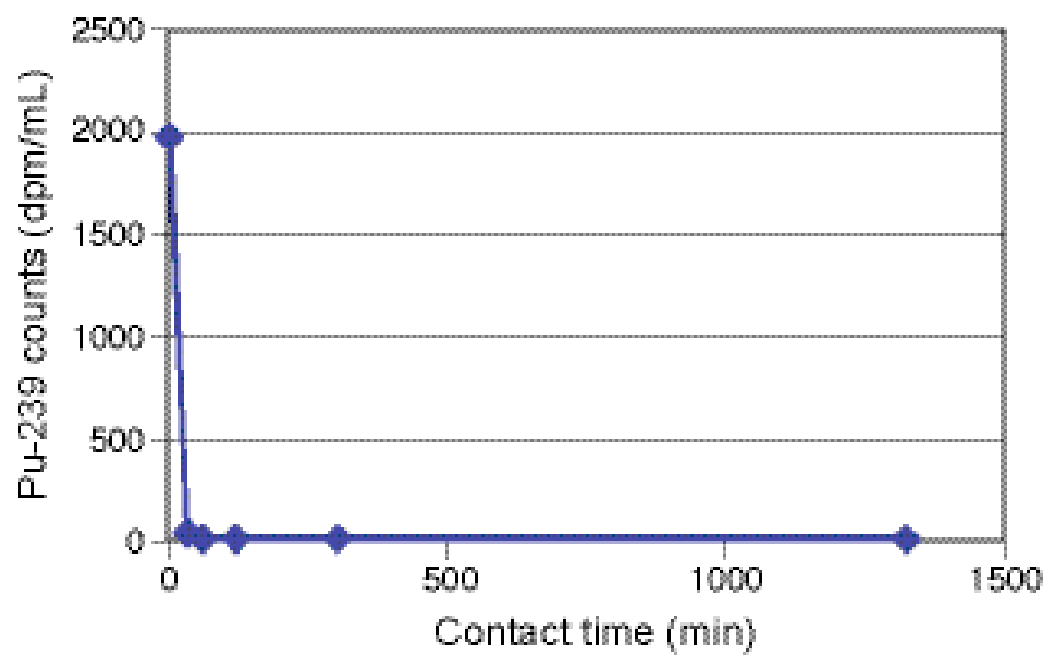

Figure I. Kinetics of $\mathrm{Pu}(\mathrm{IV})$ adsorption on mesoporous Ti phosphate

\section{Accomplishments}

Synthesized Zr phosphates had pore sizes ranging from 4.01 to $4.53 \mathrm{~nm}$. Electron micrography of a typical product showed a uniform hexagonal array of pores. As expected, the pore size of the products increased with increasing chain length of the templating surfactant.

Calcination of the product to remove the cationic template resulted in significant reduction in pore size. Such reduction in pore size upon calcination was indicative of densification of the zirconium-phosphate $(\mathrm{Zr}-\mathrm{P})$ structures. Removal of template by a solvent (ethanol) also reduced the pore size, but to a lesser extent than calcination. Such partial reduction in pore size from solvent extraction (infrared spectroscopy data) resulted from incomplete removal of the templating surfactant from the pores of the synthesized metal phosphate.

Preliminary ${ }^{31} \mathrm{P}$ MAS NMR studies of Zr-P structures indicated that three- and four-oxygen bonding environments (-20.7 and -27.1 ppm peak shifts with respect to $\mathrm{H}_{3} \mathrm{PO}_{4}$, respectively) were typical of nanoporous $\mathrm{Zr}-\mathrm{P}$ structures.

Synthetic Ti phosphates exhibited pore sizes ranging from 3.0-9.0 $\mathrm{nm}$. Using the same reactant concentrations and surfactant, we found that the rate of addition for phosphoric acid and the reaction temperature resulted in Ti phosphates with differing pore sizes. We also found that changing surfactant concentration did not significantly affect the pore size of the resulting products. Using the same Ti reactant (Ti- $\mathrm{NH}_{4}$ lactate) and surfactant (Tergitol), but changing the type of reactant phosphate, also resulted in pore-size changes in the Ti-P products.

To evaluate the ability of these materials to sequester radionuclides, preliminary batch contact studies were carried out with these materials using a stock solution of ${ }^{239} \mathrm{Pu}(\mathrm{IV})$ nitrate in $0.1 \mathrm{M} \mathrm{HNO}_{3}$ and $0.1 \mathrm{M} \mathrm{NaNO}_{3}$. Equilibrium was achieved in approximately 20-30 minutes at a solution-to-solids ratio of 100; therefore, a contact time of 2 hours was used to insure that these values represent true 
equilibrium conditions. Under these conditions, all of these mesoporous Ti-P products demonstrated good affinity for $\mathrm{Pu}(\mathrm{IV})$, typically removing $>95 \%$ of the $\mathrm{Pu}(\mathrm{IV})$ from solution (Figure 1).

Binding studies of ${ }^{236} \mathrm{~Np}(\mathrm{~V})$ were carried out using a 1,000 $\mathrm{dpm} / \mathrm{mL}$ initial concentration in a matrix of $0.002 \mathrm{M}$ $\mathrm{NaHCO}_{3}$ (to mimic the groundwater conditions of a representative repository). Most of these mesoporous Ti-P showed good affinity for binding Np, revealing that $>98 \%$ of the Np was sequestered by these materials. This is particularly noteworthy for this difficult target.

The materials investigated in this task were found to adsorb and sequester the long-lived actinides $\mathrm{Np}$ and $\mathrm{Pu}$ in tests designed to mimic the expected conditions at the proposed Yucca Mountain repository. Their emplacement in the repository invert may significantly reduce the migration of $\mathrm{Np}$ and $\mathrm{Pu}$ to the biosphere in the event that a waste package is breached. We were able to successfully synthesize a series of nanoporous Zr- and Ti-P structures. Initial syntheses showed that pore sizes of the resulting products are highly dependent on factors such as the type of surfactant, the types of metal and phosphate reactants, and the rate of phosphate reactant additions. We explored the synthesis envelope for these nanoporous phosphates and determined the synthesis pathways that resulted in products with consistent pore size and ion adsorptive properties. Mesoporous Ti-P and Zr-P structures have demonstrated their ability as radionuclide sorbent materials, and are particularly noteworthy for their ability to sequester $\mathrm{Pu}(\mathrm{IV})$ and $\mathrm{Np}(\mathrm{V})$. 


\section{New Nanoporous Phosphate-Based Getter Materials: Design, Synthesis, and Testing}

Shas V. Mattigod, Dawn M. Wellman, Glen E. Fryxell, and Kent E. Parker

Pacific Northwest National Laboratory (PNNL)

\section{Research Objectives}

The objectives of this work are to develop novel nanoporous phosphate materials that are structurally tailored to enhance the selective sequestration of long-lived radionuclides. Metal phosphate materials are inherently bifunctional and, through ligand field and oxidation state manipulation, can be tailored for binding specific applications. The materials will be employed as getter materials to sequester any radionuclides that may leach from spent nuclear fuel and vitrified waste forms.

\section{Approach}

We successfully synthesized a number of thermally stable, nanoporous tin (Sn) (II), (IV), and phosphates (Np-SnPO) using cationic surfactants, such as hexa/octadecyltrimethylammonium halides, metal salts, and phosphoric acid. We calcined the resulting materials at $500^{\circ} \mathrm{C}$ to remove the surfactant. We observed that high-temperature calcination did not change the pore size of these sorbents, indicating these materials have good thermal and pore stability. The resulting nanoporous phosphates were characterized by using $x$-ray diffraction (XRD), high-resolution transmission electron microscopy (HR-TEM), x-ray absorption near edge spectroscopy (XANES), and extended absorption fine structure spectroscopy (EXAFS).

\section{Accomplishments}

Selected-area electron diffraction analysis of a typical tin phosphate (Np-SnPO) illustrates a completely amorphous structure (Figure 1a). Analyses with HR-TEM revealed a spherical particle morphology approximately $150 \mathrm{~nm}$ across, with uniform pore distribution narrowly distributed around $2 \mathrm{~nm}$ (Figures $1 \mathrm{~b}$ ). As expected, the pore size of the products increased with increasing chain length of the templating surfactant. Calcination of the product to remove the cationic template resulted in minimal reduction in pore size.

We conducted adsorption studies of these materials to assess their effectivness in sequestering radionuclides: $\mathrm{Tc}(\mathrm{VII}), \mathrm{Np}(\mathrm{V}), \mathrm{Th}(\mathrm{IV})$, and a toxic metal, $\mathrm{Cr}(\mathrm{VI})$. Equilibrium was achieved rapidly ( $<1$ hour) at a solutionto-solid ratio of 100 . Therefore, a batch contact time of 2 hours was used to ensure that these values represented true equilibrium conditions. The data showed that nanoporous calcined $\mathrm{Sr}(\mathrm{II})$ phosphate effectively removed $>95 \%$ of all target elements from solution (Table 1 ).

Distribution coefficients, $\mathrm{K}_{\mathrm{d}}$, are defined as a mass-weighted partition coefficient. At a solution-to-solids ratio of 100, a $K_{d}$ value of 100,000 indicates that at equilibrium there was 1,000 times as much ${ }^{99} \mathrm{Tc}$ in the nanoporous metal phosphate phase as there was remaining in the supernantant solution.
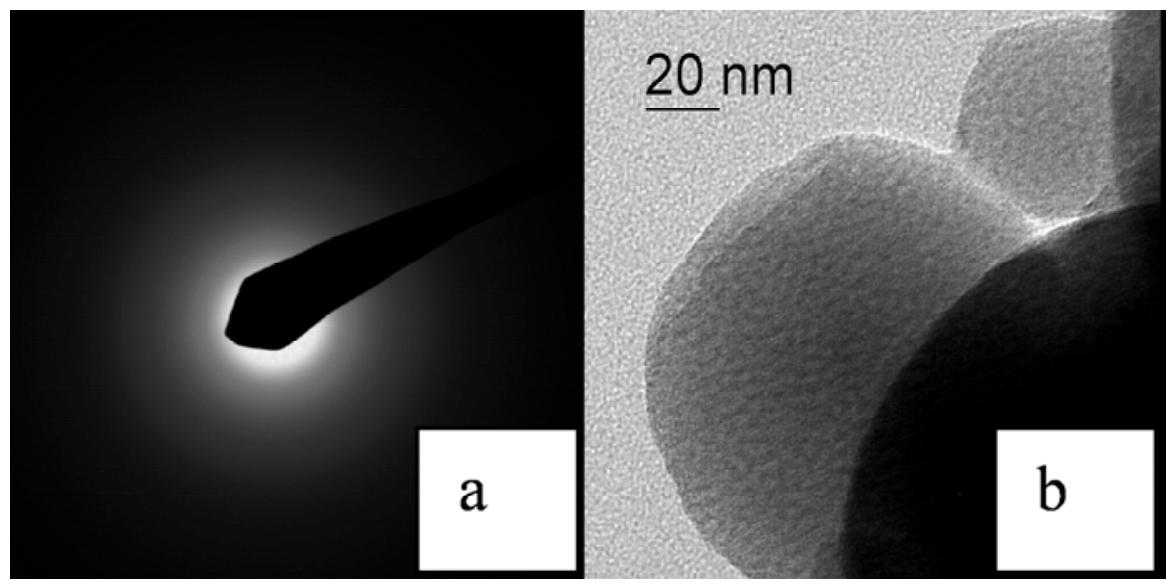

Figure I. (a) Selected-area electron diffraction pattern indicating amorphous structure; (b) nanoporous tin (II) phosphate with uniform pore distribution narrowly distributed around $2 \mathrm{~nm}$
Data obtained via XANES/EXAFS clearly illustrate that sequestration of $\mathrm{Tc}(\mathrm{VII}), \mathrm{Np}(\mathrm{V})$, and $\mathrm{Cr}(\mathrm{VI})$ with $\mathrm{Np}$ SnPO occurs through redox-coupled reactions, with the target metals being reduced to their least-soluble valence states - namely, Tc(IV), Np(IV), and $\mathrm{Cr}(\mathrm{III})$ (Figure 2).

Although lacking spectroscopic data, we surmise that Th(IV) adsorption on $\mathrm{Np}-\mathrm{SnPO}$ results from a Lewis acidbase interaction with $\mathrm{PO}_{4}$ groups.

We have also synthesized other stable nanoporous metal phosphates (Np-MPO) using indium, niobium, palladium, and 
Table I. Affinity of NP-SnPO

\begin{tabular}{lll} 
Sorbate & Text matrix & $\mathbf{K}_{\mathbf{d}}(\mathbf{m L} / \mathbf{g})$ \\
$\mathrm{Tc}(\mathrm{VII})$ & $0.002 \mathrm{M} \mathrm{NaHCO}_{3}$ & $>9.0 \times 10^{4}$ \\
$\mathrm{~Np}(\mathrm{~V})$ & $0.002 \mathrm{M} \mathrm{NaHCO}_{3}$ & $>1.1 \times 10^{5}$ \\
$\mathrm{Th}(\mathrm{IV})$ & DI Water & $>2.2 \times 10^{4}$ \\
$\mathrm{Cr}(\mathrm{VI})$ & $0.002 \mathrm{M} \mathrm{NaHCO}_{3}$ & $>5.6 \times 10^{4}$ \\
$\mathrm{Cr}(\mathrm{VI})$ & $\mathrm{GW}+0.02 \mathrm{M}$ & $>4.4 \times 10^{4}$ \\
& $\mathrm{Na}_{2} \mathrm{SO}_{4}$ & \\
\hline
\end{tabular}
for $\operatorname{Tc}(\mathrm{VII}), \mathrm{Np}(\mathrm{V})$, $\mathrm{Th}(\mathrm{IV})$, and $\mathrm{Cr}(\mathrm{VI})$

Table 2. Characteristics of synthetic nanoporous metal phosphates synthesized with CTAC template

$\begin{array}{lll}\text { Sample } & \text { Reagent } & d \text { Spacing }(\mathbf{n m}) \\ \mathrm{InPO} & \mathrm{InF}_{3} / \mathrm{H}_{3} \mathrm{PO}_{4} / \mathrm{NH}_{4} \mathrm{OH} & 3.68 \\ \mathrm{NbPO} & \mathrm{NbCl}_{5} / \mathrm{H}_{3} \mathrm{PO}_{4} / \mathrm{NH}_{4} \mathrm{OH} & 8.13 \\ \mathrm{PdPO} & \mathrm{PdCl}_{2} / \mathrm{H}_{3} \mathrm{PO}_{4} & 1.96 \\ \mathrm{FePO} & \mathrm{FeF}_{3} / \mathrm{H}_{3} \mathrm{PO}_{4} / \mathrm{NH}_{4} \mathrm{OH} & 4.74\end{array}$

\section{Sample Reagent}

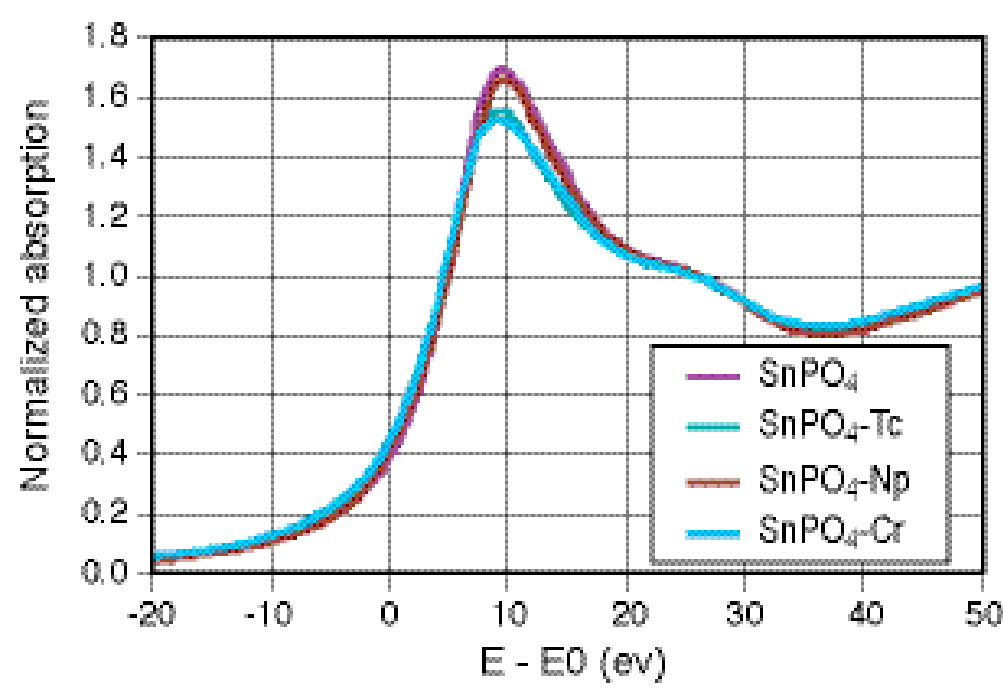

iron (Table 2). Characterization of these materials, including their radionuclide sequestration properties, is in progress.

Development of reduced Lewis metal nanoporous phosphate materials is a novel approach with added functionality. This enhances the inherent capability of these materials for sequestration of redox-sensitive radionuclides and metals based on two possible mechanisms: (1) sorption to nanoporous ligand sites and (2) reduction of the oxidized contaminant to less-soluble valence states by coupled reaction of nanoporous metal oxidation. This capability enhancement provides defense in depth at the proposed Yucca Mountain repository, by reducing radionuclide mobility.

A patent application has been filed that includes our successful synthesis of nanoporous metal phosphates and the demonstration of their radionuclide sequestration ability.

Figure 2. XANES spectra of Np-SnPO collected after batch sequestration tests with $\mathrm{Tc}(\mathrm{VII}), \mathrm{Np}(\mathrm{V})$, and $\mathrm{Cr}(\mathrm{VI})$. Data clearly illustrate the reduced state of the target metal contaminants. 


\section{Optimization of Layer Double Hydroxides and Related Materials}

Yifeng Wang and Huizhen Gao

Sandia National Laboratories (SNL)

\section{Research Objectives}

Our objective is to synthesize a diverse range of layers of double hydroxide (LDH) materials by varying synthesis conditions and chemistry to optimize material compositions and structures for the sorption of Tc and I anions. We also seek to measure the capacity and rate of adsorption on the synthesized LDH as a function of materials composition/structure and solution chemistry. In addition, this research pursues a mechanistic understanding of anion interactions with LDH surfaces and interlayers, as well as an exploration of the LDH deposited onto the pore surface of nanoporous alumina.

\section{Approach}

The general approach for synthesis of LDH is hydrolysis and co-precipitation of a pair of divalent and trivalent cations in the aqueous solution. In the preparation, a divalent metal M(II) salt solution and trivalent metal M(III) salt solution are mixed at a desired $\mathrm{M}$ (II)/ $\mathrm{M}$ (III) molar ratio to form a first mixture. The mixture is titrated with basic solution until the $\mathrm{pH}$ is above the logarithm of the dissociation constant. The solution is stirred, aged, filtered, and finally vacuum-dried or calcined at elevated temperature. In this work, the following divalent and trivalent metals are exploited: $\mathrm{M}(\mathrm{II})-\mathrm{Mg}, \mathrm{Zn}, \mathrm{Co}, \mathrm{Ni}, \mathrm{Cu}, \mathrm{Fe}, \mathrm{Cd}, \mathrm{Pd}$, and

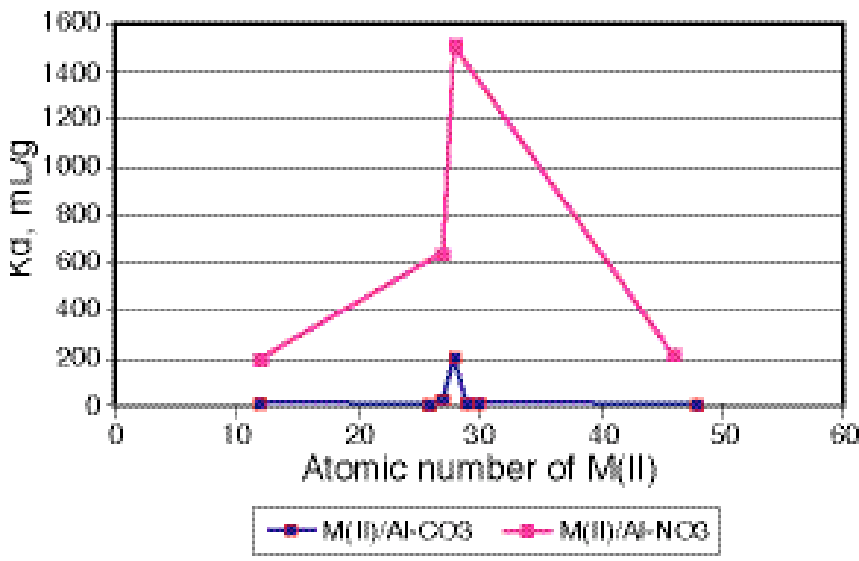

Figure I. Ni-Al- $\mathrm{NO}_{3}$ layered double hydroxide exhibits the highest sorption capability for $\mathrm{TcO}_{4}^{-}$. Materials tested were not calcined.
Mn; and M(III) - Al, Fe, Cr, V, Y, Yb, La, Ga, and Bi. With the metals selected from the aforementioned metals, the $\mathrm{M}(\mathrm{II}) / \mathrm{M}(\mathrm{III})$ molar ratio ranges from approximately 1 to 10 , with the most effective ratio generally in the range of 2 to 5. In the case of LDH deposited onto the surface of porous material, a mesoporous alumina surface was treated with nitric acid and then coprecipitated with $\mathrm{Ni}\left(\mathrm{NO}_{3}\right)_{2}$.

All the synthesized materials were subjected to the screening test for Tc adsorption capability. The activity of Tc is measured by liquid scintillation count and converted to the mass concentration. The distribution of Tc in the solid phase and liquid phase were calculated to obtain the partition coefficient $\left(\mathrm{K}_{\mathrm{d}}\right)$ values. Sorption experiments were conducted for Ni-Al LDH materials with different interlayer anions, including carbonate, nitrate, and sulfate.

\section{Accomplishments}

The accomplishments can be expressed in Figure 1 and Figure 2. Our study shows that:

1. A divalent metal $\mathrm{M}(\mathrm{II})$ salt solution and trivalent metal $\mathrm{M}$ (III) salt solution are mixed at a desired $\mathrm{M}(\mathrm{II}) / \mathrm{M}$ (III) molar ratio to form a first mixture, with the metals selected from the aforementioned metals in a $\mathrm{M}(\mathrm{II}) / \mathrm{M}(\mathrm{III})$ molar ratio ranging from

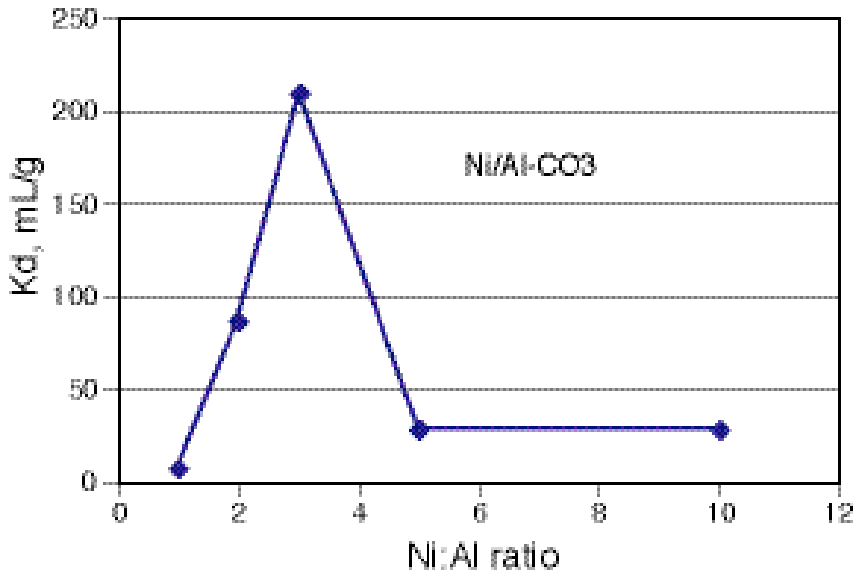

Figure 2. Ni/Al ratio effect on Tc adsorption (carbonate as the interlayer anion) 
approximately 1 to 10 , with the most effective ratio generally in the range of 2 to 5 . Among the $\mathrm{M}(\mathrm{II}) / \mathrm{M}(\mathrm{III})$ combinations, $\mathrm{Ni} / \mathrm{Al}$ is the best (Figure 1).

2. A comparison of synthesized LDHs with different interlayer anions shows that nitrate intercalation has the highest Tc removal among anions, such as carbonate and sulfate.

3. $\mathrm{Ni} / \mathrm{Al}=3$ is the best ratio for the $\mathrm{LDH}$ structure and adsorption capability (Figure 2).

4. LDH material is deposited on a nanoporous alumina support, which enhances the adsorption capacity. A similar treatment was performed using $\mathrm{ZnCl}_{2}$ solution, instead of $\mathrm{Ni}\left(\mathrm{NO}_{3}\right)_{2}$. The treated nanoporous alumina exhibits an extremely high sorption capability for oxyanions as compared with other tested materials (that includes $85 \%$ Tc removal from a synthesized Hanford waste water).

5. The mechanism of oxyanion adsorption by LDH includes both ion exchange and complexation with surface functional groups.

Synthesized LDH in this study has a high sorption capability for oxyanions, including $\mathrm{TcO}_{4}^{-}, \mathrm{AsO}_{4}{ }^{2-}, \mathrm{ClO}_{4}{ }^{-}, \mathrm{SeO}_{4}{ }^{2-}$, $\mathrm{IO}_{3}^{-}, \mathrm{CrO}_{4}^{-}$, and $\mathrm{ReO}_{4}^{-}$, etc. The formulated materials can potentially be used for chemical separation, water purification, and waste isolation related to either radioactive or toxic oxyanions. Our systematic study has provided solid support for further theoretical research on LDH structure and its functions. Such an effort would likely result in a class of materials capable of selectively adsorbing and sequestering pertechnetate under proposed Yucca Mountain repository conditions, thus reducing the likelihood of radionuclide migration from the proposed repository horizon. 


\section{Hydroxyapatite for Technetium Sequestration}

Katheryn B. Helean

Sandia National Laboratories (SNL)

\section{Research Objectives}

Apatite, $\mathrm{Ca}_{5}\left(\mathrm{PO}_{4}\right)_{3}(\mathrm{~F}, \mathrm{OH}, \mathrm{Cl})$, is the most abundant phosphate mineral on Earth. Apatite is, therefore, a common accessory phase in all three major rock-types-igneous, metamorphic, and sedimentary. The end-member, hydroxyapatite, $\mathrm{Ca}_{5}\left(\mathrm{PO}_{4}\right)_{3} \mathrm{OH}$, is the primary mineral component in bones and teeth, and tends to scavenge and sequester heavy metals in the human body. The crystal structure of apatite tolerates a great deal of distortion caused by extensive chemical substitutions. Metal cations (e.g., REE, actinides, K, Na, Mn, Ni, Cu, Co, Zn, $\mathrm{Sr}, \mathrm{Ba}, \mathrm{Pb}, \mathrm{Cd}, \mathrm{Fe}$ ) substitute for $\mathrm{Ca}$ and oxyanions (e.g., $\mathrm{AsO}_{4}{ }^{3-}, \mathrm{SO}_{4}{ }^{2-}, \mathrm{CO}_{3}{ }^{2-}$, $\left.\mathrm{SiO}_{4}{ }^{4-}, \mathrm{CrO}_{4}{ }^{2-}\right)$ substitute for $\mathrm{PO}_{4}{ }^{3-}$, through a series of coupled substitutions to preserve electroneutrality. The ability of apatite to incorporate "impurities," including actinides, gives rise to its proposed use as a waste form for radionuclides. Recent work at Sandia National Laboratories demonstrated that hydroxyapatite has a strong affinity for $\mathrm{U}, \mathrm{Pu}, \mathrm{Np}, \mathrm{Sr}$, and Tc reduced from pertechnetate $\left(\mathrm{TcO}_{4}^{-}\right)$by $\mathrm{SnCl}_{2}$. Based on these earlier promising results, an investigation was initiated into the use of apatite-type materials doped with aliovalent cations (cations with different oxidation states than the host cation, creating a charge imbalance) including iron (Fe), copper $(\mathrm{Cu})$, and manganese $(\mathrm{Mn})$ as Tc-scavengers under proposed-repository-relevant conditions.

Table I. Batch sorption results for HA doped with 10 $\mathrm{mol} \% \mathrm{Fe}(\mathrm{II})$ and iron metal

\begin{tabular}{|c|c|c|c|c|}
\hline \multirow[t]{2}{*}{ Water Type } & \multirow[t]{2}{*}{ Material } & \multicolumn{3}{|c|}{ Percent Sorbed } \\
\hline & & Day 1 & Day 2 & Day 3 \\
\hline \multirow[t]{2}{*}{ Groundwater } & Fe metal & 60 & 93 & 100 \\
\hline & $\begin{array}{l}10 \% \mathrm{Fe}- \\
\mathrm{HA}\end{array}$ & 94 & 98 & 96 \\
\hline \multirow[t]{2}{*}{$0.1 \mathrm{M} \mathrm{NaCl}$} & Fe metal & 56 & 95 & 98 \\
\hline & HA & 79.5 & 96.5 & 97 \\
\hline \multirow[t]{2}{*}{$0.01 \mathrm{M} \mathrm{NaCl}$} & Fe metal & 54.7 & 93.8 & 96 \\
\hline & & 78.3 & 95.7 & 94 \\
\hline
\end{tabular}

\section{Approach}

Hydroxyapatite (HA) materials doped with ferrous iron, $\mathrm{Fe}(\mathrm{II})$, and $\mathrm{Cu}$ were synthesized by the slow addition of ammonium phosphate to Ca-acetate. The aliovalent metal cations were introduced as chlorides and maintained in their reduced state by adding stannous chloride to the acetate solution. The slurry was stirred at $80^{\circ} \mathrm{C}$ for 3 hours while the $\mathrm{pH}$ was manually adjusted to 7.6 by adding phosphoric acid or ammonium hydroxide. The precipitate was stirred at room temperature for 24 hours and then filtered and allowed to dry at $110^{\circ} \mathrm{C}$ for several hours. HA with 2, 5, and $10 \mathrm{~mol} \% \mathrm{Fe}^{2+}$ and HA with 2 and $5 \mathrm{~mol} \%$ $\mathrm{Cu}$ were obtained.

Doped HA samples were characterized using multiple techniques to determine structure, crystallinity, surface area, and stoichiometry. X-ray powder diffraction (XRD) was used for structure and crystallinity measurements. Scanning electron microscopy (SEM) with energy dispersive spectrometry (EDS) will be used to assess sample homogeneity. Transmission electron microscopy (TEM) allowed characterization of nanocrystalline and amorphous samples. Brunhauer Emmett Tuller (BET), a gas adsorption method, was used for determining specific surface area. A potassium dichromate titration method was used to confirm the presence of Fe(II) in the samples.

To evaluate the sorption characteristics of $\mathrm{Fe}(\mathrm{II})$ - and $\mathrm{Cu}$ doped HA with respect to $\mathrm{TcO}_{4}^{-}$, short-term batch sorption tests were conducted using a Yucca Mountain pore water $(\mathrm{YMPW})\left(\mathrm{Si}, \mathrm{Na}\right.$, Ca-saturated equilibrated with $\mathrm{HCO}_{3}$ ), "J-13," and simple solutions of varying ionic strength as controlled by $\mathrm{NaCl}$ concentration. Typically, $0.2 \mathrm{~g}$ sorbent is placed in a vial with $30 \mathrm{~mL}$ fluid spiked with $10^{-6} \mathrm{M}$ Tc. The fluid was sampled as a function of time, and the total radioactivity remaining in the solution was determined using liquid scintillation counting (LSC). Additional sorption tests were conducted on promising candidate materials as a function of fluid composition. Desorption tests were used to measure how easily HA materials release Tc into initially unspiked fluids. 


\section{Accomplishments}

A number of batch sorption tests were conducted on the $\mathrm{Fe}(\mathrm{II})$-doped HA materials. The sorption characteristics of those samples containing low quantities of ferrous iron were moderate, with up to $56 \%$ of the initial $\mathrm{TcO}_{4}{ }^{-}$activity removed after 3 days. The HA sample doped with 10

$\mathrm{mol} \%$ ferrous iron adsorbed Tc at a rate and with a capacity similar to iron metal (Table 1). Both materials adsorbed greater than $95 \%$ of the Tc in the first 3 days of the tests. Three fluid types were tested, and the materials performed comparably in all three fluids. The groundwater referred to in the table is YMPW. Two $\mathrm{NaCl}$ solutions were included in the test matrix for comparison. Remarkably, the Tc, once adsorbed, did not desorb even after several months.
Hydroxyapatite is a chemically durable, radiation-damage-resistant, and inexpensive material that has been studied extensively for its ability to scavenge and sequester radionuclides. Most of the previous work on this material has focused on actinides. This study demonstrates that when treated with aliovalent cations that may reduce oxidized species, hydroxyapatite also adsorbs Tc from pertechnetate in solution under YMP-relevant conditions. HA exhibits a great deal of structural "flexibility," allowing this material to be doped with a wide range of cations. HA may also be chemically "tuned" to target specific radionuclides and heavy metals (e.g., Cu-doped HA may adsorb $\mathrm{IO}_{3}^{-}$), thus providing a cost-effective, yet significant barrier to radionuclide migration from the proposed repository horizon to the biosphere. 


\section{lodine Getter Development}

James L. Krumhansl, Jason D. Pless, and J. Benjamin Chwirka

Sandia National Laboratories (SNL)

\section{Research Objectives}

One strategy for confining radionuclides to the immediate vicinity of the proposed Yucca Mountain repository involves mixing materials into the invert beneath the highlevel-waste (HLW) waste packages to scavenge radionuclides from waters that may have percolated through breached waste packages. Although several radionuclides are of concern in this context, this particular research targets the problem of finding ways to mitigate ${ }^{129}$ I releases.

\section{Approach}

Our strategy involved first assessing the range of environments and characteristics of fluids likely to occur in the proposed repository. Next, a test matrix was developed (Table 1) that reflected a prioritized approach to assessing the suitability of various getter materials in these environments. Three general classes of fluids were identified: (1) normal groundwaters ("J-13-like"); (2) brines formed early in the proposed repository site's history as a consequence of thermally driven evaporation; and (3) fluids with chemistries dominated by constituents derived from corroding waste packages. Radionuclide sorption from the brines is not of concern because they appear, and should be gone, long before the waste packages breach. However, their impact on the phase stability of getters residing in the invert is still relevant.

The selection of materials for initial screening was made based on past experience in developing products for similar applications at Hanford and Savannah River, and from hints that had been gleaned over the years from published literature. In a few cases, the materials could be purchased commercially, but more often it was necessary to synthesize materials before they could be tested. Batch $\mathrm{K}_{\mathrm{d}}$ tests were adopted as the screening procedure of choice, because large numbers of samples could be inexpensively and quickly assessed. In the first year of the program, only short-term (several days to a week) "Primary Tests" (Table 1) were performed.

\section{Accomplishments}

The strategy outlined above not only successfully located potentially effective iodine getters (Table 2), it also set the stage for developing the $\mathrm{Bi}$-based $\mathrm{TcO}_{4}^{-}$(and $\mathrm{ReO}_{4}^{-}$) getters described elsewhere. The problem of developing iodine scavengers is complicated by the fact that iodine can exist in two oxidation states, giving rise to $\mathrm{I}^{-}$and $\mathrm{IO}_{3}^{-}$. Considering the amount of metallic iron at the proposed repository site, one could infer that iodide would be the primary concern. However, the YMP regards the in-repository environment as strongly oxidizing, so consideration was also given to finding iodate scavengers. In all, several classes of materials were evaluated: (1) delaflossite

Table I. Prioritization matrix for batch $K_{d}$ measurements. Actual batch testing to be performed at room temperature on variously pretreated materials.

$\begin{array}{lllll}\text { Solid Pre-Treatment } \rightarrow \text { As Received } & \text { Dry Heated } & \text { Dry Heated } & 90^{\circ} \mathrm{C}, \text { DI or } & 90^{\circ} \mathrm{C} \text { "Brines"and } \\ 130^{\circ} \mathrm{C} & 200^{\circ} \mathrm{C} & \mathrm{J}-13 \text { water } & \text { "200-Year Corrosion Fluid" }\end{array}$

Fluid for $\mathrm{K}_{\mathrm{d}}$ tests $\downarrow$

"Dilute" J-13-like

(Low Ionic Strength) Primary Test Stage 4 Test Stage 2 Test Stage 2 Test Stage 3 Test

10X-Waste Leach

(With Rust) Stage 3 Test Stage 4 Test Stage 3 Test Stage 3 Test Stage 3 Test

Waste Leach

(No Rust, Late)

Stage 4 Test

Stage 4 Test

Stage 4 Test

Stage 4 Test

Stage 4 Test 
Table 2. $\mathrm{K}_{\mathrm{d}}$ Values of $\mathrm{I}^{-}, \mathrm{IO}_{3}{ }^{-}, \mathrm{ReO}_{4}{ }^{-}$and $\mathrm{TcO}_{4}^{-}$( $\mathrm{HTC}$ denotes derivation from hydrotalcite)

\begin{tabular}{|c|c|c|c|c|}
\hline Phases (by XRD) & $\log K_{d} I^{-}$ & $\log \mathrm{K}_{\mathrm{d}} \mathrm{IO}_{3^{-}}^{-}$ & $\log \mathrm{K}_{\mathrm{d}} \mathrm{ReO}_{4}^{-}$ & $\log \mathrm{K}_{\mathrm{d}} \mathrm{TcO}_{4}^{-}$ \\
\hline $\mathrm{Mg} / \mathrm{Al}$ - HTC & 0.0 & 0.52 & 0.89 & - \\
\hline $\mathrm{Co} / \mathrm{Al}-\mathrm{HTC}$ & 2.4 & 4 & 2.2 & - \\
\hline $\mathrm{Cu} / \mathrm{Al}-\mathrm{HTC}$ & 4.0 & $>4.7$ & 2.4 & 3.0 \\
\hline Zn/Al - HTC & 2.3 & 3.8 & 2.0 & - \\
\hline $\mathrm{Pd} / \mathrm{Al}$ - HTC & 1.6 & 1.9 & No sorption & - \\
\hline $\mathrm{Co} / \mathrm{Cr}-\mathrm{HTC}$ & 2.0 & 4.5 & 2.1 & - \\
\hline $\mathrm{Ni} / \mathrm{Cr}-\mathrm{HTC}$ & 2.6 & $>4.7$ & 2.6 & 3.2 \\
\hline $\mathrm{Cu} / \mathrm{Cr}-\mathrm{HTC}$ & 3.6 & $>4.7$ & 2.7 & 3.3 \\
\hline $\mathrm{Co} / \mathrm{Fe}-\mathrm{HTC}$ & 1.5 & 3.9 & 2.0 & - \\
\hline $\mathrm{Ni} / \mathrm{Fe}-\mathrm{HTC}$ & 2.2 & 4.8 & 2.2 & 3.2 \\
\hline $\mathrm{Cu}_{4}\left(\mathrm{NO}_{3}\right)_{2}(\mathrm{OH})_{6}[\mathrm{Cu} / \mathrm{Fe}-\mathrm{HTC}]$ & 2.9 & 4.2 & 1.9 & - \\
\hline $\mathrm{Co} / \mathrm{La}-\mathrm{HTC}$ & 1.8 & 2.7 & 0.95 & \\
\hline $\mathrm{Ni} / \mathrm{La}-\mathrm{HTC}$ & 1.8 & 3.2 & 2.5 & 2.4 \\
\hline $\mathrm{Cu}_{4}\left(\mathrm{NO}_{3}\right)_{2}(\mathrm{OH})_{6}[\mathrm{Cu} / \mathrm{La}-\mathrm{HTC}]$ & 1.6 & 1.8 & 0.26 & - \\
\hline Layered $\mathrm{Bi}(\mathrm{OH})_{3}$ made with $\mathrm{Ni}^{++}$ & $2.8-3.4$ & 3.4 & 1.4 & - \\
\hline Layered $\mathrm{Bi}(\mathrm{OH})_{3}$ made with $\mathrm{Zn}^{++}$ & $3.5-4.1$ & 4.9 & 3.8 & - \\
\hline Layered $\mathrm{Bi}(\mathrm{OH})_{3}$ made with $\mathrm{Li}^{+}$ & $3.9-4.4$ & 4.6 & $2.3-3.8$ & 3.9 \\
\hline Layered $\mathrm{Bi}(\mathrm{OH})_{3}$ made with $\mathrm{Na}^{+}$ & $3.3-3.7$ & 2.5 & 0.9 & \\
\hline Layered $\mathrm{Bi}(\mathrm{OH})_{3}$ made with $\mathrm{K}^{+}$ & $3.7-4.0$ & 3.5 & $2.1-2.2$ & - \\
\hline $\mathrm{Bi}_{2} \mathrm{O}_{3}$ fused in $\mathrm{LiNO}_{3}$ & 3.5-3.6 & 2.3 & $1.2-1.3$ & - \\
\hline Untreated $\mathrm{Bi}_{2} \mathrm{O}_{3}$ & 3.0 & 1.7 & No sorption & - \\
\hline
\end{tabular}

$\left[\mathrm{CuFe}_{2} \mathrm{O}_{4}\right]$ and related materials derived by substituting other metals for iron; (2) other miscellaneous Cu-containing minerals, mixed-metal oxides, carbonates, phosphates, arsenate, etc.; (3) divalent metal tungstates; (4) minerals derived from hydrotalcite $\left[\mathrm{Mg}_{6} \mathrm{Al}_{2} \mathrm{CO} 3(\mathrm{OH})_{16} \cdot 4 \mathrm{H}_{2} \mathrm{O}\right]$ by substituting other metals for $\mathrm{Mg}$ and $\mathrm{Al}$ and other anions for carbonate; and (5) "layered" hydrous Bi oxy-hydroxides. Materials from the last two categories greatly outperformed the other materials. It is worth noting that the layered Bi oxy-hydroxides do not contain a second metal in the lattice. However, the presence of a second metal in the synthesis fluid evidently exerts an influence on the type of precipitate formed and, consequently, on the performance of the precipitates as getters.

A good start has been made: two classes of materials were identified that are both geologically stable and have signif- icant capacities for scavenging radioiodine. Further, some of the hydrotalcite-derived materials may be formed as waste packages corrode and provide the degrading waste package with its own barrier to ${ }^{129}$ I releases. As a rule of thumb, a $K_{d}$ in excess of $10^{3}$ is needed before an in-repository getter can materially alter iodine releases at a distant point of compliance. This has (apparently) been achieved, but with a significant caveat. The existing data are insufficient to show whether iodine was removed from experimental solutions by the same linear sorption mechanism as is implied when a $\mathrm{K}_{\mathrm{d}}$ is used to predict radionuclide migration in groundwaters. Further, we are also essentially ignorant of how the many other environmental variables inherent in the proposed repository environment could impact getter performance. Thus, much remains to be learned before these initially auspicious results can be applied in ways that actually benefit the YMP. 


\section{BiOX-Based Solid Radionuclide (Tc) Getters}

Ranko P. Bontchev

Sandia National Laboratories (SNL)

\section{Research Objectives}

The objectives of this work were to identify, synthesize, characterize, test, and evaluate the technetium (Tc)-sorption properties of solid anionic getters for radionuclide confinement. Our studies were focused on Bi-based oxides of general formula $\mathrm{BiOX}$, where $\mathrm{X}=$ inorganic or small organic anions. The structure of these compounds is based on a stacking of positively charged $(\mathrm{BiO})^{+}$layers, the charge balance being provided by the $X$-anions located in the space between them. The main idea was that in aqueous solution and upon proper conditions (concentration, $\mathrm{pH}$, temperature), anionic radioactive species such as $\mathrm{TcO}_{4}{ }^{-}$and $\mathrm{I}^{-}$will exchange for the original anions $\mathrm{CO}_{3}{ }^{2-}$, $\mathrm{Cl}^{-}, \mathrm{Br}^{-}$, etc., and thus become confined in a solid matrix.

\section{Approach}

Our technical approach was based on extended exploratory synthesis of $\mathrm{BiOX}$-type derivatives and their structural and chemical characterization. The main goals were to develop simple and practical synthetic methods for, as well as characterize, test, and evaluate the sorption properties of, these solids with respect to their potential use as solid getters for radionuclide (and specifically Tc) confinement.

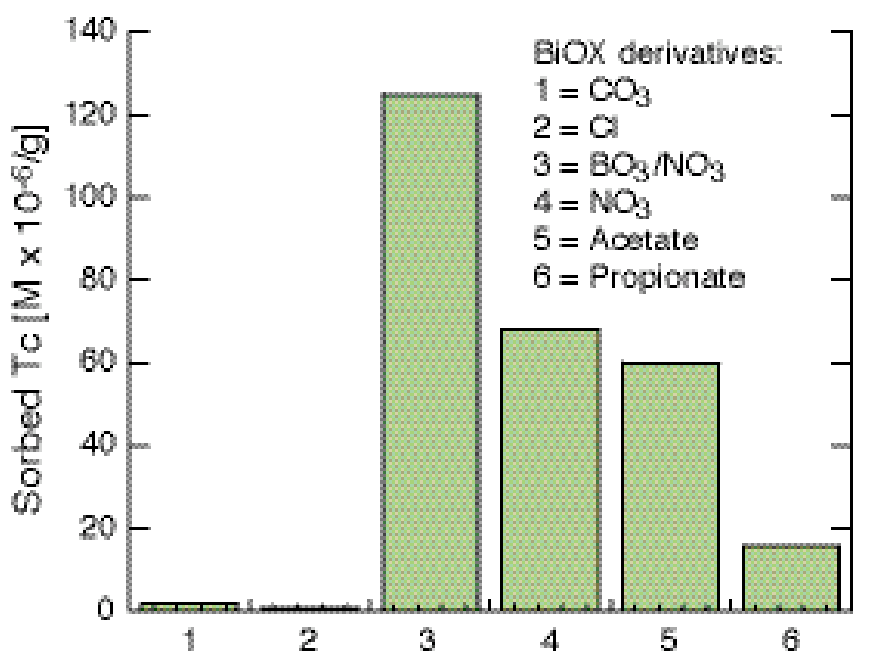

Figure I. Tc sorption capacity $\left[\mathrm{M} \times 10^{-6} / \mathrm{g}\right]$ of the BiOX derivatives

\section{Accomplishments}

\section{Synthesis}

Two different methods for the synthesis of BiOX-type phases have been developed and successfully applied for the preparation of laboratory-scale amounts (up to $20 \mathrm{~g}$ ) of test solids. The first one is based on direct precipitation at room temperature, using $\mathrm{Bi}\left(\mathrm{NO}_{3}\right)_{3}$ and the corresponding $\mathrm{HX}$ or $\mathrm{NaX}$, and adjusting the $\mathrm{pH}$ within the range 9-12 using sodium or ammonium hydroxide. The second method is based on hydrothermal synthesis at $120-150^{\circ} \mathrm{C}$ under autogeneous pressure, using Bi nitrate, the corresponding sodium $\mathrm{NaX}$ salts, and, again, adjusting the $\mathrm{pH}$ within the range 9-12. Both methods are simple and straightforward and yield well-crystallized products for relatively short periods of time (typically overnight, 8-12 hours). As a result of these efforts, five new BiOX derivatives have been successfully synthesized and structurally and chemically characterized by powder x-ray diffraction (XRD) and Fourier transform infrared (FTIR) methods.

\section{Structural and Chemical Characterization}

The new BiOX derivatives have been characterized by powder XRD and FTIR methods. The main crystallographic features of these phases are summarized below.

\section{Tc Sorption Capacity}

Several series of experiments have been run with different amounts of solid BiOX and Tc solutions of different concentrations. The results shown below were obtained for 0.2 $\mathrm{g}$ BiOX immersed in $30 \mathrm{~mL}$ Tc solutions (total initial $\mathrm{Tc}=$ $25.4 \times 10^{-6} \mathrm{M}$ ) for 10 days. The data were comparable with previously obtained data and provided a good basis for evaluation of the best solid $\mathrm{BiOX}$ sorbents, those being the derivatives with $\mathrm{X}=\mathrm{NO}_{3}{ }^{-},\left(\mathrm{NO}_{3}-\mathrm{BO}_{3}{ }^{3-}\right)$, and (acetate)-

Two different methods for the synthesis of BiOX-type phases have been developed and successfully applied for the preparation of laboratory-scale amounts (up to $20 \mathrm{~g}$ ) of test solids. Typically, reactions are completed within 8-12 hours using relatively cheap and available reagents such as Bi nitrate, ammonium hydroxide, and the corresponding $\mathrm{NaX}$ salts. Five new BiOX derivatives have been suc- 
Table I. Basic structural data for the new BiOX derivatives

\begin{tabular}{|c|c|c|c|}
\hline Formula & Space group & Cell parameters & Main structural features \\
\hline $\mathrm{Bi}_{3} \mathrm{O}_{4}\left(\mathrm{NO}_{3}\right)$ & $\mathrm{P} 4 / \mathrm{mmm}$ & $\begin{array}{l}\mathrm{a}=5.693(1) \AA \\
\mathrm{c}=10.368(1) \AA\end{array}$ & $\begin{array}{l}\text { Triple } \mathrm{BiO} \text { layers } \\
\text { Single } \mathrm{NO}_{3} \text { layers }\end{array}$ \\
\hline $\mathrm{Bi}_{6} \mathrm{O}_{8}\left(\mathrm{NO}_{3}\right)\left(\mathrm{BO}_{3}\right)$ & $\mathrm{I} 4 / \mathrm{mmm}$ & $\begin{array}{l}\mathrm{a}=3.924(1) \AA \\
\mathrm{c}=14.109(1) \AA\end{array}$ & $\begin{array}{l}\text { Double } \mathrm{BiO} \text { layers } \\
\text { Single } \mathrm{NO}_{3} / \mathrm{BO}_{3} \text { layers }\end{array}$ \\
\hline $\mathrm{Bi}_{6} \mathrm{O}_{8}\left(\mathrm{NO}_{3}\right)\left(\mathrm{BO}_{3}\right)$ & Immm & $\begin{array}{l}\mathrm{a}=3.844(1) \AA \\
\mathrm{b}=3.904(1) \AA \\
\mathrm{c}=14.554(1) \AA\end{array}$ & $\begin{array}{l}\text { Double } \mathrm{BiO} \text { layers } \\
\text { Single } \mathrm{NO}_{3} / \mathrm{BO}_{3} \text { layers }\end{array}$ \\
\hline $\mathrm{Bi}_{2} \mathrm{O}_{4}\left(\mathrm{CH}_{3} \mathrm{COO}\right)_{2}$ & $\mathrm{P} 4 / \mathrm{nmm}$ & $\begin{array}{l}\mathrm{a}=3.964(1) \AA \\
\mathrm{c}=12.694(1) \AA\end{array}$ & $\begin{array}{l}\text { Double } \mathrm{BiO} \text { layers } \\
\text { Double }\left(\mathrm{CH}_{3} \mathrm{COO}\right) \text { layers }\end{array}$ \\
\hline $\mathrm{Bi}_{2} \mathrm{O}_{4}\left(\mathrm{ClO}_{4}\right)_{2}$ & $\mathrm{P} 4 / \mathrm{mmm}$ & $\begin{array}{l}\mathrm{a}=3.803(1) \AA \\
\mathrm{c}=17.045(1) \AA\end{array}$ & $\begin{array}{l}\text { Double } \mathrm{BiO} \text { layers } \\
\text { Single }\left(\mathrm{ClO}_{4}\right) \text { layers }\end{array}$ \\
\hline
\end{tabular}

cessfully synthesized, and structurally and chemically characterized by powder XRD and FTIR methods. Three of these new materials, namely the $\mathrm{X}=\mathrm{NO}_{3}{ }^{-},\left(\mathrm{NO}_{3}{ }^{-} \mathrm{BO}_{3}{ }^{3-}\right)$ and (acetate) ${ }^{-}$derivatives, have significant $\mathrm{Tc}$ sorption/containment capacity. In fact, the Bi materials investigated in this task have been shown to selectively adsorb and sequester pertechnetate, thus potentially decreasing the mobility of this anionic radionuclide in the event that a waste package is breached at the proposed Yucca Mountain repository.

\section{References}

Bontchev, R. P., F. Bonhomme, J. Krumhansl, and R. C. Moore, Structural relations and phase transformations in the system $\mathrm{BiOX}\left(\mathrm{X}=\mathrm{Cl}^{-}, \mathrm{BO}_{3}^{-}, \mathrm{NO}_{3}^{-}, \mathrm{CO}_{3}{ }^{2-}\right.$ and $\left.\mathrm{CH}_{3} \mathrm{COO}^{-}\right)$. 229 th $A C S$ National Meeting, INOR 866, San Diego, CA, March 13-17, 2005. 


\section{Exploring the Use of Manganese Oxides as Anionic Getters}

Michael Hochella and Heike Pieper

Virginia Polytechnic and State University

\section{Research Objectives}

Recent research has shown that several manganese (Mn) oxides have the ability to sorb aqueous metal cations much more efficiently than even iron oxides, which are well known as very active sorbents ( $\mathrm{O}^{\prime}$ Reilly and Hochella, 2003). This ability for manganese oxides is, at least in part, related to the internal sites available in those species that have tunnel and sheet structures. Additionally, a new, naturally occurring $\mathrm{Mn}$ oxide, a vernadite-like phase (nominally $\mathrm{MnO}_{2} \cdot \mathrm{nH}_{2} \mathrm{O}$ ), collected along the Clark Fork River

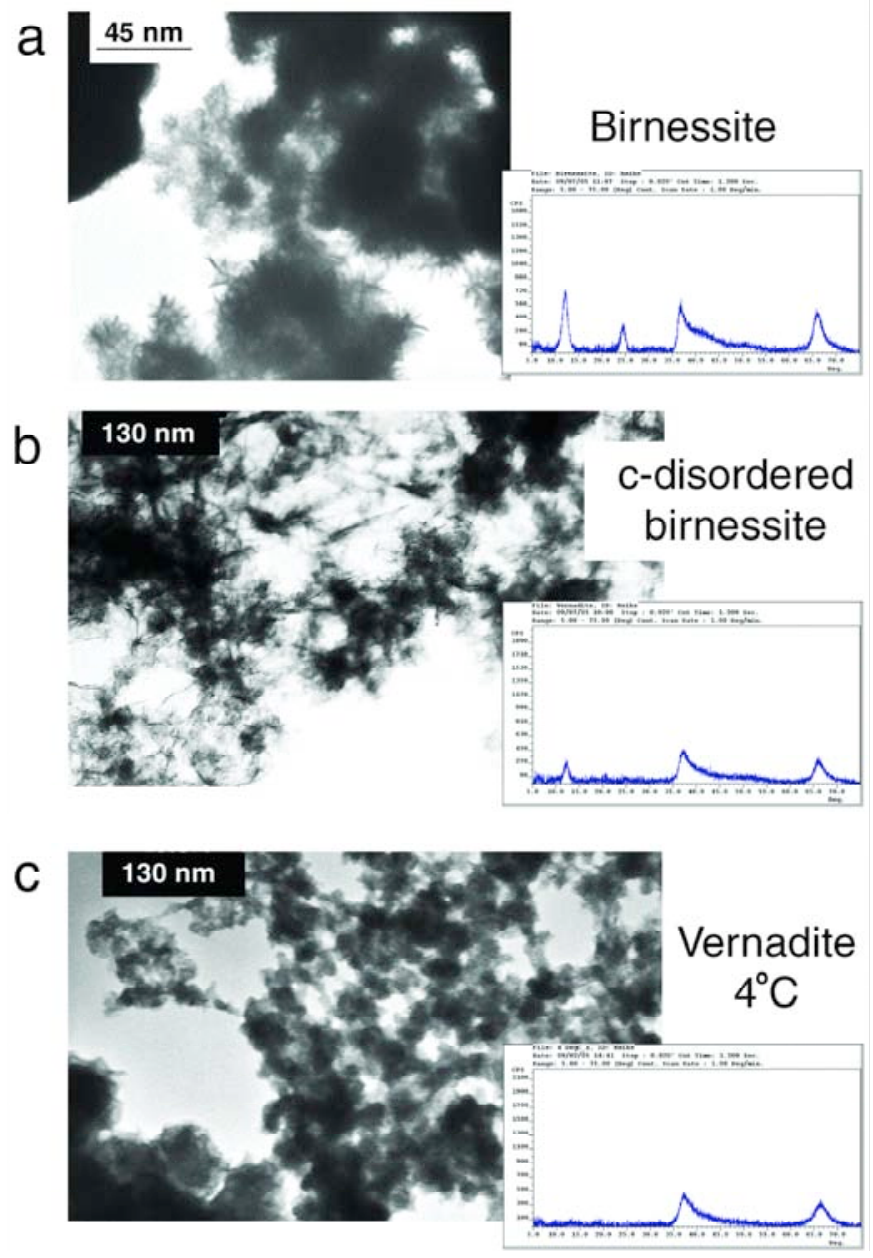

Figure I. TEM images and XRD powder patterns of the three synthetic products from this study in western Montana, USA, has shown the ability to aggressively sorb arsenate, an anionic complex (Hochella et al., 2005a, b). The potential for Mn oxides to sorb anions has made it an attractive material as a radionuclide getter.

\section{Approach}

The focus of our project was to synthesize nanosized grains of sheet Mn oxides and to run flow-through sorption experiments to quantitatively assess their uptake ability for perrhenate (a rhenium anionic complex used as a nonradiogenic surrogate of technetium [Tc]).

All synthesis reactions utilized in this study require the reduction of $\mathrm{Mn}(\mathrm{VII})$ salts to $\mathrm{Mn}(\mathrm{III}, \mathrm{IV})$ oxides. Different products were obtained, depending on the starting materials and the temperatures and rates of formation. Each synthesis requires multiple washing steps to free the product of unwanted salts.

Our adsorption experiments ran under chemical steadystate conditions by using flow-through reactors. In contrast to batch reactors, where the solution varies with reaction time, fresh solution with the ion of interest passes through a bed of the sorbing mineral. The experiments were run in duplicate and carried out with an influent perrhenate concentration of $10 \mathrm{ppm}$. Each influent solution was adjusted to the chosen $\mathrm{pH}$ value of $5.0,7.0$, or $9.0 \pm$ 0.2 , and an ionic strength of $0.01 \mathrm{~mol} / \mathrm{L} \mathrm{NaNO}_{3}$. The effluent solutions were analyzed for Re and Mn by inductively coupled plasma (ICP) methods as a function of reaction time.

\section{Accomplishments}

We have synthesized birnessite, a sheet Mn oxide, as well as a "c-disordered" birnessite, and vernadite, another layered Mn oxide, but presumably with a nonperiodic stacking of the layers. The c-disordered variety may be a structural intermediate between birnessite and vernadite.

The morphology of the synthetic Mn oxides was characterized by transmission electron microscopy (TEM), and the results are shown in Figure 1, along with the x-ray diffraction (XRD) patterns for each. All products have nanoscale dimensions. The birnessite reaction product consists of balls of fine, short needles and plates. The c-disordered 
birnessite has a complex and variable morphology, consisting of very thin platelets and ribbon-like particles. In contrast, the vernadite (synthesized at $4^{\circ} \mathrm{C}$, instead of room temperature) forms small, often round particles with a sharp grain boundary (10-20 $\mathrm{nm})$.

In the flow-through experiments for each of these three synthesis products, we observed similar sorption efficiency for birnessite and the c-disordered birnessite. The minerals sorbed 1.35 and $1.27 \pm 0.1 \mathrm{ppm}$ perrhenate/run, respectively, at $\mathrm{pH} 5$. The sorption efficiency decreases slightly, but within the error, under $\mathrm{pH} 7$ conditions $(1.20$ and $1.14 \pm 0.1 \mathrm{ppm} / \mathrm{run})$. However, at $\mathrm{pH} 9$, the amount of sorbed perrhenate was significantly smaller ( 0.40 and 0.41 $\pm 0.1 \mathrm{ppm} /$ run, respectively). This $\mathrm{pH}$ dependency of the sorption efficiency is not unexpected for anion complexes on birnessite-like minerals, because the surface charge on birnessite becomes highly negative with increasing $\mathrm{pH}$.

In contrast, the sorption efficiency of vernadite synthesized at $4^{\circ} \mathrm{C}$ is lower at pH 5 and 7, compared to birnessite and c-disordered birnessite; but, interestingly, this sorption efficiency does not decrease at $\mathrm{pH} 9$ (all $0.70 \pm 0.1 \mathrm{ppm}$ perrhenate/run). Therefore, the amount of sorbed $\mathrm{ReO}_{4}{ }^{-}$at $\mathrm{pH} 9$ compared to birnessite and c-disordered birnessite is almost 2 times higher.

All three nanoscale Mn-oxide synthesis products obtained from this study are powerful $\mathrm{ReO}_{4}{ }^{-}$anion complex sorbents over a wide $\mathrm{pH}$ range. We anticipate that their sorptive capability for aqueous Tc will be similar. These minerals can be readily synthesized in the lab at low temperature using inexpensive starting materials, meaning that scaling-up to industrial production would be economical. Considering the fact that minerals like these have also already been observed to aggressively capture both cationic and anionic heavy metal complexes in natural settings (Hochella et al., $2005 \mathrm{a}, \mathrm{b}$ ), they remain highly promising candidates as a reactive medium in permeable barriers around nuclear waste repositories, such as that proposed for Yucca Mountain, Nevada.

\section{References}

Hochella, M.F., Jr., J.N. Moore, C. Putnis, A. Putnis, T. Kasama, and D.D. Eberl, Direct observation of toxic metal-mineral association from a massive acid mine drainage system: Implications for metal transport and bioavailability. Geochim. Cosmochim. Acta, 69, 1651, 2005a.

Hochella M.F., Jr., T. Kasama, A. Putnis, C. Putnis, and J.N. Moore, Environmentally important, poorly crystalline $\mathrm{Fe} / \mathrm{Mn}$ hydrous oxides: Ferrihydrite and a vernaditelike mineral from a massive acid mine drainage system. Amer. Mineral., 90, 718, 2005b.

O'Reilly S.E., and M.F. Hochella, Jr., Lead sorption efficiencies of natural and synthetic Mn and Fe-oxides. Geochim. Cosmochim. Acta, 67, 4471, 2003. 
This page intentionally left blank. 


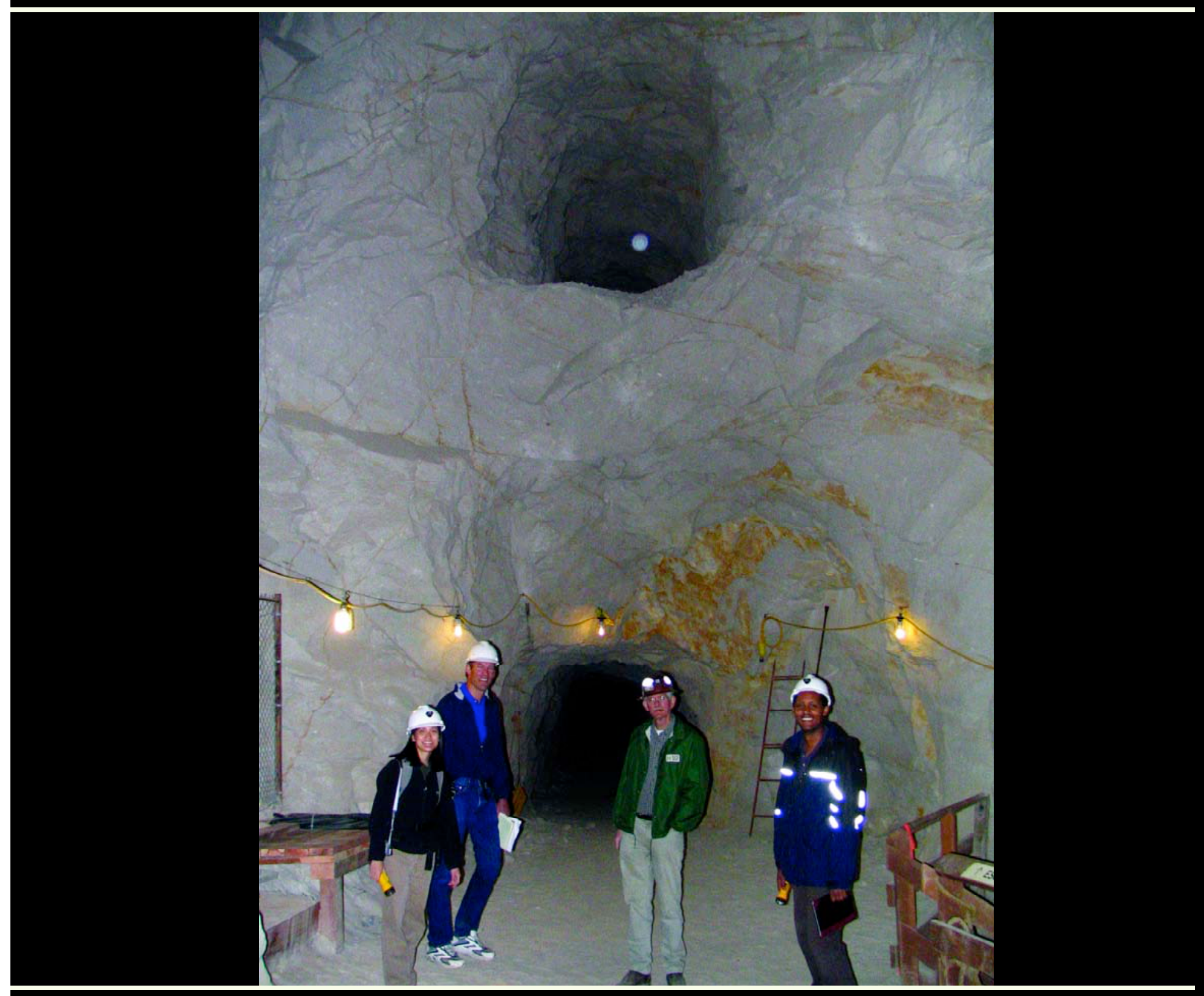

Parallel overlying drifts in the Hazel-Atlas Mine 


\section{NATURAL BARRIERS THRUST}

\author{
G.S. (Bo) Bodvarsson, Director, Natural Barriers Thrust \\ Lawrence Berkeley National Laboratory (LBNL) \\ Contact: 510.486.4789 | bo_bodvarsson@ymp.gov
}

For the Office of Science and Technology and International (OST\&I), the Natural Barriers Thrust supports scientific studies of the natural system at the proposed repository site of Yucca Mountain, Nevada. This natural system is composed of the unsaturated and saturated zones at that site, and the hydrothermal-chemical environment within waste emplacement drifts. It complements more specific areas of research covered by the other science thrusts: the Source Term Thrust, which focuses on waste forms, and on the speciation and solubility of radionuclides; the Material Performance Thrust, which emphasizes issues pertaining to corrosion of drip shields and waste packages; and the Radionuclide Getters Thrust, focusing on trapping and retardation of radionuclides within the waste package and emplacement drifts. The Natural Barriers Thrust stresses the realistic representation of the natural system with respect to processes and parameters, by means of laboratory, field, and modeling studies.

During the last 15 to 20 years, a substantial amount of research has been devoted to Yucca Mountain. Site characterization of Yucca Mountain has been successfully carried out through experiments in tens of surface-based boreholes and an underground facility. Extensive computation models have also been developed to simulate and understand the relevant processes at the site. However, in spite of the quantity of data collected and the knowledge acquired, the complexity of processes in the fractured rock, as well as the scarcity of studies in the unsaturated zone fractured rock prior to the recent research on Yucca Mountain, make it necessary for the project to adopt significant conservatism in the Total System Performance Assessment (TSPA). This overconservatism has been noted by many review committees. In an International Peer Review of the Yucca Mountain Project TSPA for Site Recommendation, the Nuclear Energy Agency (NEA) of the Organization for Economic Cooperation and Development (OECD), and the International Atomic Energy Agency (IAEA), wrote that (Total System Performance Assessment for the Site Recommendation (TSPA-SR),(OECD, Paris, 2002, Page 12):

...demonstrating understanding should be complementary to demonstrating compliance and of at least equal importance. Two approaches are needed. The first is to present what is considered to be a realistic (i.e., nonconservative) analysis of the likely performance of the repository using realistic assumptions and data....The second approach is an analysis for compliance purposes where conservative assumptions and parameter values are used to make the case more defensible.

More recently, NEA wrote (Post-closure Safety Case for Geological Repositories, Nature and Purpose (OECD, Paris, 2004), pp. 43-44), regarding a TSPA analysis related to showing compliance:

Due to the use of pessimistic parameter values and conservative assumptions, the performance of the repository is likely to be more favourable than that indicated by the analyses. Conservatism of the analyses constitutes an additional qualitative argument for safety, although conservatism in and of itself may also be interpreted as a lack of knowledge, and may thus detract from confidence. Conservatism is inevitable, and greatly to be preferred to optimism, but should be used and managed judiciously.

The Natural Barriers Thrust recognizes that conservatism may be interpreted as a lack of knowledge, and aims to reduce conservatism through increasing knowledge. We believe that if certain key conservatisms can be successfully addressed, it may be that it can then be shown that Yucca Mountain provides sufficient public health protection-even in the unlikely event that engineered systems have lost their integrity earlier than expected.

The proposed 2005 Environmental Protection Agency (EPA) two-tier standard beyond the original period of 10,000 years emphasizes the significance of the natural system's contribution to repository performance over geological time scales. Human civilization with recorded history has existed for approximately 10,000 years. On the other hand, geologic records over tens of thousands to millions of years are well established for natural attributes.

The Natural Barriers Thrust has the following objectives:

1. To demonstrate that the natural barriers can make large contributions to repository performance, supporting the multiple-barrier concept for geological disposal of high-level radioactive waste.

2. To strengthen the natural barriers analysis for periods up to and beyond the expected occurrence of peak dose, when the extrapolation of engineered performance may not be relied upon.

3. To reduce the overall cost of repository development by elimination of unnecessary engineered components, given the demonstrated natural barriers performance. 


\section{Specific Purpose and Focus}

The purpose of the Natural Barriers Thrust is to investigate various important aspects of the natural barriers; to demonstrate their significance to the performance of the repository; and to provide data, process understanding, and new models to enhance the defensibility of the license application. The TSPA represents the entire natural system in a conservative manner, thus emphasizing a reliance on the engineered barrier system. However, the success of the proposed Yucca Mountain repository hinges on the very significant performance of each of the multiple barriers (natural and engineered).

The natural barriers will have to play a key role in reducing long-term concentration of radionuclides that may enter the accessible environment. Findings to date have indicated that the natural barriers at Yucca Mountain have the potential to retard or mitigate transport.

The focus for natural barriers studies is on:

- Peak Dose Evaluation: Realistically accounting for the probability of water contacting waste packages and waste may significantly reduce the calculated peak dose.

- Radionuclide Transport Evaluation: Realistically accounting for enhanced matrix diffusion and sorption to retard and disperse the radionuclides, breakthrough at the compliance boundary may be significantly delayed, allowing radioactive decay to reduce dose.

- Uncertainty Reduction: With realistic representation, uncertainties can be constrained, and conservative assumptions can be replaced with more reasonable and defensible scenarios and calculations, leading to a reduction in the calculated peak dose.

- Process Understanding: With a unified thermal, hydrological, and chemical model that addresses key issues from three thrust areas-Source Term, Materials Performance, and Natural Barriers investigators can more accurately determine the potential extent of waste package corrosion, waste dissolution, and in-drift radionuclide transport, which controls radionuclide release into the nearfield rock formation.

- Significant Cost Reduction: With increased reliance on a more realistic representation of the natural barriers, costly engineered components may be eliminated.

\section{Basic Elements of the Natural Barriers Thrust}

From the repository drifts to the accessible environment, the basic elements of the Natural Barriers Thrust are:

1. Drift Seepage

2. In-drift Environment

3. Drift Shadow

4. Unsaturated Zone (UZ) Flow and Transport

5. Saturated Zone (SZ) Flow and Transport.

As illustrated in Figure 1, the natural system components are interrelated and coupled to waste form and waste packages within the drifts, encompassing the unsaturated zone (UZ), through the saturated zone (SZ), to the compliance boundary.

\section{Drift Seepage}

Representation of drift seepage and the amount and chemistry of water contacting waste packages and waste in the TSPA is believed to be conservative. The Natural Barriers Thrust is investigating various ways of obtaining an improved understanding of the seepage process under different repository conditions. This effort includes enhanced data collection to reduce uncertainty, investigation of coupled processes during the thermal period, and the use of natural ventilation to greatly reduce or eliminate seepage.

- Suppression of seepage by natural ventilation. Ventilation and heat-induced circulation, caused by air-density variations resulting from temperature differences within drifts, can lead to evaporation and removal of moisture, preventing it from contacting waste packages. It is likely that these processes prevent drip formation and thus seepage into the drifts, thus alleviating the need for costly in-drift engineered components.

- Self-sealing due to chemical precipitation around the drift. This results from coupled thermal, hydrological, chemical, and mechanical processes; it could change the flow pattern around the drift and potentially greatly reduce seepage into drifts.

The OST\&I Natural Barriers funded projects related to drift seepage (pp. 147-152) are:

- "Coupled In-Drift, Near-Field, and MountainScale Fluid and Heat Flow Processes" (FY2005 start-up) by Danko et al. 
- " Integrated Assessment of Critical Chemical and Mechanical Processes Affecting Drift Performance: Laboratory and Modeling Studies" (FY2005 startup) by Elsworth et al.

\section{In-Drift Environment}

The in-drift chemical environment plays a key role in determining the potential extent of waste package corrosion and the subsequent possibility of radionuclide release into the near-field rock. In the current Yucca Mountain Project (YMP) approach, the coupled thermal, hydrological, and chemical processes within the drift are described by several zero- or one-dimensional models, which leads to multiple accounting of water available for waste dissolution and thus to an overconservative representation of the drift barrier function in preventing release of radionuclides to the near-field rocks. Three of the OST\&I Program thrust areas described in this report-Source Term, Materials Performance, and Natural Barriers - have a joint approach toward investigating ways to remove the conservatism in the current project approach, thus achieving a more realistic representation of the drift barrier performance:

- Integrated model to replace disjointed models: The current approach of employing several disparate models, each describing an individual process - contributing discretely to (for example) the water composition of the end members, or salts on the waste package surfaces, or interactions with dust within the drift-limits the YMP's ability to address key questions concerning the in-drift chemical environment. A fully coupled approach that rigorously accounts for mass balance will greatly improve the representation of the drift barrier function.

- Coupling of in-drift transport with UZ processes in sur rounding rocks. There is currently no integrated treatment of transport of gas, vapor, or water between the near-field rocks and the waste emplacement drifts, nor within the drift. Capture of

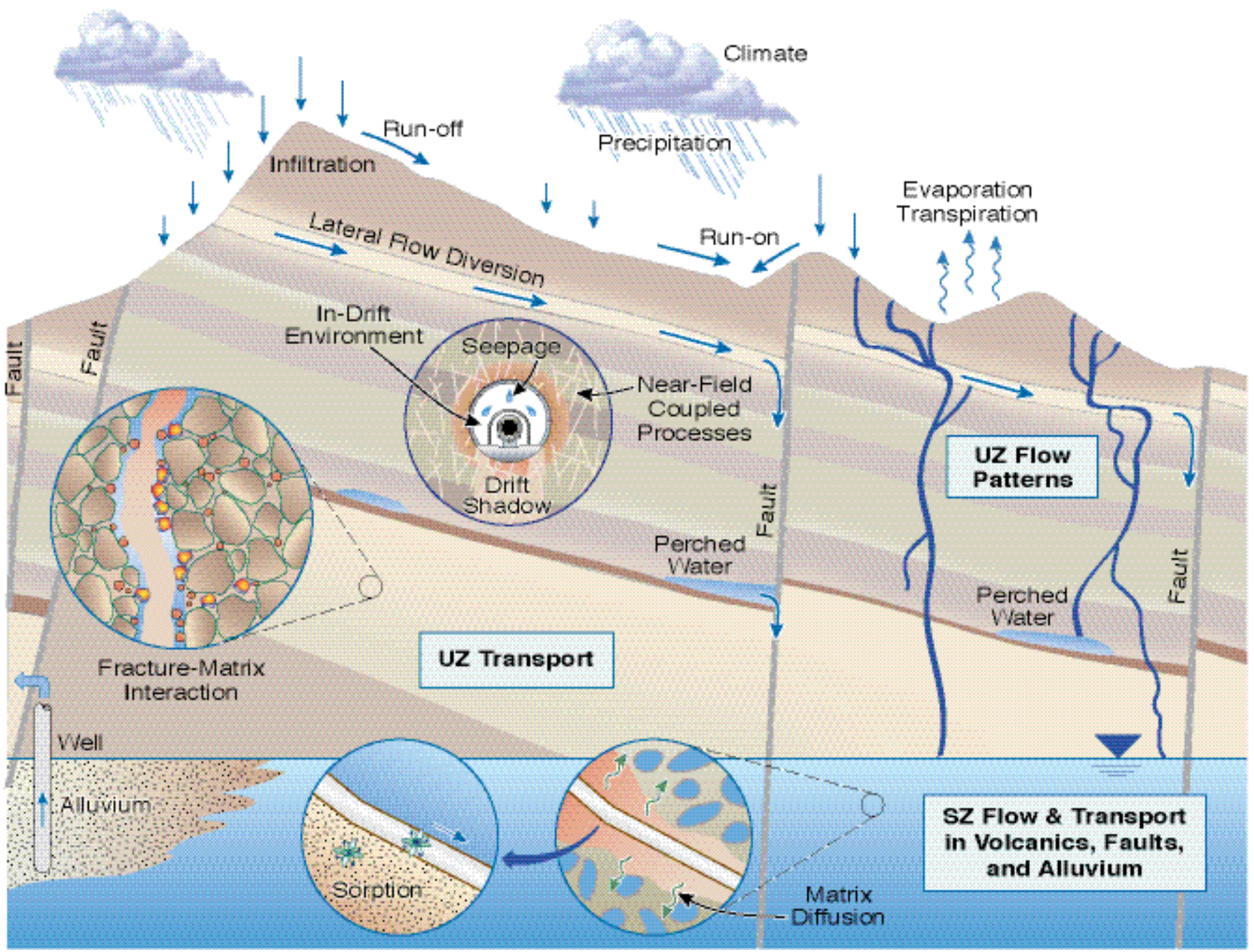

Figure I. The Natural Barriers Thrust area 
in-drift moisture transport along the drift into an enhanced model would enable realistic representation of evaporation and condensate movement.

The OST\&I funded projects related to the in-drift environment are:

- "An Integrated In-Drift/Near -Field Flow and Transport Model with Reactive Chemistry" (FY2005 start-up) by Birkholzer et al., pp. 155-156.

- "Coupling Thermal-Hydrological-Chemical Models to Process Models on Waste Packages" (FY2005 start-up) by Spycher et al., under Materials Performance Thrust project descriptions, pp. 113-114.

- "A Model for Radionuclide Release from Commercial Spent Nuclear Fuel" (FY2005 startup) by Steefel et al., under Source Term Thrust project description, pp. 49-50.

\section{Drift Shadow}

The drift shadow concept is not incorporated into the TSPA, which assumes release of radionuclides into and fast transport through the fractures whenever seepage at the top of the drift occurs. The drift shadow, once demonstrated and validated, could greatly enhance repository performance by:

- Delaying radionuclide release by thousands or tens of thousands of years. Drift shadow is the natural consequence of water diversion around an underground opening (resulting from the negative capillary pressure in the rock), giving rise to greatly reduced water flux immediately below the opening - thus significantly limiting the mobility of radionuclides immediately below the drift.

- Reducing peak dose potentially by orders of magnitude. Significantly reduced transport velocity in the shadow zone leads to delayed radionuclide breakthrough and reduced peak dose.

The OST\&I Natural Barriers funded projects related to drift shadow (pp. 157-164) are:

- "Nature of Drift Shadows at Analogue Sites" by Kneafsey et al.

- "Testing the Concept of Drift Shadow" by Paces et al.

- "Testing the Concept of Drift Shadow with X-ray Absorption Imaging Experiments" by Altman et al.

\section{Unsaturated Zone (UZ) Flow and Transport}

The UZ is the main natural-barrier component: it delays, retards, and sorbs radionuclides, and if represented realistically, can contribute to orders-of-magnitude dose reduction. The TSPA representation of UZ transport is overly conservative. The Natural Barriers Thrust is investigating the different $\mathrm{UZ}$ retardation processes, with the aim of greatly reducing the uncertainty and conservatism of the present model:

- Effectiveness of matrix diffusion in retarding radionuclide transport

- Validity of the $\mathrm{K}_{\mathrm{d}}$ approach and measurements based on crushed rock samples

- Validation of radionuclide transport and TSPA approaches

- Other processes such as lateral diversion, permeability barriers below perched water bodies, and flow in faults.

The OST\&I Natural Barriers funded projects related to UZ flow and transport (pp. 165-174) are:

- "Enhanced Retardation of Radionuclide Transport in Fractured Rock" by Liu et al.

- "Peña Blanca Natural Analogue" by Levy et al.

- "Matrix/Fracture Flow in Subrepository Units" by Neymark et al.

- "Pore Connectivity, Episodic Flow, and Unsaturated Diffusion in Fractured Tuff" by Hu et al.

\section{Saturated Zone (SZ) Flow and Transport}

Many processes that contribute to the SZ barrier function are represented conservatively in the TSPA. Improved understanding of the SZ can greatly improve the description of the SZ barrier function, thus removing the overconservatism in the present project model description. The Natural Barriers Thrust addresses the following topics related to the SZ:

- Determining if reducing conditions are pervasive in the $S Z$ for enhanced retardation. One possible natural barrier to radionuclide migration in the $\mathrm{SZ}$ is the presence of nonoxidizing or reducing environments; the mobility of some radionuclides is known to greatly diminish in reducing groundwater.

- Removing conservatisms in description of the retarda tion mechanisms. Processes leading to retarded radionuclide transport include dilution, matrix diffusion, and sorption in the SZ.

- Investigating the dispersive nature of plumes in fractured volcanic rocks. In the current SZ models, radionuclide plumes are predicted to disperse to a small extent, and therefore have a relatively narrow shape. Such a representation of plumes limits the possibility of sorption (and thus retardation) processes to occur. The small lateral dispersion exhibited by these plumes as represented in the 
current models may be relatively unusual, compared to dispersion observed with chemical plumes at other sites in similar geologic settings.

The OST\&I Natural Barriers Thrust places significant focus on the SZ to explore whether orders-of-magnitude dose reduction by dilution, diffusion, retardation, and other mechanisms can be demonstrated. Funded projects related to SZ Flow and Transport (pp. 173-191) are:

- "Determining the Redox Properties of Yucca Mountain-Related Groundwater, Using Trace Element Speciation for Predicting the Mobility of Nuclear Waste" (FY2005 start-up) by Cizdziel et al.

- "Field Studies for the Determination of Transport Properties of Radioactive Solutes and Colloids, Using Chemical Analogues" (FY2005 start-up) by Freifeld et al.

- "Improved Characterization of Radionuclide Retardation in Volcanics and Alluvium" by Reimus et al.

- "Carbon-14 Groundwater Analysis" by Patterson and Thomas

- "Large-Scale Natural Gradient Tracer Test" by Umari et al.

- "Large-Scale Drawdown Test" by Reimus et al.

- "Integration of Data and Models for the Coupled Regional- and Site-Scale Models" by Eddebbarth et al.

- "Saturated Zone Plumes in Volcanic Rock" (FY2005 start-up) by Kelkar et al.

\section{Long-Term Strategy for Contributions to OCRWM OST\&I}

The OST\&I Natural Barriers five-year strategic plan has the stretch goal to establish a solid scientific basis for the natural system alone meeting the regulatory standard for repository performance.

Near-field studies - addressing seepage diversion, in-drift coupled processes, and drift shadow effects - hold great promise for substantial contributions toward reducing dose and delaying transport by at least two to four orders of magnitude. Steps taken in FY2005 to closely couple the Natural Barriers Thrust with the Materials Performance and Source Term Thrusts target the challenge of dose compliance to the new proposed EPA standard. For the far field, various studies - including the new starts in FY2005 on (1) field experiments investigating retardation mechanisms and colloidal transport, and (2) determining the pervasiveness of reducing conditions in SZ water for mitigating transport-all aim to greatly reduce uncertainties in transport predictions within the UZ and the SZ.
Beyond process understanding, realistic representation, and uncertainty reduction, the Natural Barriers Thrust's long-term strategy is also to cultivate alternative approaches that may demonstrate enhanced performance. For example, the currently used $\mathrm{K}_{\mathrm{d}}$ approach implies that sorption is reversible. In light of the new regulatory compliance period of 1 million years, it is fitting for the OST\&I program to initiate experimental and modeling studies to investigate whether irreversible sorption is possible or even pervasive at Yucca Mountain. It is also in the longterm strategy of the Natural Barriers Thrust to investigate radionuclide precipitation in the $\mathrm{UZ}$ as the $\mathrm{pH}$ changes from 5 to 6 near the waste packages to about 9 in the UZ below the drifts. A readily feasible in situ testing program is to drill microboreholes in the Forty-Mile Wash east of Yucca Mountain to collect transport data from the water disposed from the SZ testing, and thus evaluate if our models can reproduce these observations.

More far-reaching questions include the following: Should the natural geothermal gradient, which influences postemplacement convection (controlling water contacting waste packages and waste and therefore impacting peak dose), be integrated into the design of the repository layout? Should emplacement drifts be designed to be smaller and to have alternative configurations, in order to suppress seepage and water contacting waste? Can sealants or bacteria be introduced to the drift walls to enhance isolation? Can microsensors be developed to detect radiation leaks and corrosion onsets? Can geophysical tools be advanced to delineate $\mathrm{pH}$ changes and flow paths?

The long-term goal of the Natural Barriers Thrust is to improve our ability to predict the performance of the proposed Yucca Mountain repository. The focus on fundamental understanding of processes and realistic representation of the natural system would strengthen the defense of the license application, address the issues that concern the Nuclear Waste Technical Review Board (NWTRB), and respond to EPA's requirement of realistic modeling and improved understanding of processes.

Although the Natural Barriers Thrust has only been conducting research for less than two years, there have already been very significant results that could potentially lead to substantial improvement in demonstrated performance of the natural system. These include:

- Integration of Natural Barriers, Source Term, and Materials Performance Thrusts in developing unified in-drift models, leading to potential performance enhancement and greater transparency and defensibility.

- Several-orders-of-magnitude enhancement in matrix diffusion within both the UZ and SZ.

- Data indicating trapped colloids at water/air 
interfaces at an analogue site may imply potential significant reduction of colloid transport at Yucca Mountain (TSPA shows that $\mathrm{Pu}^{239}$ colloids are the second-largest contributor to overall dose, after $\mathrm{Tc}^{99}$ ).

- Potential for one or more orders-of-magnitude increase in $K_{d}$ values for several important radionuclides.

\section{Acknowledgments}

This work is supported by the Director, Office of Civilian Radioactive Waste Management, Office of Science and Technology and International, of the U.S. Department of Energy. We are also very appreciative of the comments and suggestions made by Abe Van Luik of DOE, greatly improving the Natural Barriers Thrust report. 


\section{DRIFT SEEPAGE}

Coupled In-Drift, Near-Field, and Mountain-Scale Fluid and Heat Flow Processes

George Danko, University of Nevada, Reno; Jens T. Birkholzer and Stefan Finsterle, Lawrence Berkeley National Laboratory (LBNL)

Integrated Assessment of Critical Chemical and Mechanical Processes Affecting Drift Performance: Laboratory and Modeling Studies

Derek Elsworth, Abraham S. Grader, and Chris J. Marone, Pennsylvania State University; Jonny Rutqvist and Eric Sonnenthal, Lawrence Berkeley National Laboratory (LBNL) 
This page intentionally left blank. 


\title{
Coupled In-Drift, Near-Field, and Mountain-Scale Fluid and Heat Flow Processes
}

\author{
George Danko', Jens T. Birkholzer², and Stefan Finsterle ${ }^{2}$ \\ IUniversity of Nevada, Reno | ${ }^{2}$ Lawrence Berkeley National Laboratory (LBNL)
}

\section{Research Objectives}

The heat output of the nuclear waste to be emplaced at Yucca Mountain will strongly affect the thermal-hydrological $(\mathrm{TH})$ conditions in and near the proposed geologic repository. Recent analysis of gas flows within emplacement drifts (Bechtel SAIC Company, 2004) has demonstrated that the drifts will act as important conduits for natural convection and ventilation processes. For example, as a result of natural convection driven by axial temperature gradients, water will evaporate from the drift walls in elevated-temperature sections of the drifts, migrate along the drifts, and condense in cooler sections (i.e., the end sections with no emplaced waste). Furthermore, natural ventilation will occur in the drifts as a result of buoyant gas flows through shafts and access tunnels, forcing relatively cool and dry air into the tunnels. Evaporation driven by natural convection or natural ventilation may significantly reduce the moisture content in the near-drift fractured rock, which in turn will reduce the potential for seepage of formation water into the drift. Preliminary modeling results shown in Figure 1 indicate how important this process could be. However, in-drift gas flows and their potentially beneficial impact have been neglected in the seepage models supporting the Total System Performance

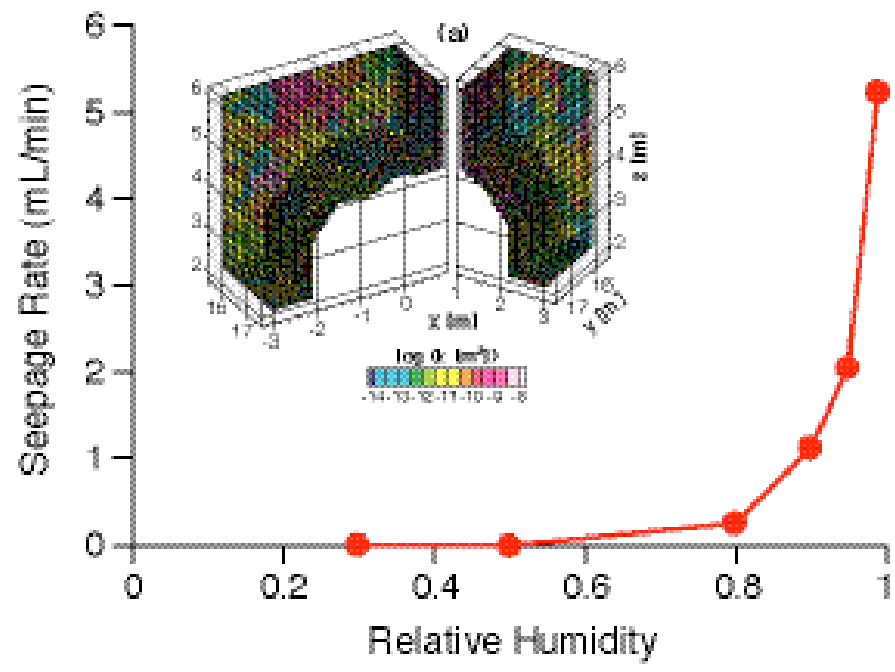

Figure I. Predicted seepage as influenced by in-drift relative humidity
Assessment (TSPA) of Yucca Mountain, which conservatively assume a $100 \%$ relative-humidity condition at the drift wall, i.e., evaporation is neglected.

The research project described in this report aims at developing a multiscale, coupled seepage modeling approach that accounts for natural convection and natural ventilation. The potential of in-drift gas flows to remove moisture from emplacement drifts is examined, and the impact of axial moisture movement on seepage is determined. The new modeling approach will significantly improve our understanding of near-field and in-drift processes (specifically the evaporation of potential seepage water and its impact on in-drift relative humidity), will thus increase realism in performance calculations, and will significantly reduce conservatism.

\section{Approach}

A new seepage modeling approach is developed that quantifies the impact of evaporation caused by natural convection and ventilation processes. A process model that predicts seepage rates affected by evaporation must address water, vapor, air, and heat transport, and must be coupled to a model for predicting in-drift gas flows. While the flow and transport processes in the fractured formation are simulated with the multiphase, multicomponent simulator TOUGH2, the in-drift gas flows are solved with the MULTIFLUX code (Danko and Bahrami, 2004). MULTIFLUX uses a lumped-parameter approach in which the turbulent mixing in the drift is approximated as a binary diffusion process, with effective diffusion coefficients estimated from supporting computational fluid dynamics (CFD) analyses. MULTIFLUX also provides an efficient iterative coupling technique for the mass and heat transfer between the drift and the fractured formation.

Numerical analyses are conducted on two different scales: First, transient mountain-scale simulations are performed with the MULTIFLUX-TOUGH2 scheme to obtain temperature, pressure, relative humidity, water, and gas saturation in a three-dimensional model domain comprising a representative emplacement drift and the surrounding fractured rock. These coupled simulations allow for a detailed evaluation of the overall impact of in-drift convection on the moisture content in the near-field rock. 
Second, seepage predictions are conducted using a heterogeneous, high-resolution model of a short drift section plus a few meters of fractured rock surrounding the drift (Ghezzehei et al., 2004), with boundary conditions provided by the mountain-scale predictions. To estimate seepage under evaporative conditions, the drift-scale model accounts for flow of water, vapor, air, and heat, with conductive, radiative, convective, and diffusive transport mechanisms.

Application of the new MULTIFLUXTOUGH2 model provides seepage rates for a variety of conditions, locations, and times after waste emplacement. Each seepage sensitivity case is accompanied by a comparative seepage simulation assuming that the relative humidity in the drift is $100 \%$ (i.e., that the evaporative

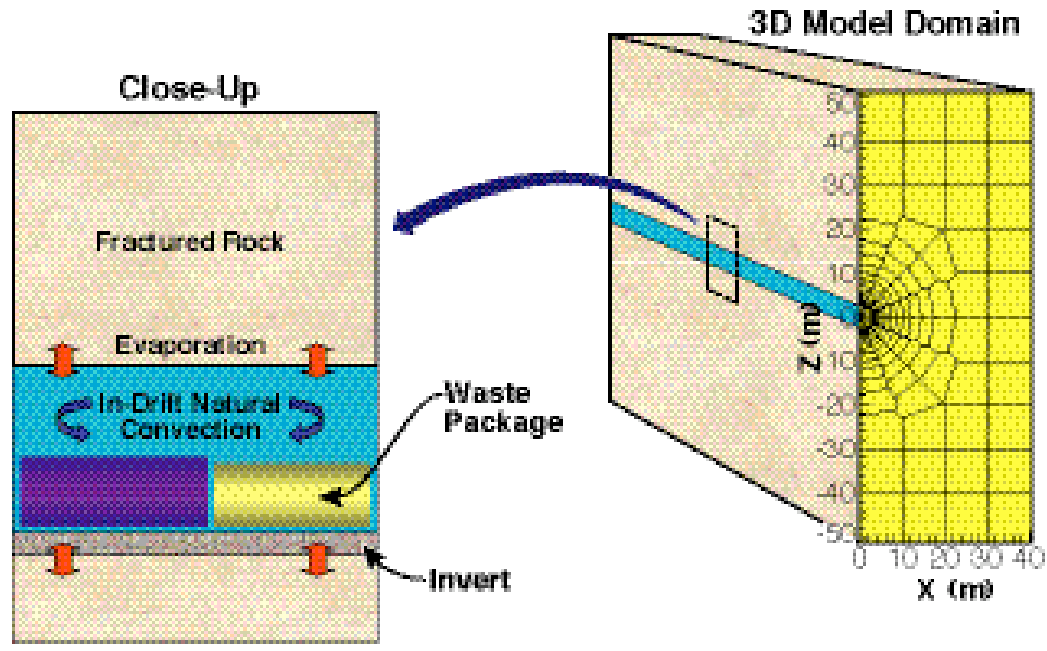

Figure 2. Schematic showing 3-D model domain with emplacement drift and fractured rock potential is zero). The final result from this modeling work is a thorough understanding of the reduction in seepage caused by evaporation from natural convection and natural ventilation processes, as a function of location and time (or temperature and time) and other selected properties.

\section{Accomplishments}

The iterative coupling scheme between MULTIFLUX and TOUGH 2 has been defined and implemented. The necessary couplings are being tested and optimized. Once the testing stage is complete, the new version of MULTIFLUX will be qualified, scheduled for early 2006. The qualified version will be used to conduct the mountain-scale and drift-scale simulation studies.

We expect that the new drift seepage prediction approach, which includes the impact of natural convection, natural ventilation, and their impact on evaporation and condensation of water at the drift wall and within the drift itself, will significantly reduce seepage rates at Yucca Mountain

and thereby improve the predicted performance of the proposed repository over ten-thousands (natural convection) to hundred-thousands (natural ventilation) of years.

This work supports graduate education.

\section{Related Publications}

Bechtel SAIC Company, In-drift natural convection and condensation. Yucca Mountain Project Report, MDLEBSMD-000001 REV 00, Bechtel SAIC Company, Las Vegas, NV, 2004.

Danko, G., and D. Bahrami, Heat and moisture flow simulation with MULTIFLUX. Proceedings of ASME, Heat Transfer/Fluid Engineering, July 11-15, 2004, Charlotte, North Carolina, USA, pp. 1-12, 2004.

Ghezzehei, T.A., R.C. Trautz, S. Finsterle, P J. Cook, and C.F. Ahlers, Modeling coupled evaporation and seepage in ventilated tunnels. Vadose Zone J., 3, 806-818, 2004. 


\title{
Integrated Assessment of Critical Chemical and Mechanical Processes Affecting Drift Performance: Laboratory and Modeling Studies
}

\author{
Derek Elsworth', Jonny Rutqvist ${ }^{2}$, Abraham S. Grader ', Chris J. Marone', and Eric Sonnenthal ${ }^{2}$ \\ IPennsylvania State University | 2Lawrence Berkeley National Laboratory (LBNL)
}

\section{Research Objectives}

This work will recover unusually well-constrained laboratory data to define changes in the mechanical and transport properties of fractures as a result of hydrothermal conditions anticipated in the drift-local environment. These data will be incorporated into novel thermal-hydrological-mechanical-chemical (THMC) process simulators to evaluate the influence of strong couplings between stress and chemistry on drift performance.

\section{Approach}

We are examining the implication of critical coupled chemical-mechanical processes on drift performance at Yucca Mountain through a coordinated suite of experimental and modeling studies. The experimental studies include measurements of changes in permeability, and of linked mechanical constitutive behavior, under representative hydrothermal conditions, replicating anticipated in situ stresses (0-30 MPa) and temperatures $\left(50-300^{\circ} \mathrm{C}\right)$. Experiments are constrained by concurrent monitoring of influent and effluent chemical reactants and products, and by intermittent nondestructive imaging by x-ray computed tomography (CT). These unusually well-constrained measurements will be used to provide new insights into processes of hydrothermal alteration and their influence on transport and deformation behavior.

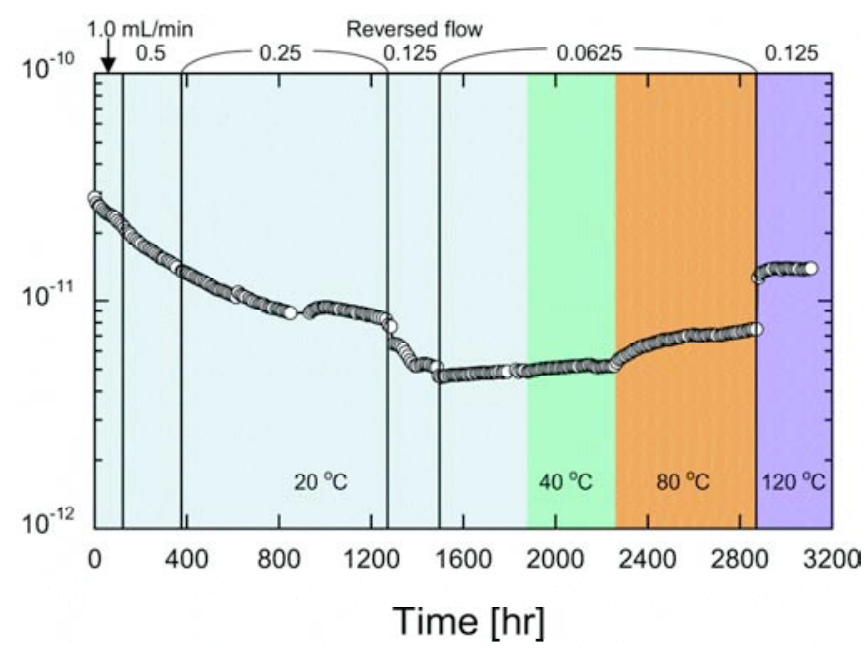

Figure I. Evolution of permeability for water circulation in a fracture under constant stress, with variable flow rates (Yasuhara et al., 2005)
The modeling studies include the development and application of novel coupled THMC simulators to study critical mechanical and chemical interactions around emplacement drifts at Yucca Mountain. These coupled THMC simulators will be capable of accommodating the complex chemical and mechanical interactions in both continuum and discontinuum representations of the drifts. The modeling and experimental studies are fully integrated. Development and application of the model are closely linked and critically dependent upon the experimental data for model validation, for development of constitutive models, and for constraining input data. The code development will be accompanied by application and code testing. Separate simulations will be conducted to define important trends in behavior, which are representative of: (1) the experimental geometries, (2) THMC effects around emplacement drifts, (3) Drift Scale Test behavior, and (4) long-term behavior of drifts.

\section{Accomplishments}

This is a start-up project that will first utilize recent experimental findings and code developments by the authors, enabling, for the first time, analysis of coupled THMC effects in fractured rocks.

Recent experimental results involving the circulation of hydrothermal fluids $\left(20^{\circ}-150^{\circ} \mathrm{C}\right)$ through a natural fracture in novaculite (Polak et al., 2003; Yasuhara et al., 2004) have shown the potential for large changes (over two orders of magnitude) in permeability to evolve as a result of dissolution and precipitation. Other results (Polak et al., 2004; Yasuhara et al., 2005) have indicated spontaneous switching between permeability reduction and permeability increase as only temperatures and flow-rates were changed (Figure 1). The coupled chemical-mechanical effects are particularly surprising, since they show permeability reduction of over two orders of magnitude under modest temperature and stresses over the period of only a few weeks. Recent development of models for coupled THC and THM (Rutqvist et al., 2002) analyses are being incorporated to develop the coupled THMC simulator (Figure 2).

Funding for this study has just started. The recent experimental observations are important because (1) they are 
counter-intuitive-permeability reduces with net dissolution; (2) they occur under conditions anticipated to endure over substantial periods in drift-local environments; (3) the effects are of large magnitude; and (4) to date, these effects have not been considered in performance assessment. Relative to current predictions, these mechanicalchemical effects could significantly decrease permeability around an emplacement drift during drift warm-up and increase them during cool-down, impacting seepage into drifts. In addition, these mechanical-chemical effects may produce significant changes in the strength properties of the fractured rock mass near an emplacement drift.

This work supports graduate education.

\section{Related Publications}

Polak, A., D. Elsworth, J. Liu, and A. Grader, Spontaneous switching of permeability changes in a limestone fracture under net dissolution. Water. Resour. Res., 40, W03502, doi:10.1029/2003WR002717, 2004.

Polak, A., D. Elsworth, H. Yasuhara, A.S. Grader, and P.M. Halleck, Permeability reduction of a natural fracture under net dissolution by hydrothermal fluids.

Geophys. Res. Lett., 30 (20), 2020, doi:10.1029/2003GL017575, 2003.

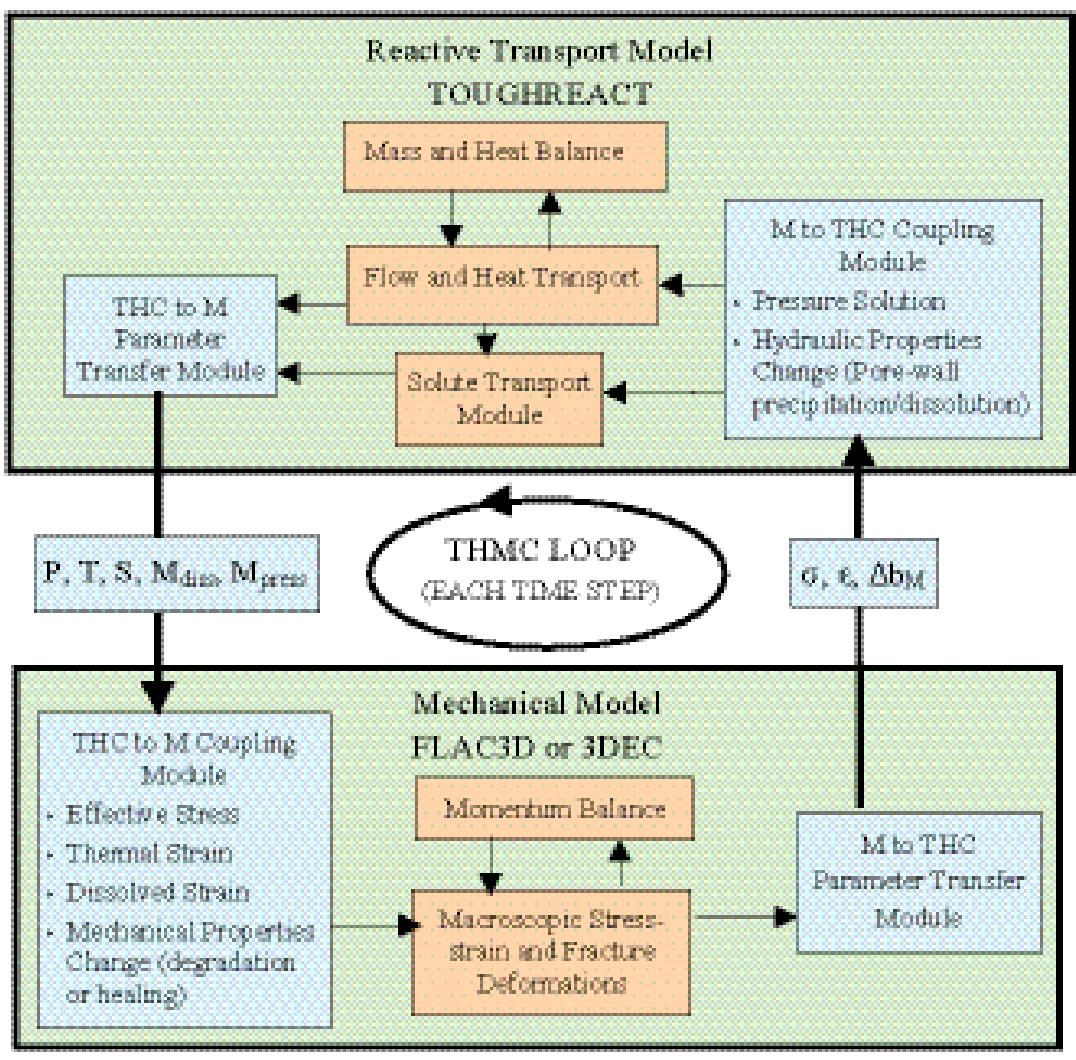

Figure 2. Conceptual logic for the proposed coupling of TOUGHREACT with both FLAC3D and 3DEC, for linked mechanical-chemical effects (blue boxes signify components that will be added to existing codes in this project). TOUGHREACT is a solute transport simulation code for THC processes. FLAC3D and 3DEC are thermal-mechanical codes, FLAC3D using a continuum approach and $3 D E C$ using a discrete approach.

Rutqvist, J., Y.-S. Wu, C.-F. Tsang, and G. Bodvarsson, Modeling approach for analysis of coupled multiphase fluid flow, heat transfer, and reformation in fractured porous rock. Int. J. Rock Mech. Min. Sci. 39, 429-442, 2002.

Yasuhara, H., D. Elsworth, and A. Polak, The evolution of permeability in a natural fracture: significant role of pressure solution. J. Geophys. Res., 109, B03204, doi:10.1029/2003JB002663, 2004.

Yasuhara, H., A. Polak, Y. Mitani, A. Grader, P. Halleck, and D. Elsworth, Evolution of fracture permeability through fluid-rock reaction under hydrothermal conditions. 2005 (submitted). 
Natural Barriers Thrust

\section{IN-DRIFT ENVIRONMENT}

An Integrated In-Drift/Near-Field Flow and Transport Model with Reactive Chemistry

J. Birkholzer, E. Sonnenthal, S. Mukhopadhyay, M. Reagan, and T. Xu, Lawrence

Berkeley National Laboratory (LBNL) 
This page intentionally left blank. 


\title{
An Integrated In-Drift/Near-Field Flow and Transport Model with Reactive Chemistry
}

\author{
J. Birkholzer, E. Sonnenthal, S. Mukhopadhyay, M. Reagan, and T. Xu
}

Lawrence Berkeley National Laboratory (LBNL)

\section{Research Objectives}

During the early postclosure period, the in-drift thermalhydrological-chemical (THC) environment is key to waste package and drip-shield integrity, because the contact of highly concentrated brines with the waste package and the drip shield can accelerate corrosion. One of the processes that could cause brines to contact these metal surfaces is seepage of formation water into the drifts. Thus, for the purpose of evaluating the corrosion potential, it is important to quantify the mass and chemistry of seepage water and to track its physical and chemical evolution inside the drifts. All these parameters are strong functions of the thermal and hydrologic environment in the drifts and in the fractured formation surrounding them.

In previous studies, the in-drift and near-field environments have been predicted with a suite of independent submodels, which resulted in a conservative estimation of water fluxes into and through the waste emplacement drifts, also affecting the chemical composition of water potentially contacting drip shields and waste packages. The research project described in this report aims at developing an integrated, fully coupled model for flow and transport processes within and near waste emplacement drifts (see Figure 1). The model development provides input to related OST\&I projects targeting the small-scale chemical environment on waste packages, waste package corrosion potential, and radionuclide release from breached waste packages.

\section{Approach}

An integrated THC model is being developed for the indrift and near-field environments, in which heat, water, and solute transport are combined with a rigorous thermodynamic approach applicable to highly concentrated brines at variable water activities. The new model is built on an enhanced version of the simulator TOUGHREACT, which is currently used for modeling flow, transport, and reactive chemistry in the fractured rocks at Yucca Mountain. To be capable of modeling in-drift THC processes, new capabilities are being incorporated into TOUGHREACT. These include modeling of additional chemical processes, handling of in-drift radiation and convection processes, and development of modern object-ori- ented computer architectures to allow for greater computing efficiency. Before building the fully integrated THC model, the relevant near-field and in-drift components and THC processes are being identified. This step requires detailed investigation of, for example, (1) the effect of hydrological and chemical properties changes on seepage; (2) the small-scale processes of drop formation, detachment, drop interaction with drip shield or waste package, and film flow along metal surfaces; and (3) the effect of indrift axial flow and transport of water and gases.

\section{Accomplishments}

Three main research activities have been conducted during the period from March 1, 2005, to September 30, 2005. These activities can be summarized as follows:

\section{Evaluate Details of Water Movement within Drifts}

We started substantial research work to better understand the physics of seepage water movement within drifts and to investigate modeling possibilities with porous-medium approximations (which form the basis for the TOUGHREACT code). The chemical evolution of seepage water can be adequately modeled only when the water movement in drifts is described in sufficient detail. We have collaborated with researchers at Sandia National Laboratories to model the behavior of single droplets in heated drifts using the Fluent computational fluid dynamics (CFD) code. Test simulations of seepage water flow in the drifts have been conducted with both Fluent and TOUGHREACT models, and preliminary comparisons have been performed to identify the porous-medium flow approximation best suited for predicting in-drift water movement.

\section{Incorporate and Test Additional Chemical Processes in TOUGHREACT}

New numerical approaches have been implemented into TOUGHREACT that link water and gas flow with solute transport and salt precipitation/dissolution in the drift environment. Of particular concern are conditions where the mass of solvent water is quite small (i.e., after evaporation of most of the water). Efficient numerical approaches for evaporation and precipitation have been developed and are currently in the testing stages. 


\section{Conduct Preliminary THC Coupled Simulations}

Based on the above research activities, we have conducted p reliminary test simulations with an enhanced version of TOUGHREACT, developing a fully integrated THC model for the in-drift environment and the near-field fractured rock. The model predicts the thermal-hydrological perturbation of liquid and gas fluxes in the fractured formation next to a re $\mathrm{p}$ resentative waste emplacement drift. With water and gas chemistry affected by the significant temperature increase, mineral precipitation and dissolution occurs, changing the fracture porosity and permeability in the drift vicinity. Water may build up at local lowpermeability zones close to the drift wall, and seepage occurs as the saturation buildup causes the capillary barrier to break. The model then tracks the migration of the seepage water within the drift, and determines the temporal and spatial evolution of water chemistry and in-drift conditions. These coupled near-field and in-drift processes are dealt with in one integrated model, so that consistency is maintained at the interfaces between and within the natural (near-field rock) and engineered (in-drift) systems.

The integrated model accounts - in a fully coupled manner-for THC processes occurring within the near-field rock and the drift (as well as at interfaces between different near-field and in-drift components), allowing for a realistic quantification of the mass and chemistry of seepage waters and their physicochemical evolution within the drifts. The approach results in a defensible, transparent, and realistic assessment of the corrosion and waste-dissolution potential of seepage water, which greatly affects the mobilization and release of radionuclides from the proposed repository.

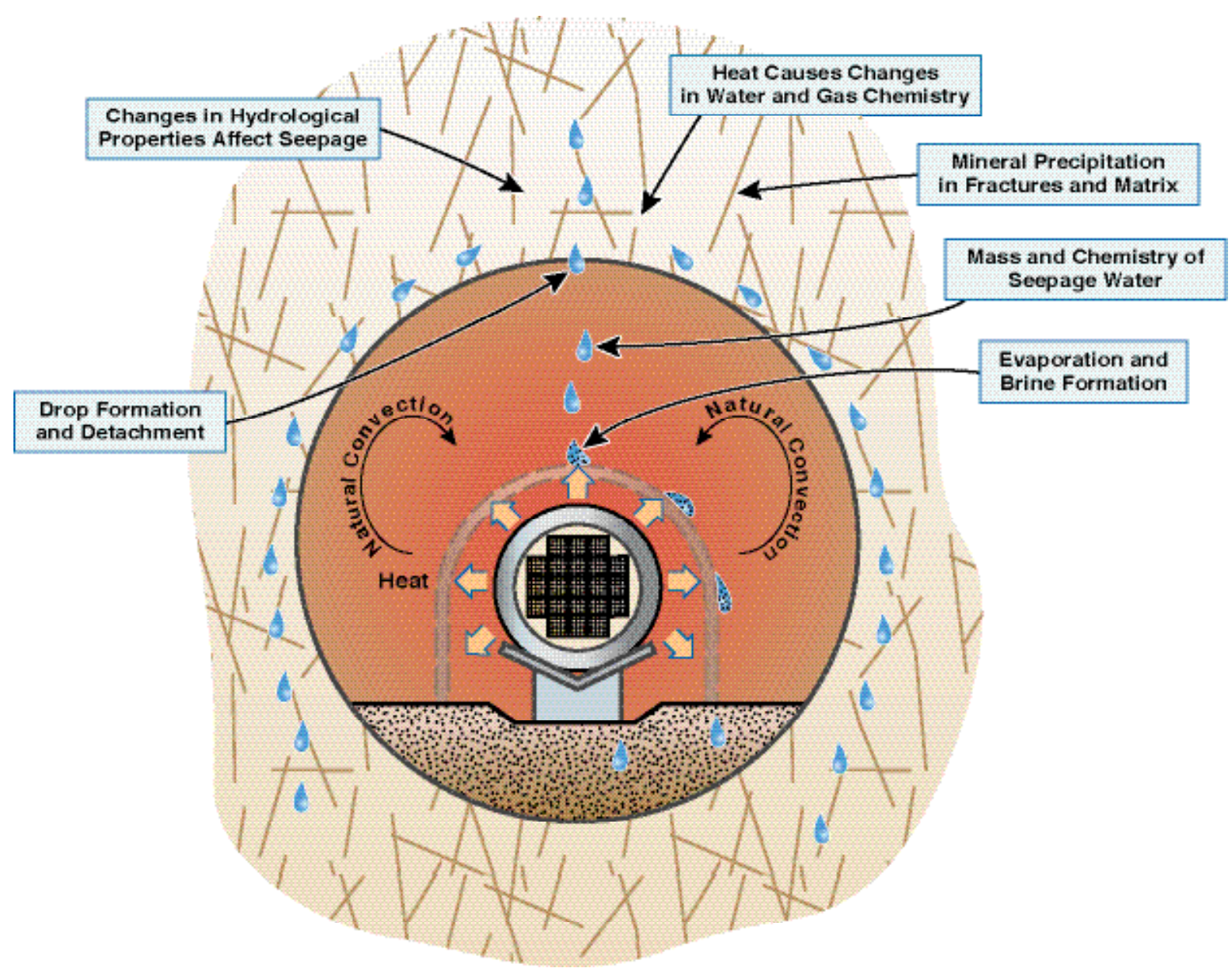

Figure I. Schematic showing processes affecting seepage and brine formation inside and near waste emplacement drifts 


\section{DRIFT SHADOW}

\section{Nature of Drift Shadows at Analogue Sites}

T. Kneafsey, T. Ghezzehei, G. Su, and P. Dobson, Lawrence Berkeley National Laboratory (LBNL), and B. Marshall, United States Geological Survey (USGS)

\section{Testing the Concept of Drift Shadow}

James Paces and Leonid Neymark, United States Geological Survey (USGS); Teamrat Ghezzehei, Ernest Majer, and Patrick Dobson, Lawrence Berkeley National Laboratory (LBNL)

\section{Testing the Concept of Drift Shadow with X-Ray Absorption Imaging} Experiments

Susan J. Altman, Clifford K. Ho, Aleeca Forsberg, and William Peplinski, Sandia National Laboratories (SNL) 
This page intentionally left blank. 


\title{
Nature of Drift Shadows at Analogue Sites
}

\author{
T. Kneafsey, T. Ghezzehei ', G. Su', P. Dobson', and B. Marshall2 \\ 'Lawrence Berkeley National Laboratory (LBNL) | 2United States Geological Survey (USGS)
}

\section{Research Objectives}

The drift shadow is a region below a void in an unsaturated environment that is partially sheltered from downward-percolating water. It forms when capillary forces are too weak to fully draw the percolating water into this region (Figure 1). Our objective is to investigate the presence and characteristics of a drift shadow at an analogue site. Demonstration of the drift shadow would allow its consideration as a barrier to radionuclide transport at the proposed Yucca Mountain repository, and allow

Performance Assessment models to take credit for reduced transport.

\section{Approach}

Our approach to investigating the drift shadow is to find a

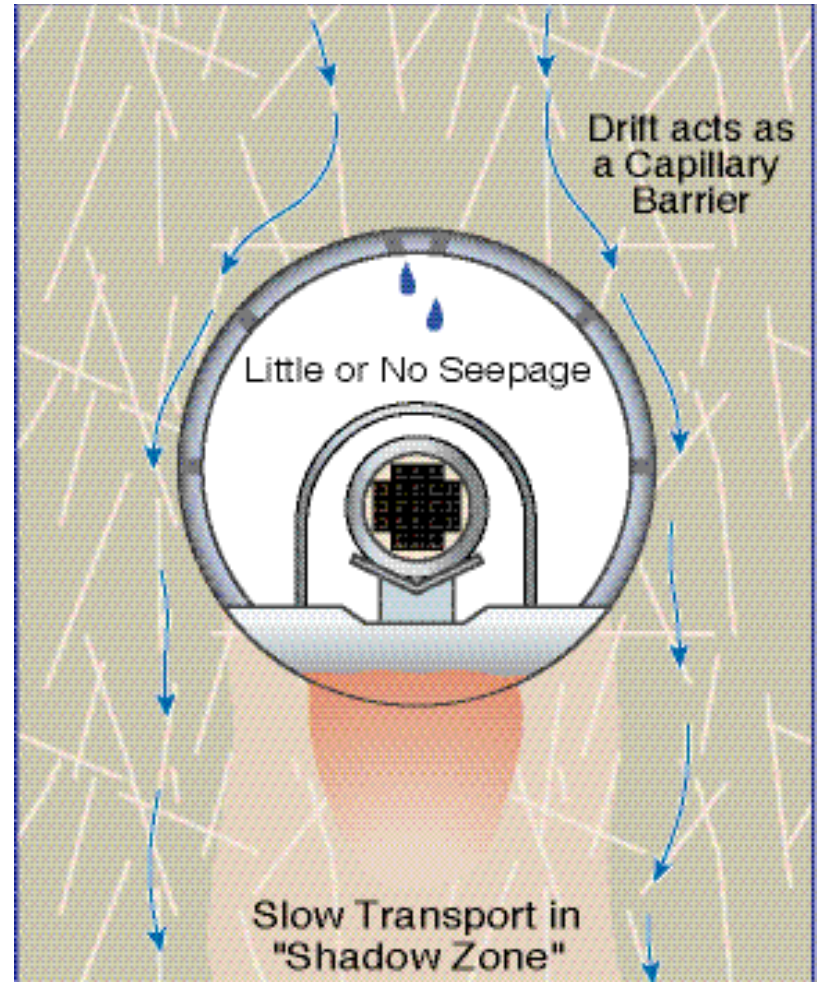

Figure I. Conceptual model of flow around a drift showing the capillary barrier at the drift crown, and the drift shadow below the drift field site containing a natural or mined cavity in the unsaturated zone, measure flow-affecting parameters, predict the drift shadow numerically, and use geophysical, hydrologic, and geochemical tools to assess its presence and extent.

\section{Accomplishments}

We performed detailed modeling studies to understand conditions needed for the formation of a drift shadow and to evaluate drift shadow characteristics (such as size and dryness). Based on this understanding, we evaluated many sites for applicability (caves in New Mexico and California, mines in California, and concrete pads in Nevada and Colorado). We have selected the Hazel-Atlas Mine near Antioch, California, for further investigation.

The location and configuration of the Hazel-Atlas silicasand mine make it an excellent site to confirm the exis-

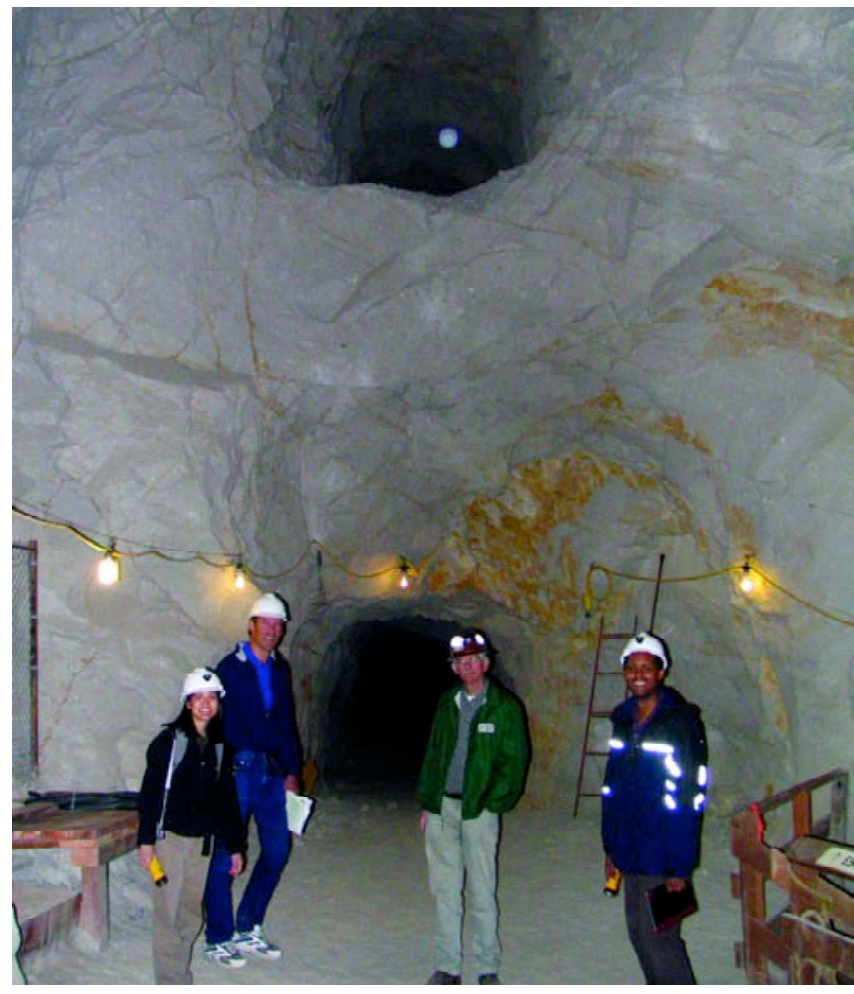

Figure 2. Parallel overlying drifts in the Hazel-Atlas Mine 
tence of drift shadows and to observe and measure their characteristics. The mine is located in a massive porous sandstone unit. The mining method required the development of two parallel drifts, one above the other (Figure 2). These parallel drifts provide a nearly ideal opportunity to investigate an existing drift shadow below the upper drift, and to introduce water into the floor of the upper drift in order to observe and measure its flow around the lower drift.

In our investigation, we will obtain cores from borehole arrays surrounding both drifts for hydrologic and geochemical analysis, use the boreholes for ground-penetrating radar and neutron logging assessment of existing moisture content, and perform an active test in which water is introduced into a region in the top drift and monitored in the boreholes surrounding the lower drift. Preliminary measurements performed on an initial set of short
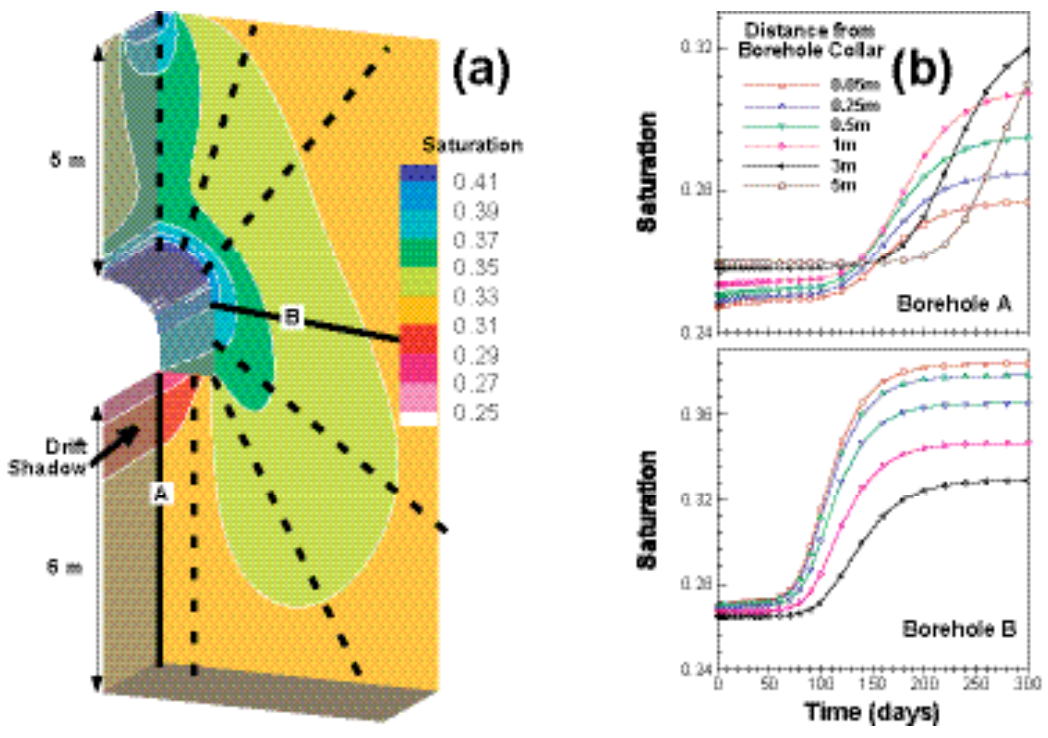

Figure 3. (a) Saturation profile after 300 days of infiltration into the base of the upper drift, and (b) saturation changes with time along the two identified boreholes cores include moisture content and leachate chemistry. X-ray computed tomography (CT) was used to examine density variations in the cores resulting from the presence of evaporite minerals.

We have used numerical modeling to evaluate different field test designs. The test design under consideration involves imposing a controlled water flux in the upper drift within an infiltration bed, and monitoring the development of the wetting plume and drift shadow below the lower drift. The simulated saturation distribution after 300 days of continuous infiltration at $40 \mathrm{~L} /$ day is shown in Figure 3.

We have identified an appropriate site at which a field investigation can be safely and effectively carried out to explore the drift shadow. Through our modeling efforts, we have gained significant insight into the factors affecting the drift shadow, including porosity, permeability, water flux, and time, and have used these results to guide our design of the field test. The modeling approach used at Yucca Mountain is used in our investigation to allow the extension of our results to the proposed Yucca Mountain repository. We are preparing to initiate field experiments at the Hazel-Atlas Mine to further investigate the drift shadow concept.

\section{Publications}

Ghezzehei, T., T. Kneafsey, and G. Su, Nature of the dry shadow below cavities in the vadose zone. To be presented at the AGU Fall Meeting, San Francisco CA, December 2005.

Su, G., T. Kneafsey, T. Ghezzehei, B. Marshall, and P.J. Cook, Field investigation of the drift shadow. To be presented at the AGU Fall Meeting, San Francisco CA, December 2005.

Ghezzehei, T., T. Kneafsey, and G. Su, Characteristic dimensions of drift shadow zone. Water Resources Research (in preparation), 2005.

Dobson, P., T. Ghezzehei, T. Kneafsey, and G. Su, Evaluation of the drift shadow zone: Formation time, dimensions, and transport properties. Water Resources Research (in preparation), 2005.

\section{Acknowledgments}

The authors wish to thank John Waters of the East Bay Regional Parks District for providing access and support at the Hazel-Atlas Mine. 


\section{Testing the Concept of Drift Shadow}

James Paces', Leonid Neymark', Teamrat Ghezzehei², Ernest Majer ${ }^{2}$, and Patrick Dobson ${ }^{2}$

'United States Geological Survey (USGS) | 2 Lawrence Berkeley National Laboratory (LBNL)

\section{Research Objectives}

Capillary forces at emplacement drift walls may divert seepage of percolating water away from waste canisters and the underlying rock mass, resulting in drift shadows with decreased water saturations and flow velocities relative to background flow through undisturbed rock. This investigation is designed to identify isotopic and chemical differences around natural lithophysal cavities (primary voids formed during emplacement and cooling of tuffs) in the proposed Yucca Mountain repository horizon that can be used to evaluate whether drift shadows are present.

\section{Approach}

${ }^{234} \mathrm{U} /{ }^{238} \mathrm{U}$ activity ratios (AR) are affected by water/rock interaction resulting in radioactive disequilibrium in rocks $(234 \mathrm{U} / 238 \mathrm{U}$ AR typically <1.0) and water $(234 \mathrm{U} / 238 \mathrm{U}$ AR $>1.0$ ). Differences in disequilibrium in both media are expected where cavities modify unsaturated zone flow in fractured tuffs. Isotopic data from rock and pore-water samples associated with lithophysal cavities exposed in tunnel walls and new drill core at Yucca Mountain, along

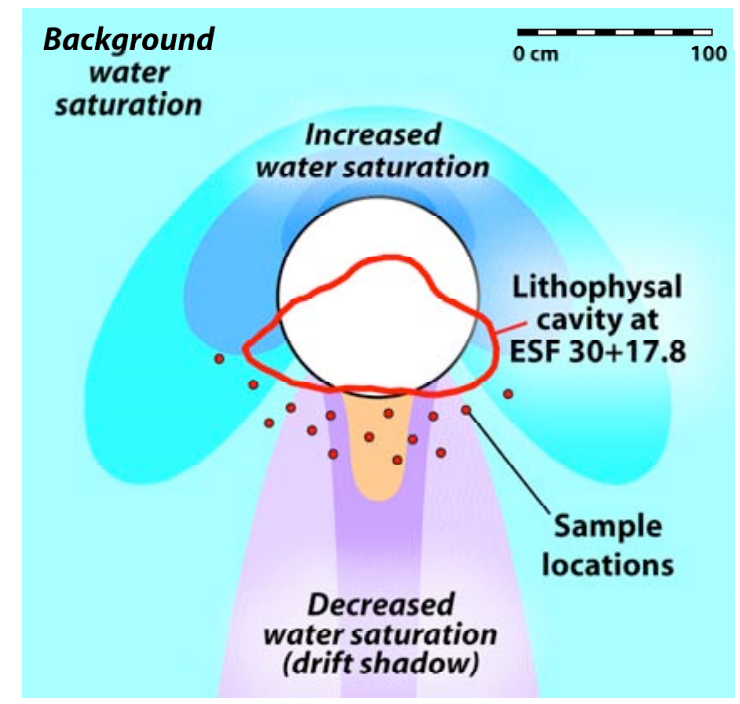

Figure I. Schematic depiction of numerical simulations showing relative distributions of water saturation around a hypothetical spherical cavity. The outline of a natural lithophysal cavity with sample locations is shown for comparison. with numerical simulations, are being used to test the concept of drift shadow under hydrologic flow conditions likely during the next several $100 \mathrm{k} . \mathrm{y}$.

\section{Accomplishments}

Modeling: Analytical solutions of seepage exclusion were used to estimate sizes of shadow zones that might develop beneath lithophysal cavities (Figure 1). Preliminary simulations indicate that shadows could develop under advective fracture-continuum flow regimes but not under conditions of matrix diffusion. Initial results imply that shadow length below cavities is related to rock hydraulic properties and cavity radius. Simulations of spherical cavities estimate shadow zones shorter than about one tenth the diameter for $1 \mathrm{~m}$ diameter cavities, with increasingly longer shadow lengths for larger cavities. Cases involving seepage into cavities were not modeled.

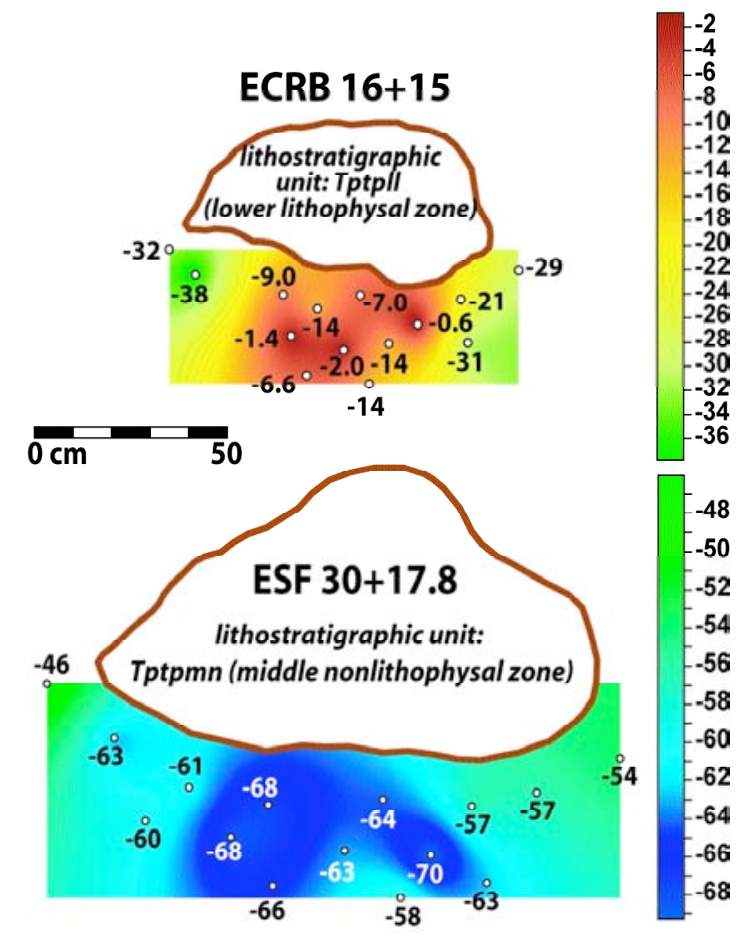

Figure 2. Preliminary whole-rock ${ }^{234} U / 238 \cup$ AR data in permil (\%o) deviations from secular equilibrium for samples from beneath two lithophysal cavities. Colors represent interpolations between sample values determined by kriging methods. Analytical uncertainties are between I and $2 \%$. 
Analyses: Rock samples were collected from beneath large (0.6 to $1.2 \mathrm{~m}$ diameter) lithophysal cavities in the Mioceneaged Topopah Spring Tuff exposed in the Exploratory Studies Facility (ESF) tunnel and the Enhanced Characterization of Repository Block (ECRB) Cross Drift. Twenty-nine whole-rock isotope analyses were completed for two cavities. Preliminary data indicate that water interacted with rock to varying degrees during the past $10^{5}$ years; however, patterns of ${ }^{234} \mathrm{U} /{ }^{238} \mathrm{U}$ AR variation are different beneath the two cavities (Figure 2). Samples beneath the larger cavity at tunnel station ESF 30+17.8 have greater overall disequilibrium (mean ${ }^{234} \mathrm{U} / 238 \mathrm{U}$ AR of $0.939=$ $61 \%$ ) than samples beneath the smaller cavity at ECRB $16+15$ (mean ${ }^{234} \mathrm{U} /{ }^{238} \mathrm{U}$ AR of $0.984=16 \%$ ). The pattern of whole-rock ${ }^{234} \mathrm{U} /{ }^{238} \mathrm{U}$ disequilibrium at ECRB $16+15$ is consistent with a drift shadow where ${ }^{234} \mathrm{U} /{ }^{238} \mathrm{U}$ AR in samples beneath the cavity show less disequilibrium than samples at cavity margins. The opposite pattern is observed at ESF 30+17.8. Both cavities have secondary mineral deposits on cavity floors, indicating past seepage. However, thicker deposits at ESF 30+17.8 imply greater seepage over time, which may be focused at the cavity floor.

New Borehole Targeting and Drilling: Seismic reflection methods proposed in the original task plan to target meter-sized cavities behind the tunnel-wall dryout zone $(\sim 2 \mathrm{~m})$ were tested in Alcove \#5. The combination of high seismic velocities of the tuffs, interference of tunnel-wall surface waves, and imprecise source-signal timing precluded accurate detection of seismic reflections from cavities. Without targets identified from seismic surveys, drilling plans were modified to exploit the large number of lithophysal cavities in the ECRB Cross Drift. Five drydrilled boreholes between ECRB 16+10 and 16+18 were completed. Video logging revealed a number of 50 to 90 $\mathrm{cm}$ diameter cavities beyond the dryout zone. Core associated with these intervals will be used for pore-water extraction by ultracentrifugation or leaching. Additional drilling is planned in FY2006 to intersect shadow zones beneath targeted cavities.

Whole-rock ${ }^{234} \mathrm{U} /{ }^{238} \mathrm{U}$ AR data are useful for assessing time-integrated water/rock interactions around lithophysal cavities at Yucca Mountain. Preliminary data are interpreted as evidence that flow may be diverted from beneath some cavities and focused under others. The extent and applicability of the drift shadow concept requires additional testing of tunnel-wall and drillcore samples planned for this activity in FY2006. 


\title{
Testing the Concept of Drift Shadow with X-Ray Absorption Imaging Experiments
}

\author{
Susan J. Altman, Clifford K. Ho, Aleeca Forsberg, and William Peplinski \\ Sandia National Laboratories (SNL)
}

\section{Research Objectives}

The current Yucca Mountain models conservatively assume that the percolation flux directly under the drifts is the same as that away from the drifts. X-ray absorption imaging during laboratory experiments of capillary diversion around an opening (the drift) provides quantitative and visual evidence to test whether only a fraction of the total percolation flux is available beneath the drift. This reduced flux due to capillary diversion is referred to as the drift shadow and could lead to reduced transport of radionuclides.

\section{Approach}

X-ray absorption imaging (Tidwell et al., 2000; Altman et al., 2004) is an experimental technique that allows for the visualization and quantification of transport through geological media. Test cells with dimensions $10 \mathrm{~cm} \times 15 \mathrm{~cm}$ were prepared with different fracture configurations (multi-fracture and in-plane configurations) and apertures (Figure 1). Prior to starting an experiment, test cells were saturated with water. At the start of the experiment, a tracer was dripped at a controlled flow rate through three or four ports at the top of the test cells. Transport through the cell was measured by collecting and weighing sponges both in the drift and at collection ports at the bottom of the cell. $X$-ray images were collected prior to the start of the experiment and at different times during the experiment. By subtracting the image taken prior to the start of the experiment from the images taken during the experiment, the x-ray absorption caused by the geological media was removed, and the tracer pathways in the geological samples became visible.

\section{Accomplishments}

To date, 14 experiments have been run (Table 1). A total of four test cells have been constructed from Topapah Spring

A

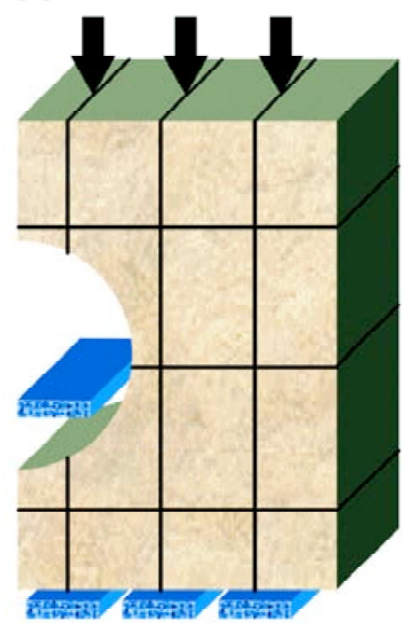

B

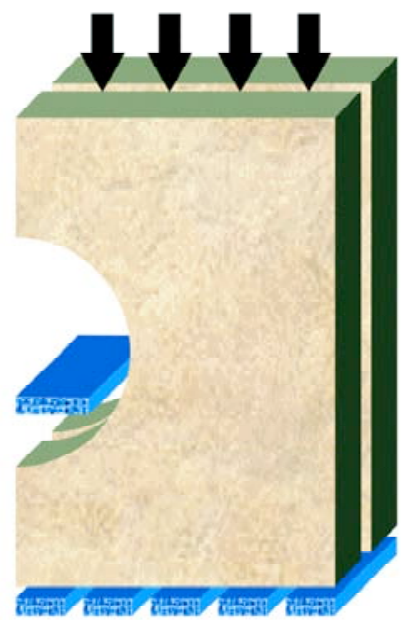

Figure I. Schematic of multi-fracture $(A)$ and in-plane fracture $(B)$ configurations

A

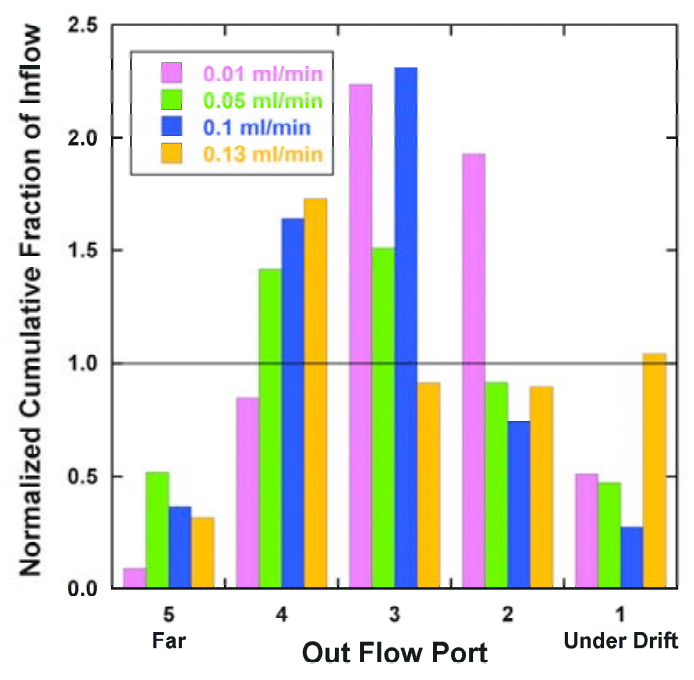

B

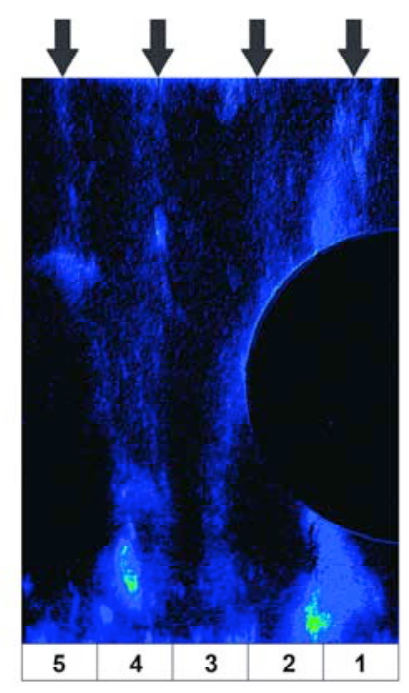

Figure 2. Fraction of inflow discharging through outflow ports for four tests run at different flow rates on the in-plane fracture system with a $250 \mu \mathrm{m}$ aperture fracture $(A)$. Fractions are normalized such that if the inflow was discharged uniformly, the normalized discharge would be I. X-ray image of the tracer taken 5 hours after the start of the experiment $(B)$. This experiment is run on the in-plane fracture system with a $250 \mu \mathrm{m}$ aperture fracture with a flow rate of $0.05 \mathrm{~mL} / \mathrm{min}$. 
Tuff samples. Mass balances have been calculated on all of the tests, and the discharge data have been analyzed.

Software has been developed that allows for the alignment of x-ray images, which is necessary for image analysis (subtracting one image from another). X-ray images from the experiments have been digitized, and the data are being processed and analyzed.

Evidence for the drift shadow effect is observed through both the imaging and measurements of the outflow mass. The fraction of inflow that discharges into the drift is less than $1 \%$ in all but two of the tests (Table 1). Furthermore, for the in-plane fracture systems with $250 \mu \mathrm{m}$ apertures, the majority of the inflow discharged through the port at the edge of the drift in three separate tests (Port 3, Figure 2A). In the fourth test, most of the tracer discharged through the port even further away from the drift (Port 4). In many of the tests, a flow path was observed starting from the injection port above the drift, flowing around the edge of the drift, and discharging through Port 3 (Figure 2B). There is also some evidence of discharge below the drift. Further tests are required to determine whether the discharge below the drift is controlled by experimental artifacts, film flow on the interior of the drift, or heterogeneities in the sample. Nevertheless, visual and quantitative evidence support the drift-shadow-zone concept.
X-ray absorption imaging provided strong visual evidence of the capillary-barrier diversion around the drift. There is also evidence of decreased flux under the drift, the drift shadow effect. The extent to which the flux decreases is dependent on heterogeneities in the system. The capillary diversion could have a strong effect on the release rate of radionuclides from the waste emplacement drifts, and the drift shadow effect could affect the transport time through the near field and the UZ. Understanding and predicting the drift shadow zone would allow TSPA to realistically implement the flow field at the critical interface between the EBS and the fractured formation, and account for its retarding effect on radionuclide transport through the UZ.

This work supports graduate education.

\section{Related Publications}

Altman, S.J., M. Uchida, V.C.Tidwell, C.M. Boney, and B.P. Chambers, Use of x-ray absorption imaging to examine heterogeneous diffusion in fractured crystalline rocks. J. Contam. Hydrol., 69(1-2), 1-26, 2004.

Tidwell, V.C., L.C. Meigs, T. Christian-Frear, and C.M. Boney, Effects of spatially heterogeneous porosity on matrix diffusion as investigated by x-ray absorption imaging. J. Contam. Hydrol., 42(2-4), 285-302, 2000.

\begin{tabular}{|c|c|c|c|c|c|}
\hline Date Run & Test \# & \multirow{2}{*}{$\begin{array}{l}\text { Flow Rate } \\
\text { (ml/min) }\end{array}$} & $\begin{array}{l}\text { Fracture Aperture } \\
(\mu \mathrm{m})\end{array}$ & $\begin{array}{l}\text { Mass Balance } \\
\text { Error (\%) }\end{array}$ & $\begin{array}{l}\text { Cum. Mass } \\
\text { into Drift (\%) }\end{array}$ \\
\hline \multicolumn{5}{|c|}{ In-Plane Fracture Tests } & \\
\hline $07 / 27 / 2005$ & $5 \mathrm{P}$ & 0.01 & 100 & 10 & 0.9 \\
\hline $07 / 27 / 2005$ & $5 \mathrm{P}$ & 0.01 & 250 & -4.5 & 0.0 \\
\hline $06 / 2 / 2005$ & $2 \mathrm{P}$ & 0.05 & 100 & 11 & 0.6 \\
\hline $06 / 2 / 2005$ & $2 \mathrm{P}$ & 0.05 & 250 & 10 & 1.2 \\
\hline $05 / 10 / 2005$ & $1 \mathrm{P}$ & 0.09 & 100 & 7.9 & 0.2 \\
\hline $05 / 10 / 2005$ & $1 \mathrm{P}$ & 0.09 & 250 & 1.6 & 0.3 \\
\hline $08 / 24 / 2005$ & $2 B$ & 0.10 & 250 & 10.4 & 0.2 \\
\hline $06 / 22 / 2005$ & $3 \mathrm{P}$ & 0.12 & 100 & 9.9 & 0.9 \\
\hline $06 / 22 / 2005$ & $3 \mathrm{P}$ & 0.13 & 250 & 9.7 & 0.3 \\
\hline \multicolumn{6}{|c|}{ Multi-fracture Tests } \\
\hline 08/17/2005 & $1 \mathrm{~B}$ & 0.009 & 250 & -10.0 & 3.0 \\
\hline $02 / 17 / 2005$ & $1 \mathrm{M}$ & 0.1 & 100 & 3.8 & 0.8 \\
\hline 02/17/2005 & $1 \mathrm{M}$ & 0.1 & 250 & 3.4 & 0.3 \\
\hline $05 / 25 / 2005$ & $3 \mathrm{M}$ & 0.1 & 250 & 11.4 & 0.5 \\
\hline $08 / 24 / 2005$ & $2 \mathrm{~B}$ & 0.1 & 100 & 8.7 & 0.5 \\
\hline
\end{tabular}




\section{UNSATURATED ZONE FLOW AND TRANSPORT}

Enhanced Retardation of Radionuclide Transport in Fractured Rock Hui-Hai Liu, Yinqi Zhang, and Quanlin Zhou, Lawrence Berkeley National Laboratory (LBNL); Fred J. Molz, Clemson University

\section{Peña Blanca Natural Analogue}

Schön S. Levy and Michael T. Murrell, Los Alamos National Laboratory (LANL); Patrick F. Dobson, Lawrence Berkeley National Laboratory (LBNL); Mostafa Fayek, University of Tennessee-Knoxville; Philip Goodell, University of Texas-El Paso (UTEP); Richard Ku, University of Southern California (USC)

\section{Matrix/Fracture Flow in Subrepository Units}

Leonid Neymark and James Paces, US Geological Survey; David Vaniman and Steve Chipera, Los Alamos National Laboratory (LANL)

Pore Connectivity, Episodic Flow, and Unsaturated Diffusion in Fractured Tuff Qinhong Hu, Lawrence Livermore National Laboratory (LLNL); Robert P. Ewing, lowa State University; Liviu Tomutsa, Lawrence Berkeley National Laboratory (LBNL) 
This page intentionally left blank. 


\section{Enhanced Retardation of Radionuclide Transport in Fractured Rock}

Hui-Hai Liu', Yinqi Zhang', Quanlin Zhou', and Fred J. Molz ${ }^{2}$

'Lawrence Berkeley National Laboratory (LBNL) | ${ }^{2}$ Clemson University

\section{Research Objectives}

Matrix diffusion in fractured rock refers to the exchange (through molecular diffusion) of solute mass between fractures and the surrounding rock matrix. Owing to the much slower water velocity in the rock matrix compared to fractures, matrix diffusion can significantly retard contaminant transport and increase the spreading of a contaminant plume. The effective matrix diffusion coefficient is an important parameter controlling this process. Matrix-diffusion-coefficient values measured from small-scale rock samples in the laboratory have often been used for modeling large-scale contaminant transport processes at many different sites, including the proposed Yucca Mountain nuclear waste repository site. Our recent study indicated that the effective matrix diffusion coefficient may be scale dependent and generally increases with test scale (Liu et al., 2004). The major objective of this work is to further evaluate this scale-dependent behavior and its likely impact on the performance of the proposed Yucca Mountain repository.

\section{Approach}

A literature survey of estimates for the effective matrix diff usion coefficient (as a function of testing scale) is conducted,

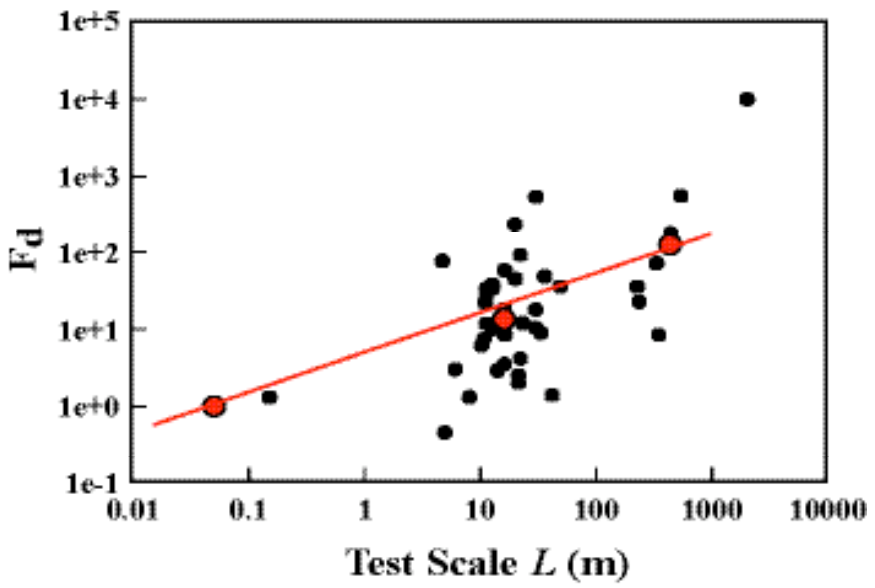

Figure I. The ratio of observed effective matrix diffusion coefficient to the labscale value $\left(F_{d}\right)$ as a function of test scale. Red points correspond to average values (of many data points) at lab scale, a scale on the order of tens of meters, and a scale on the order of hundreds of meters, respectively. and selected tracer-test results in the literature are reanalyzed to evaluate the values for the effective diffusion coefficient reported by other researchers and to provide additional evidence of scale dependence. Two-dimensional fracture-network models (with matrix) are used to perform numerical experiments to investigate the mechanisms behind the scale dependency. Yucca Mountain site-scale flow and transport models are used for simulating radionuclide transport to demonstrate the conservatism of the Total System Performance Assessment, which does not consider matrixdiffusion-coefficient scale dependence.

\section{Accomplishments}

A comprehensive literature survey (taking into account field tracer tests and the corresponding effective diffusion coefficient values) has been completed (Zhou et al., 2005). Forty field tracer tests at about 20 fractured geologic sites were selected for this study, based on data availability and quality. For the field tracer tests without reported matrixdiffusion coefficient values, reanalysis of the tracer breakthrough curves was carried out to calibrate transport parameters that include the effective matrix diffusion coefficient. Figure 1 summarizes the survey and analysis results. Although a high degree of fluctuation exists, the results confirm that the effective matrix diffusion coefficient is scale dependent and tends to increase with testing scale.

Several studies have considered a variety of mechanisms for interpreting this scale dependence (Zhang et al., 2005; Liu et al., 2005). They have found that this scale dependence results from the fundamental geometric properties of a flow path in a fracture network. Water flow in a single flow path (or channel) has been often simplified as a flow process within a single straight fracture. In reality, however, flow structure is more complicated than that, owing to the complexity of fracture-network geometry. Based on the percolation theory, a flow path consists of both globally connected (Level 1) fractures and relatively small (higherlevel) fractures forming local flow loops, as shown in Figure 2. Results from a number of numerical experiments demonstrate that the effective matrix diffusion coefficient (determined without considering the flow loops) is indeed 
theoretically scale dependent, as shown in Figure 3.

Since a large degree of fluctuation exists in Figure 1, a rigorous study using a realistic fracture network is in progress.

While the scale dependence of permeability and dispersivity has been an active research topic for many years, this study shows that the effective matrix diffusion coefficient is also scale dependent. The performance of the Yucca Mountain site may be significantly underestimated when the scale dependence of the effective matrix diffusion coefficient is not considered; substantial increases in matrix diffusion (resulting from its scale dependence) significantly retard radionuclide transport in natural systems.

\section{Related Publications}

Liu, H.H., G.S. Bodvarsson, and G. Zhang, The scaledependency of the effective matrix diffusion coefficient. Vadose Zone Journal, 3, 312-315, 2004.

Liu, H.H., Y. Zhang, Q. Zhou and F. J. Molz, An interpretation of the scale dependence of effective matrix diffusion coefficient. In review, 2005.

Zhang Y., H.H. Liu, Q. Zhou and F. J. Molz, Effect of dualscale diffusive property heterogeneity on effective matrix diffusion coefficient for fractured rock. In review, 2005.

Zhou, Q, H. H. Liu, F.J. Molz, Y. Zhang and G.S. Bodvarsson, Effective matrix diffusion coefficient for fractured rock: Results from literature survey. In review, 2005.

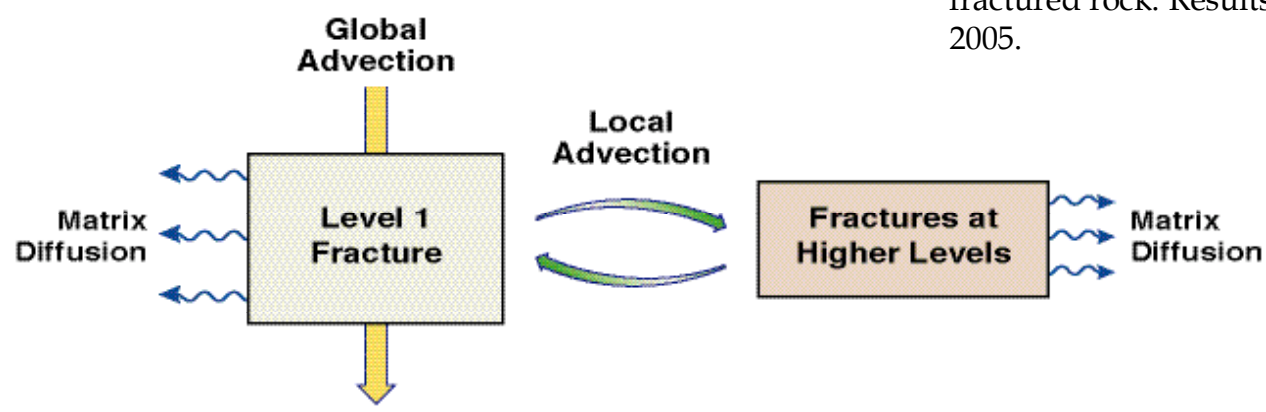

Figure 2. Effective matrix diffusion as a combination of local-scale advection and matrix diffusion in fractures at different scales

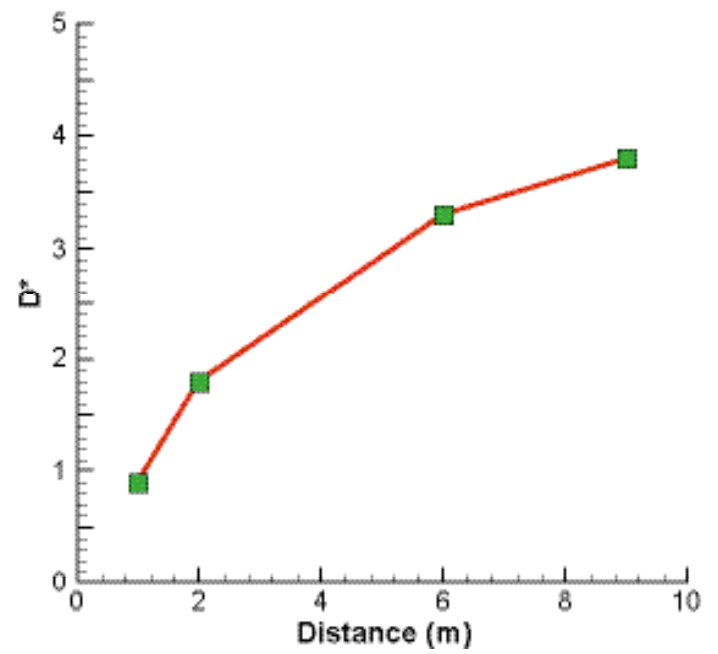

Figure 3. Fitted relative effective-matrix-diffusion coefficient values ( $\left.D^{*}\right)$ as a function of distance for a flow path consisting of flow loops 


\section{Peña Blanca Natural Analogue}

Schön S. Levy', Patrick F. Dobson², Mostafa Fayek ${ }^{3}$, Philip Goodell ${ }^{4}$, Richard Ku , and Michael T. Murrell

'Los Alamos National Laboratory (LANL) | ${ }^{2}$ Lawrence Berkeley National Laboratory (LBNL)

${ }^{3}$ University of Tennessee-Knoxville | 4 University of Texas-El Paso (UTEP) | 5 University of Southern California (USC)

\section{Research Objectives}

The objective is to study radionuclide transport at a site with characteristics analogous to the proposed nuclearwaste repository at Yucca Mountain, and to use the results to test an entire process model and Total System Performance Assessment (TSPA). This will be accomplished by using field and laboratory measurements and process-model results from Peña Blanca, the site of a uranium ore body in fractured, welded tuff. A three-dimensional conceptual and numerical model of radionuclide transport in the unsaturated and saturated zones will be developed. Specific objectives for improved understanding include (1) identifying active fractures and the extent of fracture-matrix geochemical interaction; (2) investigating aqueous transport behavior in the unsaturated and saturated zones; (3) studying the role of colloid transport and colloid-facilitated transport of radionuclides; and (4) studying surficial and shallow subsurface transport processes.

\section{Approach}

The Peña Blanca site, in Chihuahua, México, is a former mine in a uranium $(\mathrm{U})$ ore body in fractured tuff similar to the proposed repository host rock at Yucca Mountain. The site is in the southern Basin and Range province in an arid environment with a thick (>200 m) unsaturated zone. Field work includes subsurface water and core sampling, sam-

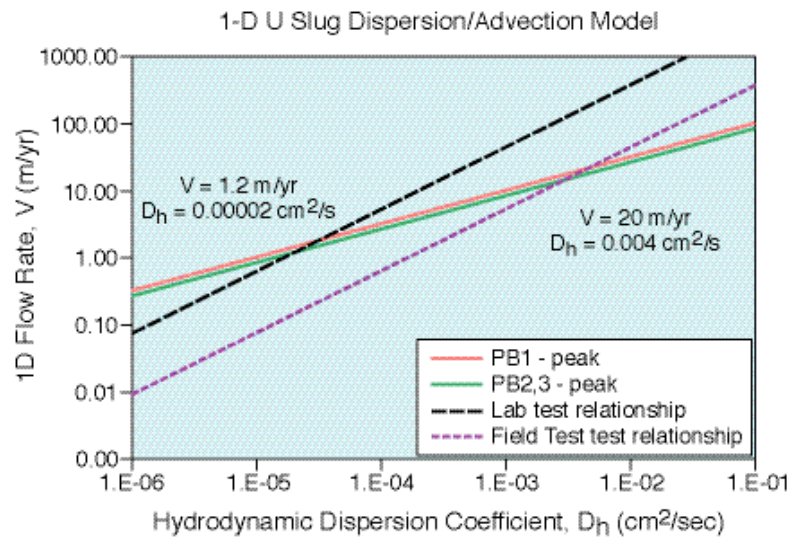

Figure I. Estimation of groundwater flow velocity and longitudinal dispersion pling of fractured rock at various distances from the ore body, and mapping, sampling, and in situ gamma surveying of surficial materials related to previous surface storage of high-grade ore. Structural and stratigraphic studies provide a basis for the assembly and analysis of geochemical data. Field data, plus chemical and isotopic analysis of rock and water samples, provide the input for process models and total systems performance assessment for this analogue site.

\section{Accomplishments}

We made two successful field trips to the Peña Blanca site in FY2005. Accomplishments are as follows:

- We designed and constructed an improved seepage collection system in the Nopal +00 adit.

- We took spectral gamma-ray measurements of samples from a block of high-grade $U$ ore and from surface and near-surface soil downslope of the block.

- A suite of samples collected from the ore body and surrounding areas is being analyzed for mineral parageneses by electron microscopy and wavelength-dispersive spectroscopy.

- We initiated analysis of rock samples for sorptivity and smectite content.

- U concentrations and isotopic activity ratios were measured in samples from three Peña Blanca wells collected over several months. The decreasing U con-

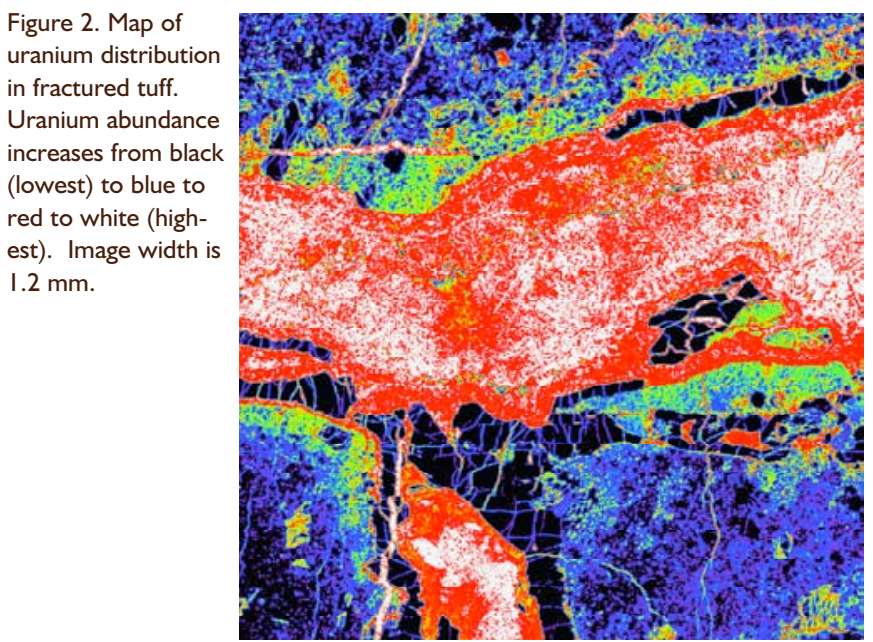


centrations observed over that time were modeled with a 1-D advection-dispersion model.

- We made first measurements of short-lived U-daughter isotopes in large-volume water samples from Peña Blanca wells and modeled the analytical results in terms of a three-pool (solid, sorbed, and dissolved) radionuclide transport model.

- We made first measurements of colloid sizes and concentration, and larger water samples are being filtered for $\mathrm{U} / \mathrm{Th}$ isotope measurements.

- Developed and ran the Peña Blanca Natural Analogue Model to simulate mobilization and transport of radionuclides from the ore deposit.

- Assembled input data and began initial seepage modeling for the mine adit area.

- Organized a special session on Peña Blanca for the 2005 Geological Society of America annual meeting.

- $\mathrm{U}$ isotopic activity ratios suggest limited mixing between three site wells. The 1-D advection-dispersion model yielded estimates of saturated zone groundwater velocity (1-20 m/yr) and dispersion coefficient $\left(10^{-5}\right.$ to $\left.10^{-3} \mathrm{~cm}^{2} / \mathrm{s}\right)$ (Figure 1$)$. These estimates will be used to design future tracer tests.

- Modeling of the Ra-222, Pb-210, and Po-210 contents of well-water samples indicates that migration rates of the isotopes are three to six orders of magnitude slower than groundwater movement. The modeling also yielded estimates of average fracture apertures, an important input parameter for higher-level models. Higher activities of Pb-210 and Po-210 in one well could reflect an association of these isotopes with colloids in the groundwater. These results confirm the influence of retardation processes. Measured size distributions and concentrations of colloids in Peña Blanca waters are similar to those observed near Yucca Mountain, a significant aspect of similarity.

- U minerals show zonation within the ore body, indicative of alteration processes (Figure 2). A revised chronology was developed for formation of the $U$ ore deposit at Nopal I. These results help determine the source term for the TSPA being prepared for this analog site, with the uranium deposit mimicking spent fuel.

The natural analogue studies at Peña Blanca provide a wealth of data and understanding on radionuclide transport processes and the overall system behavior. This understanding will provide the basis for the development and validation of realistic process and abstraction models with reduced conservatism.

\section{Related Publications}

Dobson, P.F., P.C. Goodell, M. Fayek, F. Melchor, M.T. Murrell, A. Simmons, I.A. Reyes-Cortés, R. de la Garza, and R.D. Oliver, Stratigraphy of the PB-1 well, Nopal I uranium deposit, Sierra Peña Blanca, Chihuahua, Mexico. Geol. Soc. Amer. Abstracts with Programs, 37 (7), 196, 2005.

Fayek, M., P. Goodell, M. Ren, and A. Simmons, Geochronology and fluid-rock interaction associated with the Nopal I uranium deposit, Peña Blanca, Mexico. Geol. Soc. Amer. Abstracts with Programs, 37 (7), 197, 2005.

F rench, D.C., E. Anthony, and P. Goodell, Gamma-ray characterization of the U-series intermediate daughters from soil samples at the Peña Blanca natural analog, Chihuahua, Mexico. Geol. Soc. Amer. Abstracts with Programs, 37 (7), 268, 2005.

Goldstein, S.J., M.T. Murrell, and A.M. Simmons, Uranium elemental and isotopic constraints on groundwater flow beneath the Nopal I uranium deposit, Peña Blanca, Mexico. Geol. Soc. Amer. Abstracts with Programs, 37 (7), 197, 2005.

Ku, T.L., S. Luo, M.T. Murrell, and S.J. Goldstein, Modeling uranium transport in unsaturated zone at Peña Blanca, Mexico. Geol. Soc. Amer. Abstracts with Programs, 37 (7), 198, 2005.

Luo, S., T.L. Ku, V. Todd, M.T. Murrell, J.A. Rodríguez, J.C. Dinsmoor, and A.J. Mitchell, In-situ radionuclide transport near the Nopal I uranium deposit at Peña Blanca, Mexico: Constraints from short-lived decay series radionuclides. Geol. Soc. Amer. Abstracts with Programs, 37 (7), 198, 2005.

Oliver, R.D., J.C. Dinsmoor, S.J. Goldstein, I.A. ReyesCortés, and R. de la Garza, Initial test well conditioning at Nopal I uranium deposit, Sierra Peña Blanca Chihuahua, Mexico. Geol. Soc. Amer. Abstracts with Programs, 37 (7), 197, 2005.

Ren, M., P.C. Goodell, A.B. Kelts, M. Fayek, C. Fan, and C. Beshears, Phase analyses of uranium bearing minerals from the Nopal I deposit, Peña Blanca, Mexico. Geol. Soc. Amer. Abstracts with Programs, 37 (7), 197, 2005.

Rodríguez-Pineda, J.A., P. Goodell, P.F. Dobson, J. Walton, R.D. Oliver, R. de la Garza, and S. Harder, Regional hydrology of the Nopal I site, Sierra de Peña Blanca, Chihuahua, Mexico. Geol. Soc. Amer. Abstracts with Programs, 37 (7), 196, 2005.

Saucedo, A., M. Fayek, I.A. Reyes, and P.F. Dobson, Structural analysis of the Nopal I uranium deposit, Peña Blanca, Mexico. Geol. Soc. Amer. Abstracts with Programs, 37 (7), 196, 2005.

Saulnier, G.J., Jr., and W. Statham, The Peña Blanca natural analogue model. Geol. Soc. Amer. Abstracts with Programs, 37 (7), 269, 2005.

Walton, J., P. Goodell, C. Beshears, D. French, and A. Kelts, Radionuclide dispersion rates by aeolian, fluvial, and porous media transport. Geol. Soc. Amer. Abstracts with Programs, 37 (7), 268, 2005. 


\section{Matrix/Fracture Flow in Subrepository Units}

Leonid Neymark', James Paces', David Vaniman², and Steve Chipera ${ }^{2}$

IUS Geological Survey | ${ }^{2}$ Los Alamos National Laboratory (LANL)

\section{Research Objectives}

The objective of this study is to investigate the time-integrated hydrologic behavior of zeolitized tuffs below the proposed repository at Yucca Mountain, by measuring chemical and isotopic disequilibrium existing between rock samples from fracture surfaces and from intact core interiors representing rock matrix.

\section{Approach}

A positive attribute of natural barriers at Yucca Mountain is sorption of radionuclides on flow-path surfaces in rock units beneath the repository horizon. Although tuffs constituting this part of the unsaturated zone (UZ) are variably altered to zeolites having high sorptive capacities, the nature of flow through these units remains poorly constrained. Because zeolitization reduces permeability in these tuffs, flow through fractures, rather than matrix, may dominate percolation beneath the proposed repository, resulting in less effective radionuclide retardation.

However, evidence of matrix flow through these units would allow inclusion of the rock matrix as a natural barrier in Total System Performance Assessment.

In systems older than $\sim 1$ million years that remain closed to mass transfer, isotopes in the decay chain of natural uranium-238 $(238 \mathrm{U})$ reach a state of radioactive secular equilibrium where $234 \mathrm{U} / 238 \mathrm{U}$ and ${ }^{230} \mathrm{Th} / 238 \mathrm{U}$ activity ratios (AR) are equal to unity. However, water/rock interaction results in radioactive disequilibrium, the degree of which depends on water velocity, rate of rock dissolution, $\alpha-$ recoil processes, adsorption and desorption rate constants, and precipitation rates of secondary minerals. Whole-rock U-series disequilibrium and chemical compositions in intact and rubblized core, as well as material milled from

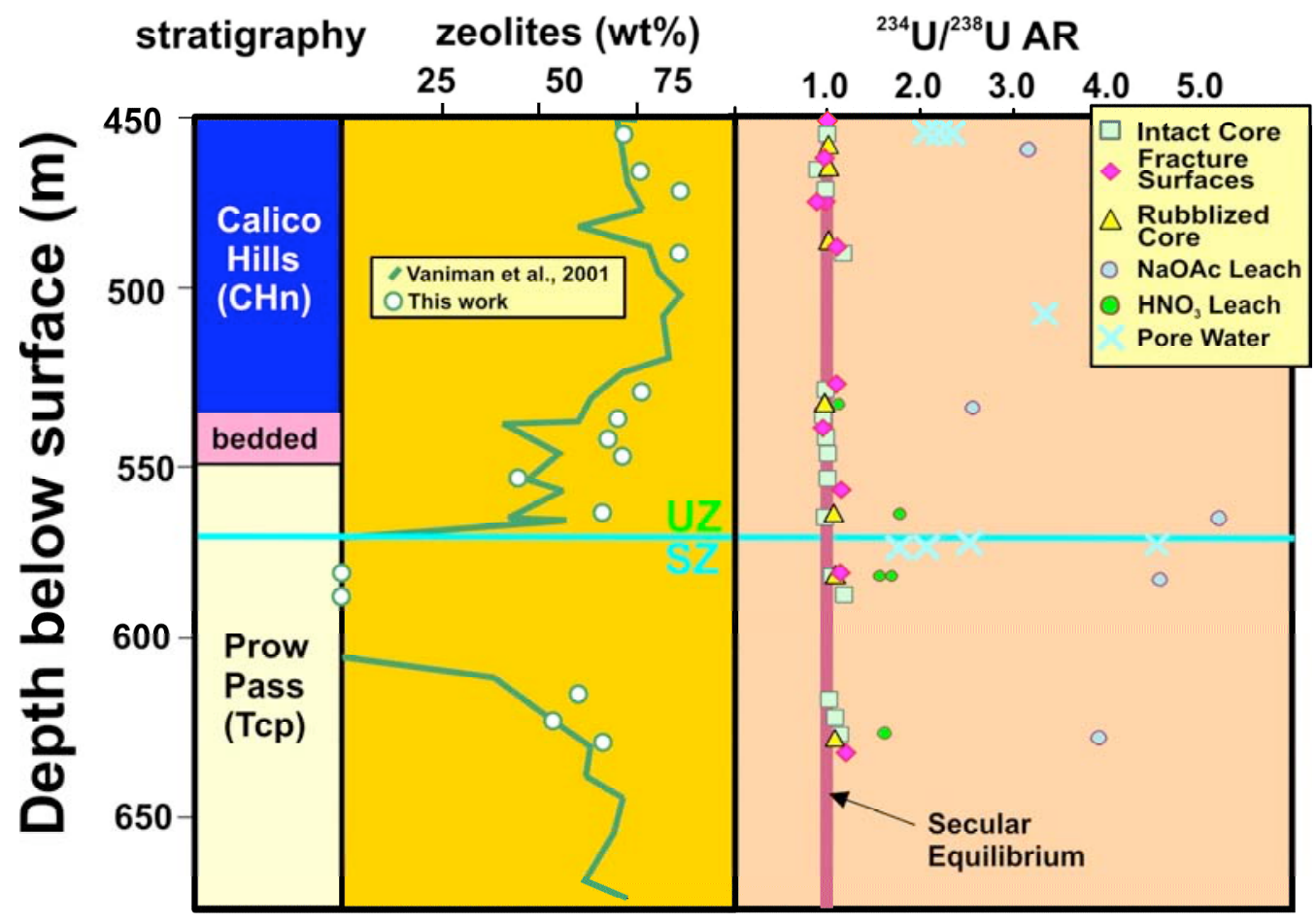

Figure I. Stratigraphy, abundance of zeolites, and ${ }^{234} \mathrm{U} / 238 \mathrm{U}$ activity ratios in pore waters, rocks, and rock leachates from USW SD-9 core samples relative to the depth below surface 
fracture surfaces within subrepository units in borehole USW SD-9 (depth interval from 451.1 to $633.7 \mathrm{~m}$ ), are being used to evaluate differences in water/rock interaction between fractured and unfractured rock. In addition, estimates of time-integrated in situ $\mathrm{U}$ partition coefficients $\left(\mathrm{K}_{\mathrm{d}}=\mathrm{C}_{\text {solid }} / \mathrm{C}_{\text {water }}\right)$ under natural flow conditions were obtained from U concentrations in rock, water, and rock leachate samples.

\section{Accomplishments}

Chemical compositions in USW SD-9 whole-rock samples vary systematically with depth, reflecting lithostratigraphic changes. Preliminary zeolite (mordenite and clinoptilolite) abundances measured by quantitative x-ray diffraction (XRD) methods vary from 0 to $\sim 79 \%$, (Figure 1). Opal$\mathrm{CT}$ and smectite were also detected in all samples. Several devitrified tuff samples in the Prow Pass Tuff (Tcp) were not zeolitized and retain subequal amounts of quartz, potassium feldspar, and plagioclase.

Isotopic compositions of $U$ and Th were measured by isotope-dilution thermal ionization mass spectrometry, with relative $2 \sigma$ uncertainties of about 0.2 and $0.5 \%$, respectively. Samples of intact core have preliminary ${ }^{234} \mathrm{U} /{ }^{238} \mathrm{U}$ AR between 0.93 and 1.18, indicating both enrichments $\left({ }^{234} \mathrm{U} /{ }^{238} \mathrm{U} \mathrm{AR}>1\right)$ and depletions $\left({ }^{234} \mathrm{U} /{ }^{238} \mathrm{U} A R<1\right)$ in the daughter ${ }^{234} \mathrm{U}$ relative to the parent ${ }^{238} \mathrm{U}$ (Figure 1).

Because Yucca Mountain UZ water is consistently enriched in ${ }^{234} \mathrm{U}$ relative to ${ }^{238} \mathrm{U}$, whole-rock samples with
${ }^{234} \mathrm{U} /{ }^{238} \mathrm{U}>1$ indicate scavenging of $U$ from water by zeolitic rocks, although no obvious correlations are observed between the zeolite abundance and the degree of U-series disequilibrium. These preliminary results contrast with whole-rock data from nonzeolitized repository horizon units, which invariably have $234 \mathrm{U} / 238 \mathrm{U}<1$ due to ${ }^{234} \mathrm{U}$ losses through $\alpha$-recoil processes. Preliminary ${ }^{234} \mathrm{U} /{ }^{238} \mathrm{U}$ AR (between 0.94 and 1.10) in samples from fracture surfaces in zeolitized tuffs are similar to intact core.

In contrast to rocks, all subrepository pore water and rock leachate samples are enriched in ${ }^{234} \mathrm{U}(234 \mathrm{U} / 238 \mathrm{U}$ AR from 1.1 to 5.2 ). The largest ${ }^{234} \mathrm{U} /{ }^{238} \mathrm{U}$ AR are in pore water samples and sodium acetate rock leachates, which reflect uranium sorbed on mineral surfaces. Preliminary data for pore water and the leachates allowed estimation of in situ $\mathrm{K}_{\mathrm{d}}$ values for $\mathrm{U}$ ranging from tens to hundreds of $\mathrm{mL} / \mathrm{g}$.

Similar deviations from secular isotopic equilibrium existing between rock samples from fracture surfaces and from intact core interiors representing rock matrix indicate similar time-integrated hydrologic behavior over the past 1 million years, and may also indicate that matrix flow constitutes a greater fraction of subrepository water flux than is currently modeled. Preliminary U-series data show that zeolitized subrepository units can scavenge $U$ with elevated ${ }^{234} \mathrm{U} /{ }^{238} \mathrm{U}$ from percolating water, and that amounts of retardation of radionuclides and dose reduction may be greater than currently credited to this natural barrier. 


\section{Pore Connectivity, Episodic Flow, and Unsaturated Diffusion in Fractured Tuff}

Qinhong Hu', Robert P. Ewing², and Liviu Tomutsa ${ }^{3}$

'Lawrence Livermore National Laboratory (LLNL) | ${ }^{2}$ lowa State University | ${ }^{3}$ Lawrence Berkeley National Laboratory (LBNL)

\section{Research Objectives}

Current models of how radionuclide movement is slowed by diffusion into and sorption to the rock matrix ignore two important factors. First, Yucca Mountain tuffs may have sparsely connected pore spaces, resulting in scaledependent diffusion - but models currently use a constant diffusion term. Second, the rock matrix in the unsaturated zone is constantly imbibing or draining water, which both drives advective movement of radionuclides and changes the effective diffusion coefficient of the matrix - but models currently assume constant wetness conditions. The objectives of this work are to reexamine our understanding of matrix diffusion, to provide insights into upscaling laboratory-scale diffusion experiments, and to evaluate the impact on diffusive retardation of episodic fracture flow and low pore connectivity.

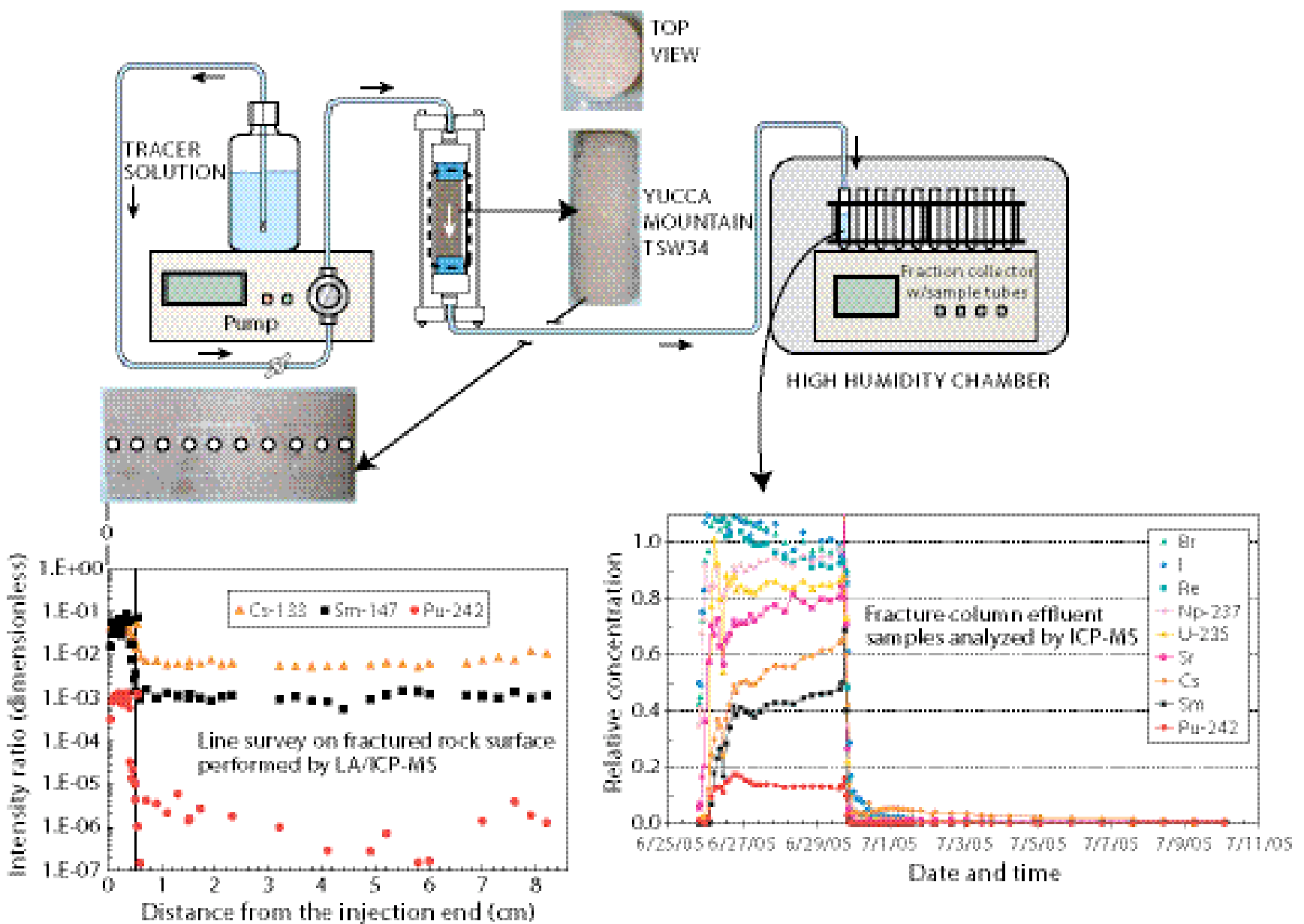

Figure I. Radionuclide transport in a fractured core column 


\section{Approach}

- Acquire samples of the major tuff types below the proposed repository at Yucca Mountain.

- Measure water imbibition over time into samples of several height:diameter ratios to get information on pore connectivity.

- Measure gas diffusion in samples of several lengths to investigate potential scale effects.

- After tracer imbibition or vacuum-saturation, use laser ablation interfaced with inductively coupled plasma-mass spectrometry (LA/ICP-MS) to measure the fine-scale distribution of tracers with distance from the rock face.

- Analyze the iso-concentration surfaces in the three tuffs, indicative of pore connectivity, from 3-D images acquired using the synchrotron microtomography system at Lawrence Berkeley National Laboratory's (LBNL's) Advanced Light Source (ALS).

- Compare tracer net movement and concentration profiles from episodic (4 cycles of flow and noflow, each cycle containing a different suite of sorbing and nonsorbing tracers) and nonepisodic flow experiments.

- Predictively simulate these experiments in a porescale network model, using both classical and anomalous diffusion, with wetting and drying where appropriate.

\section{Accomplishments}

We acquired 21 samples from boreholes UE-25 UZ\#16, USW SD-9, and USW SD-12, representing all unsaturated zone layers between the proposed repository and the water table: Topopah Spring devitrified (middle nonlithophysal, lower lithophysal, and lower nonlithophysal zones), and Calico Hills vitric and zeolitic tuff. We measured water imbibition into rock samples of several height:diameter ratios. The slope of log(imbibed mass) versus $\log$ (time) is related to the rock's pore connectivity. In devitrified rock, slopes are sensitive to the sample's shape, with tall thin samples being more likely to have a slope of 1/4 (anomalous behavior), sometimes followed by crossover to a slope of $1 / 2$ (classical). Short squat samples rarely display 1/4-type behavior. These results confirm that the devitrified rock pore space is sparsely connected. We performed a nonepisodic flow experiment in a saw-cut fracture core initially equilibrated at $>97 \%$ relative humidity. Tracers were ${ }^{3} \mathrm{H}, \mathrm{ReO}_{4}^{-}$(an analog for ${ }^{99} \mathrm{TcO}_{4}^{-}$), $\mathrm{I}^{-}$(for ${ }^{129} \mathrm{I}^{-}$), Sr and $\mathrm{Cs}$ (for ${ }^{90} \mathrm{Sr}$ and ${ }^{137} \mathrm{Cs}$ ), plus the radionuclides ${ }^{235} \mathrm{U},{ }^{237} \mathrm{~Np}$, and ${ }^{241} \mathrm{Pu}$. These tracers span a variety of sorption strengths and represent many of the radionuclides of concern. The nonsorbing ${ }^{3} \mathrm{H}$ and $\mathrm{ReO}_{4}{ }^{-}$serve as diffusivity tracers with different diffusion coefficients. Effluent from the flow reactor was collected and analyzed to obtain breakthrough curves of non- or less-retarded tracers. At the end of the experiment, distribution of strongly retarded tracers within the core was characterized by LA/ ICP-MS (Figure 1). Future episodic flow experiments will entail four cycles of tracer solution flow, with high humidity air flow between each flow cycle, within the fracture.

We set up a system for measuring gas diffusion in consolidated rock, using a mass spectrometric technique developed at LLNL, which has a dynamic measurement range spanning several orders of magnitude. We tested the system using helium and sulphur hexafluoride, which have different diffusion coefficients.

At the LBNL Advanced Light Source, we imaged a dry TSw34 tuff core (4 $\mathrm{mm}$ diameter, $40 \mathrm{~mm}$ long). The energy used was $35 \mathrm{keV}$, just above the iodine $\mathrm{K}$ edge, maximizing detection of the iodine tracer. We took 35 scans at 1.6 micron/pixel resolution, covering the full sample length. We simulated imbibition experiments using a random walk technique that reproduces the experimental sensitivity to pore connectivity. Novel speed-up techniques enabled us to use networks measuring $\sim 17$ million pores.

This work integrates experimental and simulation approaches using new experimental methods, state-of-theart synchrotron microtomography, and pore-scale network modeling. Results from this work will address uncertainties regarding how pore connectivity, changes in saturation, and episodic flow affect diffusive retardation of radionuclides. This will help to resolve questions central to fracture/matrix interactions and their impact on total proposed repository performance. 


\title{
SATURATED ZONE \\ FLOW AND TRANSPORT
}

\begin{abstract}
Determining the Redox Properties of Yucca Mountain-Related Groundwater Using Trace-Element Speciation for Predicting the Mobility of Nuclear Waste James Cizdziel, University of Nevada, Las Vegas; Vernon Hodge, University of Nevada, Las Vegas; Karen H. Johannesson, University of Texas at Arlington
\end{abstract}

Field Studies for the Determination of Transport Properties of Radioactive Solutes and Colloids Using Chemical Analogues

Barry Freifeld, John Apps, and George Moridis, Lawrence Berkeley National Laboratory (LBNL); Paul Reimus, Los Alamos National Laboratory (LANL); Dale Hammermeister, Nye County Nuclear Waste Repository Project Office, Nye County, NV

Improved Characterization of Radionuclide Retardation in Volcanics and Alluvium

Paul W. Reimus, Mei Ding, Cindy Scism, Cheryl Sedlacek, Schon Levy, and Steve Chipera, Los Alamos National Laboratory (LANL)

Carbon- 4 Groundwater Analysis

Gary L. Patterson, United States Geological Survey (USGS); James Thomas, Desert Research Institute

Large-Scale Drawdown Test

A Collaborative Effort between the United States Geological Survey (USGS) and Los Alamos National Laboratory ( LANL)

M.J. Umari (Co-P.I.), Allen Shapiro (Co-P.I.), John Earle, and Mike Fahy, United States Geological Survey (USGS); Paul Reimus (Co-P.I.) and Ed Kwicklis, Los Alamos National Laboratory (LANL)

Integration of Data and Models for the Coupled Regional- and Site-Scale Models

A.A. Eddebbarh and G.A. Zyvoloski, Los Alamos National Laboratory (LANL); S.C. James, Sandia National Laboratories (SNL); Steffen Mehl and Mary C. Hill, United States Geological Survey (USGS)

Saturated Zone Plumes in Volcanic Rock

Sharad Kelkar and Robert Roback, Los Alamos National Laboratory (LANL) 
This page intentionally left blank. 


\title{
Determining the Redox Properties of Yucca Mountain-Related Groundwater Using Trace-Element Speciation for Predicting the Mobility of Nuclear Waste
}

\author{
James Cizdziel', Vernon Hodge², and Karen H. Johannesson ${ }^{3}$ \\ 'Harry Reid Center for Environmental Studies, University of Nevada, Las Vegas \\ 2Department of Chemistry, University of Nevada, Las Vegas \\ ${ }^{3}$ Department of Earth and Environmental Sciences, University of Texas at Arlington
}

\section{Research Objectives}

The primary objective of this project is to provide a more complete description of the redox properties of Yucca Mountain-related groundwater. To that end, we will determine the oxidation-state species of ten elements in samples of the Nye County Early Warning Drilling Program (NCEWDP) groundwater and other available samples beneath and downgradient from the proposed Yucca Mountain repository site. Percentages of major redox species of these elements and total concentrations will be measured and tabulated. We will build a qualitative model of redox condition distributions in the aquifer, and subsequently will provide a 3-D "map" that could then be overlain with regional groundwater flow models. The purpose is to predict likely zones within the flow system where changing redox conditions could lead to sequestering of radionuclides. By combining our geochemical measurements of groundwater and PHREEQC simulations (for aqueous geochemistry) with regional groundwater flow models, stakeholders will possess a powerful tool for evaluating the potential mobilization and retardation of radionuclides in the system.

It is our goal that the data gathered in the proposed study, along with our modeling, will provide seminal information for the next step, which will include construction of a reactive transport model that also accounts for redox transformations and for oxyanion-forming trace-element species transport in the aquifer system. Ultimately, we expect to deliver valuable information essential for predicting the oxidation states, solubility, and mobility of plutonium $(\mathrm{Pu})$ - and many other elements present in nuclear waste -in the sampled waters.

\section{Approach}

A possible natural barrier to radionuclide migration in the saturated zone (SZ) is the presence of nonoxidizing or reducing environments. For example, the mobility of Tc-99 in oxic groundwater, ascribed to the pertechnetate ion, is greatly diminished in reducing groundwater. The containment of radionuclides away from the accessible environment is a key feature in the Yucca Mountain Total System Performance Assessment. Despite the significant implications of a potential natural barrier in the SZ, little is known about the true oxidizing/reducing (redox) conditions in the SZ below and downgradient of Yucca Mountain. This lack of knowledge is not surprising, considering that accurately measuring the redox properties of groundwater hundreds of feet below the surface is no small feat.

The term "Eh" is used to describe the redox potential of groundwater as determined by an inert metal electrode. Over the last few decades, there has been much discussion about the utility of Eh measurements in natural waters as a valid indicator of the actual redox conditions, and its use in predicting the distribution of a soluble element between its various oxidation state species or redox couples (Stumm and Morgan, 1970; Cherry et al., 1979). The Eh is a value based on thermodynamic quantities such as the free energy $(\Delta G)$ and chemical equilibrium constants $(K)$. Typically, a platinum electrode is used to measure Eh; however, most redox couples do not react on a platinum surface at near-neutral $\mathrm{pH}$ values. Groundwater samples in southern Nevada typically have $\mathrm{pH}$ values that range from 7.2 to 8.2. In addition, natural systems are rarely in equilibrium, which is a necessary assumption in a thermodynamically controlled system. Equilibration time for many environmentally important reactions is on the order of years to centuries. So Eh data may not reflect the actual conditions in the SZ and could, with regard to Yucca Mountain performance assessment models, lead to an overly conservative model.

Thus, an approach for determining redox properties other than Eh is critically needed. To that end, we have developed a methodology to measure the concentrations of redox active species of a number of trace elements (i.e., arsenic, antimony, selenium, chromium, manganese, copper, molybdenum, vanadium, tungsten, and uranium) in groundwaters by the hyphenated ion chromatographyinductively coupled plasma mass spectrometry (ICICPMS) technique. Furthermore, we have used the data garnered from the application of this technique to show a tentative proof of concept for this approach (Task 33 YMP). Indeed, data from that study has shown that Eh measurements do not successfully predict, for example, the observed distribution of arsenic between its oxidized and reduced forms $\left(\mathrm{As}^{+5}\right.$ and $\mathrm{As}^{+3}$, respectively). The new hyphenated approach is also advantageous because it is based on measurements of the redox species at low con- 
centrations (from about $10^{-7} \mathrm{M}$ to $10^{-11} \mathrm{M}$ ), which are not likely to react at the surface of the platinum electrode (at circumneutral $\mathrm{pH}$ ) used to obtain the Eh measurement.

\section{Accomplishments}

Funding for this work has just begun. What is new here is the approach to determine in situ redox conditions found in the SZ. The motive for developing a novel redox scale is that trace-element speciation is expected to provide a more accurate picture of the redox conditions of groundwater in the vicinity of Yucca Mountain, to help determine whether a natural reducing barrier exists, and if such a barrier is identified, to establish its magnitude and spatial distribution.

It is likely that spatial patterns of redox variation may fluctuate little with future climates, but the degree of reduced conditions may be affected by greater regional precipitation rates. Potential climate changes that produce more precipitation may introduce more oxidized water and raise the water table, but would also be expected to increase the hydrostatic head on the lower carbonate aquifer. That, in turn, would increase the driving force for reduced waters to well up from that lower aquifer into the tuff aquifer under and south of Yucca Mountain. The locations where this upwelling occurs, however, would not be expected to change.

The redox information will be interpreted to shed light on the solubilities and mobilities of key radionuclides in the SZ environment. We will target multiple areas of high interest, below and downgradient of Yucca Mountain. The fact that we have already developed, tested, and applied the IC-ICPMS methodology greatly increases the likelihood of success in the proposed work, since method development is always a major hurdle to overcome. Future advances, such as the inclusion of the redox species of iron and rhenium, should be realized with a minimum investment of time.

This work supports graduate education.

\section{References}

Cherry, J.A., A.U. Shaikh, D.E. Tallman, and R.V. Nicholson, Arsenic species as an indicator of redox conditions in groundwater. J. Hydrology, 43, 373-392, 1979.

Stumm, W., and J.J. Morgan, Aquatic Chemistry. John Wiley and Sons, pp. 362 and 545, 1970. 


\title{
Field Studies for the Determination of Transport Properties of Radioactive Solutes and Colloids Using Chemical Analogues
}

\author{
Barry Freifeld', Paul Reimus², Dale Hammermeister³, John Apps', and George Moridis' \\ 'Lawrence Berkeley National Laboratory (LBNL) | ${ }^{2}$ Los Alamos National Laboratory (LANL) \\ ${ }^{3}$ Nye County Nuclear Waste Repository Project Office, Nye County, NV
}

\section{Research Objectives}

The primary objective of this work is to provide an enhanced understanding of the transport behavior of radionuclides and colloid-bound radionuclides in the saturated zone (SZ), using field measurements conducted with chemical analogues. These measurements will be performed within wellbores penetrating the volcanic rock types of primary importance to radionuclide transportdevitrified and zeolitic tuffs - within the SZ. Since many of the retardation mechanisms controlling radionuclide transport in the SZ have been difficult to quantify using current indirect methods, the conservative assumption has been not to incorporate them into process models. Specifically, the SZ process models do not account for (1) irreversible sorption or very slow desorption of some solutes, (2) the possibility of lowered redox potentials that could result in precipitation or enhanced sorption of some solutes, (3) irreversible colloid filtration, and (4) highly sorptive mineral surface coatings in primary advective fracture pathways. Direct measurement of these processes in the natural system, using chemical analogues, will facilitate their incorporation into models predicting radionuclide transport through the SZ. Next-generation reactive transport models will be developed that incorporate distributions of sorption, desorption, and colloidal filtration parameters, and recommendations on how these mechanisms could best be incorporated into Yucca Mountain Total System Performance Assessment models will be made.

\section{Approach}

Injection/pump-back tests will be performed using chemical analogues for radioactive solutes and colloid-borne radionuclides. Conservative tracers will also be injected to serve as a baseline for understanding sorptive processes.

Figure 1 is a schematic of the testing sequence showing the three stages in the field tests: (1) chemical analogue and colloid tracer injection, (2) waiting while natural processes are allowed to proceed, and (3) tracer pump-back. A novel sampling system, referred to as the U-tube, will be employed during pump-back to provide high-quality geochemical samples (Freifeld et al., 2005). The benefit of the U-tube system is that fluid samples are collected at in situ pressure, preventing degassing and exposure to external contaminants, particularly oxygen, which would result in changes in sample fluid chemistry.
The use of chemical analogues poses challenges in extrapolating from the observed transport behavior to each analogue's respective radioelement. Batch laboratory studies of radionuclide sorption and desorption and their surrogates will be undertaken to compare their sorptive behavior. Ion exchange, surface complexation, and co-precipitation of the radioelements and selected surrogates will be assessed. When practical, batch testing will proceed with waters and rock samples from the proposed injection pump-back testing intervals. The core selected to be used for batch testing will be weighted towards more densely fractured and higher-permeability samples, to account for the predilection of fluid flow through those regions and to allow for testing of fracture coating minerals. Natural colloids collected from Nye County wells (known to be primarily smectite clays) as part of other Yucca Mountain studies will be used for adsorption and desorption testing of radionuclides and surrogates onto colloids. Tests will be conducted over a range of $\mathrm{pH}$ and carbonate/bicarbonate concentrations to help elucidate mechanistic similarities and differences between the surrogates and radionuclides. The batch sorption/desorption studies will be supplemented with a limited number of XPS (x-ray photoelectron spectroscopy) comparisons of tuff surfaces (with special emphasis on fracture mineral coatings) that have significant concentrations of radionuclides or surrogates adsorbed to them. XPS effectively interrogates about $100 \AA$ of a solid sample surface and will provide the following information (Ding et al., 2000):

- The nature of interaction between adsorbates and surfaces (e.g., chemisorption or physisorption) with some information on surface complexation

- Qualitative estimation of the affinity (degree of bonding) between adsorbates and surfaces.

The analysis of the tracer elution data will involve inverse modeling (history matching) of the tracer concentration in the fluid withdrawn from the well. In the proposed analysis approach, inverse modeling will be used to correlate the elution curves with different models of sorption or filtration behavior. The results from the laboratory batch tests of tracer sorption or filtration, and data from previous studies, will provide an indication as to the type of process occurring under field conditions. Kinetic sorption, equilibrium sorption (linear, Langmuir, and Freundlich), 
and site complexation models will be considered.

Significant mismatches between current models and observed transport behavior may necessitate fuller model development that accounts for distributions of sorption, desorption, and colloidal filtration parameters.

Recommendations on how these transport models could best be incorporated into Yucca Mountain performance assessment models will be made as a result of this research.

\section{Accomplishments}

This project has just started. The testing, sampling, and analysis approaches developed for the investigation of transport phenomena in the SZ are likely to provide accurate data for the development and validation of realistic transport models. These models will appropriately account for potentially significant retardation effects, including irreversible sorption and irreversible colloid filtration, in the SZ, which affect travel time and dose estimates.

\section{Related Publications}

Ding, M., B.H.W.S De Jong, S.J. Roosendaal, and A. Vredenberg, XPS studies on the electronic structure of bonding between solid and solutes: Adsorption of arsenate, chromate, phosphate, $\mathrm{Pb}^{2+}$, and $\mathrm{Zn}^{2+}$ ions on amorphous black ferric oxyhydroxide. Geochim. Cosmochim. Acta, 64 (7), 1209-1219, 2000.

Freifeld, B.M., R.C. Trautz, K.K. Yousif, T.J. Phelps, L.R. Myer, S.D. Hovorka, and D. Collins, The U-Tube: A novel system for acquiring borehole fluid samples from a deep geologic $\mathrm{CO}_{2}$ sequestration experiment. Journal of Geophysical Research Solid Earth (in press), 2005.
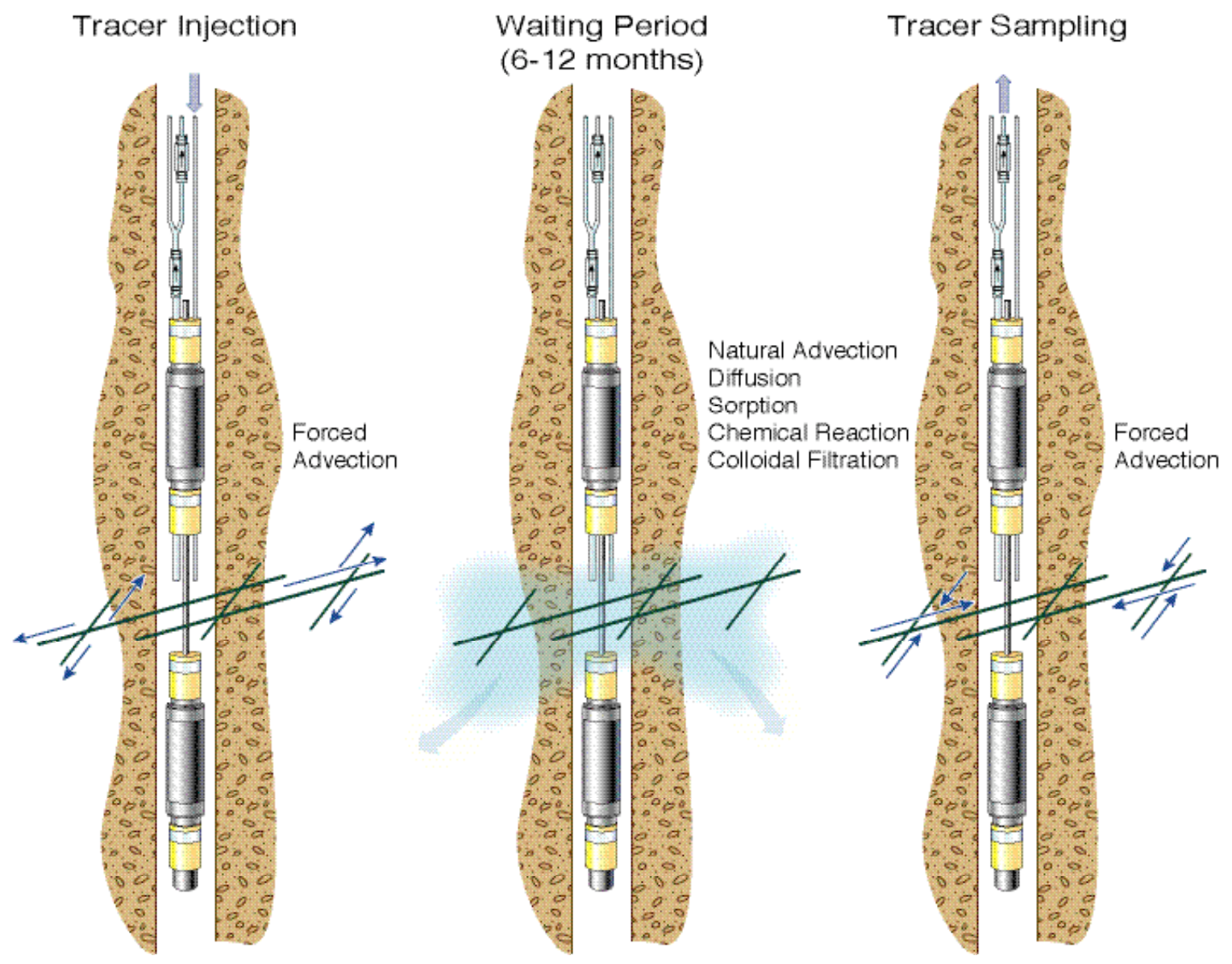

Figure I. Sequence of steps performed for conducting injection/pump-back tracer tests showing the three test phases: (I) tracer injection, (2) waiting while natural processes are allowed to proceed, and (3) pump-back 


\section{Improved Characterization of Radionuclide Retardation in Volcanics and Alluvium}

Paul W. Reimus, Mei Ding, Cindy Scism, Cheryl Sedlacek, Schon Levy, and Steve Chipera

Los Alamos National Laboratory (LANL)

\section{Research Objectives}

The primary objective of this project is to demonstrate that significantly more credit can be taken for radionuclide sorption in the saturated zone (SZ) than is taken in the Yucca Mountain Project (YMP) Total Systems Performance Assessment (TSPA). Ancillary objectives that support this primary objective include:

- Developing a reactive-transport-modeling approach compatible with YMP SZ process models that could be readily incorporated into TSPA

- Identifying the role of minor phases, especially fracture coating minerals, in enhancing radionuclide sorption in the $\mathrm{SZ}$

- Determining whether a correlation exists between sorption parameters and hydraulic conductivity in saturated alluvium

- Determining the potential for reduction/sorption of pertechnetate $\left({ }^{99} \mathrm{Tc}\right)$ in the SZ.

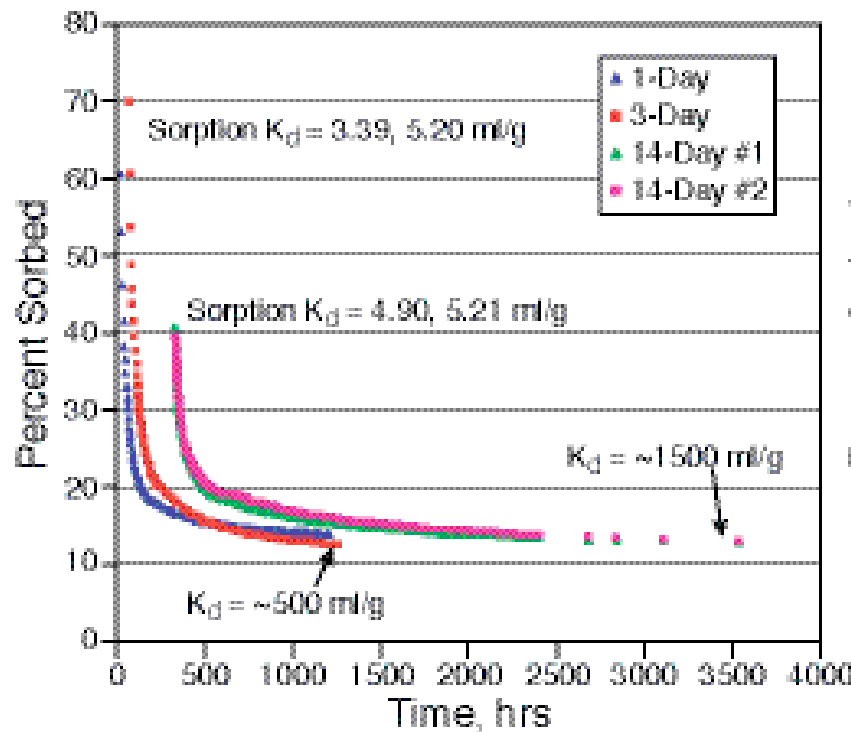

\section{Approach}

The experimental approach so far has focused on radionuclides of uranium (U) and neptunium (Np) because of their high solubility, relatively weak sorption, and their high contributions to dose in the Yucca Mountain TSPA. The experimental focus has also been on desorption measurements rather than sorption measurements, as desorption rates very likely control radionuclide fate and transport to a much greater degree than sorption rates. We have developed a flow-through experimental technique that provides a nearly continuous measure of desorption rates over a long period of time (Scism et al., 2004). Almost all previous experiments conducted by the Yucca Mountain Project have focused on sorption measurements or veryshort-duration desorption measurements, which tend to significantly underestimate radionuclide sorption parameters. Additionally, we plan to investigate the correlation of radionuclide sorption/desorption with hydraulic conductivity, by conducting $\mathrm{U}$ and $\mathrm{Np}$ transport experiments in columns packed with alluvium from different depth inter-

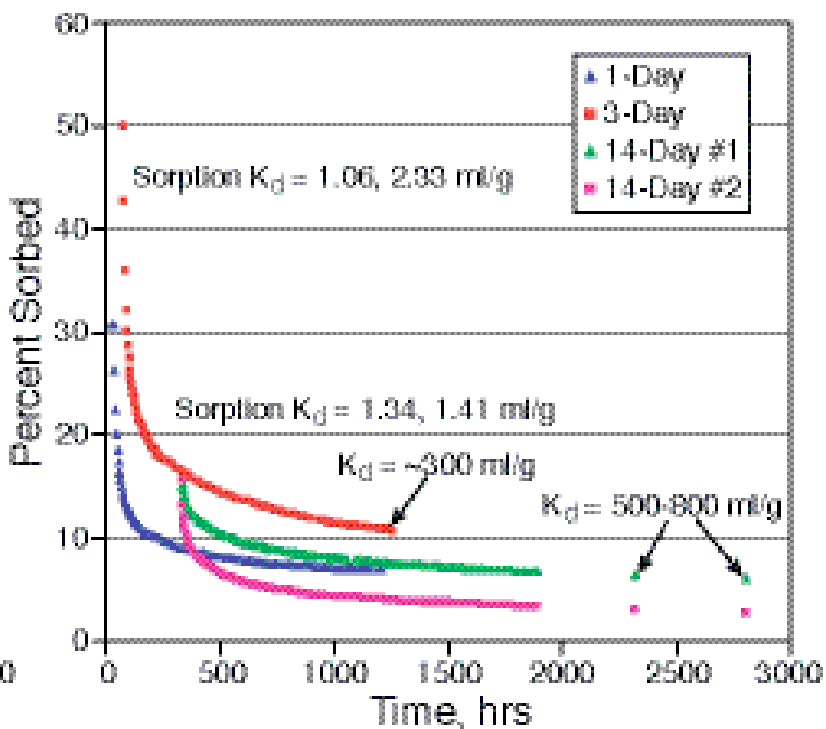

Figure I. Percentages of uranium sorbed as a function of time in flow-through desorption experiments after different times of sorption. Alluvium is from NC-EWDPI $91 \mathrm{MIA}$ and water is from NC-EWDP-I9D zone I (shallow) and zone 4 (deep). Zone 4 water has a higher pH and higher bicarbonate concentration, which suppresses uranium sorption because of carbonate complexation. $K_{d}$ values are ratios of sorption to desorption rates. First point on each curve is the end of a sorption experiment. The $\mathrm{K}_{\mathrm{d}}$ values at late times are the ratios of the sorption-rate constants measured in the batch sorption experiments, to the desorption-rate constants measured in the flow-through desorption experiments. 
vals from sonic drilling operations. The columns were packed carefully to match in situ bulk densities, and they were determined to have hydraulic conductivities spanning over a two-order-of-magnitude range. Quantitative $x$ ray diffraction and other methods are being used to characterize the materials being used in all experiments.

We are developing a generalized sorption residence-timedistribution modeling approach to account for the significantly different desorption rates that have been experimentally observed (Reimus et al., 2004). This approach is consistent with a conceptual model that involves multiple sorption sites, where rates of sorption onto the sites are similar but rates of desorption differ dramatically. The model so far has been able to qualitatively account for desorption behavior observed in the flow-through desorption experiments, as well as some anomalous radionuclide transport results in previous YMP column experiments that did not exhibit standard equilibrium or first-order sorption-kinetics behavior. Through continued experiments, we plan to develop a mechanistic basis for the modeling approach and to validate the approach.

\section{Accomplishments}

We have conducted 18 long-term $\mathrm{U}$ desorption experiments and 8 long-term $\mathrm{Np}$ desorption experiments. These experiments have been conducted with three different alluvium samples and three different waters collected from the alluvium south of Yucca Mountain. Each experiment has consisted of a 1- to 14-day sorption period (with sorption times being varied) followed by several months of desorption in the flow-through experimental apparatus. The experiments are consistently indicating that both $\mathrm{U}$ and $\mathrm{Np}$ initially desorb from the alluvium rather quickly, but their desorption rates eventually slow down, and the ratio of sorption to desorption rates (i.e., effective $\mathrm{K}_{\mathrm{d}}$ value) for the last $5-25 \%$ of the sorbed radionuclide is as much as two orders of magnitude higher than the initial ratio. Figure 1 shows an example for $U$.
Our experiments suggest a distribution of sorption sites with widely ranging desorption rates, and hence widely ranging effective $K_{d}$ values. In short-term experiments, the results are biased toward low $\mathrm{K}_{\mathrm{d}}$ values that reflect the weaker sorption sites. However, it is apparent from the desorption measurements that, even in these short-term experiments, a significant fraction of the $\mathrm{U}$ and $\mathrm{Np}$ binds to much stronger sorption sites than the batch $K_{d}$ value would suggest. The expectation is that as time and distance scales increase, all the $\mathrm{U}$ and $\mathrm{Np}$ will eventually come in contact with these stronger sites. (Even if they tend to be limited in a batch experiment, they represent an essentially unlimited sorption capacity in a field setting.) Thus, the effective $K_{d}$ value over large scales will tend toward a site-density-weighted average of individual $K_{d}$ values on the rock surfaces, which will be much larger than the simple $K_{d}$ value obtained in short-term experiments.

Our results to date suggest that the Yucca Mountain TSPA is extremely conservative in its modeling of $\mathrm{U}$ and $\mathrm{Np}$ transport through the saturated zone. Based on our experiments and modeling, $\mathrm{K}_{\mathrm{d}}$ values over large time and distance scales are likely to be 1-2 orders of magnitude higher than what is used in the TSPA. The TSPA $K_{d}$ values are based on observations from simple batch sorption experiments that do not account for desorption rates.

\section{Related Publications}

Scism, C., P. Reimus, and M. Ding, Sorption and desorption behavior of uranium in Yucca Mountain alluvium. LAUR-04-7796, Presented at Geological Society of America 2004 Annual Meeting, Denver, CO, November 2004.

Reimus, P., C. Scism, and M. Ding, Modeling of early breakthrough behavior of ${ }^{237} \mathrm{~Np}$ and ${ }^{233} \mathrm{U}$ in Yucca Mountain alluvium. LA-UR-04-7797, Presented at Geological Society of America 2004 Annual Meeting, Denver, CO, November 2004. 


\section{Carbon- 4 Groundwater Analysis}

Gary L. Patterson' and James Thomas ${ }^{2}$

IUnited States Geological Survey (USGS) | ${ }^{2}$ Desert Research Institute

\section{Research Objectives}

The current range of groundwater travel times being used in performance assessment modeling of Yucca Mountain is overly conservative, due to the uncertain age estimates available using traditional groundwater age-dating techniques. The objective of this work is to provide improved estimates of groundwater ages along flow paths downgradient from Yucca Mountain. These ages can then be used to provide more realistic estimates of the time required for any potential contaminants to reach the accessible environment.

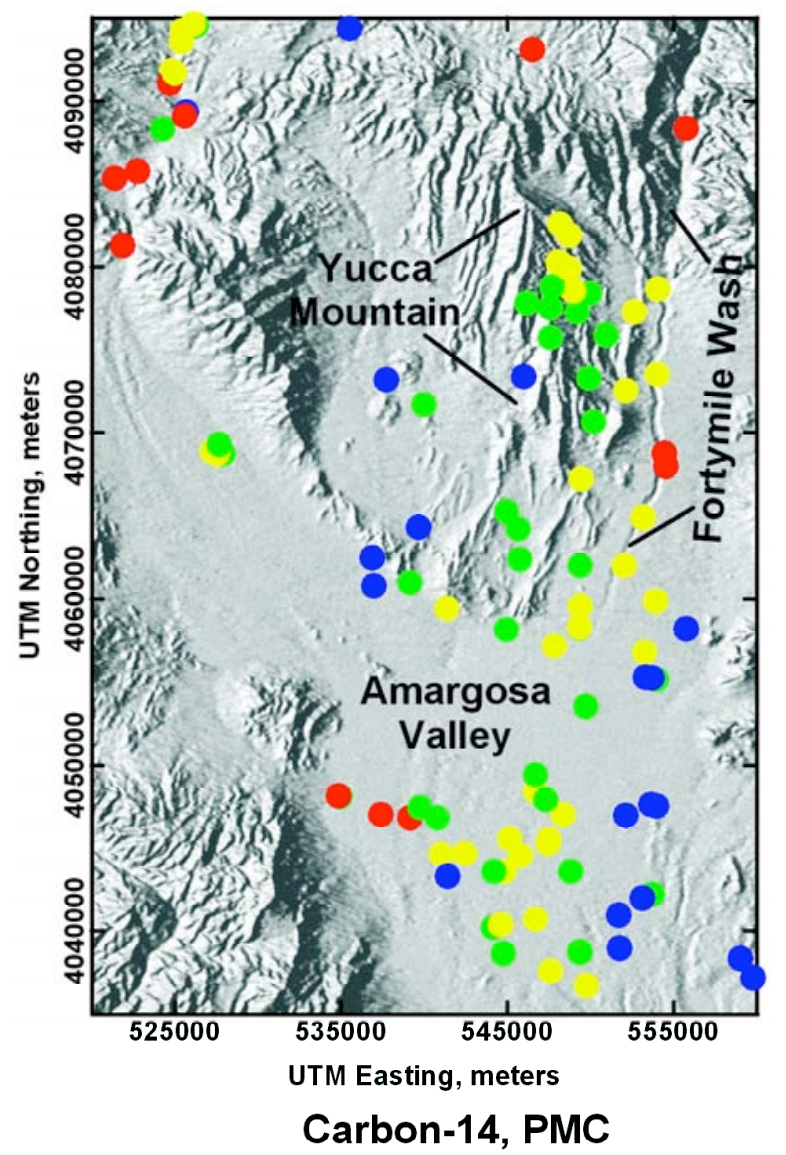

Figure I. Dissolved inorganic carbon- $14\left({ }^{14} \mathrm{C}\right.$-DIC) in groundwater samples in the Yucca Mountain vicinity

\section{Approach}

The approach to this problem involves the measurement of carbon $14\left({ }^{14} \mathrm{C}\right)$ activities in both dissolved inorganic carbon (DIC) and dissolved organic carbon (DOC) in groundwater at and downgradient from Yucca Mountain.

Traditional DIC radiocarbon dating assumes that the ${ }^{14} \mathrm{C}$ percent modern carbon (pmc) acquired during recharge through the soil zone only changes along a flow path as a

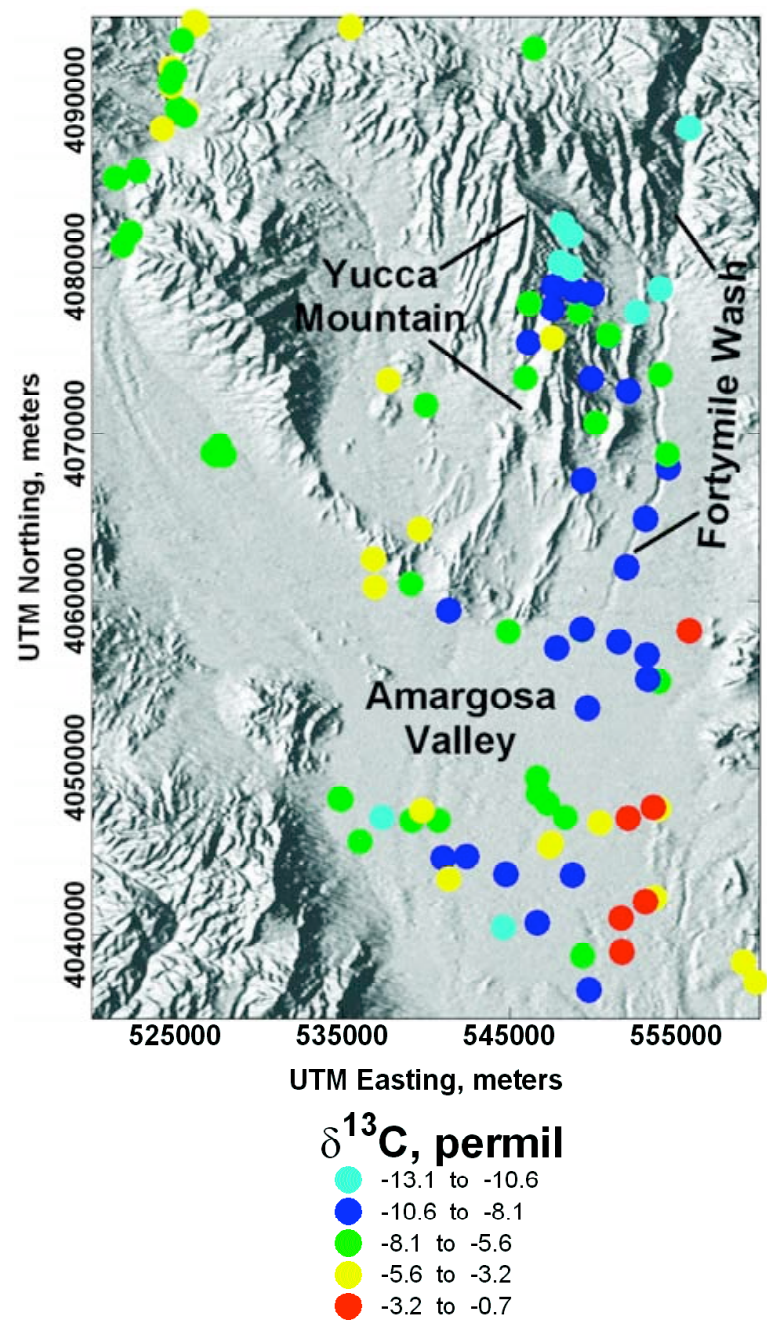

Figure 2. Delta Carbon- $13\left(\delta^{13} \mathrm{C}\right)$ in groundwater samples in the Yucca Mountain vicinity 
result of radioactive decay. This assumption is invalid when the aquifer material contains old carbon with 0 pmc ${ }^{14} \mathrm{C}$ activity ("dead" carbon) that can be dissolved into the water, thus altering the total $\mathrm{pmc}^{14} \mathrm{C}$. Corrections for this open-system behavior are made by examining $\delta^{13} \mathrm{C}$ of solid-carbon-containing phases such as calcite and dolomite, and $\mathrm{CO}_{2}$ gas, and by making assumptions about the degree of water-rock interaction. Large uncertainties in these assumptions translate into large uncertainties in the calculated DIC groundwater ages.

Radiocarbon dating of DOC has the advantage of not requiring corrections based on assumed models of water-rock interaction. Like DIC, DOC is acquired from the soil zone during recharge; however, ${ }^{14} \mathrm{C}$ bearing DOC is not likely to be present in aquifer materials along the flow paths (due to the age of the aquifer materials). Thus, radiocarbon dating of DOC should give a direct measure of the amount of time elapsed since the groundwater entered the system.

The two sets of measurements will be used, along with $\delta^{13} \mathrm{C}$ and hydrochemical modeling, to develop methods to more accurately estimate the age of groundwater along specified flow paths.

\section{Accomplishments}

Eighteen new sets of samples were collected in July and September of 2005. These include nine samples from wells in Amargosa Valley and nine samples from new Nye County EWDP boreholes located south of Yucca Mountain. Preliminary analysis of existing ${ }^{14} \mathrm{C}$-DIC pmc (uncorrected) and $\delta^{13} \mathrm{C}$ (Figures 1 and 2) reveals a plume of relatively younger (higher pmc) water flowing from eastern Yucca Mountain to and along Fortymile Wash into Amargosa Valley. The lighter (more negative) $\delta^{13} \mathrm{C}$ and younger or equal-age groundwater south of Yucca Mountain is evidence supporting the presence of local recharge that infiltrated through the alluvium downgradient from Yucca Mountain.

One preliminary interpretation, based on chemical analysis of saturated zone pore water from Nye County boreholes NC-EWDP-19PB and 22PC, is the possibility of a two-component saturated zone system in the alluvium south of Yucca Mountain. The water chemistry in the shallow part of the saturated zone appears to be influenced by the pres-

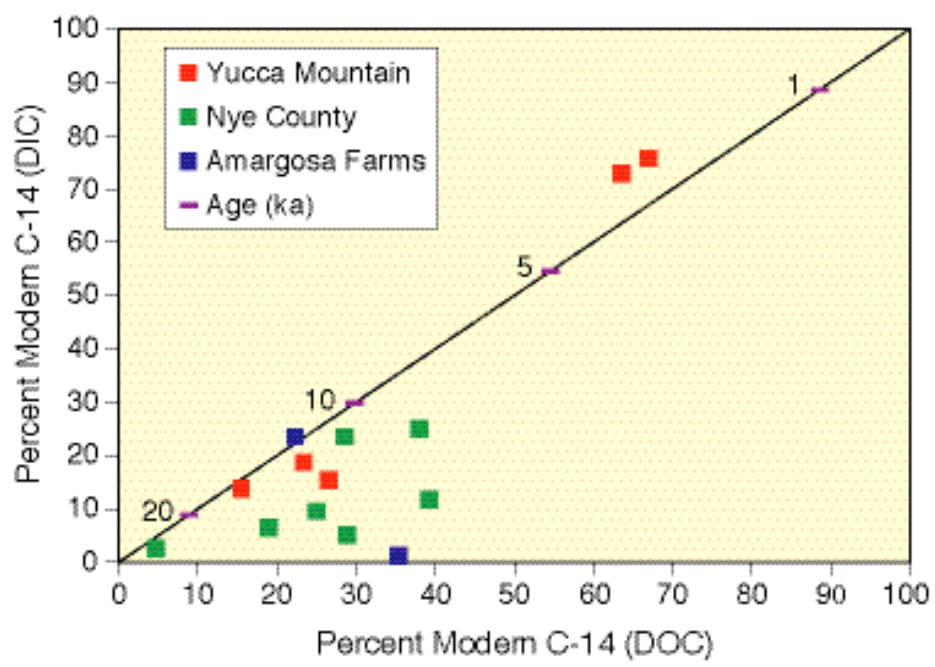

Figure 3. Comparison of radiocarbon measurements of inorganic and organic dissolved carbon-I4 ( ${ }^{14} \mathrm{C}$-DIC and ${ }^{14} \mathrm{C}$-DOC) in groundwater samples from the Yucca Mountain vicinity. The line is equal percentages of modern carbon for ${ }^{14} \mathrm{C}$-DIC and ${ }^{14} \mathrm{C}$-DOC, showing age in thousands of years (ka).

ence of local recharge, while the water chemistry in the deeper system could represent water flowing from beneath Yucca Mountain. Hydrochemical modeling of existing stable isotope data is currently under way to assess the extent of mixing with local recharge and the effect on estimated groundwater ages.

Existing ${ }^{14} \mathrm{C}$-DOC pmc data (Figure 3 ) indicate that ${ }^{14} \mathrm{C}$ DIC measurements from wells in volcanic aquifers beneath Yucca Mountain require little correction, owing to the small amount of "dead" carbon in the aquifer materials. The ${ }^{14} \mathrm{C}$-DIC measurements from wells primarily in alluvium, however, require more correction. The amount of correction required in alluvial wells will become more apparent when the ${ }^{14} \mathrm{C}$-DOC results from the 18 new samples are obtained. This new data should provide a means by which we can correct many ${ }^{14} \mathrm{C}$-DIC measurements already in the Yucca Mountain database.

This work, along with other hydrochemical interpretation, has led to the development of new ideas on the nature of saturated zone flow downgradient from Yucca Mountain. The presence of significant local recharge through the alluvium and the possible presence of two-layered saturated zone flow may result in longer estimates of travel time than are currently assumed. 


\section{Large-Scale Natural Gradient Tracer Test}

\section{A Collaborative Effort between the United States Geological Survey (USGS) and Los Alamos National Laboratory ( LANL)}

M.J. Umaril (Co-P.I.), Allen Shapiro' (Co-P.I.), Paul Reimus² (Co-P.I.), Ed Kwicklis², John Earle', and Mike Fahy'

'United States Geological Survey (USGS) | ${ }^{2}$ Los Alamos National Laboratory (LANL)

\section{Research Objectives}

Our goal is to quantify the dispersion and matrix diffusion values for solute transport in groundwater at a large scale and natural gradient at Yucca Mountain.

\section{Approach}

Our approach is to conduct large-scale (over several kilometers) in situ natural-gradient tracer tests in groundwater, develop interpretive methods that quantify the formation properties (dispersion and diffusion) governing solute transport, and obtain direct estimates of solute travel times in the fractured saturated tuff at Yucca Mountain.

Prototype testing will be done at the Alluvial Testing Complex (ATC).

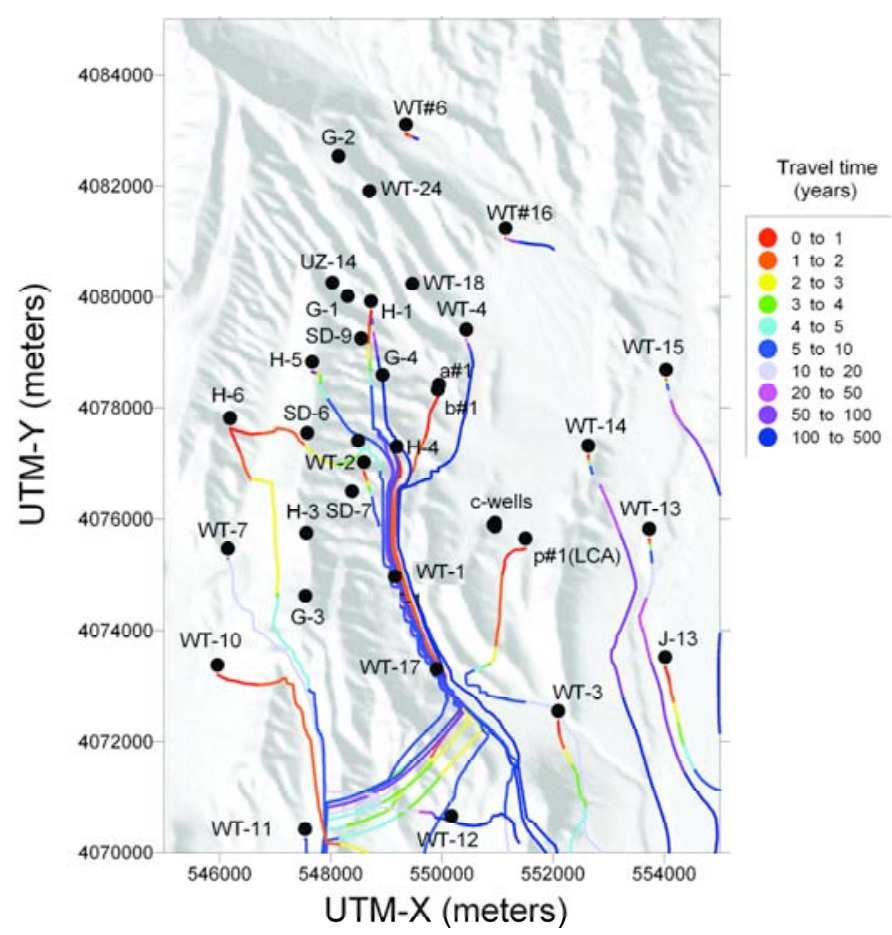

Figure I. Preliminary simulations of advective travel times in the volcanic rocks using a preliminary site-scale model with added faults (not shown in figure) and a porosity of 0.01 . Well $\mathrm{p \# I}$ is completed in the underlying Lower Carbonate Aquifer (LCA). The proposed repository is approximately in the area north of well SD-7, south of $\mathrm{H}-\mathrm{I}$, east of SD-6, and west of a\#I.

\section{Accomplishments \\ (Preliminary Results in Italics)}

Scientific notebooks were initiated for the project.

A number of equivalent-porous-medium (EPM) modeling activities were done for scoping calculations. The

Saturated Zone (SZ) Site-Scale Flow Model was revised by LANL with a refined grid and explicit fault representation and used to simulate flow directions and advective travel times (Figure 1). In the particle-tracking simulation, particles (representing the tracer) were released in open intervals of selected wells in the vicinity of the proposed repository. Simulations assumed faults as conduits, steady-state flow, effective porosity of 0.01 for all hydrogeologic units,

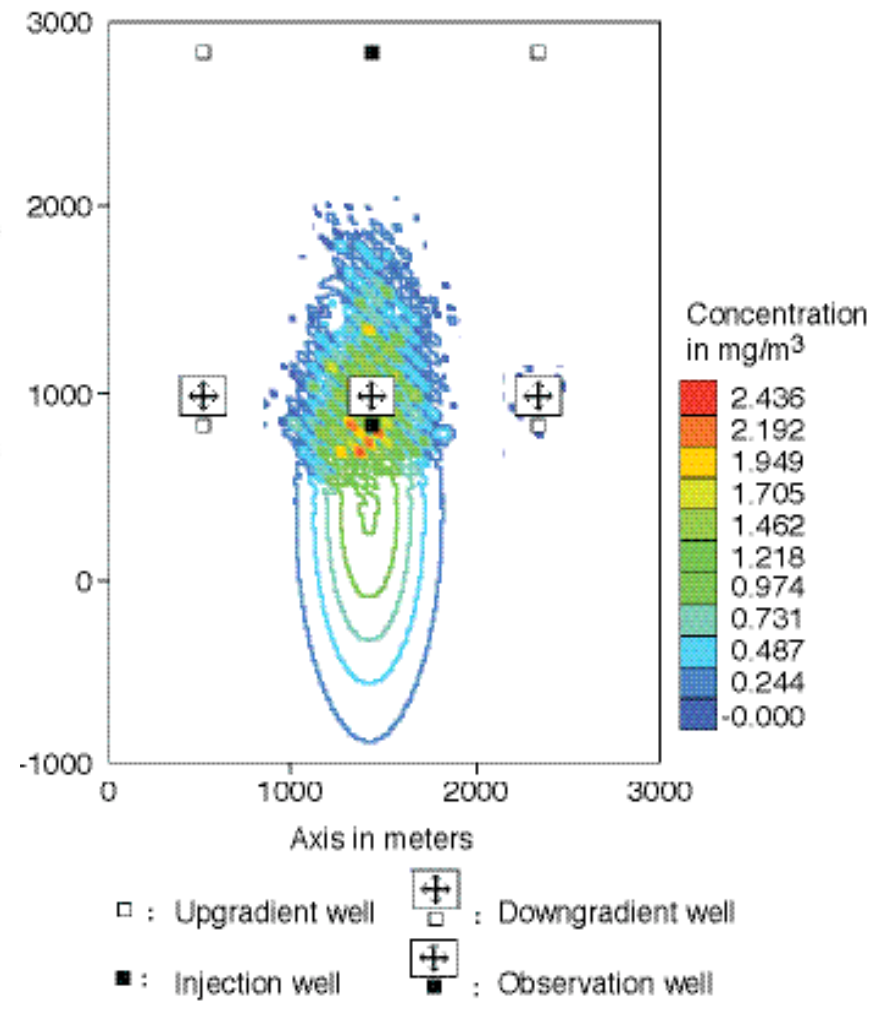

Figure 2. Preliminary simulated large-scale natural-gradient tracer test in volcanic rocks showing plume at 2,000 days resulting from release of I kilogram of tracer at the injection well 
and no matrix diffusion. Preliminary results indicate that par ticles originating at wells near the proposed repository will flow toward the Dune Wash area (essentially between WT-1 and WT-17, Figure 1), and that existing wells such as WT-1 may be good monitoring wells. A spreadsheet to calculate preliminary plume dilution as a function of transport distance was created.

A $3 \times 4 \mathrm{~km}$ non-site-specific advective-dispersive preliminary numerical model for calculating travel times, dispersion, and dilution in the fractured volcanic rocks was developed by the USGS for simulation of a large-scale, natural gradient tracer test (Figure 2). The model consists of a $50 \times 50 \mathrm{~m}$ areal grid and three $30 \mathrm{~m}$ thick layers.

Assumptions include a specific discharge of $4.4 \mathrm{~m} / \mathrm{y}$, hydraulic conductivity of $2.6 \mathrm{~m} / \mathrm{d}$ in $\mathrm{x}$ and $\mathrm{y}$ directions and $0.26 \mathrm{~m} / \mathrm{d}$ in the $\mathrm{z}$ direction, natural gradient of 0.0046 , effective porosity of 0.01 , longitudinal dispersivity of 100 $\mathrm{m}$, transverse horizontal dispersivity of $10 \mathrm{~m}$, transverse vertical dispersivity of $1 \mathrm{~m}$, no matrix diffusion, and no retardation. One kilogram of tracer is simulated as being injected 2,000 $\mathrm{m}$ upgradient from a row of three observation wells. Preliminary simulation results indicate that break through (in the middle of the downgradient row of three observa tion wells, Figure 2) occurs after 650 days (1.8 years), peaks at 1,410 days (3.9 years) and dilutes from a concentration of 132 $\mathrm{mg} / \mathrm{L}\left(132,000 \mathrm{mg} / \mathrm{m}^{3}\right)$ to $0.0018 \mathrm{mg} / \mathrm{L}\left(1.8 \mathrm{mg} / \mathrm{m}^{3}\right)$, i.e., 4.7 orders of magnitude. The breakthrough curve is fully developed in 3,500 days (9.6 years). A similar EPM model is planned for the prototype testing at the Alluvial Testing Complex (ATC). The heterogeneity of the alluvium in the ATC model will be captured from borehole information (such as grain-size distributions and geophysical logs).

Several gaseous and liquid tracers were identified for possible use in the large-scale natural gradient tracer test in the volcanic rocks and the prototype testing at the ATC: dissolved gases (noble gases, $\mathrm{SF}_{6}$, halon), fluorinated benzoic acids, halides, perfluorocarbons, and perrhenate.

Nye County will be working with the USGS and LANL on the prototype testing at the ATC complex. A technical information letter was prepared for Nye County to request a tracer permit from the State of Nevada.

Batch tests to determine the long-term stability of the tracers and to confirm that they are conservative with respect to the volcanic water/rock environment will be conducted using water and core from wells WT-1, WT \#17 (WT-17 in Figure 1), and WT \#3 (WT-3 in Figure 1). These wells are located from northwest to southeast of Dune Wash along a probable flow path for the large-scale natural-gradient tracer testing in the volcanic rocks. Preliminary results from these samples indicated that the waters from WT-1 and WT \#17 were reducing and the water from WT \#3 was oxidizing. Reducing conditions lead to decreased solubility and increased sorption for some radionuclides.

As part of the planning process for the Large-Scale Natural-Gradient Tracer Test, equipment requirements were developed for a downhole sampling, monitoring, and injection system. 


\section{Large-Scale Drawdown Test}

Paul Reimus', Robert C. Roback', Ed Kwicklis', M. J. Umari², John Earle², Michael Fahey², Richard L. Beauheim³, Randall M. Roberts $^{3}$, Susan J. Altman ${ }^{3}$, Bill Arnold ${ }^{3}$, Stephanie Kuzio ${ }^{3}$, Chin-Fu Tsang ${ }^{4}$, Hui-Hai Liu ${ }^{4}$ and Kenzi Karasaki ${ }^{4}$

'Los Alamos National Laboratory (LANL) | 2United States Geological Survey (USGS)

${ }^{3}$ Sandia National Laboratories (SNL) | ${ }^{4}$ Lawrence Berkeley National Laboratory (LBNL)

\section{Research Objectives}

Evidence from field and laboratory tests indicates large variability in permeability and hydraulic conductivity in saturated tuff at Yucca Mountain. It is important for both risk assessment and groundwater monitoring to understand to what extent high-permeability zones influence groundwater flow and elemental transport. For example, highly channelized flow in a few, widely separated fracture zones would result in little matrix diffusion and faster radionuclide migration; whereas groundwater flow distributed among numerous, closely spaced fractures would result in greater matrix diffusion and slower radionuclide migration.

This project is a multidisciplinary, multiphase approach aimed at providing an understanding of physical and chemical heterogeneity of groundwater flow near the proposed repository at Yucca Mountain. Much of the investigation will focus on testing discrete vertical intervals with different physical and chemical properties. We currently envision selecting one well (possibly $\mathrm{H}-4$ ) for long-term pumping and several wells surrounding the pumping well as observation wells. Prior to conducting studies, selected wells will be cleaned and instrumented as required. In situ flow and hydrochemical profiles will aid in final selection and instrumentation of wells that will ultimately be used for long-term pumping and/or tracer tests.

\section{Approach}

The plan for the large-scale drawdown test was written based on a thorough review of the available data with respect to hydraulic properties, geochemistry, and geophysics. Scoping calculations were performed with the existing site-scale saturated zone (SZ) flow model (BSC, 2004 ) that had been modified to include: (1) local grid refinement, (2) addition of numerous fault zones, and (3) recalibration of permeabilities using transient drawdown data from the C-wells. The modeling and data assessment led to the following plan for large-scale drawdown testing.

\section{Accomplishments}

The test plan has been written, reviewed, and is ready to be implemented. The proposed work has multiple objectives and benefits, as described below:

Large-scale drawdown testing would yield information on anisotropy and heterogeneity of horizontal hydraulic conductivity in the saturated volcanics near Yucca Mountain. This information may enhance the prediction of flow pathways and groundwater travel times using the SZ Site-Scale Flow Model (BSC, 2004).

Detailed flow surveys would yield information on the spatial distribution of flowing intervals in the fractured volcanics and on the distribution of volumetric flow rates between these intervals. This information may reduce uncertainty in effective flow porosity and groundwater travel-time estimates in the volcanics, and it may also reduce uncertainty in predicting radionuclide attenuation in the SZ caused by matrix diffusion. Anisotropy and heterogeneity in hydraulic conductivity within the volcanics were apparent from a long-term pumping test conducted at the C-wells from 1996 to 1997.

Single-well tracer tests in observation wells conducted in selected intervals prior to and at the end of large-scale drawdown testing would yield information on ambient and induced flow velocities as well as on matrix diffusion. This information would provide local estimates of groundwater flux for calibration of the SZ Site-Scale flow model, estimates of flow porosity, and valuable constraints for interpreting the large-scale drawdown test, which could reduce uncertainty in the parameters estimated from the test.

Discrete-interval geochemical sampling would provide information on the spatial distribution of major ions, natural isotopic tracers, $\mathrm{Eh} / \mathrm{pH}$ conditions, and colloids in the $\mathrm{SZ}$. This information may reduce uncertainties in predictions of flow pathways, vertical mixing, colloid facilitated 
transport, and $\mathrm{Eh} / \mathrm{pH}$ variability (which could result in significant attenuation of key radionuclides, such as technetium $[\mathrm{Tc}]$ and neptunium [Np]). Geochemical data from both high- and low-permeability zones would also yield information on fracture-matrix interactions and on the potential role of "fast pathways" such as faults or fracture zones in the SZ.

Data from the field tests planned under this project would enhance characterization of properties affecting matrix dif- fusion. Uncertainties in the spacing between actively flowing zones may be reduced. The work proposed would enhance our understanding of matrix diffusion in the saturated zone.

\section{References}

BSC, Saturated Zone Site-Scale Flow Model. MDL-NBSHS-000011, Rev 02, Las Vegas, Nevada, Bechtel SAIC Company, 2004. 


\title{
Integration of Data and Models for the Coupled Regional- and Site-Scale Models
}

\author{
A.A. Eddebbarh', G.A. Zyvoloski', S.C. James², Steffen Mehl'3 ${ }^{3}$ and Mary C. Hill3 \\ 'Los Alamos National Laboratory (LANL) | 2 Sandia National Laboratories (SNL) | 3 United States Geological Survey (USGS)
}

\section{Research Objectives}

Our goal is to develop further understanding of flow and transport in the saturated zone (SZ), from the water table below the proposed Yucca Mountain repository to the accessible environment, and to predict the transport of radionuclides from the water table beneath the proposed repository site to the accessible environment. The programmatic objective of this work is to couple the regionaland site-scale models and perform flow and transport simulations using the coupled model. This newly developed technology may allow the improvement of the current flow and transport models by:

- Providing the tools to allow integrated model simulations for the Yucca Mountain Project's (YMP's) site-scale SZ flow and transport model

- Calculating the SZ model output parameters with a higher degree of confidence by utilizing methods to isolate, and perhaps quantify, areas of uncertainty within the flow and transport simulations

- Facilitating both uncertainty and sensitivity analyses to address such concerns as long-term water table rise, associated discharge to the surface, and uncertainty regarding larger-scale geochemical flow paths.

\section{Approach}

A flexible, robust method of iterative local grid refinement has been developed to link finite-difference and finite-element models. This method enables coupling of a larger, "parent" model, which can represent a regional groundwater flow system, and a "child" model, which can represent a small area of interest within the region. A child model, having a higher grid resolution, can represent local flow conditions and transport of contaminants with greater accuracy than the parent (regional) model. However, boundary conditions to the child model may be difficult to define because natural hydraulic boundaries to groundwater flow may exist at farther distances that are best represented by a regional model. By iteratively cou- pling the models, the boundary conditions of the child model can be more accurate, because these are calculated by the regional model. Furthermore, the solution of the regional model is improved by the higher accuracy of the child model.

\section{Accomplishments}

The project has successfully coupled regional models and site-scale models using the codes MODFLOW 2000

(Harbaugh et al., 2000) and FEHM (Zyvoloski et al., 1997). The model coupling routine has been developed to allow for various grid resolutions between the models and within each model. The model grids are not required to match spatially at the interface boundary, nor are the grids required to align horizontally or vertically. This means that a child cell can overlap with more than one parent cell and overlap over multiple parent model layers. Models can be coupled for either two-dimensional or three-dimensional flow systems.

Results of the two-dimensional coupling indicate that the grid-refinement accuracy is significantly lower compared to previous iterative local-grid-refinement methods, which use the same model (MODFLOW; see Mehl and Hill, 2002; 2004). This loss in accuracy could result from the different model codes and different methods of model solution (e.g., finite-difference and finite-element methods). Generally, the error in the parent and child models decreases for small grids in the child model. This suggests, as Mehl and Hill $(2002 ; 2004)$ have also determined, that the reduction of error within the child model improves the error within the parent model. This error reduction in the parent model is produced by improved values of boundary conditions from the child model.

Coupling of the regional-scale and site-scale models of Yucca Mountain results in an integrated model that will allow for quantifying the uncertainty in the regional model as it propagates into the site model. Specifically, the coupled model can be used to study the impact of a potential long-term water table rise, and to perform uncertainty analyses regarding larg e r-scale geochemical flow paths. 


\section{Related Publications}

Harbaugh, A.W., E.R. Banta, M.C. Hill, and M.G. McDonald, MODFLOW-2000, the U.S. Geological modular ground-water model-User guide to modularization concepts and the ground-water flow process. U.S. Geological Survey Open-File Report 90-392, 2000.

Mehl, S., and M.C. Hill, Development and evaluation of a local grid refinement method for block-centered finitedifference ground-water models using shared nodes. Adv. Water Resour., 25, 497-511, 2002.
Mehl, S., and M.C. Hill, Three-dimensional local grid refinement for block-centered finite-difference groundwater models using iteratively coupled shared nodes: a new method of interpolation and analysis of errors. Adv. Water Resour., 27, 899-912, 2004.

Zyvoloski, G.A., B.A. Robinson, Z.V. Dash, and L.L. Trease, Summary of the models and methods for the FEHM application: A finite-element heat- and mass-transfer code. Los Alamos National Laboratory Report LA13306-MS, 1997. 


\section{Saturated Zone Plumes in Volcanic Rock}

Sharad Kelkar and Robert Roback

Los Alamos National Laboratory (LANL)

\section{Research Objectives}

In the current Yucca Mountain saturated zone (SZ) models, radionuclide plumes are predicted to have a relatively narrow shape. This small lateral dispersion exhibited by these plumes may be relatively unusual compared to dispersion observed with chemical plumes at other sites in similar geologic settings. This study constitutes a systematic investigation of transport plumes in volcanic rock.

The objective of this work is to provide information that will allow OST\&I to determine if there is sufficient evidence to support a substantial effort in characterizing potential plume geometry, to constrain the prediction of plumes at the proposed Yucca Mountain repository with greater confidence.

\section{Approach}

This scoping study will include a literature survey of radionuclide-plume occurrences in saturated, fractured volcanic rocks worldwide, to determine the common characteristics of plume geometry and controlling hydrologic parameters. The survey will focus on fractured volcanic rock and will emphasize systems similar to Yucca Mountain, such as the Nevada Test Site, but will include insights from other types of fractured, layered rock as well. The goal is to begin with a broad literature search. Sites identified during the literature survey that are well characterized with sufficient supporting data may be recommended for future in-depth analysis and interpretation. The survey will encompass a variety of types of plumes, including natural chemical/isotopic plumes, contaminant plumes, and plumes generated by controlled tracer tests.

\section{Accomplishments}

A draft technical white paper (TWP) has been completed (will be submitted to OST\&I by December 30, 2005), in which information on dispersion in the SZ at sites around the world has been identified and analyzed. The LANL scientists compiled data from the DOE-Energy, Georef, Science Server, Search Plus, and LANL Library Catalog databases to identify and catalog published information from sites at Olkiluato (Finland), Palmottu (Finland), Mizunami (Japan), Kamaishi (Japan), Stripa (Sweden), Grimsel (Switzerland), Pinawa (Canada), Sellafield (England), Konrad (Germany), Anay-Augeres (France), Itatskiy (Russia), Kamennyi (Russia), Navak (Russia), Tomsk (Russia), Beishan (China), Kaloakkam (India), the Idaho National Engineering and Environmental Laboratory (INEEL) (USA), Nevada Test Site (NTS-USA), the Yucca Mountain Project (YMP-USA) and LANL (USA). USGS scientists identified and catalogued the available information on fractured rock tracer testing. They found that the open literature contains a very limited number of field-scale tracer test results. However, they were able to identify some tests that may be applicable to the tracerscale issues at Yucca Mountain. Publications that did contain field-scale tracer-test results were generally limited to the Journal of Contaminant Hydrology, Ground Water, Nuclear Regulatory Commission and Department of Energy publications, and a limited number of USGS and university publications. Specific geographical areas where tracer tests were conducted in fractured rock and the results published in the open literature include INEEL, Idaho; the DOE Hanford site, Washington; the DOE Creston site, Washington; the Mirror Lake Research site, New Hampshire; and the El Berrocal Research site, Spain.

The white paper will provide a discussion of the processes of plume spreading, including dispersion and diffusion in fractured media as applied to the SZ at Yucca Mountain, along with a description of the literature survey, and identify the well-characterized sites. The paper will provide conclusions and recommendations, if warranted, for further studies that may include modeling and characterization of SZ transport at Yucca Mountain.

Flow patterns play a significant role in the barrier function of the SZ, since very narrow plumes would obviate the benefits of sorptive characteristics of Yucca Mountain volcanic rocks to retard transport. An improved understanding of plume behavior in volcanic rocks is essential as a basis for developing realistic transport models. 


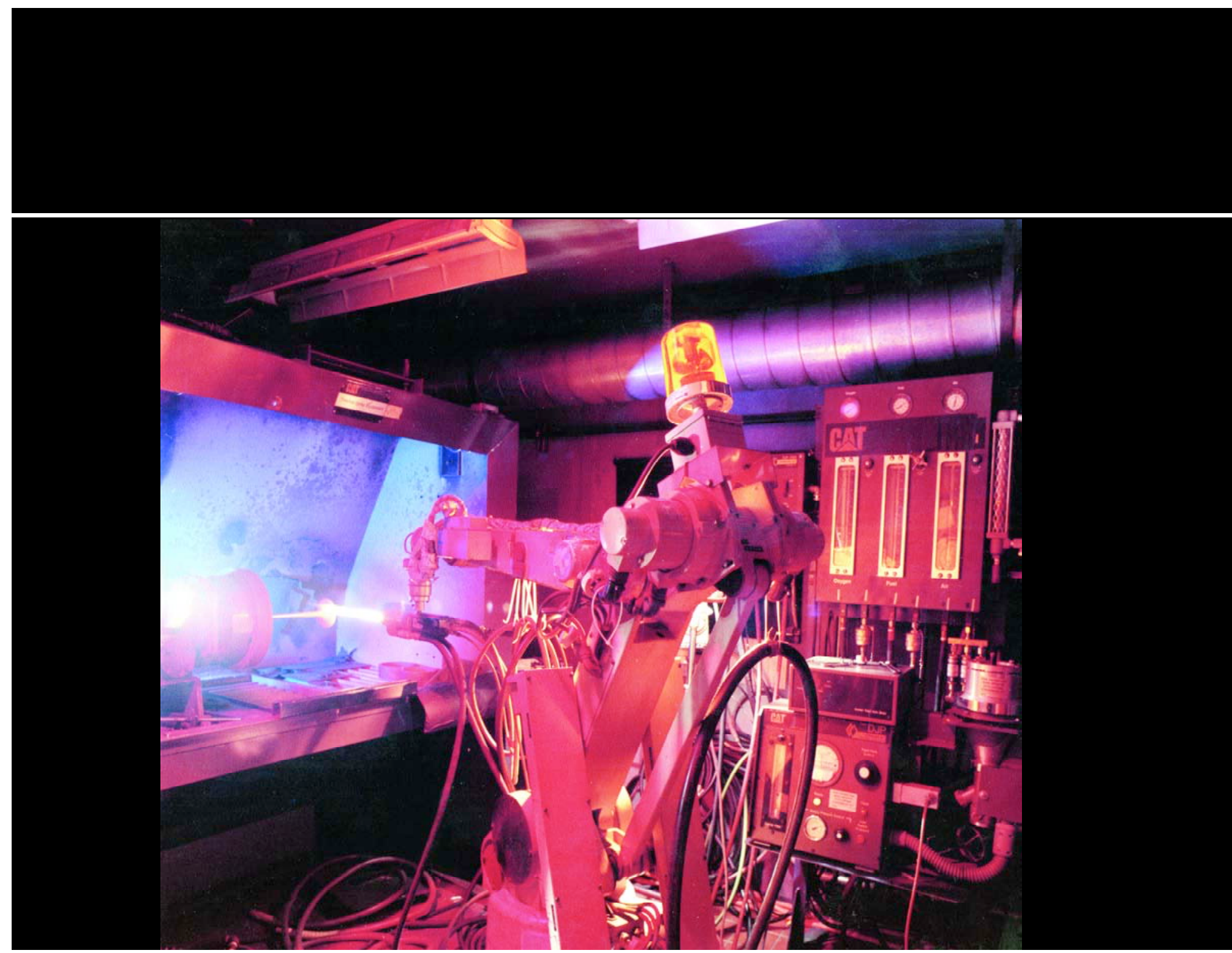

Remote spray coating using the High Velocity Oxy-Fuel (HVOF)

process. The HVOF spray coating process can be used with newly

developed iron-based alloys to produce a low-cost, durable metal

coating with a corrosion resistance equal to or greater than Alloy 22. 


\section{ADVANCED TECHNOLOGIES THRUST}

\author{
Jeffrey Walker \\ Office of Civilian Radioactive Waste Management (OCRWM), \\ U.S. Department of Energy (DOE) \\ Contact: jeffrey.walker@rw.doe.gov
}

The purpose of the Advanced Technologies Thrust (ATT) is to:

- Identify/develop technologies and processes.

- $\quad$ Reduce the cost of proposed repository development, construction, and operation with the application of these new technologies and processes.

- Provide the data necessary to demonstrate feasibility of new technologies and processes.

Fiscal Year 2005 was the inaugural year for this thrust. Several of the projects were already under way when this thrust team was formed; however, it was not until this year that a focused approach to managing these projects was established. The 11 projects supporting the initatives listed below are described in the following pages (pp. 195-218):

- The Evaluation of Improved Waste Package Materials and Fabrication Processes

- Advanced Approaches for Improved Waste Package Closure Welds

- Advanced Tunneling Technology

- Improved Understanding of Extreme Ground Motions Predicted Using Probabilistic Seismic Hazard Analysis.

In each of these initiatives, there are one or more projects. If successfully completed, these technologies will increase the efficiency, enhance the safety, improve the design, or reduce the cost, of constructing and operating the proposed repository. Details of the projects within each of the initiatives are included in this report.

Fiscal Year 2005 saw the initiation of many new projects and the maturation of several projects, to a point where they are nearing a stage where technology transfer to the Office of Repository Development (ORD) can begin. For example, thermally sprayed structurally amorphous metal coatings give the ORD design team the option, for the first time, of an easily applied coating with corrosion resistance equal to or better than Alloy 22 at a fraction of the cost.
Similarly, reduced-pressure electron-beam welding will produce a single-pass weld in thick metals that will significantly reduce the time and thereby the cost of manufacturing the current waste package design, and could possibly do the same for the final closure weld. Both of these projects will be reviewed by ORD for transfer in Fiscal Year 2006.

The approach of the ATT is to first investigate the potential of emerging technologies or approaches through a directed scoping study. Technologies demonstrating promise for use at the proposed Yucca Mountain repository in terms of cost savings, operational, or safety improvements, and have a clear pathway to implementation, are assigned to an initiative and are proposed as a project in the next fiscal year. If selected, the projects are usually directed to the laboratories or to industry, with proposals solicited in a competitive manner. If selected, the principal investigators for these projects assemble teams of researchers, scientists, engineers, and technicians from universities, national laboratories, private industry, other federal offices, and the proposed repository, to develop work plans and performance criteria for the technology. Ideally, integrated teams perform all projects with close links to ORD. The ATT projects not only tailor the technology to the ORD application, but must also include an analysis of the economic, technical, and regulatory feasibility of the new application of technology or knowledge prior to technology transfer.

The framework within which the Office of Science and Technology and International (OST\&I) investigates new technologies and information is structured so that OST\&I activities are not part of the Yucca Mountain Project and do not require regulatory approval or oversight by the Nuclear Regulatory Commission. Activities within the projects are performed at a level of quality expected to easily transfer to a " $Q$ " level quality assurance if accepted by the proposed repository, and to provide robust data for safety analyses, certification, and licensing. Upon acceptance of a new technology for, or additional knowledge of, the proposed repository, ORD incorporates the project into the regulatory scheme.

In Fiscal Year 2006, it is anticipated that the ATT will continue all of the projects initiated this year. If funding is available, new projects associated with the generation and suppression of silica dust, robotic applications, and the next generation of radiation-hardened electronics will be initiated.

\section{Acknowledgments}

The work reported in the following papers describing this thrust was supported by the Director, Office of Civilian Radioactive Waste Management, Office of Science and Technology and International, of the U.S. Department of Energy. 
This page intentionally left blank. 
Assessment of Welding Technology and Welding-Related Issues for Alloy 22 Nuclear Waste Packages

John C. Lippold, Ohio State University

Evaluation of Reduced-Pressure Electron-Beam Welding Technologies for Nuclear Waste Containment

Frank Wong, Lawrence Livermore National Laboratory (LLNL)

Solicitation for Conceptual Design, Development, and Demonstration of Alternative Approaches to the Final Waste Package Closure Weld at Yucca Mountain

Choon Quan, U.S. DOE; T. James Dorsch, BAE Systems; and Ron Kaplan, Joseph Oat Corporation

High-Performance Corrosion-Resistant Metal Coatings

Craig Blue, Oak Ridge National Laboratory (ORNL); Nancy Yang, Sandia National

Laboratories (SNL); and Joe Farmer, Lawrence Livermore National Laboratory (LLNL)

Evaluation of the Feasibility and Benefit of Cutting a Flat-Bottomed Drift in a Single Pass

Choon Quan, U.S. DOE; Ray Mele, Booz Allen Hamilton; and Frank Wong, Lawrence Livermore National Laboratory (LLNL)

Scoping Study to Evaluate Advances in Robotic Technologies That Support Enhanced Efficiencies for Proposed Yucca Mountain Repository Operations Thomas W. Burgess, Mark W. Noakes, and Philip T. Spampinato, Oak Ridge National Laboratory (ORNL)

Workshop on State-of-the-Art Tele-Operated Robotic Manipulators and Other Technology Improvements to Enhance Yucca Mountain Remote MaterialHandling Capabilities

Thomas W. Burgess, Mark W. Noakes, and Philip T. Spampinato, Oak Ridge National Laboratory (ORNL)

Low-Alkalinity Phosphate-Bonded and Portland Cements as Cost-Effective Cementitious Material Compatible with Proposed Yucca Mountain Repository Geochemistry Les Dole, Catherine Mattus, and Lee R. Riciputi, Oak Ridge National Laboratory (ORNL); Arun Wagh, Argonne National Laboratory (ANL)

Evaluation of Structurally Amorphous Materials to Improve Rock-Cutting Tools for Subsurface Excavation

Frank Wong, Lawrence Livermore National Laboratory (LLNL); and Craig Blue, Oak Ridge National Laboratory (ORNL)

Development of a Methodology to Produce Hazard-Consistent Structural Demands and In-Structure Design Response Spectra

Tom Houston, Los Alamos National Laboratory (LANL); Carl Costantino, City University of New York (CUNY); and Walt Silva, Pacific Engineering and Analysis (PEA)

Development and Verification of an Improved Model for Extreme Ground Motions Produced by Earthquakes

Norm Abrahamson and Lloyd Cluft, Pacific Gas and Electric (PG\&E) 
This page intentionally left blank. 


\title{
Assessment of Welding Technology and Welding-Related Issues for Alloy 22 Nuclear Waste Packages
}

\author{
John C. Lippold \\ Ohio State University
}

\section{Research Objectives}

The closure weld and postweld processing of Alloy 22 waste packages are important to the Yucca Mountain Project (YMP) goal of ensuring that these containers will survive their design lifetime in the emplacement environment. Numerous welding processes can potentially be used to fabricate these containers and to make the final closure weld. This scoping study was designed to summarize the current "state-of-the-art" of welding process technology in the context of waste package fabrication in support of YMP. The motivation of the study was to assist OCRWM in evaluating and selecting alternative welding methods to improve the reliability and efficiency of closure welds for the Alloy 22 nuclear waste packages.

\section{Approach}

All relevant welding processes were evaluated. In consideration of the optimum process (or processes) for completing the final closure weld, reliability, efficiency, and longterm performance were weighed more heavily than overall cost of developing or implementing the technology.

A number of welding processes can be used to perform the final closure weld on Alloy 22 nuclear waste storage containers for YMP. This assessment attempted to evaluate both current and future welding technology that can impact the selection of a closure welding process. The major factors considered were efficiency (how fast the closure weld can be completed), reliability (weld integrity from the standpoint of freedom from defects and metallurgical stability), and long-term performance (mechanical and corrosion properties, and reduction of residual welding stresses). All of these factors were weighted equally in the analysis of various welding processes.

\section{Accomplishments}

Of the welding processes evaluated, inertia friction welding (IFW) and electron beam welding (EBW) were considered to be the leading candidates based on the assessment factors noted above. Both processes are "single shot" in that the weld can be made in a single pass in the case of EBW, or a single event in the case of IFW. Both would allow the final closure weld to be made in minutes rather than the hours required for arc welding processes. IFW is an extremely robust process that can produce welds of high integrity and low residual stress in Alloy 22.

EBW technology is mature, and equipment is commercially available to achieve the weld-penetration characteristics required for the closure weld. Other processes considered included laser welding, hybrid welding (arc plus laser), and conventional arc welding including gas tungsten arc welding and gas metal arc welding. These last two processes are widely used for the fabrication of thick section stainless steels and nickel (Ni)-based alloys, but are unattractive for the closure weld from the standpoint of efficiency and reliability.

No single "ideal" process for the closure weld exists: a number of these processes could, in fact, be used to perform the final closure weld. While IFW is very attractive from an efficiency and reliability standpoint, commercial equipment does not exist that is capable of making the closure weld in Alloy 22. While technically feasible, considerable effort would be required to design and build such a machine. EBW is quite efficient since the closure weld could be made in a few minutes, but provisions for weld defect repair and residual stress management must be made.

Arc welding processes are quite popular for similar applications because of general familiarity and the experiencebase that exists. For the case of closure welds on nuclear waste containers, these processes are quite unattractive because they are quite inefficient (even with narrow-gap technology) and, more importantly, because they will generate extremely high residual stresses that must be mitigated through some type of undefined postweld processing. Failure to properly mitigate these stresses can potentially compromise the corrosion resistance of the waste package in its service environment.

While the IFW process would require an extension of the current technology to build a machine large enough to make a waste package closure weld, the long-term benefit in terms of process robustness, metallurgical integrity, and management of residual stresses make this process a leading contender for the closure weld. The results of this investigation were used as the basis for the development of a commercial solicitation to develop and test alternative welding processes. 
This page intentionally left blank. 


\section{Evaluation of Reduced-Pressure Electron-Beam Welding Technologies for Nuclear Waste Containment}

Frank Wong

Lawrence Livermore National Laboratory (LLNL)

\section{Research Objectives}

This project is designed to explore the use of advanced welding techniques, such as reduced-pressure electronbeam (RPEB) welding, for potential cost savings in fabrication of Yucca Mountain Project (YMP) waste packages.

The current YMP waste package design employs gas tungsten arc (GTA) welding in fabricating the waste package for the nickel-chromium-molybdenum (Ni-Cr-Mo) alloy, Alloy 22, outer barrier and 316NG inner shell. While GTA welding is widely used in industry for many applications, it requires multiple weld passes (e.g., approximately eight passes are required for the Alloy 22 outer barrier), which will produce weld distortions and regions of tensile residual stresses at the surface. By comparison, single-pass welding methods inherently use lower heat input, which results in lower levels of weld distortion and also narrower regions of residual stresses at the weld.

Electron beam (EB) welding is widely used in industry and typically results in faster welding times (since it is a singlepass method) and a more favorable distribution of residual stresses. However, conventional EB welding usually requires the work piece to be contained in a good vacuum environment during welding. A vendor has developed an RPEB welding process that allows EB welding in a reduced-pressure environment ( $\leq 1 \mathrm{mbar})$, achieved by local sealing and pumping. The RPEB method has been used by SKB (the Swedish nuclear waste program) in their waste package mockup program ( 40 waste package mockups fabricated with RPEB welding since 1992) (Figure 1).

\section{Approach}

A comparison of multi-pass GTA and the single-pass RPEB welds in Ni-Cr-Mo-W alloys is shown in Figure 2.

\section{Accomplishments}

Initial evaluation of RPEB welding for fabrication of Yucca Mountain waste packages indicates that it provides similar performance to GTA in terms of corrosion behavior and $\mathrm{Mo} / \mathrm{Ni}$ segregation characteristics. These evaluations have also shown that RPEB may result in a more favorable distribution of as-welded residual stresses compared to GTA. In addition, the inherent characteristics of RPEB, especially the ability to make single-pass welds with reduced distortion, will offer the potential for significant cost reduction. The cost savings of using RPEB welding instead of GTA for waste package fabrication are estimated to be approximately $25 \%$.

If an RPEB welding technique was used in fabricating the YMP waste packages, it would provide the following benefits to the Office of Civilian Radioactive Waste Management (OCRWM) program:

- Equal or better materials performance in terms of corrosion, metallurgical stability, and as-welded residual stress

- Increased repeatability and reliability on waste package welding because of its single-pass nature

- Significant potential cost savings in waste package manufacturing, primarily resulting from:

o Elimination of weld filler material

o Faster welding times

o Elimination of plate overstock

o Reduced machining times

o More favorable distribution of residual stresses. 


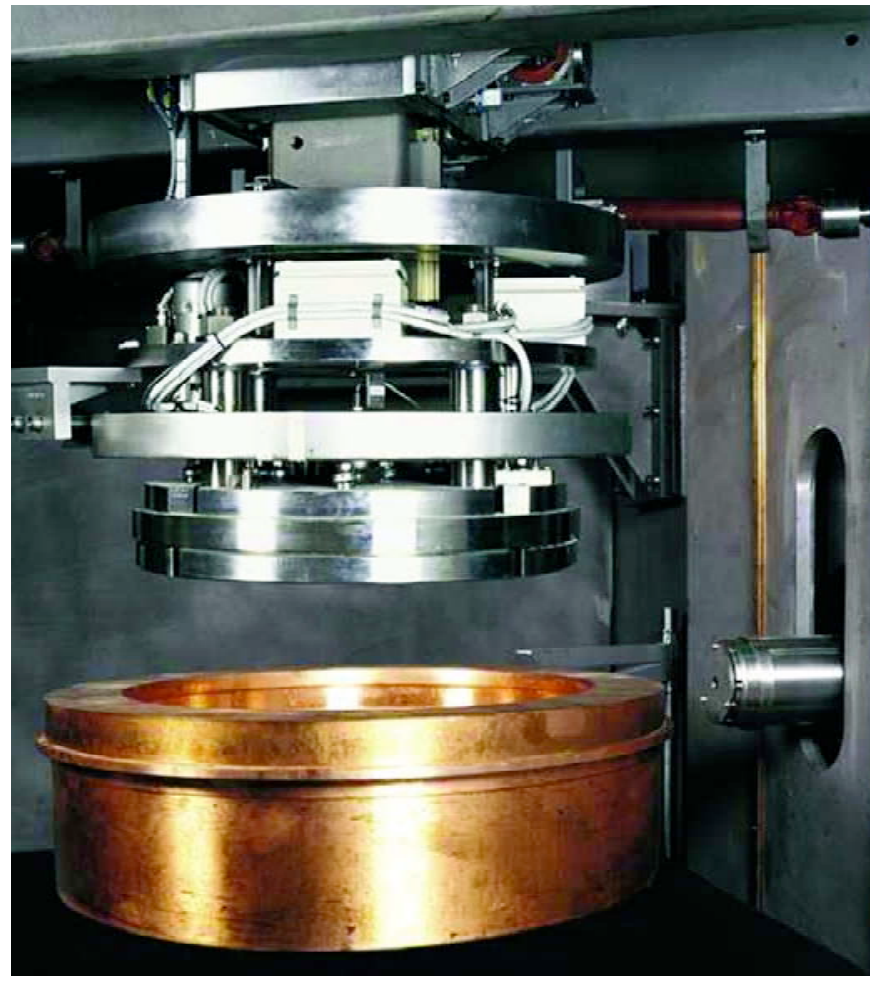

Figure I. A mockup of the RFEB welding system proposed for use in Sweden, showing the electron beam gun on the right. Use of the noncontact single-pass welding process would reduce welding time, reduce stress, increase

repeatability and reliability, and decrease overall cost of waste package closure.

Multi-Pass GTA Weld

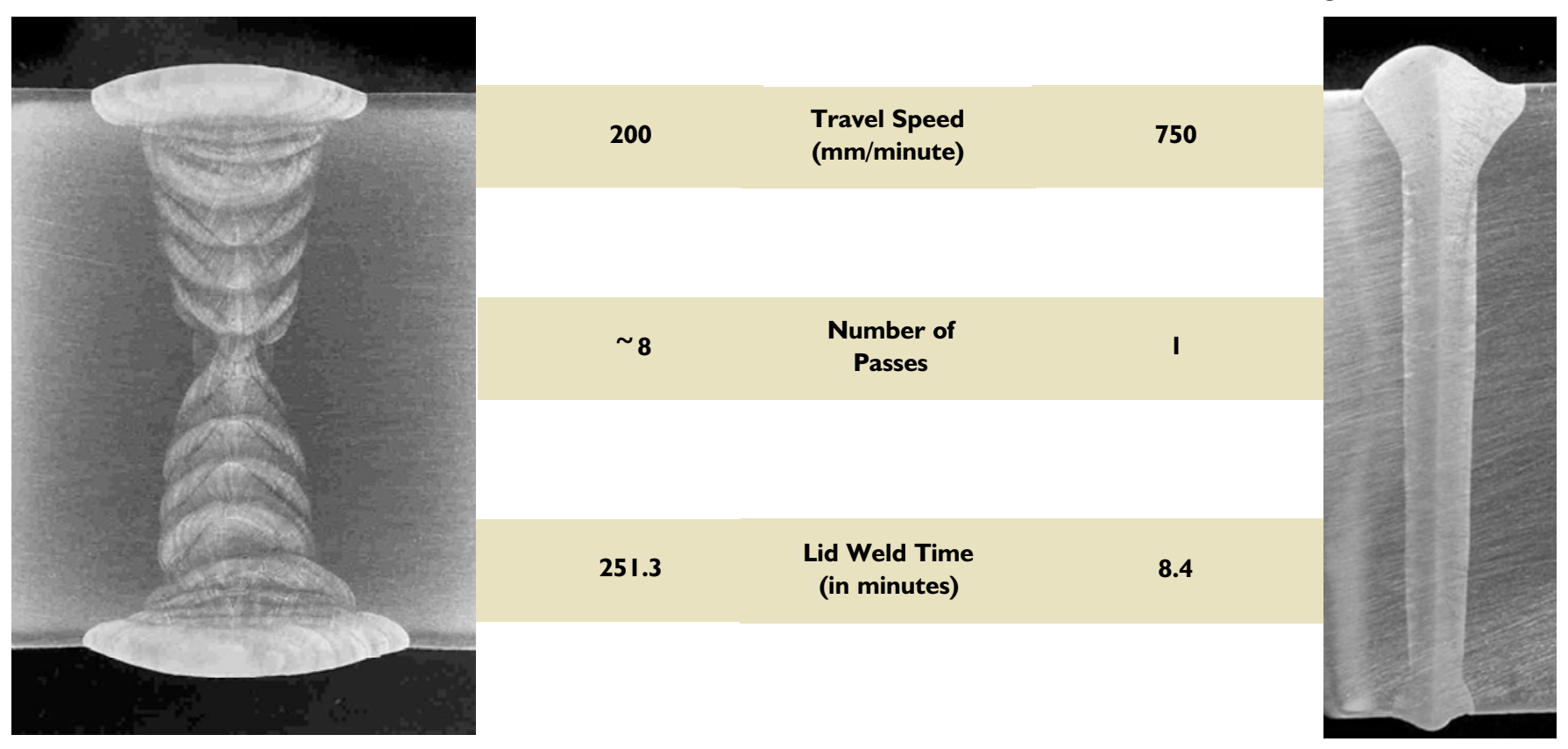

Figure 2. Multi-pass GTA (left) and single-pass RPEB (right) welds in Ni-Cr-Mo alloys of comparable thickness 


\title{
Solicitation for Conceptual Design, Development, and Demonstration of Alternative Approaches to the Final Waste Package Closure Weld at Yucca Mountain
}

\author{
Choon Quan', T. James Dorsch², and Ron Kaplan 3 \\ IU.S. DOE | 2BAE Systems | 3Joseph Oat Corporation
}

\section{Research Objectives}

The Yucca Mountain Project (YMP) expects that the waste packages to be placed within the proposed repository would have a service life of at least 10,000 years. The current baseline welding practice, based on the gas tungsten arc (GTA) welding process, has relatively low productivity, owing to its multi-pass requirements and additional stressrelief steps. Studies to date have indicated that, to achieve such long regulatory service life, the high tensile residual stresses in the final closure welds must be reduced. At the same time, microstructural stability of the weld should be enhanced to ensure its long-term mechanical properties.

In September 2004, the Office of Civilian Radioactive Waste Management, Department of Energy, issued a solicitation, "Alternative Welding Technology for Final Closure Welds on Waste Packages." The purpose of the solicitation was to procure alternative welding technologies that may be used for welding the closure lids on waste packages that are to be emplaced in the proposed repository at Yucca Mountain in Nevada. Nine proposals were received in response to the solicitation, of which two were selected for Phase I work in April 2005.

The closure weld and postweld processing of Alloy 22 waste packages are important to the YMP goal of ensuring that the waste package containers will isolate radioactive materials for the design lifetime in the emplacement environment.

Phase I will include concept demonstration, i.e., demonstrating that use of the alternative technology is possible and beneficial in the desired application - through small proof-of-principle activities, analytical studies, reviews, and development of a detailed project plan based on specific requirements of the YMP.

The recipients of Phase I contracts were United Defense (now BAE Systems) and Joseph Oat Corporation. Both proposals have very good potential for meeting the objectives of the solicitation and provide opportunities for improvement of the baseline welding technology.

\section{Approach}

The proposed program consists of three phases. In Phase I, the technical merit and feasibility of the above individual approaches as applied to Alloy 22 closure welding conditions will be evaluated independently. Phase II and Phase III will focus on integration of these innovative approaches to provide a comprehensive field-deployable solution that would greatly increase process efficiency, minimize residual stress, and improve the weld microstructure of the final closure welds.

At the end of Phase I (December 2005), a final report will be submitted to DOE for evaluation of Phase I activities, and for DOE to consider continuing into Phase II based on the results. One or both companies may be chosen to continue into Phase II. The work in Phase II will include a demonstration of the alternative technology to perform a full-circumferential weld on a half-scale mock-up of an Alloy 22/stainless steel waste package. Phase II is planned for the beginning of January 2006, and will last about 9-10 months. Phase III is planned to begin in January 2007.

Joseph Oat Corporation has proposed a novel approach for improving the current GTA welding process through use of a "narrow gap" welding process coupled with one of several innovative postprocessing techniques, which include dynamic cooling, friction stir welding, and several other emerging techniques. The key outcome from this Phase I effort will be the evaluation and selection of the postprocessing technique to be used with narrow gap GTA welding.

BAE Systems proposes the use of a reduced-pressure electron-beam welding process in partnership with TWI, the inventor of the technology. The outcome of the Phase I effort will be the demonstration that this single-pass welding system can produce a weld compatible with the Alloy 22 material, while not impacting its corrosion resistance. The Phase I report will also document the claim by the reduced pressure electron beam (RPEB) welding developers that no postprocessing will be required and that if necessary, a second pass, using the RPEB equipment, will relieve any welding-induced stresses. 
While extensive due-diligence engineering is expected, there are no anticipated major technical and/or equipment obstacles to the proposed approach to scale-up for full-size waste package fabrications. The proposed approach also offers great flexibility: the proactive residual stress-management technique and the microstructure-modification technique can be used in connection with other linear welding processes under consideration for YMP. The residual stress management and/or high-productivity welding technique can be readily developed for other closure welds, as can the fabrication seam and girth welds in the waste package.

\section{Accomplishments}

Phase I has been completed and the preliminary findings are as follows:

- Use of a thermal management process during
RPEB welding is indicated to eliminate tensile stresses.

- Thermal management in conjunction with GTAW reduces but does not eliminate tensile stresses.

- Laser remelting and friction-stir-surface processing appear to have promise as postwelding stress ameloration techniques. Final results are not expected to be available until January 2006.

- The narrow gap GTAW process will reduce the number of passes needed to complete the closure weld; however, data from the postweld stress tests are not expected to be available until January 2006.

If successful, this project will provide a less expensive closure welding system with greater throughput. 


\title{
High-Performance Corrosion-Resistant Metal Coatings
}

\author{
Craig Blue', Nancy Yang ${ }^{2}$, and Joe Farmer ${ }^{3}$ \\ IOak Ridge National Laboratory (ORNL) | 2Sandia National Laboratories (SNL) \\ ${ }^{3}$ Lawrence Livermore National Laboratory (LLNL)
}

\section{Research Objectives}

The purpose of this project is to develop an iron-based, structurally amorphous metal (SAM) as a high-performance corrosion-resistant coating, in lieu of or in conjunction with Alloy 22 or titanium (Ti). SAM are believed to be more corrosion-resistant than wrought metals because they have no crystalline structure, which means that there are no grain boundaries at which corrosion can occur. The use of an iron-based material could result in a cost savings to the program on the order of \$3-5 billion, depending on the application. These cost savings would result from the lower cost of the iron (Fe)-based SAM coating as compared to the nickel (Ni)-based Alloy 22, the use of a simplified high-velocity spray-coating process as compared to rolling and turning Alloy 22 sleeves for the stainless steel waste packages, and the elimination of the $\mathrm{Ti}$ in the proposed drip shields.

The multi-institutional High Performance Corrosion Resistant Materials (HPCRM) Team is co-sponsored by the Defense Advanced Research Projects Agency (DARPA) Defense Science Office (DSO) and the Department of Energy (DOE) Office of Civilian Radioactive Waste Management (OCRWM). This team has developed new corrosion-resistant, iron-based amorphous metals that can

\section{(a)}

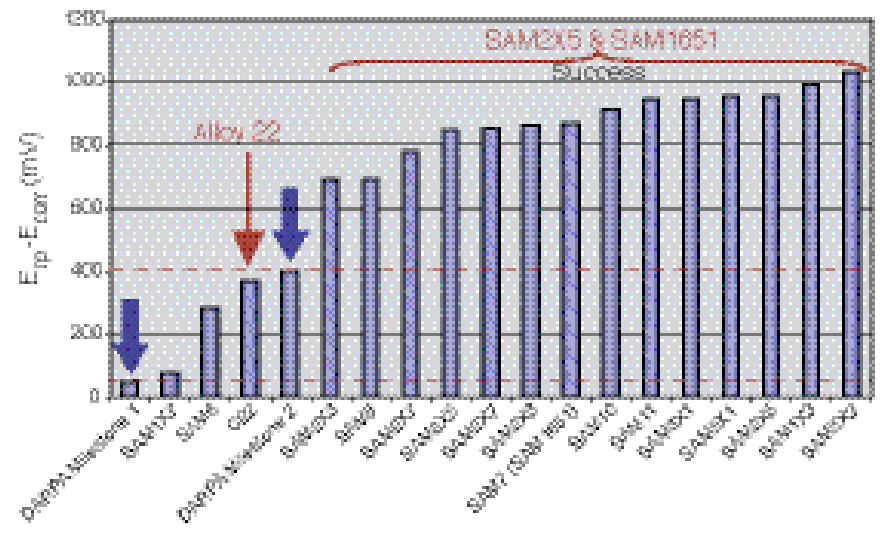

be applied as coatings with advanced thermal spray technology. Two compositions have corrosion resistance superior to wrought Ni-based Alloy 22 (UNS \# N06022) in very aggressive environments, including concentrated calciumchloride brines at elevated temperature. These coatings are designated SAM2X5 and SAM1651.

\section{Approach}

This work is directed at the further development of ironbased SAM and optimization of High-Velocity Oxy-Fuel (HVOF) coatings that will possess the corrosion resistance of high-performance materials currently proposed for use, such as Ni-based Alloy 22 and Ti-based Ti Grade 7. An iterative approach including computational evaluation of alloy compositions will be used. The resultant materials promise outstanding performance on all fronts and will be readily applied using established thermal-spray technology, augmented by new state-of-the-art postprocessing. Consequently, performance improvements, along with considerable cost savings, can be achieved through the replacement of more expensive corrosion-resistant bulk alloys.

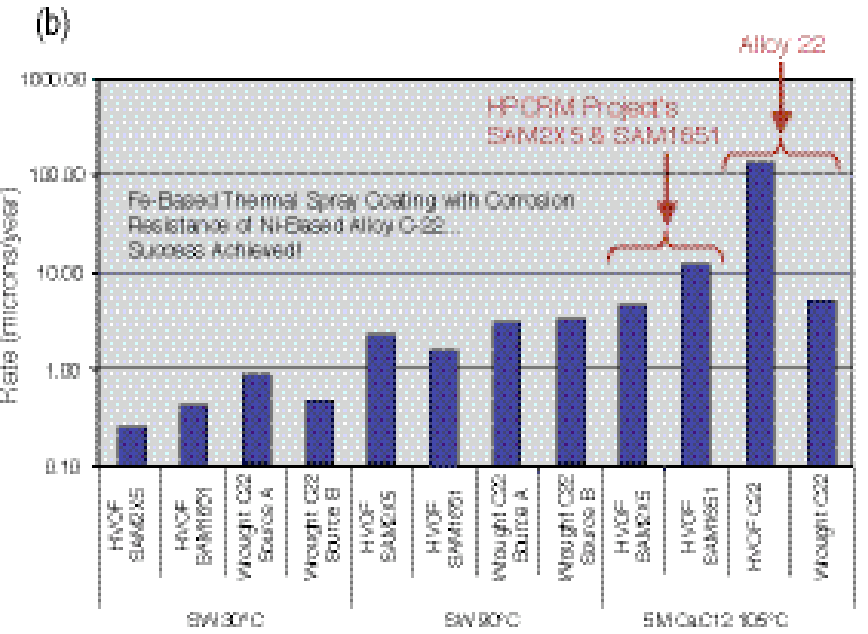

Figure I. (a) Better passive film stability-cyclic polarization data for DARPA-DOE Fe-based amorphous metals in $5 \mathrm{M}$ CaCl at $105^{\circ} \mathrm{C}$; (b) $\mathrm{HPCRM}$ materials corrode more slowly than Alloy 22 in seawater (chloride-based electrolyte). 


\section{Accomplishments}

- More than 10 compositions have been developed that have corrosion-resistance properties better than Alloy 22.

- Two compositions have been selected for further testing.

- The HVOF spray-coating process has been optimized to produce a fully amorphous coating.

- Coating is thermally stable up to $600^{\circ} \mathrm{C}$ (Figure 1).
Iron-based amorphous-metal thermal-spray coatings provide Yucca Mountain designers with a new option for waste package design, repair, and protection. There are several applications of this material being considered - for example, the use of an "integral drip shield" on spent nuclear fuel (SNF) containers and protective coatings that could be applied over welds, thereby preventing exposure to environments that might cause stress corrosion cracking. In the future, it may be possible to substitute these (and other) new high-performance Fe-based materials for more-expensive Ni-based alloys, thereby enabling a reduction in the life-cycle cost for the long-term storage of U.S. 


\title{
Evaluation of the Feasibility and Benefit of Cutting a Flat- Bottomed Drift in a Single Pass
}

\author{
Choon Quan', Ray Mele², and Frank Wong 3 \\ IU.S. DOE | ${ }^{2}$ Booz Allen Hamilton | ${ }^{3}$ Lawrence Livermore National Laboratory (LLNL)
}

\section{Research Objectives}

The current subsurface design for the proposed Yucca Mountain repository includes circular drifts for emplacement of waste packages. These drifts would be developed using tunnel boring machines (TBMs). While circular drifts provide structural stability, they require a heavy steel invert structure and crushed rock ballast to support the waste packages, the pallets on which the packages sit, and the structures, systems, and components associated with waste emplacement operations (e.g., rails and emplacement gantry). A mechanically excavated, flat-bottomed drift configuration would eliminate the need for the invert structure, as well as the need to remove, crush, size, and re-emplace the waste tuff, a potential dust inhalation issue. A change to mechanical excavation of flat-bottomed emplacement drifts, if implemented, would have the potential to affect operational aspects of proposed repository construction, construction costs, and licensing (Figure 1).

\section{Approach}

This evaluation will consist of two independent but related studies:
- Analysis of the feasibility, cost, regulatory acceptance, and operational impact of excavation of flatbottomed emplacement drifts, using mechanical excavation techniques. This analysis is being performed by the Management and Technical Services contractor, Booz Allen Hamilton.

- Evaluation of the technical feasibility, cost of development, and testing of the modifications needed for a TBM to cut a flat-bottomed drift in a single pass, and the interest of TBM equipment manufacturers in participating in a joint project. This evaluation is being performed by the Colorado School of Mines.

If the results of the feasibility studies are positive, then a competitive solicitation for the development and demonstration of the concept will be developed.

\section{Accomplishments}

The project is to be initiated in June 2005.

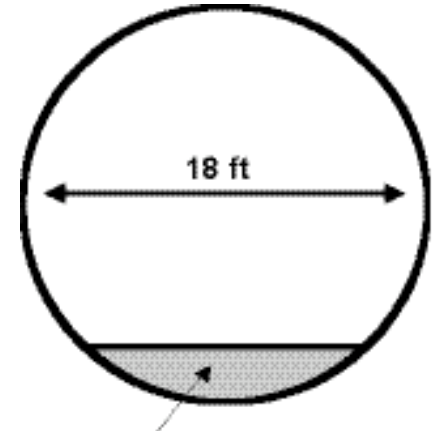

Installed invert for rail access

\section{Conventional Emplacement Drift}

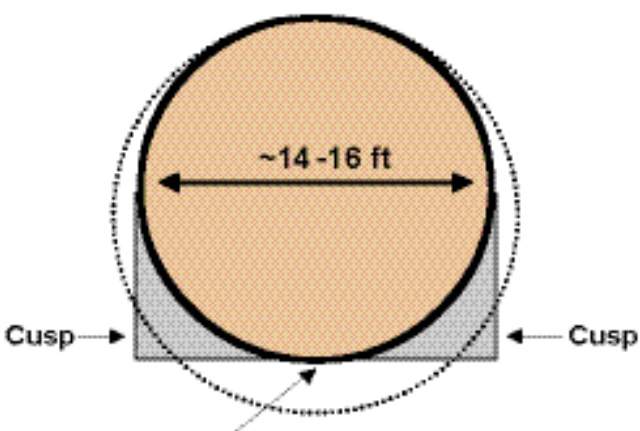

Rails can be installed on tunnel rock floor

\section{Emplacement Drift with Cusp Cut-outs}

Figure I. Flat-bottomed drifts can simplify subsurface construction: a small diameter can be used, rails can be installed right on the floor, and invert construction is eliminated. 
This page intentionally left blank. 


\section{Scoping Study to Evaluate Advances in Robotic Technologies That Support Enhanced Efficiencies for Proposed Yucca Mountain Repository Operations}

Thomas W. Burgess, Mark W. Noakes, and Philip T. Spampinato

Oak Ridge National Laboratory (ORNL)

\section{Research Objectives}

The objective of this project was to perform a scoping study to assess the Yucca Mountain Project (YMP) to determine if there were areas where advanced robotics and sensor technologies could improve the design. The candidates must be able to enhance the efficiencies of surface and subsurface operations dealing with spent nuclear fuel (SNF) casks and waste packages for disposal, leading to significant cost savings and reductions in personnel exposure.

\section{Approach}

The ORNL Robotics Team, which had just completed the design of the Spallation Neutron Source (SNS) at the Oak Ridge National Laboratory (ORNL), was contracted to evaluate the plans for the surface facilities at Yucca Mountain, in order to determine if improvements could be made in terms of flexibility, efficiency, throughput, and safety, by incorporating the lessons learned at the SNS. The ORNL team has several decades of experience in developing and applying state-of-the-art remote handling and robotic systems for material handling in hazardous environments and nuclear facilities.

\section{Accomplishments}

The evaluation found that there is potential for improvement in efficiency and operating cost if a number of tech-

nology improvements could be implemented under the Office of Civilian Radioactive Waste Management, Office of Science and Technology and International program. These include: telerobotics, with emphasis on sensor-based control and dexterous manipulation; remote operations and maintenance studies focused on a "design-for-remote" philosophy; a waste package weld inspection system and drift-wall inspection; and high-temperature radiationhardened electronics and rad-based power cell/generators. In the process of completing this study, it was identified that there were certain commercial technologies and "design-for-remote" best practices that could be used to support a baseline design that would enhance plant-operating efficiencies (Figure 1).

This evaluation has become the basis for the remote material handling initiative in the Advanced Technologies Thrust. Among the technology items discussed were manipulator improvements for telepresence and teleoperation as leading candidates for enhancing operations efficiency. These are considered high-payback technology improvements as noted in the report. In terms of technology development, the final output of this project will be a robotics and remote-systems technology-development, multi-year roadmap focused on improving the operational efficiency of the YMP's remotely operated facilities.

The recommendation that a series of workshops should be planned between ORNL and BSC to facilitate a transfer of knowledge was implemented in FY2005. 

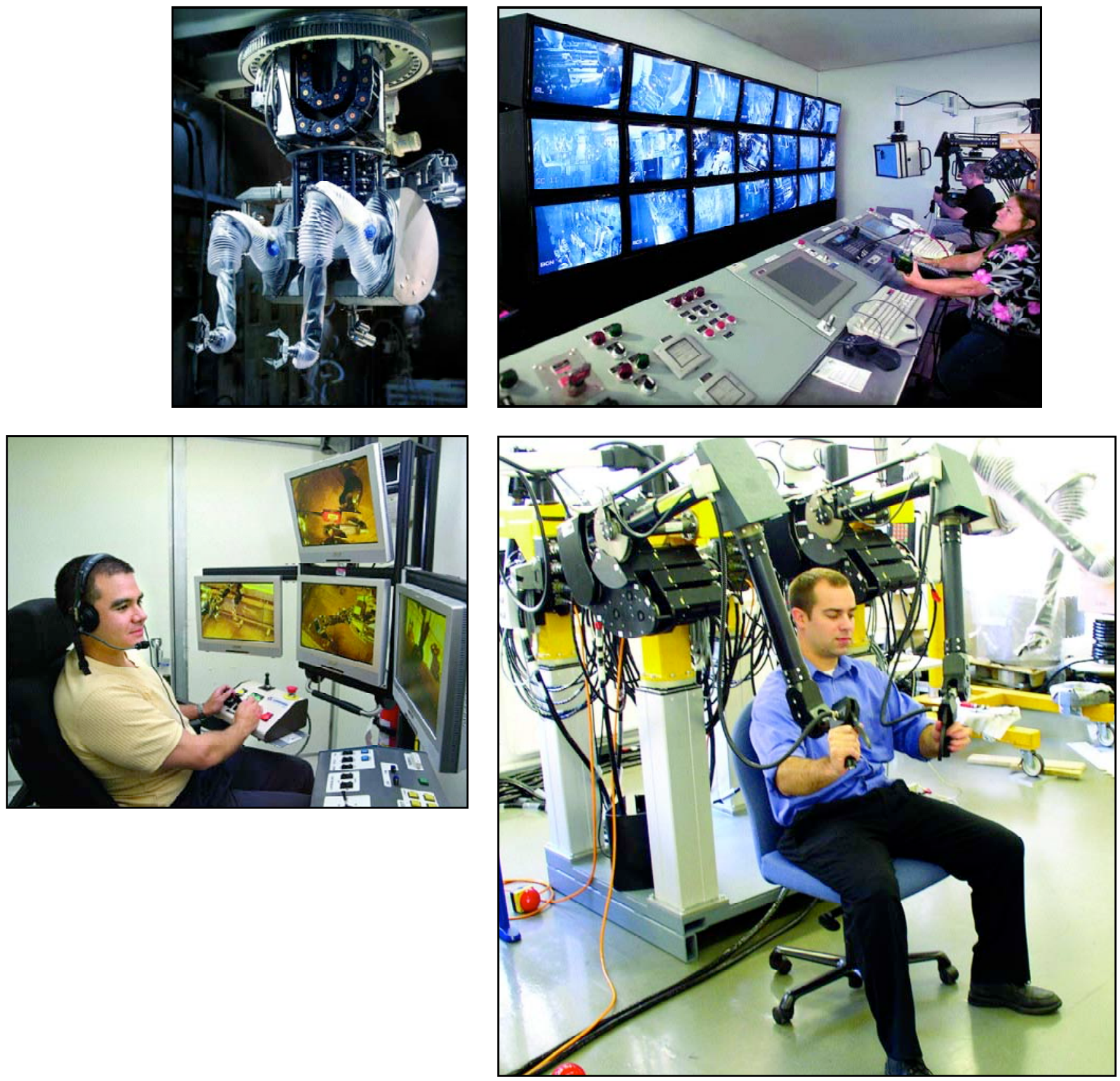

Figure I. Advanced robotics technology can enhance the efficiencies of surface and subsurface operations dealing with spent nuclear fuel casks and waste packages for disposal, leading to significant cost savings and reductions in personnel exposure. Telerobotic servomanipulators (top left) with improved human control interfaces can provide a high degree of handling dexterity in remote environments. 


\section{Workshop on State-of-the-Art Tele-Operated Robotic Manipulators and Other Technology Improvements to Enhance Yucca Mountain Remote Material-Handling Capabilities}

Thomas W. Burgess, Mark W. Noakes, and Philip T. Spampinato

Oak Ridge National Laboratory (ORNL)

\section{Research Objectives}

The objective of this project is to encourage interactions and the transfer of knowledge and experience between the ORNL Robotics Team - which recently designed the remote handling systems for the Spallation Neutron Source (SNS) at Oak Ridge-and the Yucca Mountain Design Team.

\section{Approach}

Three separate workshops were held in FY2005, with the first held at the Yucca Mountain Project Office in Nevada. This workshop was to allow interactions between the ORNL Robotics Team, which recently designed the remote handling systems at the Spallation Neutron Source at Oak Ridge, and the Yucca Mountain Design Team. The second and third workshops were held at ORNL, which gave the Yucca Mountain Design Team an opportunity to tour the SNS hot cell facilities and operate the newest remote handing equipment in the world, prior to them going "hot" (Figure 1). The purpose of these workshops was to give the Yucca Mountain designers a first-hand opportunity to discuss the process with an experienced design team and get actual hands-on experience with some of the equipment being considered for use at the proposed repository. From all reports, the workshops were a success and met the expectations of all who were involved.

\section{Accomplishments}

In addition to giving the Yucca Mountain Design Team first-hand experience with state-of-the-art remote materialhandling equipment, the workshops also identified areas where additional investigations by the Advanced Technologies Thrust would most likely provide benefit to the Yucca Mountain Project. These areas include:

- Cask unloading operations: identify design features and special handling tools and/or changes to the standard transport cask that would minimize operations by personnel and emphasize the use of remote handling capabilities to achieve as low as reasonably achievable (ALARA) risk cost, as well as improve throughput.

- Closure cell operations: conduct an operations and off-normal task analysis to determine alternatives to the current baseline design that may be more efficient and/or better address off-normal capabilities.

- Provide technical input to the Yucca Mountain Design Team on the following:

1. Examine the application of swing-free crane control to generic equipment for the dry transfer of spent nuclear fuel bundles during normal operation of the proposed Yucca Mountain facility.

2. Provide technical advice to the closure-cell automation activities.

3. Provide design input to the communications link for the emplacement gantry and the transporter with operations on the surface, for the purpose of robust radiation-tolerant operations associated with subsurface emplacement activities.

The exposure of the Yucca Mountain Design Team to the work done at the SNS, and the opportunity to actually operate the equipment prior to completing their design work, will be valuable in improving the proposed Yucca Mountain repository design process. 

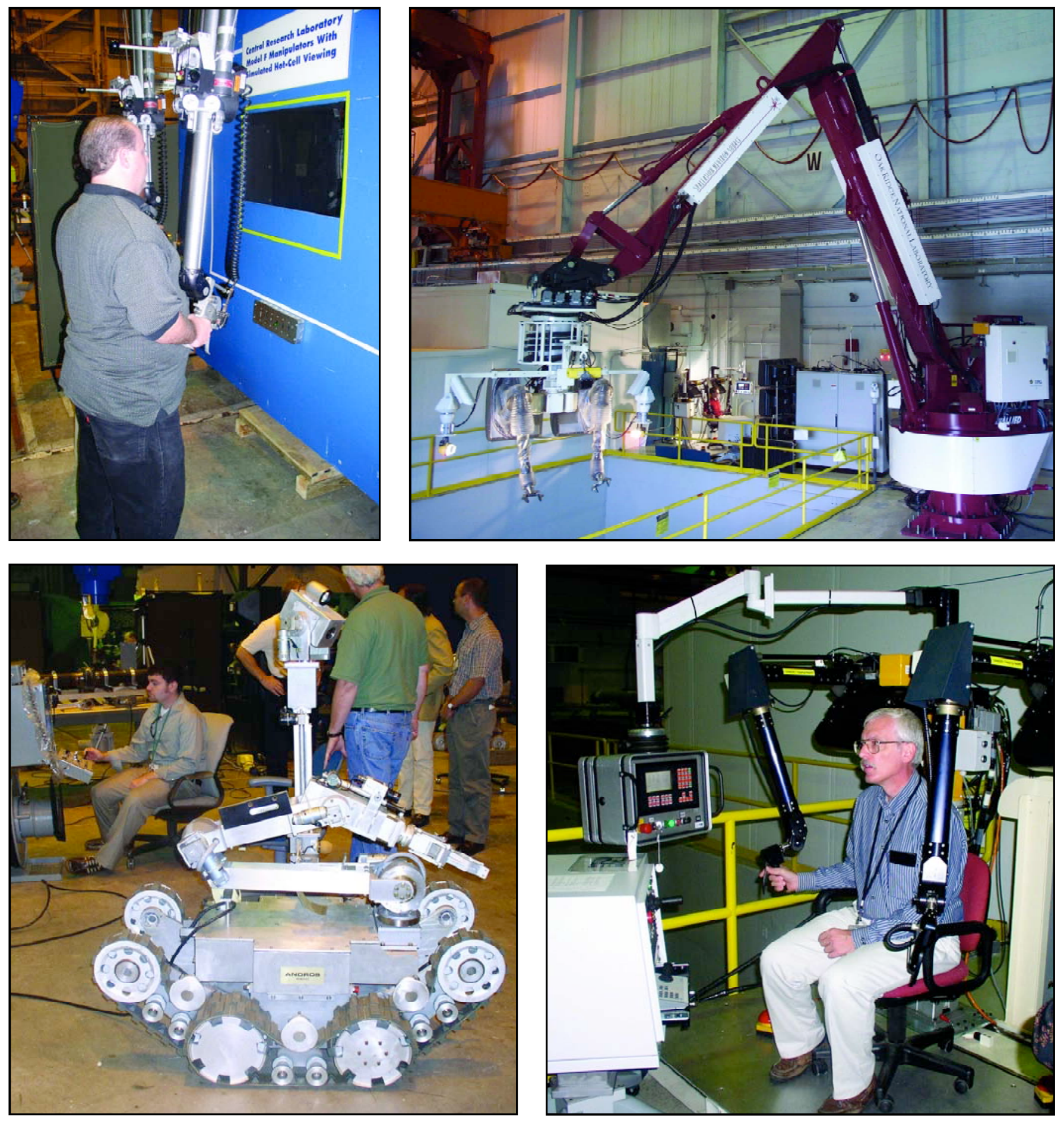

Figure I. Two remote handling technology workshops were held at ORNL to provide the Yucca Mountain Project Design Team an opportunity to tour the recently constructed hot cell facilities for the Spallation Neutron Source, and operate different remote manipulator systems. It was an opportunity for the Design Team to see and experience state-of-the-art remote handling systems prior to completing the design work of the proposed repository. 


\section{Low-Alkalinity Phosphate-Bonded and Portland Cements as Cost- Effective Cementitious Material Compatible with Proposed Yucca Mountain Repository Geochemistry}

Les Dole', Arun Wagh², Catherine Mattus', and Lee R. Riciputi I

IOak Ridge National Laboratory (ORNL) | ${ }^{2}$ Argonne National Laboratory (ANL)

\section{Research Objectives}

High-silica cements have a number of advantages for Yucca Mountain Project (YMP) applications. The evidence from archaeological and geological samples shows that high-silica cement binders are extremely durable. These cements, used by the Greeks and Romans, have survived for hundreds of years in hot water and for thousands of years in marine environments.

ORNL and ANL are developing and testing high-silica cements that are compatible with the geochemistry of Yucca Mountain and that do not result in an alkaline plume that could accelerate the release of radionuclides from the proposed repository in tuff. These cements will be chemically neutral, very low in free calcium hydroxide, and high in silica content. They will incorporate Yucca Mountain formation materials as aggregates and hence will be compatible with the proposed repository site's geochemistry.

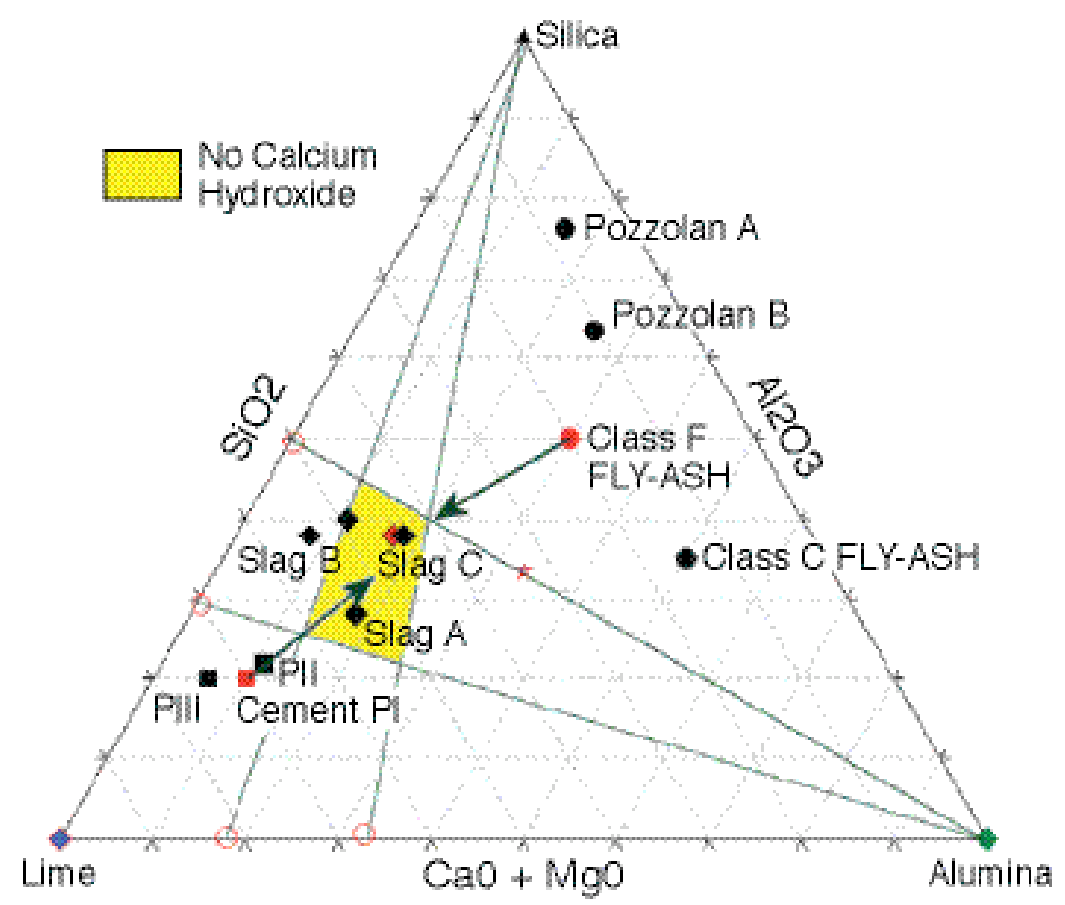

Figure I. Diagram shows the composition of the cement, fly ash, and blast furnace slag blends that are in testing.

\section{Approach}

This project will develop and test cost-effective cementitious materials for construction of Yucca Mountain inverts, drift liners, and bulkheads. Based on local materials, American Concrete Institute (ACI) guidelines, and American Standards for the Testing of Materials (ASTM), specifications will be applied to formulate one-pass slab and shotcrete formulas that meet the requirement that their high-silica chemical compositions shall not form free calcium hydroxide, therefore reducing the $\mathrm{pH}$ of their pore waters and subsequent leachates. This ensures that the mobility of radionuclides from the proposed Yucca Mountain repository will not be enhanced, and that the reliability of the waste packages will not be compromised by the presence of these cementitious materials. Furthermore, it may be shown that these high-silica cements slow the corrosion of the waste packages and potentially enhance the retention of nuclides in the proposed repository disposal zone.

This project is being performed in parallel to the design of the subsurface portions of the proposed repository. As such, it is imperative that preliminary findings and conclusions be made as quickly as possible, so that they can be realistically considered in the current design effort. The overall project is anticipated to be $<15$ months in duration, with preliminary findings and recommendations to be made in the first few months. To accelerate this project, the intent is to sponsor multiple laboratories to work in parallel so that we can more rapidly (1) identify and test multiple formulations for cementitious materials (Figure 1) and (2) perform the necessary laboratory testing, analysis, and modeling to predict the long-term performance of the material.

Focusing on a sprayed concrete formula and a slab formula, these studies are intended to: 
- Reduce costs and increase reliability of proposed repository drift build-out.

- Greatly reduce the risks during construction of the YMP drifts.

\section{Accomplishments}

- Characterized and evaluated local Nevada materials in preparation to testing proportioned mixes for the shotcrete and invert slab formulas.

- With industry consultants, developed high-silica proportional mixes to ASTM and ACI guidelines for applications in the YMP drift support and inverts.
- Evaluated silica-enhanced, phosphate-based concrete for application at the proposed repository. These phospho-silicate cements are chemically neutral ( $\mathrm{pH}$ between 7 and 8 ), exhibit high strength $(8,000-12,000$ psi for fly ash and 6,000-8,000 psi for wollastonite-based cements), and rapid-setting (2-3 hours for first setting, and 90\% strength in 5 days).

These cements (1) are lower in $\mathrm{pH}$ than ordinary Portland cements, (2) are very low in free calcium hydroxide and high in silica content, and (3) incorporate Yucca Mountain formation materials and basaltic aggregates to enhance their compatibility with the proposed repository geochemistry. If proven successful, these materials may replace the steel structures planned in the current proposed Yucca Mountain repository project and save hundreds of millions of dollars in the construction and closure phases of the project. 


\title{
Evaluation of Structurally Amorphous Materials to Improve Rock-Cutting Tools for Subsurface Excavation
}

\author{
Frank Wong' and Craig Blue 2 \\ 'Lawrence Livermore National Laboratory (LLNL) | ${ }^{2}$ Oak Ridge National Laboratory (ORNL)
}

\section{Research Objectives}

Our objective is to leverage the amorphous metal microstructure and/or processes to develop wear/impactresistant materials for longer lasting rock-cutting tools, to be used in Yucca Mountain Project earth-excavation operations. The aim of this effort is to improve the useful life of consumables for earth excavation. The ultimate goal of this project is to improve the operational life of tunnel boring machine (TBM) disc cutters, so that a 2,000 ft long emplacement drift can be excavated on a single set of TBM disc cutters. Present-day technology requires at least three complete disc-cutter changes to excavate a 2,000 ft emplacement drift.

\section{Approach}

The application of amorphous metal microstructures to earth-excavation operations has concentrated on two rock cutting tools: (1) disc cutters for TBMs and (2) conical tools used in road headers. Up to the 3rd quarter of 2005, the work had focused on the testing of the material on the conical bits. However, since that time, the work has shifted to the TBM disc cutters.

Because this project is focused on the improvement of a consumable used in tunnel boring, the intent of this work is to demonstrate the feasibility of using structurally amorphous metal (SAM) coatings to improve the performance of the cutting tools, and then transition this technology to a commercial manufacturer for further development. At present, there are three commercial partners involved in this project, providing in-kind support.

In FY2005 and FY2006, several sets of bits and cutter wheels will be coated and fused with SAM and shipped to the Colorado School of Mines for testing in their linear cutting machine. If the results of the tests are promising for the TBM disc cutters, additional sets of disc cutters will be prepared and field tested in TBMs operating in the United States. It is not possible to obtain sufficient linear travel for proper disc cutter wear-resistance assessments using labo- ratory-scale tests. Similarly, the conical bits will be placed on a road header machine for field testing either at Yucca Mountain or in similar conditions.

\section{Accomplishments}

- Laser coating of six 17-inch disc cutters has been completed; they are undergoing performance testing at the Colorado School of Mines. If successful, these cutters will then be placed on an actual TBM to measure wear and performance.

- Fully consolidated, devitrified samples have been hot pressed into 2-inch-diameter and 7-inch-diameter discs. These samples have exhibited high hardness values, $1,400 \mathrm{~kg} / \mathrm{mm} 2 \mathrm{VHN}$, and submicron crystal growth.

- Drop-cast amorphous specimens and hot pressed devitrified plates have been delivered for mechanical testing, including fracture toughness, Charpy impact, tensile, and compaction testing.

- Preliminary work has been performed on laserfusing SAM 1651 on tempered tool steel. These samples were fused to better understand the effect of changing such parameters as energy levels, coating thicknesses, phases present, etc. In the upcoming month, one 17-inch disc cutter fused with SAM 1651 and one disc thermally sprayed with a Ni-Cr-based powder will be laser-fused.

If successful, the project will demonstrate that it is possible to extend the operational life of earth-excavation consumable tools by using SAM microstructure coatings. An extension in the operational life of disc cutters will result in less job down time and more rapid excavation rates, which relate to savings in terms of excavation costs. In addition, present-day technology will not allow excavation of a 2,000 ft emplacement drift using a single set of disc cutters, which is currently planned in the underground construction schedule. 
This page intentionally left blank. 


\title{
Development of a Methodology to Produce Hazard-Consistent Structural Demands and In-Structure Design Response Spectra
}

\author{
Tom Houston', Carl Costantino ${ }^{2}$, and Walt Silva ${ }^{3}$ \\ 'Los Alamos National Laboratory (LANL) | ${ }^{2}$ City University of New York (CUNY) | ${ }^{3}$ Pacific Engineering and Analysis (PEA)
}

\section{Research Objectives}

The project is designed to develop a relatively simplified procedure for soil structure interaction (SSI) analyses that accommodate the variability in site-specific soil material p roperties and structural properties, and maintains the hazardlevel of the input bedrock design motions in the computed structural demands and design response spectra. This new process is intended to provide an analysis procedure equivalent in complexity to current deterministic p rocesses (that is, it requires the performance of only a few detailed SSI evaluations), but provides results that are consistent with probabilistically derived ground-motion hazard levels. This procedure will enable structural designs that reflect quantified hazard levels of seismic response, from which risk-informed decisions may be made. The primary objective is then to reduce conservatism contained in the current deterministic procedures used for design of structures and internal equipment, while at the same time allowing for hazard-consistent procedures.

\section{Approach}

SSI analysis procedures, as outlined in the Nuclear Regulatory Commission's (NRC's) Standard Review Plan and currently used to analyze the seismic response of critical facilities, are not consistent with the newly recommended probabilistic approach to developing free-field design ground motions. Current SSI analysis procedures are generally based on deterministic analyses scaled to the approximate 84 th percentile spectra. These approaches are not consistent with developing hazard-consistent structural responses. What is needed for design of critical facilities is a process that preserves the hazard level of the site-specific design motions in the development of in-structure spectra and member loads. Risk-informed structural design is predicated on properly characterizing the probability level of structural demands and maintaining that probability level across the structural frequency range.

The proposed approach involves comparing results (structural-element demands and in-structure response spectra) computed in a direct manner, using a Monte Carlo procedure with results from a number of simplified approaches. In the direct approach, the seismic response of the structure is computed for each realization of the groundmotion/soil-column computation to generate structural demands and in-structure spectra that are appropriate for the system, and that accommodate variability in both structural parameters and site profiles. In the randomization process, SSI analyses will be included directly with the site response analyses, using a number of structural models representative of facilities of interest to DOE and the NRC.

\section{Accomplishments}

The project was initiated late in FY2005. The initial step taken was to develop appropriate computer models for typical critical facilities for which SSI effects are to be determined and incorporated into the facility design. The first building model developed is representative for the Waste Handling Building that could be constructed at the proposed Yucca Mountain repository site. This structure is a critical facility to be designed for seismic input specific at the Performance Category Level 3 (PC3) level. The model developed is capable of incorporating the primary modes of response anticipated for the facility.

The seismic input motions for earthquake events appropriate for the Yucca Mountain seismic hazard are currently being developed. The first set of data incorporating surface ground motion, as well as soil site properties appropriate for this motion at the proposed Yucca Mountain repository site, have been developed for the earthquake events that are the primary contributors to the Yucca Mountain Project (YMP) seismic hazard. Software is now being generated to convolve this seismic input data with the structural model definition, to generate compatible instructure motions needed for design of equipment and structural elements. These computations will continue for all of the primary earthquake contributors to the YMP seismic hazard. 
This page intentionally left blank. 


\title{
Development and Verification of an Improved Model for Extreme Ground Motions Produced by Earthquakes
}

\author{
Norm Abrahamson and Lloyd Cluft \\ Pacific Gas and Electric (PG\&E)
}

\section{Research Objectives}

This purpose of this project is to develop an improved model for use in the probabilistic seismic hazard analysis (PSHA) in areas such as Yucca Mountain and the region affected by the San Andreas Fault (SAF) in California. Studies pertaining to the SAF using the current PSHA process have resulted in the prediction of extreme ground movements, which are generally believed to exceed the physical limits of the rock units at the site. These extreme ground motions, predicted by the PSHA over the extended life spans of long-lived facilities (such as roads, bridges, nuclear power plants, or other "infrastructure" type facilities), require that the PSHA be done at progressively lower hazard levels. These large-amplitude ground motions have generated considerable consternation in the scientific, engineering, and regulatory communities, because the predicted ground velocity (PGV) and predicted ground acceleration (PGA) (1) have never been recorded for earthquakes, (2) present exceptional challenges to the design and construction of surface and underground facilities, and (3) are regarded by many qualified seismologists as "physically unrealizable." Based on such expert opinion, the Yucca Mountain Project has placed limits on its modeled ground-motion and acceleration. This work will provide additional support to, and help refine, those limitations.

\section{Approach}

This "improved model" will be developed in collaboration with universities, other state and federal agencies, and private industries (like the nuclear industry) that have a stake in better defining the PSHA - from the definition of the physical limits for elastic ground movement, from empirical observations of unexceeded ground movements associated with large-magnitude earthquakes throughout the world, and from laboratory data on the elastic and nonelastic behavior of rock.

This collaborative effort will attempt to: (1) define the physical limits for ground motion from empirical observations associated with large-magnitude earthquakes throughout the world, and from laboratory (experimental, theoretical, and modeling) data on the behavior of rock at extreme accelerations, and (2) develop and validate an improved model of nonlinear seismic-source excitation and wave propagation.

Research is to be conducted into the physical limits on ground motion in two specific areas: (1) nonlinear effects caused by rock-mass degradation, including slip on preexisting fractures and creation of new fractures, along the travel path of the seismic wave as it transits from the source to the ground surface at the Yucca Mountain site, and (2) nonlinear effects at the source resulting from slip on the fault and rock-mass damage in the source region (Figure 1).

\section{Accomplishments}

- A report has been published identifying the basis for the concept and defining the scope of the project.

- Cooperative agreement has been established with PG\&E to manage this project. A partnership has

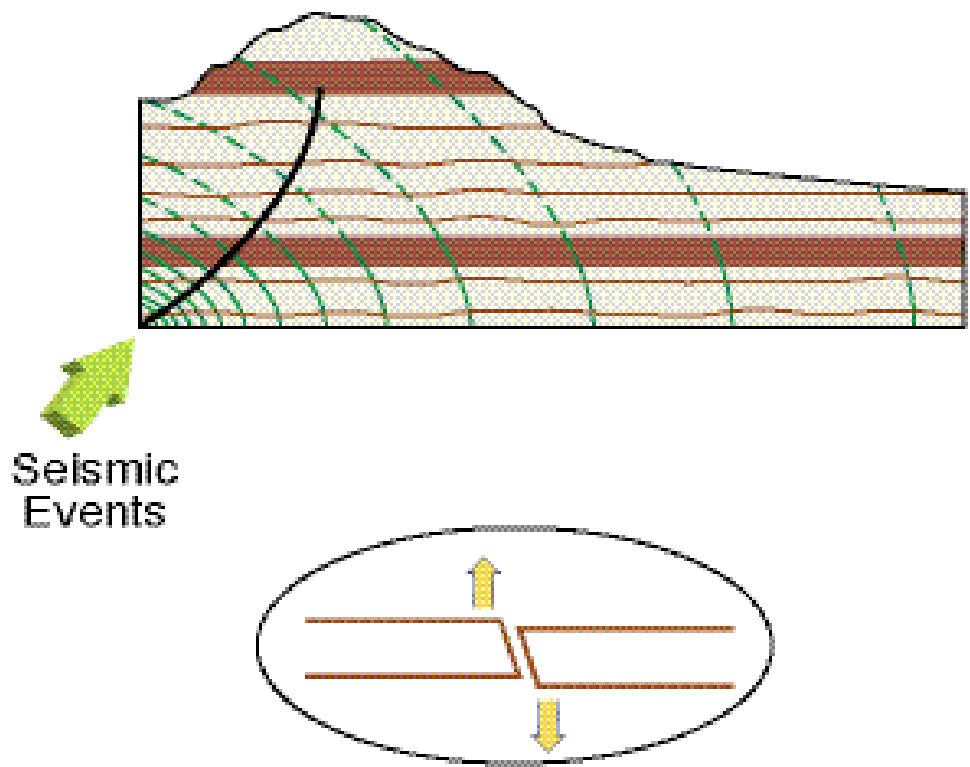

Figure I. Investigations indicate that the magnitude of the ground motions predicted at Yucca Mountain using the current linear models probably exceeds the physical limits for ground motion. 
been developed with California institutes performing similar work on sections of the SAF.

- A workshop has been held to present the proposed scope of the project and identify potential investigators.

- Preliminary modeling indicates that because of the interaction between long-wavelength incoming and reflected waves at the proposed repository horizon, stresses are reduced. Therefore, the long-wavelength component of the ground motion will have little impact on the stability of the emplacement drifts in the repository. 


\section{APPENDIX A}

\section{OST\&I}

\section{Programmatic EVALUation and Peer Review Panels}

Programmatic Evaluation Panel

Mary Jo Baedecker, Ph.D.

Scientist Emeritus, U.S. Geological Survey

Gerald Boyd

Manager, DOE Oak Ridge Operations

Darleane Hoffman, Ph.D.

Professor, University of California, Berkeley

\section{Alexander MacLachlan, Ph.D.}

Senior Vice President for R\&D, Chief Technical Officer, DuPont (retired)

Charles Metzger, Ph.D.

Panel Chair, Senior Advisor, Booz Allen Hamilton

John Stringer, Ph.D.

Technical Executive, Science \& Technology Development Division, Electric Power Research Institute (retired)

Chris Whipple, Ph.D.

Principal, Environ
Thrust Area Peer Review Panels

Source Term

Bernd Grambow, Ph.D.

Professor, School of Mines in Nantes, France, and leader in the European Community research on spent fuel

Alexandra Navrotsky, Ph.D.

Distinguished Professor, Chemical Engineering and Material Science, UC-Davis

David Sassani, Ph.D.

DOE consultant, Golder Associates Inc.

Materials Performance

Robert Baboian, Ph.D., P.E.

Retired from Texas Instruments as Head of the Electrochemical and Corrosion Laboratory

Robert Frankenthal, Ph.D.

Retired as a Distinguished Member of Technical Staff from Bell Laboratories, Lucent Technologies

A. John Sedriks, Ph.D.

Retired as Program Officer in the Materials Science and Technology Division at the Office of Naval Research

Natural Barriers

Sabodh K. Garg, Ph.D.

Science Applications Intl. Corp.

Richard Parizek, Ph.D.

Professor, Penn State University

Rien van Genuchten, Ph.D.

Scientist, U.S. Department of Agriculture

Steve Yabusaki, Ph.D.

Scientist, Pacific Northwest National Laboratory 


\section{APPENDIX B}

\section{OST\&I}

\section{PARTICIPATING}

\section{ORGANIZATIONS}

Argonne National Laboratory

Arizona State University

Atomic Energy of Canada Limited

Auburn University

BAE Systems

Booz Allen Hamilton

Case Western Reserve University

City University of New York

Clemson University

Desert Research Institute

Idaho National Laboratory

Illinois State Water Survey

lowa State University

Joseph Oat Corporation

Lawrence Berkeley National Laboratory

Lawrence Livermore National Laboratory

Los Alamos National Laboratory

Northern Illinois University

Nye County Nuclear Waste Repository Project Office, Nye County, NV

Oak Ridge National Laboratory
Ohio State University

\section{OLI Systems}

Pacific Engineering and Analysis

Pacific Gas and Electric

Pacific Northwest National Laboratory

Pennsylvania State University

Rice University

Sandia National Laboratories

United States Geological Survey

University of California, Berkeley

University of California, Davis

University of Manchester, Great Britain

University of Michigan

University of Minnesota

University of Missouri-Columbia

University of Nevada, Las Vegas

University of Notre Dame

University of Southern California

University of Tennessee-Knoxville

University of Texas at Arlington

University of Texas-El Paso

University of Toronto

University of Virginia

University of Western Ontario

U.S. Department of Energy, Office of Civilan Radioactive Waste Management

Virginia Polytechnic and State University

Washington State University 
This report was prepared by Ernest Orlando Lawrence Berkeley National Laboratory pursuant to Contract No. DE-AC02-05CHI I 23I, funded by the United States Department of Energy (DOE), Office of Civilian Radioactive Waste Management (OCRWM), Office of Science and Technology and International (OST\&I), and neither Ernest Orlando Lawrence Berkeley National Laboratory, nor any of its contractors or subcontractors, nor the DOE/OCRWM/OST\&I, nor any person acting on behalf of either:

Makes any warranty or representation, express or implied, with respect to the accuracy, completeness, or usefulness of the information contained in this report, or that the use of any information, apparatus, method, or process disclosed in this report may not infringe privately-owned rights; or

- Assumes any liabilities with respect to the use of, or for damages resulting from the use of, any information, apparatus, method, or process disclosed in this report. Reference herein to any specific commercial product, process, or service by trade name, trademark, manufacturer, or otherwise, does not necessarily constitute or imply its endorsement, recommendation, or favoring by DOE/OCRWM/OST\&I.

The views, opinions, findings, and conclusions or recommendations of authors expressed herein do not necessarily state or reflect those of the DOE/OCRWM/OST\&I.

\section{Ernest Orlando Lawrence Berkeley National Laboratory Disclaimer}

This document was prepared as an account of work sponsored by the United States Government. While this document is believed to contain correct information, neither the United States Government nor any agency thereof, nor The Regents of the University of California, nor any of their employees, makes any warranty, express or implied, or assumes any legal responsibility for the accuracy, completeness, or usefulness of any information, apparatus, product, or process disclosed, or represents that its use would not infringe privately owned rights. Reference herein to any specific commercial product, process, or service by its trade name, trademark, manufacturer, or otherwise, does not necessarily constitute or imply its endorsement, recommendation, or favoring by the United States Government or any agency thereof, or The Regents of the University of California. The views and opinions of authors expressed herein do not necessarily state or reflect those of the United States Government or any agency thereof, or The Regents of the University of California.

Ernest Orlando Lawrence Berkeley National Laboratory is an equal opportunity employer. 